REINALDO BURIAN

\title{
ALGORITMOS GENÉTICOS NA ALOCAÇÃO DE DISPOSITIVOS DE PROTEÇÃO DE DISTRIBUIÇÃO DE ENERGIA ELÉTRICA
}

Tese apresentada à Escola Politécnica da Universidade de São Paulo para obtenção do título de Doutor em Engenharia.

São Paulo

2009 
REINALDO BURIAN

\section{ALGORITMOS GENÉTICOS NA ALOCAÇÃO DE DISPOSITIVOS DE PROTEÇÃO DE DISTRIBUIÇÃO DE ENERGIA ELÉTRICA}

Tese apresentada à Escola Politécnica da Universidade de São Paulo para obtenção do título de Doutor em Engenharia.

Área de Concentração:

Sistemas Elétricos de Potência

Orientador:

Prof. Dr. Cícero Couto de Moraes

São Paulo

2009 
Este exemplar foi revisado e alterado em relação à versão original, sob responsabilidade única do autor e com a anuência de seu orientador.

São Paulo, 28 de Outubro de 2009

Reinaldo Burian

Cícero Couto de Moraes

\subsubsection{Burian, Reinaldo}

Algoritmos genéticos na alocação de dispositivos de proteção de distribuição de energia elétrica / R. Burian. - ed. rev. - São Paulo, 2009. $190 \mathrm{p}$.

Tese (Doutorado) - Escola Politécnica da Universidade de São Paulo. Departamento de Engenharia de Energia e Automação Elétricas.

1.Distribuição de energia elétrica (Automação) 2.Algoritmos genéticos I. Universidade de São Paulo. Escola Politécnica. Departamento de Engenharia de Energia e Automação Elétricas II.t. 


\section{DEDICATÓRIA}

Aos meus pais Albino e Guilhermina.

A minha esposa Fabíola e a meus filhos Heloísa e Eduardo.

Aos meus verdadeiros amigos. 


\section{AGRADECIMENTOS}

A Deus.

Ao Departamento de Engenharia de Energia e Automação Elétricas da Escola Politécnica da USP por possibilitar a realização e o desenvolvimento da pesquisa elaborada neste trabalho;

Ao Prof. Dr. Cícero Couto de Moraes, pelo acompanhamento e apoio ao longo do desenvolvimento deste trabalho;

Ao convênio EPUSP/Rockwell Automation do Brasil, que também patrocinou parte do desenvolvimento deste trabalho.

Aos colegas do GAESI, pelo apoio, amizade, consideração e paciência.

Ao meu grande amigo Dr. Annibal Hetem Jr., por dividir seu escasso tempo para discutir modelos de soluções empregando Algoritmos Genéticos. 


\section{RESUMO}

Os sistemas de distribuição de energia elétrica, sujeitos a um crescimento contínuo de uso, tornam-se cada vez mais complexos e sofisticados na demanda atual de mercado. Neste contexto, surge a necessidade de respostas rápidas para diagnósticos da manutenção preventiva e corretiva da rede de distribuição. Quatro das principais aplicações necessárias são: 1) os cálculos de índices de continuidade, a partir de um circuito elétrico; 2) a definição das topologias com os equipamentos de proteção no circuito; 3) simulação do comportamento do circuito elétrico diante de uma série histórica de contingências de ocorrências na rede; e 4) análise do conjunto dos equipamentos de proteção existentes no inventário da concessionária.

Este trabalho tem por objetivo apresentar os estudos preliminares na busca de um modelo de circuito elétrico otimizado, sob os pontos de vista técnicos e operacionais. Em seguida, passa-se à realização e detalhamento dos cálculos apresentados, de acordo com o modelo brasileiro.

O uso de uma metodologia para o desenvolvimento das soluções de software, em especial o modelo em cascata, permite desenvolver todos os seus blocos funcionais dentro do processo. Os resultados revelaram que estas soluções, desenvolvidas com inteligência artificial (algoritmos genéticos - AG), alcançam bons resultados quanto ao circuito otimizado, apresentando valores compatíveis quando comparados aos modelos estudados: resultou ainda em um esforço computacional otimizado e boa convergência de valores. A análise do histórico de contingências também retorna o estado final do circuito e os índices de continuidade (DIC, FIC e DMIC). A otimização do uso de um inventário prévio de equipamentos baseada em AG retornou o melhor circuito otimizado, considerando-se a realidade da concessionária.

Um aspecto relevante, que pode ser aplicado pelas concessionárias, refere-se aos arquivos de saída: os valores finais dos índices de continuidade e as informações gráficas do circuito otimizado proporcionam uma análise rápida sobre o comportamento do circuito.

Palavras-Chave: Distribuição da Energia Elétrica. Algoritmos Genéticos. 


\section{ABSTRACT}

The electric power distribution systems, submitted to a continuous growth, become each time more complex and sophisticated in the current demand of market. In this context, appears the need of fast answers for diagnosis of the preventive and corrective maintenance of the distribution network. Four of the main necessary applications are: 1) the calculations of continuity indices, from an electric circuit; 2) the definition of the topologies of the equipments of protection in the circuit; 3) simulation of the behavior of the electric circuit ahead of a historical series of contingencies of occurrences in the network; and 4) analysis of the set of the existing equipment of protection in the inventory of the electric power company.

This thesis aims at presenting the preliminary studies in the search of a model of optimized electrical circuit, under the technical and operational view points. After that, it is transferred the accomplishment and detailing of the presented calculations, in accordance with the Brazilian model.

The use of a methodology for the development of the solutions of software, in special the waterfall model, allows to develop all its functional blocks inside of the process. The results had disclosed that these solutions, developed with artificial intelligence (genetic algorithms - GA), reach good resulted how much to the optimized circuit, presenting compatible values when compared with the studied models: it still resulted in a computational effort optimized and good convergence of values. The analysis of the description of contingencies also returns the final state from the circuit and the continuity indices (DIC, FIC and DMIC). The optimization of the use of a previous inventory of equipments based on GA returned the best optimized circuit, considering the reality of the electric power company.

An excellent aspect, that can be applied by the electric power companies, makes the reference to the output archives: the final values of the continuity indices and the graphical informations of the optimized circuit provide a fast analysis on the behavior of the circuit.

Keywords: Distribution of the Electric Energy. Genetic Algorithms. 


\section{LISTA DE FIGURAS}

Figura 1.1 - Problema do valor inicial no método de Newton-Raphson ...................4

Figura 1.2 - Problema com múltiplas soluções.............................................5

Figura 1.3 - Exemplo de função hipotética indicando um máximo local e um máximo global.

Figura 1.4 - A ocorrência de múltiplos picos - dilema na escolha do método matemático.

Figura 1.5 - Representação do circuito por diagrama elétrico e por árvore de recursão

Figura 1.6 - Diagrama da localização dos programas TEIAA e TEIAG. 10

Figura 1.7 - Evolução do diagrama de localização dos programas TEIAA e TEIAG Análise e Síntese .12

Figura 2.1 - Partes constituintes de um sistema elétrico .16

Figura 2.2 - Circuito modelo 19

Figura 3.1 - Comportamento-padrão de algoritmos evolucionários. .30

Figura 3.2 - Algoritmos evolucionários como técnicas de busca. 31

Figura 3.3 - Etapas do AG utilizado neste trabalho 41

Figura 3.4 - Exemplo de cromossomo - alocação dinâmica de uma "palavra".... 42

Figura 3.5 - Comportamento do ff 44

Figura 4.1 - Circuito com disjuntor na subestação .51

Figura 4.2 - Topologia 1 obtida da simulação realizada pelo programa TEIAA .......54

Figura 4.3 - Circuito com religamento no disjuntor da subestação... 56

Figura 4.4 - Topologia 2 obtida da simulação realizada pelo programa TEIAA 58

Figura 4.5 - Circuito com religamento no disjuntor da subestação em coordenação com fusíveis nas laterais do circuito elétrico .60

Figura 4.6 - Topologia 3 obtida da simulação realizada pelo programa TEIAA .64

Figura 4.7 - Circuito com religador de meio de linha para a representação da topologia 4 
Figura 4.8 - Circuito com religador de meio de linha e zonas de proteção .............68

Figura 4.9 - Topologia 4 obtida da simulação realizada pelo programa TEIAA .......70

Figura 4.10 - Circuito com religadores distribuídos pelo circuito ...........................72

Figura 4.11 - Circuito com religador de meio de linha, religadores espalhados e suas zonas de proteção. .73

Figura 4.12 - Topologia 5 obtida da simulação realizada pelo programa TEIAA .....75

Figura 5.1 - Modelo em cascata. .79

Figura 5.2 - Ambiente de desenvolvimento do compilador $\mathrm{C}_{++}$Builder .81

Figura 5.3 - Organização de arquivos no compilador $\mathrm{C}++$ Builder . .82

Figura 5.4 - Tela do programa TEIAA .83

Figura 5.5 - Tela do programa TEIAG .84

Figura 5.6 - Tela do programa CONTTEIA. 85

Figura 5.7 - Tela do programa INVENTTEIA .86

Figura 5.8 - Mapa conceitual das estruturas alocadas dinamicamente. .91

Figura 5.9 - Exemplo de cromossomo alocado .91

Figura 5.10 - Primeira geração .93

Figura 5.11 - df em função do custo total. .96

Figura 5.12 - Pontos do gráfico da Figura 5.11, com a função interpoladora e a identificação dos pontos com menor df, por distribuição vertical de custo total

Figura 5.13 - Expansão do domínio da função interpoladora sobreposta à reta ct $=\kappa_{\mathrm{C}}^{*}$ (custo total) 98

Figura 5.14 - Exemplo de cromossomos com fator de fitness .99

Figura 5.15 - Operador cópia 101

Figura 5.16 - Operador crossover 102

Figura 5.17 - Operador mutação 103

Figura 5.18 - Operador descarte 104

Figura 5.19 - Exemplo de cromossomos com operadores genéticos alocados .....104

Figura 5.20 - Função Julgador: alocação de equipamentos de acordo com o melhor indivíduo 107

Figura 5.21 - Tela do programa TEIAG após um conjunto definido de iterações completas 
Figura 5.22 - Circuito com a solução otimizada..............................................110

Figura 5.23 - Campo Diagnóstico ............................................................... 110

Figura 5.24 - Campo Evolução ............................................................ 111

Figura 5.25 - Extrato de uma sequência evolutiva gerada pelo programa TEIAG .111

Figura 5.26 - Arquivo de entrada com histórico de contingências ........................113

Figura 5.27 - Circuito para análise de contingências......................................114

Figura 5.28 - Programa CONTTEIA após a análise de duas contingências ..........115

Figura 5.29 - Estado do circuito e índices resultantes do programa CONTTEIA ...116

Figura 5.30 - Circuito otimizado e diagnóstico - Programa INVENTTEIA ..............117

Figura 5.31 - Circuito e diagnóstico reais - Programa INVENTTEIA ..................118

Figura 6.1 - Valores de FEC referentes às topologias...................................121

Figura 6.2 - Valores percentuais de FEC referentes às topologias .....................122

Figura 6.3 - Valores de DEC referentes às topologias ..................................122

Figura 6.4 - Valores percentuais de FEC referentes às topologias .....................123

Figura 6.5 - Topologia final: solução otimizada ...........................................124

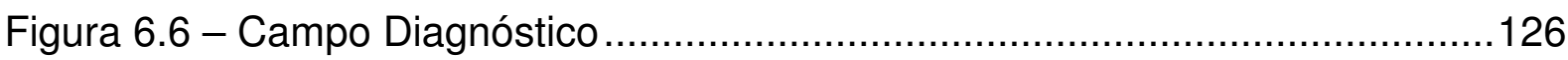

Figura 6.7 - Arquivo de parâmetros de controle do programa TEIAG ..................126

Figura 6.8 - Comportamento do programa TEIAG em 200 gerações....................127

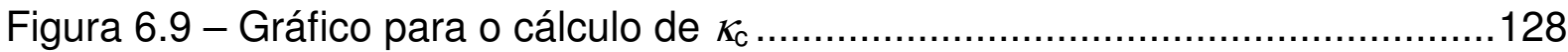

Figura 6.10 - Distribuição de valores de DEC \& FEC versus custo total dos equipamentos

Figura 6.11 - Distribuição de valores de DEC \& FEC versus número de religadores alocados 130

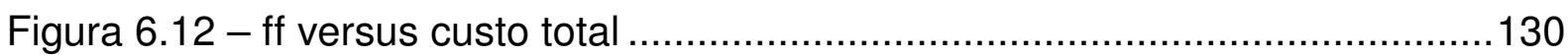

Figura 6.13 - Circuito resultante da ação das contingências...............................135

Figura 6.14 - INVENTTEIA e a comparação entre dois circuitos ..........................136

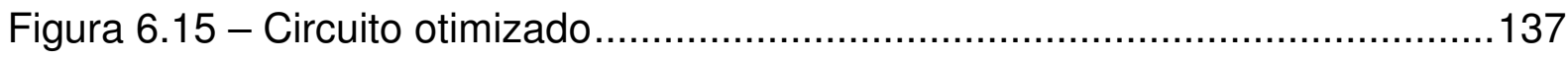

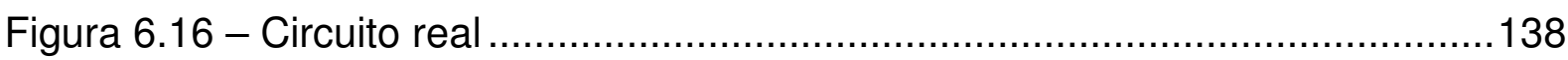




\section{LISTA DE TABELAS}

Tabela 2.1 - Comparação entre estudos preditivo e corretivo .................................18

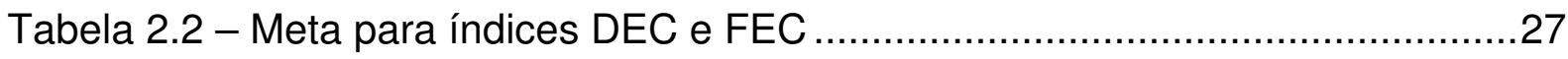

Tabela 3.1 - Comparação, evolução e solução real de um problema .......................30

Tabela 3.2 - Entrada de parâmetros do circuito elétrico de referência......................42

Tabela 3.3 - Exemplo de primeira geração, com 10 indivíduos...............................43

Tabela 3.4 - Exemplo de primeira geração, após função Avaliadora sobre 10 indivíduos

Tabela 4.1 - Representação da topologia 1 em arquivo de entrada .......................51

Tabela 4.2 - Valores de DEC do circuito ........................................................

Tabela 4.3 - Cálculo dos índices DEC e FEC para a topologia 1 ...........................55

Tabela 4.4 - Representação da topologia 2 em arquivo de entrada .......................56

Tabela 4.5 - Valores de DEC do circuito com disjuntor na subestação munido de

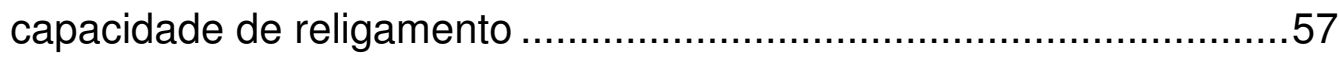

Tabela 4.6 - Cálculo dos índices DEC e FEC para topologia 2 ..............................58

Tabela 4.7 - Representação da topologia $3 \mathrm{em}$ arquivo de entrada ......................59

Tabela 4.8 - Circuito com fusíveis nas laterais e elemento com característica de

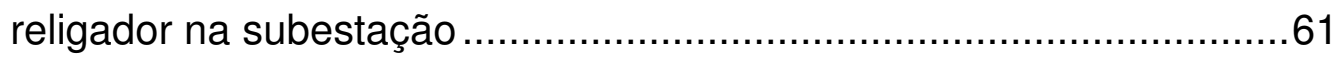

Tabela 4.9 - Distribuição dos elementos de proteção no circuito da topologia 3 .....62

Tabela 4.10 - Cálculo dos índices DEC e FEC para a topologia 3 ..........................65

Tabela 4.11 - Representação do modelo 4 em arquivo de entrada ........................66

Tabela 4.12 - Distribuição dos elementos de proteção no circuito da topologia 4 ...69

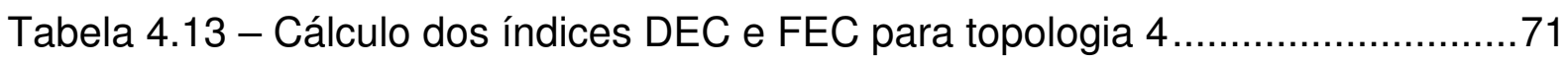

Tabela 4.14 - Representação da topologia 5 em arquivo de entrada .....................72

Tabela 4.15 - Distribuição dos elementos de proteção no circuito da topologia 5 ...74

Tabela 4.16 - Cálculo dos índices DEC e FEC para a topologia 5 ..........................76

Tabela 4.17 - Valores de DEC e FEC obtidos das topologias analisadas.................77

Tabela 5.1 - Exemplo de representação da topologia 1 por arquivo de entrada......88 


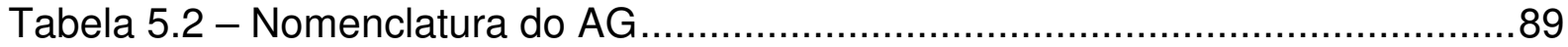

Tabela 5.3 - Cromossomo com equipamentos alocados - Primeira Geração ..........93

Tabela 5.4 - Cromossomo com equipamentos alocados e fator de fitness..............99

Tabela 5.5 - Descrição dos operadores genéticos utilizados ...............................101

Tabela 5.6 - Equipamentos alocados, fator de fitness e operadores genéticos mutação $(x)$ em destaque...........................................................105

Tabela 5.7 - Melhor indivíduo ao longo de 50 gerações.......................................108

Tabela 6.1 - Valores de DEC e FEC obtidos das topologias analisadas................121

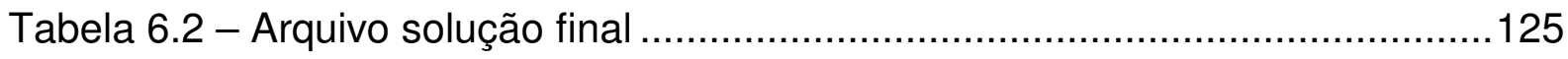

Tabela 6.3 - Valores da solução otimizada …………...................................131

Tabela 6.4 - Histórico de contingências ..........................................................132

Tabela 6.5 - Valores de DIC, FIC e DMIC ....................................................134 


\section{LISTA DE ABREVIATURAS E SIGLAS}

$1 \varnothing$

$3 \varnothing$

a

AG

ANEEL

Cl

CII

$\mathrm{C}_{\mathrm{n}}$

CONTTEIA

ct

CTM $_{\mathbf{i}}$

$\mathrm{CTT}_{\mathrm{i}}$

CustoF

CustoR

Custos

CustoTotal

DEC

DEC_Contribl DEC do trecho do circuito sem fusíveis em falhas permanentes

DEC_Contribll DEC do trecho do circuito com fusíveis em falhas transitórias

$D C_{\text {INV }}$

DEC

df

DFR

DIC

DMIC

$\mathbf{F}$

Monofásico

Trifásico

Taxa de crescimento anual do sistema

Algoritmo Genético

Agência Nacional de Energia Elétrica

Contribuição I, para trechos sem fusíveis em falhas permanentes

Contribuição II, para trechos com fusíveis em falhas transitórias

Tempo de ocorrência de fechamentos

Programa que analisa um histórico de contingências

Somatória dos custos

Comprimento do circuito em $\mathrm{km}$ do trecho monofásico

Comprimento do circuito em $\mathrm{km}$ do trecho trifásico

Custo do fusível

Custo do religador

Custo do disjuntor da subestação

Custo total do conjunto dos equipamentos alocados

Duração equivalente de interrupção por unidade consumidora

DEC do inventário

DEC do circuito otimizado

Função interpoladora para estimativa dos índices de continuidade

Sistema de distribuição baseado em confiabilidade

Duração das Interrupções por Unidade Consumidora considerada

Duração Máxima das Interrupções por Unidade Consumidora considerada

Fusível 
FatorDEC $\mathrm{i}_{\mathbf{i}} \quad$ Fator para o cálculo do FEC para incidência de falhas por $\mathrm{km}$

FatorFEC $_{i} \quad$ Fator para o cálculo do FEC para incidência de falhas por $\mathrm{km}$

FEC Frequência equivalente de interrupção por unidade consumidora

FEC_Contribl FEC do trecho do circuito sem fusíveis em falhas permanentes

FEC_Contribll FEC do trecho do circuito com fusíveis em falhas transitórias

FEC $C_{\text {INV }} \quad$ FEC do inventário

FEC ot $_{\text {FEC do circuito otimizado }}$

ff Função ou fator de fitness

FIC Frequência de Interrupções por Unidade Consumidora considerada

FS Fator de sobrecorrente

g Geração

gdm Índice de diversidade genética

GVO Disjuntor de grande volume de óleo

Horas_de_Reparo_Temp Horas de reparo para falhas temporárias

Horas_de_Reparo_Perman Horas de reparo para falhas permanentes

I IDM,Fus Corrente admissível do fusível.

IC,MAX Corrente de carga máxima no ponto de instalação

ICARGA,MAX Máxima corrente de carga

ICURTO,ASsim Maior corrente de curto-circuito, valor assimétrico, no ponto de instalação.

$\mathbf{I F}_{\mathbf{i}} \quad$ Taxa de incidência de falhas por $\mathrm{km}$

$\mathrm{I}_{\mathrm{INT}, \mathrm{CH}} \quad$ Maior corrente que a chave é capaz de interromper sem sofrer danos

$I_{N, P} \quad$ Corrente nominal primária

INOM,CH Corrente nominal da chave

INVENTTEIA Programa que analisa o inventário de uma concessionária

$\mathbf{k}_{\mathbf{t}} \quad$ Fator de elevação da temperatura do elo-fusível durante os intervalos de tempos de abertura rápida do religador

$\mathbf{K}_{1} \quad$ Fator de segurança $(1,5)$

$\mathbf{K}_{2} \quad$ Fator de segurança $(1,5)$

MT Média tensão

n Número total de trechos 
NBI Nível básico de isolamento para impulso

NC Normalmente fechada

$\mathrm{NC}_{\mathbf{i}} \quad$ Número de consumidores do trecho

NF Sem fusível

$\mathbf{N F}_{\mathbf{i}} \quad$ Número de linhas do trecho

NO Normalmente aberta

NP Tempo polinomial não-determinístico

num Número de anos do planejamento

$\mathbf{O}_{\mathrm{n}} \quad$ Tempo de ocorrência de abertura

pc Probabilidade de crossover

pm Probabilidade de mutação

PTFP $_{\mathbf{i}} \quad$ Porcentagem do tempo de falha permanente $(0,2)$

PTFT $_{\mathbf{i}} \quad$ Porcentagem do tempo de falha transitória $(0,8)$

PVO Pequeno volume de óleo

$\mathbf{Q}^{*} \quad$ Ponto de solução ideal

R Religador

RGA Algoritmo Genético baseado em substituição

$\mathbf{R L G}_{\mathbf{i}} \quad$ Reparo linha genérico (2)

$\mathbf{R}_{\mathrm{x}-\mathrm{y}} \quad$ Ramo do nó $\mathrm{x}$ até nó $\mathrm{y}$

$\mathbf{S F}_{6} \quad$ Hexafluoreto de Enxofre

SGA Algoritmo Genético Simplificado

$\mathrm{S}_{\mathrm{n}} \quad$ Cromossomo $\mathrm{n}$

SSGA Algoritmo Genético de Estado Estável

$\mathbf{t}_{\text {ABERT.OP.RAPIDA }}$ Tempo de abertura do religador na curva rápida

$\mathbf{t}_{\text {ABERT.OP.RET }}$ Tempo mínimo de abertura do religador na curva retardada

TC Transformador de corrente

TCC Curva tempo $x$ corrente

toisp.retaRd.ReLIG.NA.Frente Tempo de disparo do religador na curva retardada do religador a jusante

toISP.RETARD.RELIG.NA.RETAG Tempo de disparo do religador na curva retardada do religador a montante 
TEIAA Programa que realiza o cálculo do DEC e FEC de um circuito de distribuição de energia elétrica

TEIAG Programa que incorpora o programa TEIAA e realiza a implementação do Algoritmo Genético

t

tiNT Tempo máximo de interrupção do elo-fusível

Tipo $\mathbf{H} \quad$ Elos-fusível de alto surto

Tipo K Elos-fusível rápidos

Tipo T Elos-fusível lentos

TLG $\quad$ Tempo de linha genérico (2 horas)

$\mathbf{T L M}_{\mathbf{i}} \quad$ Tempo de linha monofásico (2,5 horas)

$\mathrm{TLT}_{\mathbf{i}} \quad$ Tempo de linha trifásico (3 horas)

TTR Tensão transitória de restabelecimento

UTR Unidade Terminal Remota

v Vazio

$\mathbf{x L} \quad \mathrm{x}$ linhas

$\Phi_{\mathrm{i}} \quad$ Operador genético

$\Gamma \quad$ Código do Algoritmo Genético

$\alpha \quad$ Coeficiente para a função interpoladora df

$\beta \quad$ Penalidade no INVENTTEIA

$\omega \quad$ Representação de um indivíduo a ser alocado no trecho considerado 


\section{SUMÁRIO}

RESUMO ...v

ABSTRACT

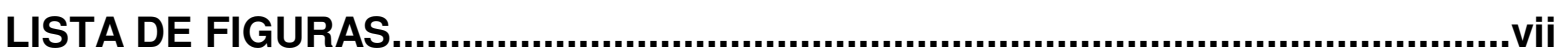

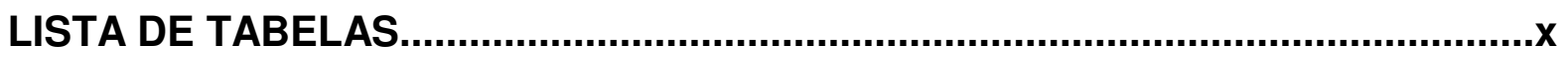

LISTA DE ABREVIATURAS E SIGLAS..............................................................i

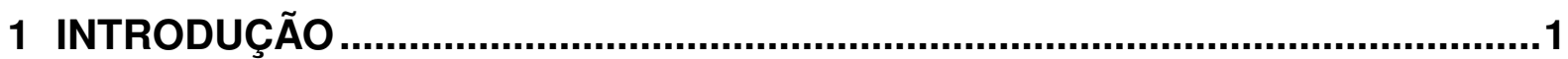

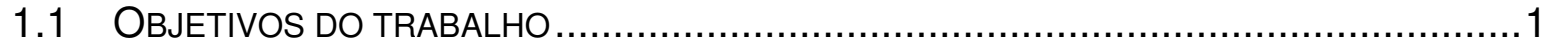

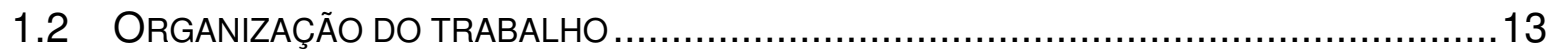

2 MODELO DE REDE DE DISTRIBUIÇÃO DE ENERGIA ELÉTRICA....................15

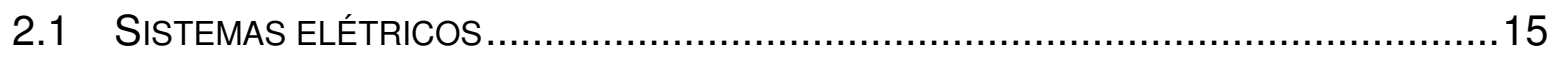

2.2 RESPOSTA DA REDE: ANÁLISE A POSTERIORI E A PRIORI.................................18

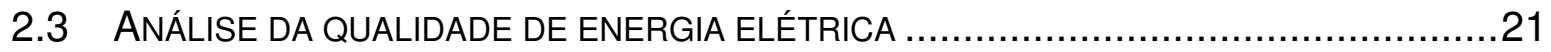

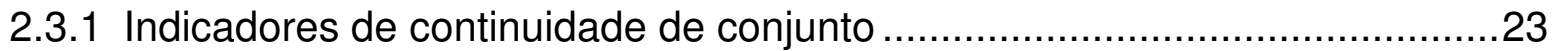

2.3.2 Indicadores de continuidade individual (por consumidor)..........................24

2.4 CENÁRIO DA DISTRIBUIÇÃO DE ENERGIA ELÉTRICA..........................................25

3 ALGORITMOS GENÉTICOS COMO MÉTODOS DE OTIMIZAÇÃO …................28

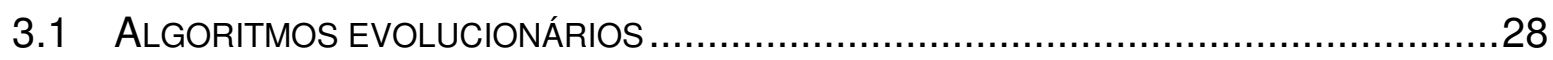

3.2 OTIMIZAÇÃO PARA PROCESSAMENTO DE SISTEMAS DE DISTRIBUIÇÃO DE ENERGIA

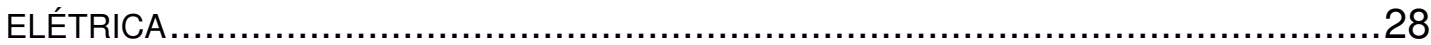

3.3 SURGIMENTO E DESENVOLVIMENTO DOS ALGORITMOS GENÉTICOS .......................31

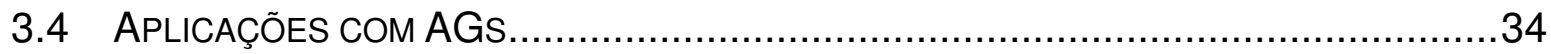

3.5 ALGORITMOS GENÉTICOS - DIFERENCIAÇÃO DOS MÉTODOS TRADICIONAIS DE BUSCA

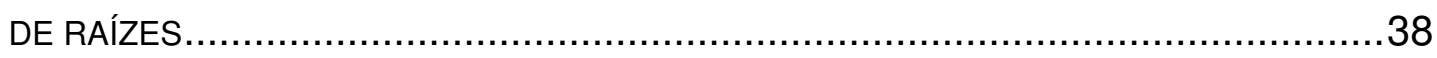

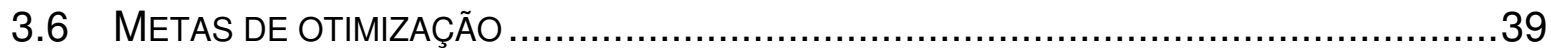

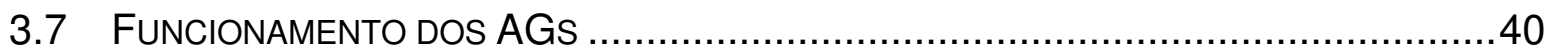


3.7.1 Definição de parâmetros e primeira geração........................................... 42

3.7.2 Aplicação da função Avaliador e cálculo do fator de fitness.........................43

3.7.3 Classificação dos cromossomos pela função Julgador ...............................45

3.7.4 Criação da próxima geração pela função Executor...................................46

4 METODOLOGIA PARA OBTENÇÃO DE ÍNDICES DE CONTINUIDADE ............47

4.1 CÁLCULOS EM CADA TOPOLOGIA DO CIRCUITO ELÉTRICO ….............................47

4.2 TOPOLOGIA 1 - CIRCUITO COM DISJUNTOR NA SUBESTAÇÃO DE ENERGIA ELÉTRICA

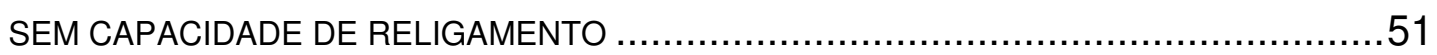

4.2.1 Considerações gerais da topologia 1 .................................................52

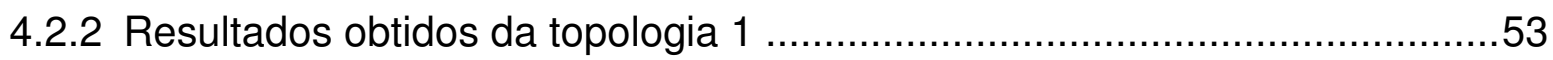

4.3 TOPOLOGIA 2 - CIRCUITO COM DISJUNTOR NA SUBESTAÇÃO DE ENERGIA ELÉTRICA,

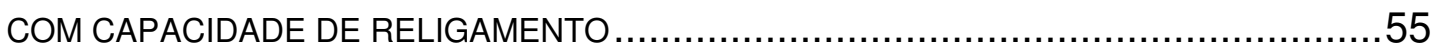

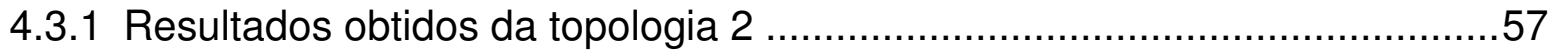

4.4 TOPOLOGIA 3 - CIRCUITO PROTEGIDO COM FUSÍVEIS NOS RAMAIS, EM RELAÇÃO AO ALIMENTADOR PRINCIPAL E DISJUNTOR, NA SUBESTAÇÃO DE ENERGIA ELÉTRICA, DOTADO DE CAPACIDADE DE RELIGAMENTO COM CURVA DE ATUAÇÃO RÁPIDA E

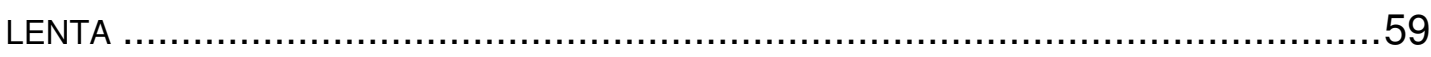

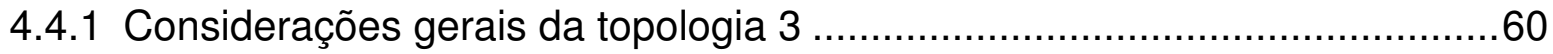

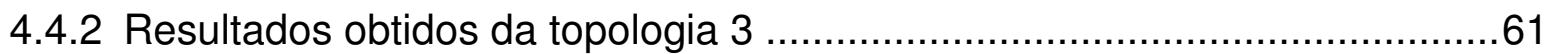

4.5 TOPOLOGIA 4 - CIRCUITO PROTEGIDO COM FUSÍVEIS NOS RAMAIS, EM RELAÇÃO AO ALIMENTADOR PRINCIPAL E DISJUNTOR, NA SUBESTAÇÃO DE ENERGIA ELÉTRICA, DOTADO DE CAPACIDADE DE RELIGAMENTO, COM CURVA DE ATUAÇÃO LENTA E RELIGADOR TRIFÁSICO NO MEIO DA LINHA DE DISTRIBUIÇÃO................................66

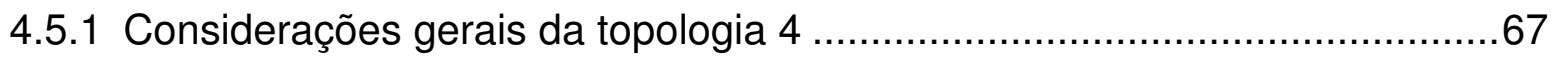

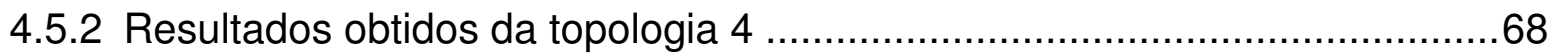

4.6 TOPOLOGIA 5 - CIRCUITO PROTEGIDO COM FUSÍVEIS NOS RAMAIS, EM RELAÇÃO AO ALIMENTADOR PRINCIPAL E DISJUNTOR NA SUBESTAÇÃO DE ENERGIA ELÉTRICA, COM CAPACIDADE DE RELIGAMENTO, COM CURVA DE ATUAÇÃO LENTA, RELIGADOR TRIFÁSICO NO MEIO DA LINHA DE DISTRIBUIÇÃO E RELIGADORES MONOFÁSICOS DISTRIBUÍDOS PELOS CIRCUITOS MONOFÁSICOS ............................................71

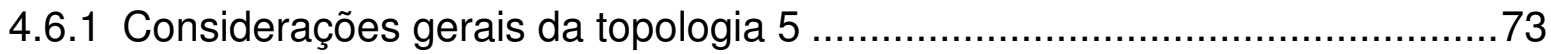

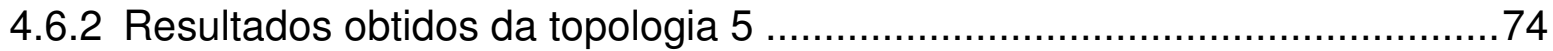




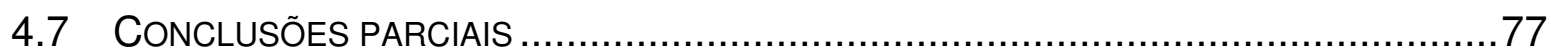

\section{APLICAÇÃO DE ALGORITMOS GENÉTICOS PARA ANÁLISE E} DIMENSIONAMENTO DA PROTEÇÃO DE SISTEMAS DE DISTRIBUIÇÃO DE ENERGIA ELÉTRICA. .78

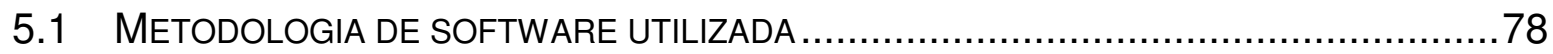

5.1.1 Análise e engenharia de sistemas ......................................................

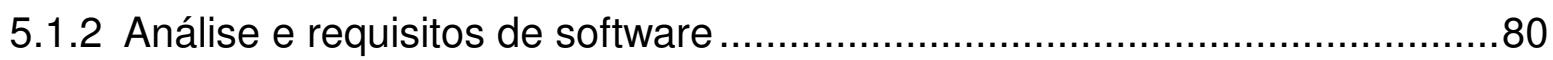

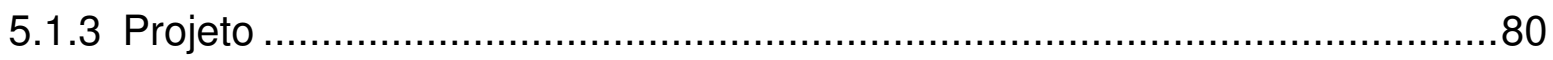

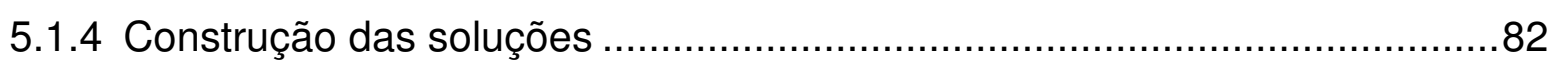

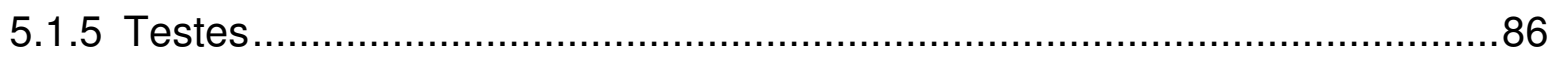

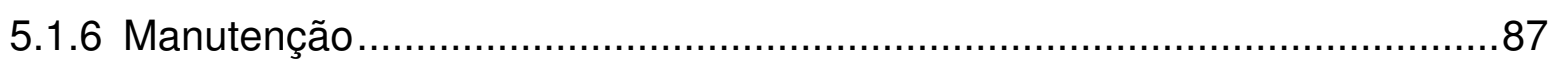

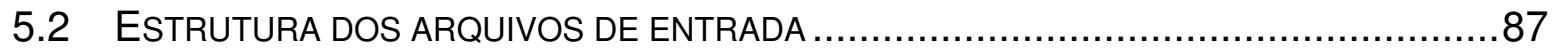

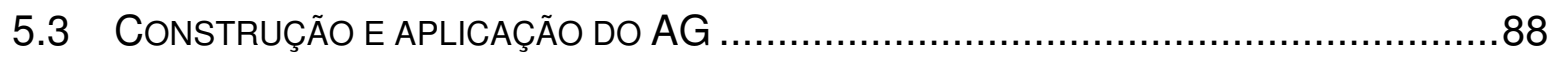

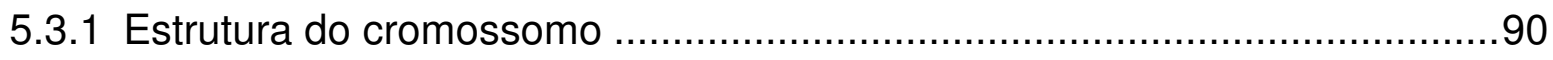

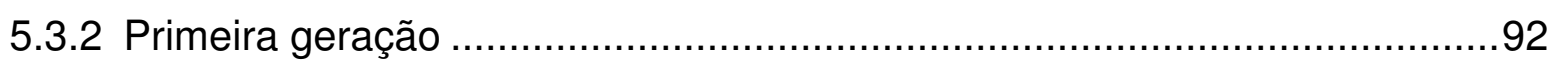

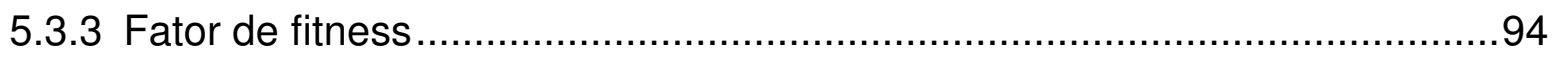

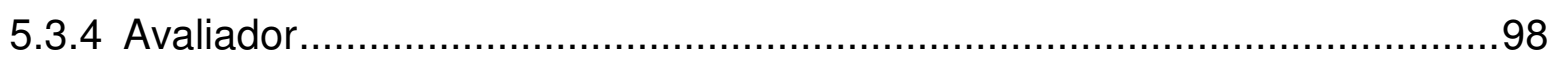

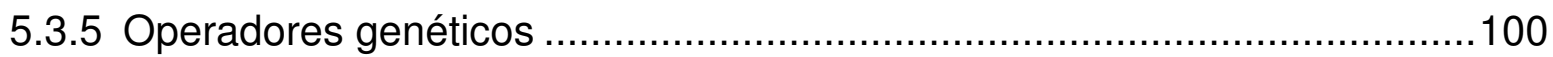

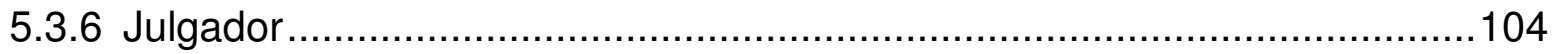

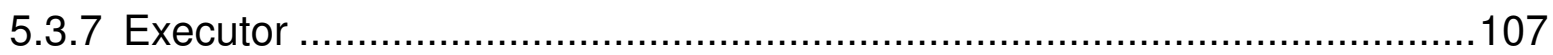

5.3.8 Critérios de parada das iterações........................................................112

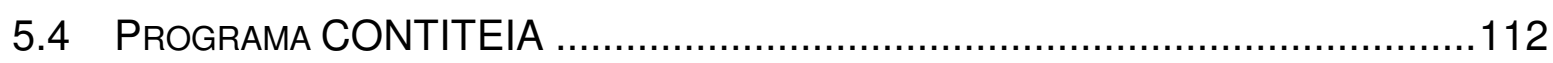

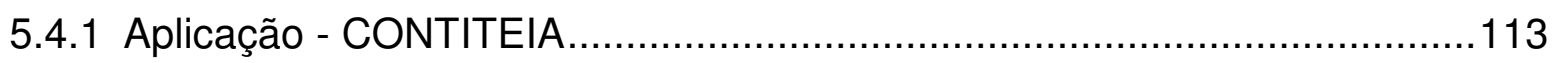

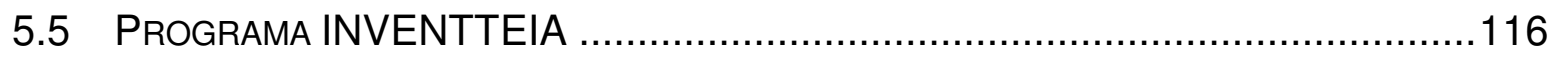

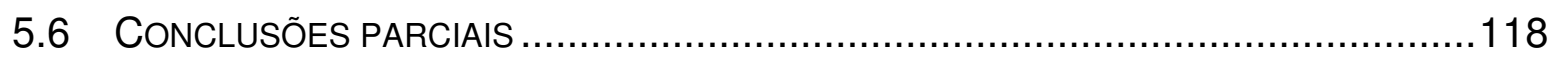

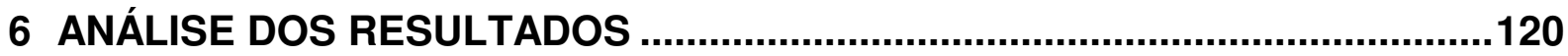

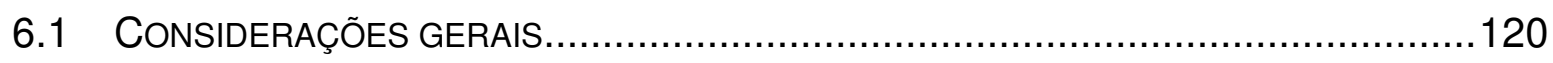

6.2 ANÁLISE DAS TOPOLOGIAS SIMULADAS NO PROGRAMA TEIAA (MODELOS) ..........120

6.3 ANÁLISE DA OTIMIZAÇÃO DO PROGRAMA TEIAG (MÉTODO) ...............................124

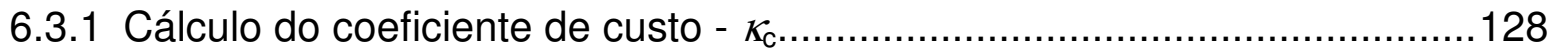

6.3.2 Análise do comportamento do AG - programa TEIAG.............................131

6.4 Resultados - Programa CONTITEIA …............................................131 
6.4.1 Resposta do circuito em relação à tabela de contingências......................132

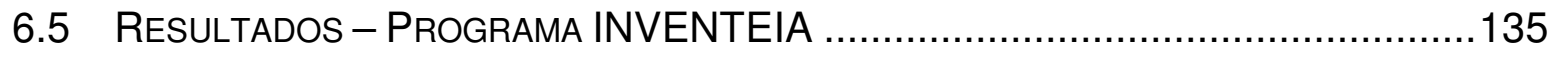

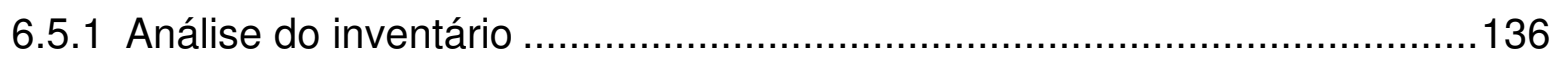

7 CONCLUSÕES E CONSIDERAÇÕES FINAIS ................................................139

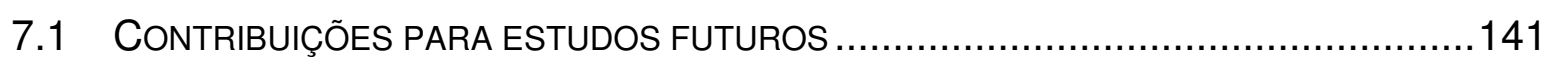

REFERÊNCIAS BIBLIOGRÁFICAS ..................................................................143

ANEXO A - FUNÇÕES: TEIAA, TEIAG, CONTITEIA E INVENTEIA.....................152 ANEXO B - EQUIPAMENTOS DE PROTEÇÃO PARA A DISTRIBUIÇÃO DE ENERGIA ELÉTRICA ...................................................................160 
Capítulo 1

Introdução

\section{Introdução}

Este capítulo apresenta as etapas realizadas no desenvolvimento e organização do trabalho.

\subsection{Objetivos do trabalho}

A alocação de equipamentos de proteção para a distribuição de energia elétrica segue critérios específicos e ditados por empresas como a ANEEL (Agência Nacional de Energia Elétrica). Este assunto tem sido objeto de estudo e motivação da literatura especializada [ANEEL № 24 (2000), Billington et al. (1996) e Brown et al. (1996)].

A escolha adequada do dispositivo de proteção baseia-se na confiabilidade operacional. Assim, é preciso considerar índices de continuidade operacionais, como DEC, FEC, DIC, FIC e DMIC, além de custos de equipamentos e perspectivas de manutenções corretivas e preventivas.

O objetivo do trabalho é encontrar a solução otimizada para a alocação de equipamentos de proteção de distribuição de energia elétrica em um circuito de distribuição, utilizando o método dos Algoritmos Genéticos, considerando custos e número de equipamentos, envolvendo:

- Cálculo de índices de continuidade: DEC e FEC;

- Análise de contingências de um circuito elétrico resultando nos índices DIC, FIC e DMIC;

- Obtenção de uma solução otimizada de alocação de equipamentos de proteção, a partir da análise do inventário de uma concessionária de energia elétrica.

Objetiva-se assim desenvolver uma solução confiável - em relação ao cliente final (consumidor de energia elétrica) - para a obtenção dos índices mencionados. 
Para tal foram desenvolvidos quatro programas, descritos a seguir:

- TEIAA que fornece a solução inicial para o cálculo dos índices de continuidade DEC e FEC [Bishop (1997)], com base em um circuito elétrico modelado por um arquivo texto. Por meio de simulações, encontraram-se resultados semelhantes aos obtidos por Bishop (1997), validando o programa.

- TEIAG que adota o protótipo do TEIAA e, a partir de um modelo inicial de circuito elétrico modelado por um arquivo texto, fornece uma resposta otimizada da alocação de equipamentos e suas perspectivas de custos, baseadas no emprego de algoritmos genéticos. Para se obter a solução otimizada, foram analisados vários métodos numéricos que buscavam encontrar valores para uma otimização operacional de alocação de equipamentos de proteção. Este procedimento garantiu, com solidez, que tal solução fosse aplicada, como ferramenta de cálculo, no programa global TEIAG, responsável pelo algoritmo genético.

- CONTTEIA que realiza o cálculo dos índices de continuidade DIC, FIC e DMIC, a partir de uma tabela que modela o histórico de contingências. Para tanto, utiliza-se um arquivo texto, que representa as contingências possíveis no circuito e suas respostas. Adota-se, inclusive, o emprego de chaves-de-manobra - normalmente, abertas ou fechadas - e de proteção;

- INVENTTEIA que verifica o número de equipamentos presentes no estoque de uma concessionária de energia elétrica. Esse programa retorna uma solução circuital otimizada por meio do AG. Teve como finalidade auxiliar a tomada de decisão para alocar equipamentos de proteção e utilizou o método AG.

Para desenvolver os programas foi necessário o desenvolvimento de:

- Pesquisa literária de um modelo confiável sob o ponto de vista técnico e operacional. Consideram-se valores adequados às normas da ANEEL, no que diz respeito à energia. Este modelo foi encontrado em Bishop (1997).

- Realização e detalhamento dos cálculos apresentados em Bishop (1997) e sua adequação ao modelo brasileiro [McCarthy et al. (2000), Kagan (1999) e ANEEL № $24(2000)]$.

- Foi criado um modelo de representação de um sistema elétrico para ser implementado de modo prático e com esforço computacional otimizado, contendo as informações elétricas necessárias. 
Dentre todas as opções experimentadas, aquela que ofereceu mais facilidade de implementação foi a solução recursiva ${ }^{1}$ [Cormen et al. (2002)]. Esta possibilitou atingir todos os ramos do circuito, com a realização de cálculos. Ela buscou as informações à montante e à jusante dos nós circuitais.

A evolução da solução computacional levou ao estudo e à escolha do método de numérico de otimização circuital a ser utilizado. Entre eles, destacam-se:

- Método da substituição, que envolve duas etapas:

a) pressuposição da forma da solução;

b) uso de indução matemática para se encontrar as constantes do programa e mostrar que a solução é válida.

O nome deste método refere-se à substituição da resposta pressuposta para a função, quando a hipótese indutiva é aplicada a um conjunto menor de parâmetros. Este método é eficiente, segundo a literatura, para ser aplicado em casos nos quais se pressupõe a forma final da solução da resposta [Cormen et al. (2002)]. Porém, esta finalidade afasta-se do escopo deste trabalho, pois não se conhecer, de antemão, a forma final da solução.

- Newton-Raphson

O método deve escolher um ponto de partida pertencente à função que garanta convergência. Esta deve ser obtida por meio de sucessivas iterações, apoiadas pela derivada da função analisada.

O procedimento deve ser repetido até que a precisão desejada seja alcançada. A idéia básica baseia-se nos seguintes procedimentos:

Toma-se uma função contínua $f(x)$, cuja raiz pode ser chamada de $\bar{x}$. Como esta não é conhecida, inicia-se tomando um valor próximo de $\bar{x}$, que é chamado de $x_{0}$ (valor inicial).

\footnotetext{
${ }^{1}$ Uma solução recursiva ocorre quando uma equação ou desigualdade descrita por uma função realiza uma chamada a si própria.
} 


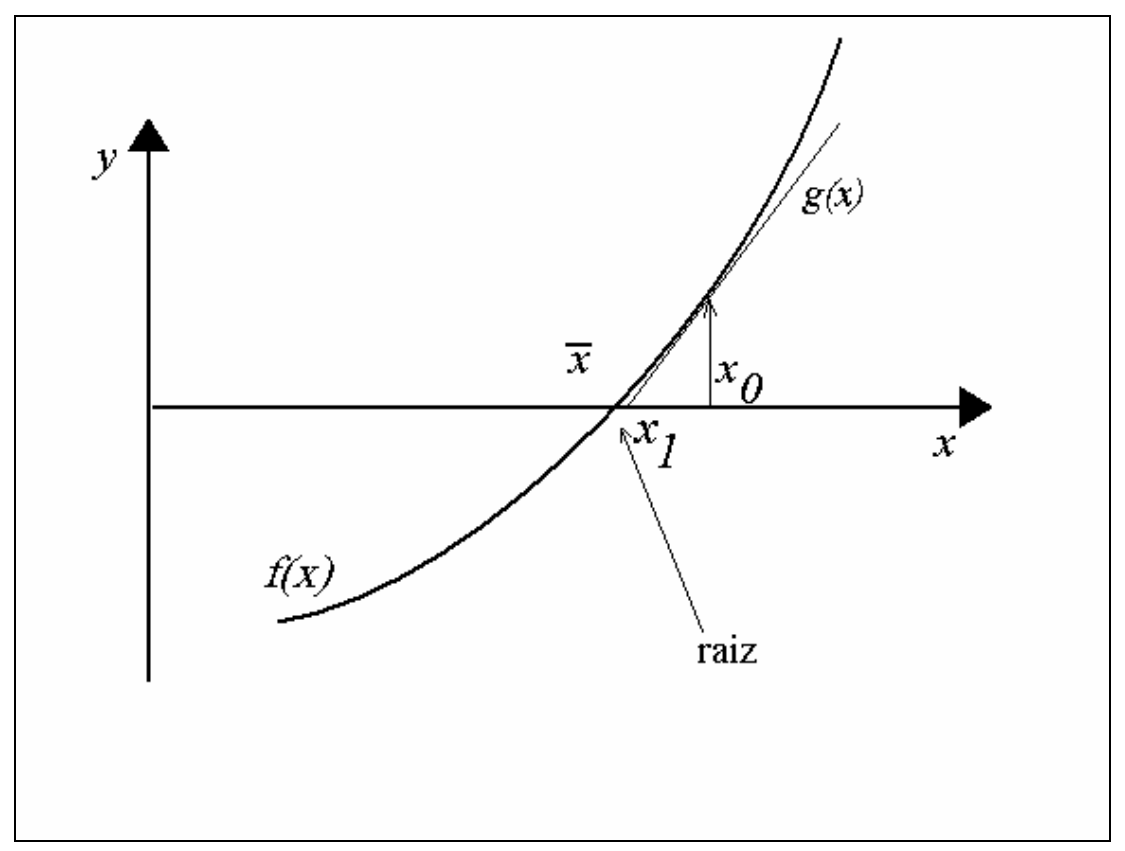

Figura 1.1 - Problema do valor inicial no método de Newton-Raphson

O ponto determinado pelo par $\left(\mathrm{x}_{0}, \mathrm{f}\left(\mathrm{x}_{0}\right)\right)$ pertence à curva definida pela função. Pode-se calcular a derivada da função no ponto $\left(\mathrm{x}_{0}, \mathrm{f}^{\prime}\left(\mathrm{x}_{0}\right)\right)$.

Como f' $\left(\mathrm{x}_{0}\right)$ corresponde ao coeficiente angular de uma reta que é tangente à função no ponto $x_{0}$, é possível determinar a expressão desta reta, pela equação (1.1):

$g(x)=f^{\prime}\left(x_{0}\right) x+b$

Como, no ponto $x=x_{0}$, tanto $g(x)$ como $f(x)$ têm o mesmo valor, $f\left(x_{0}\right)$, obtém-se o valor de b:

$b=f\left(x_{0}\right)-x_{0} f^{\prime}\left(x_{0}\right)$

Assim, é possível escrever a expressão completa de $\mathrm{g}(\mathrm{x})$ :

$g(x)=f^{\prime}\left(x_{0}\right) x+\left[f\left(x_{0}\right)-x_{0} f^{\prime}\left(x_{0}\right)\right]$

O ponto em que $g(x)$ se anula - ou seja, a raiz de $g(x)$ - pode ser obtido da seguinte maneira:

$$
g\left(x_{1}\right)=0 \Rightarrow x_{1}=x_{0}-\frac{f\left(x_{0}\right)}{f^{\prime}\left(x_{0}\right)}
$$

Dessa forma, a partir do valor $\mathrm{x}_{0}$, pode-se obter um novo valor $\mathrm{x}_{1}$, que está mais próximo da raiz $\bar{x}$.

Aplicando-se este processo novamente, substituindo $x_{0}$ por $x_{1}$, o novo valor de $x_{1}$ ficará mais próximo ainda de $\bar{x}$. Desse modo, pode-se estabelecer um méto- 
do repetitivo, com aproximações sucessivas, até que um limite de precisão seja alcançado. Assim, tem-se o termo genérico da sequência:

$$
x_{i+1}=x_{i}-\frac{f\left(x_{i}\right)}{f^{\prime}\left(x_{i}\right)}
$$

Esta sequência é conhecida como fórmula de Newton-Raphson.

No caso de múltiplas possibilidades como resposta, pode-se obter uma solução não-otimizada. Esta situação, no que se refere à alocação ótima dos elementos de proteção, inviabiliza seu uso para a aplicação em sistemas elétricos, devido à característica discreta da alocação dos equipamentos de proteção.

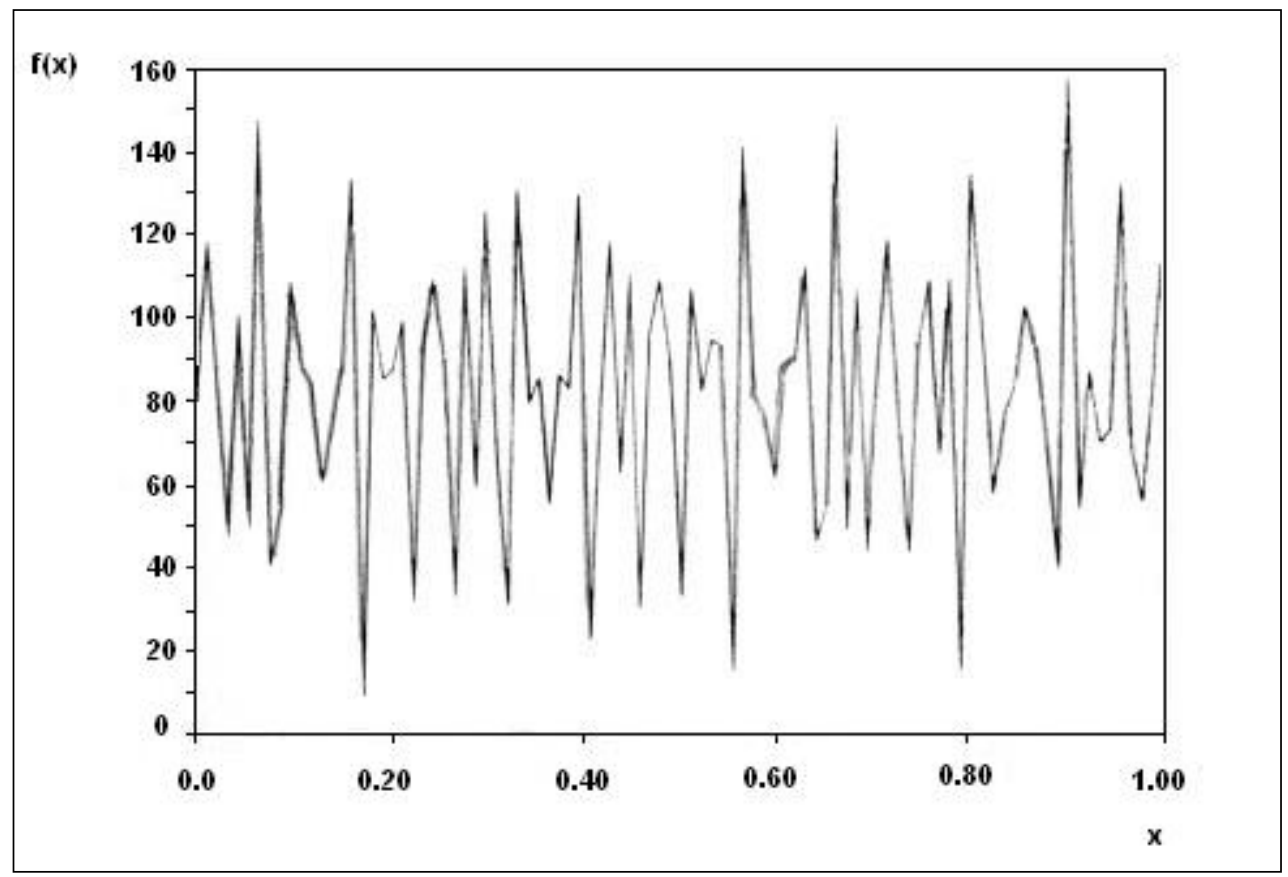

Figura 1.2 - Problema com múltiplas soluções

- Hill Climbing (Gradiente)

Este método é baseado no processo de gradientes e apresenta - dentre todas as possíveis alternativas de locação dos equipamentos de proteção de energia elétrica - o inconveniente de gerar uma solução não-otimizada na rede de distribuição.

Devido às características descritas, a opção encontrada nem sempre é a solução ótima. Tal fato ocorre porque o algoritmo pode encontrar um máximo (ou mínimo) local, encerrando a busca. Assim, ele seguirá o gradiente em que a inclinação indica a direção do crescimento maior. Finalmente, acabará preso no ponto de má- 
ximo local, marcado pelo ponto de inflexão. A Figura 1.3 [Russell et al. (2003)] ilustra bem esta situação.

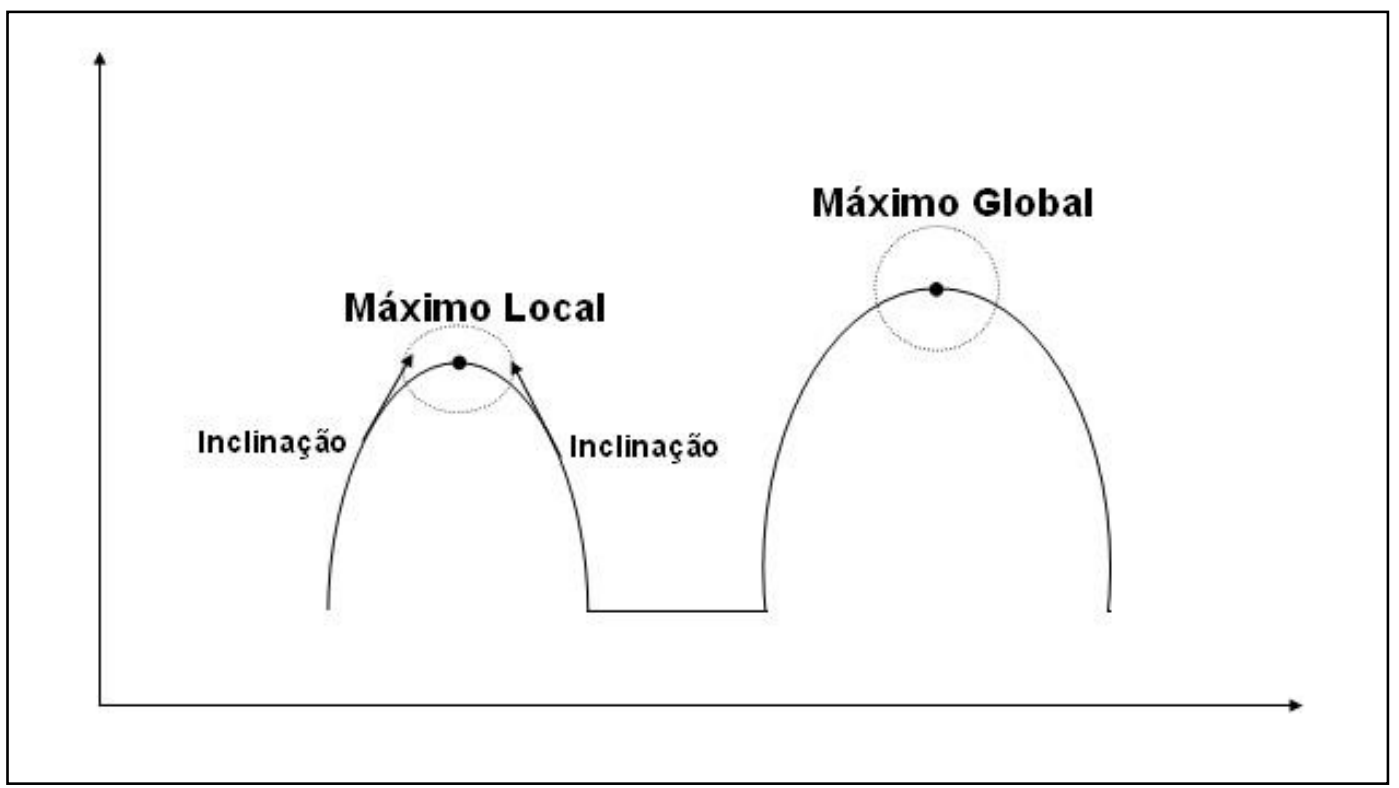

Figura 1.3 - Exemplo de função hipotética indicando um máximo local e um máximo global

- Simulated Annealing (Resfriamento Simulado)

Este método é uma técnica probabilística capaz de encontrar um mínimo global, mesmo na presença de vários mínimos locais, particularmente, nos casos em que as técnicas tradicionais de otimização falham. Deve-se observar que, como todas as técnicas aleatórias, vários testes devem ser feitos na procura da solução. Essa busca deve ser feita para aumentar a probabilidade de se obter o mínimo global. As aplicações numéricas demonstram a eficiência do método estudado em que o Simulated Anneling é aplicado na minimização de funções matemáticas e em problemas relacionados com sistemas mecânicos.

O Simulated Annealing pertence à mesma classe dos métodos das Redes Neurais e Algoritmos Genéticos, pois simula métodos Naturais. Ele hipotetiza o processo de recozimento (annealing) da metalurgia, em que o metal é aquecido a altas temperaturas, provocando um choque violento nos átomos. Caso o metal seja resfriado de maneira brusca, a microestrutura tende a um estado aleatoriamente instável. Contudo, se for resfriado lentamente, o sistema procurará um ponto de equilíbrio, caracterizado por uma microestrutura ordenada e estável. As variáveis de projeto são perturbadas randomicamente, e armazena-se o melhor valor da função a cada perturbação. A temperatura é reduzida (annealing), e novas tentativas são e- 
xecutadas. Este procedimento continua até se escapar de um mínimo local. No final do processo, é possível que se obtenha um mínimo global.

O Simulated Annealing, em comparação com o AG, não apresenta uma relação paralela tão intrínseca. No caso do AG, se o caminho estiver errado, este é eliminado, e o trabalho de busca continua em outra direção [Goldberg (1989)].

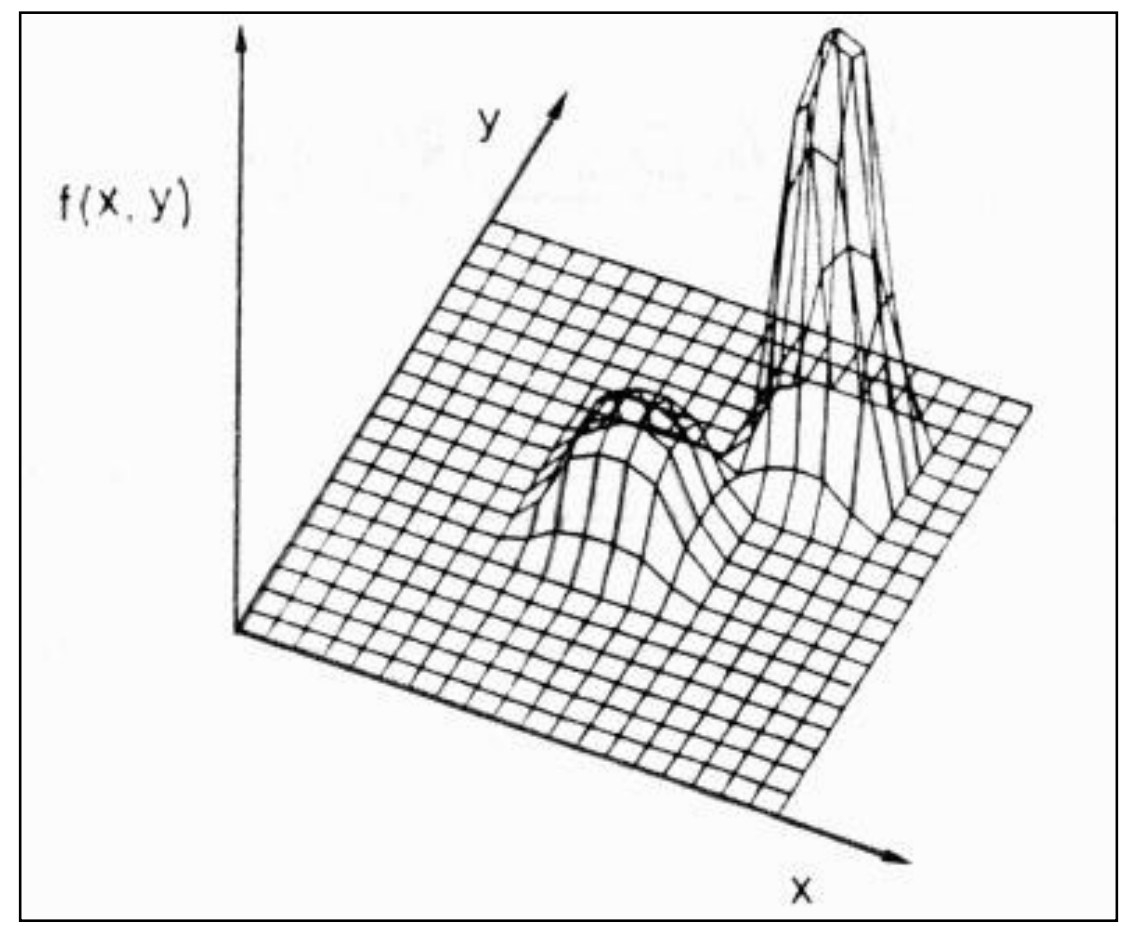

Figura 1.4 - A ocorrência de múltiplos picos - dilema na escolha do método matemático

- Redes Neurais

O modelo de rede neural trabalha com alguns nós, que são estimulados a transmitir sinais para outros nós, presentes em diferentes camadas, gerando conhecimento. A rede neural trabalha com a possibilidade de alteração do comprimento das conexões. Ela considera a possibilidade de alterar o tamanho dos neurônios (cromossomos) utilizados, o que, no escopo deste trabalho, causaria problemas, pois apesar dos cromossomos serem alocados dinamicamente, o circuito tem um tamanho fixo [Neelakanta et al. (1994)]. 
- Método de árvore de execução associado ao algoritmo genético

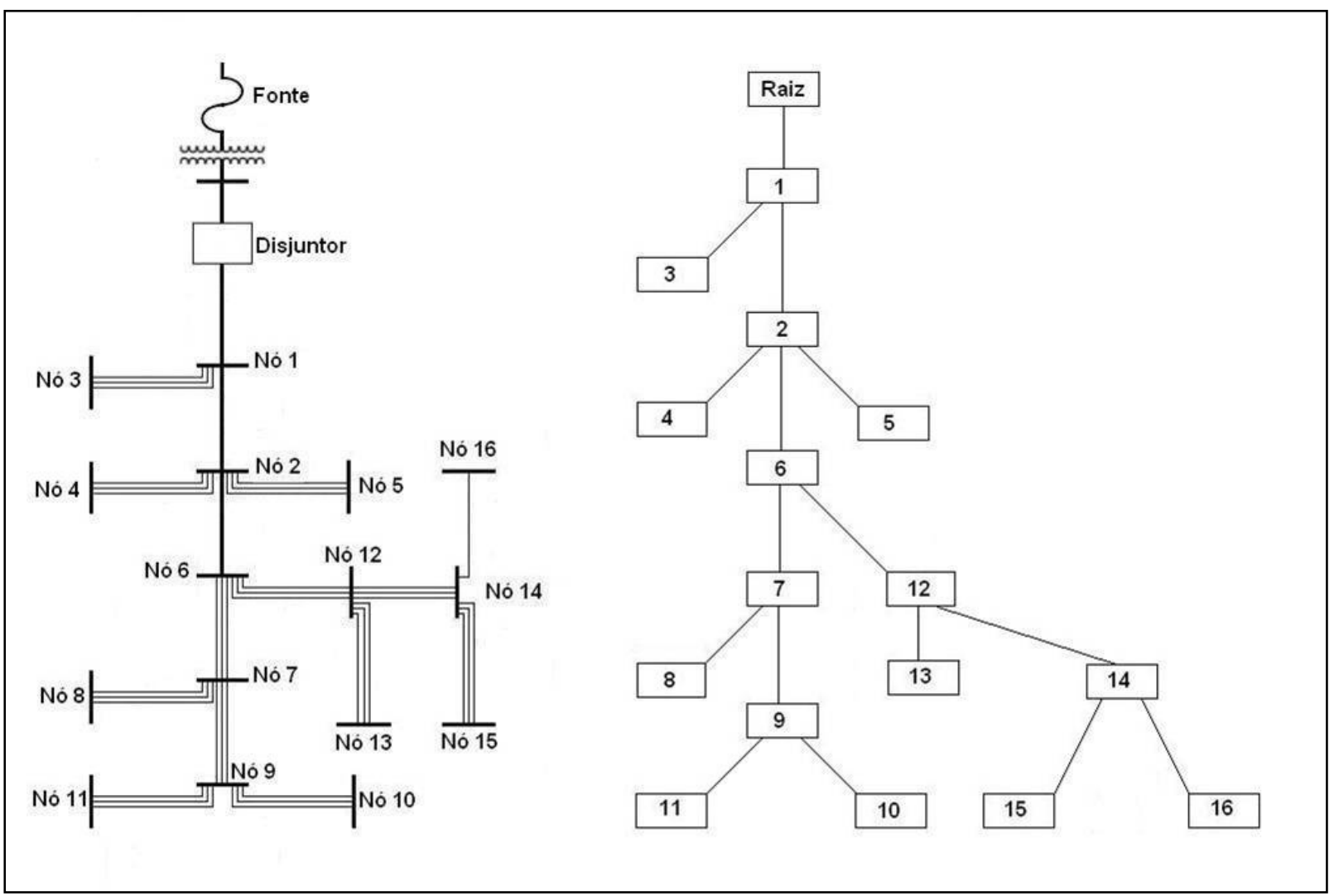

Figura 1.5 - Representação do circuito por diagrama elétrico e por árvore de recursão

Este método representa o circuito de distribuição por meio de uma árvore de recursão [Cormen et al. 2002], em que cada nó da árvore corresponde a uma barra (nó). Tal opção possibilita intercalar o componente de proteção entre nós consecutivos.

Por meio dessa forma de representação é possível percorrer o circuito e atingir toda a sua extensão, experimentando o seu comportamento operacional e colocando os elementos de proteção.

Este conceito, associado ao Algoritmo Genético (AG), permite a varredura de todos os trechos do circuito, inserindo-se ou não os componentes de proteção, de acordo com a necessidade. Por intermédio dele, vislumbram-se diversas possibilidades de solução. Estas, por sua vez, atingem o resultado otimizado, em função dos índices de continuidade, dos custos de material e da manutenção.

O AG pode ser usado também como método para a otimização do modelo e aplicações apresentadas em conjunto com a representação em árvore de execução. Ele possibilita obter um resultado consistente, ou seja, suficiente para tolerar mudanças aleatórias, como alterações da topologia de circuitos provocadas por fenô- 
menos naturais, ações temporárias necessárias em processos de manutenção e outras. Kagan (1999) verifica que os algoritmos evolucionários - em especial, os genéticos (AGs) - estão presentes em diversos problemas de Engenharia e são utilizados em soluções computacionais. Neste sentido, observa-se que alguns modelos de circuitos relacionados ao problema de sistemas de distribuição de Energia Elétrica mostraram enormes vantagens na utilização dos AGs.

É importante enfatizar que AGs são técnicas probabilísticas e não técnicas determinísticas [Linden (2006)]. Assim, um AG com a mesma população inicial e o mesmo conjunto de parâmetros, a cada vez que for executado, pode encontrar, de maneira eficaz, soluções diferentes. Estas baseiam-se nos AGs e contemplam problemas simples, que necessitam somente de informações locais no ponto avaliado. Segundo Linden (2006), essas informações verificam se tal ponto é adequado para a solução do problema em questão. Assim, o referido processo não necessita de derivadas ou de qualquer outro dado adicional para se atingir a solução otimizada.

As soluções são aplicáveis a problemas do mundo real que, em geral, incluem descontinuidades duras ${ }^{2}$. Trata-se de uma constatação que concorda com um dos objetivos principais deste trabalho: alocar equipamentos. Portanto, a impossibilidade de calcular derivadas ou gradientes descarta o uso de técnicas tradicionais que dependam das características das funções. Estas, por sua vez, não podem ser atendidas em problemas reais.

Os AGs diferenciam-se de esquemas aleatórios pelo uso de um mecanismo de busca específico. Este utiliza informação pertinente ao problema e não trabalha com percursos aleatórios (Random Walks) pelo espaço de soluções. Os AGs diferenciam sua busca por meio de seleção, equivalente ao processo natural. A determinação do conjunto de pontos a serem percorridos de forma aleatória não permite que os AGs sejam chamados de "buscas aleatórias não-direcionadas". Isso acontece porque eles exploram informações históricas para encontrar novos pontos de busca em que são esperados bons desempenhos [Linden (2006) e Carvalho (2003)].

Neste trabalho, partiu-se do modelo de Bishop (1997). Criou-se o programa TEIAA para implementar o algoritmo de cálculo dos índices de continuidade, incor-

${ }^{2}$ Descontinuidades duras descrevem situações em que os dados são discretos ou não possuem derivadas [Linden (2006)]. 
porando-o ao TEIAG como ferramenta matemática. O TEIAG inclui a solução AG, sob um caráter discreto, que é uma característica da alocação de equipamentos de distribuição.

A Figura 1.6 apresenta o diagrama de relacionamentos dos programas TEIAA e TEIAG, sob o ponto de vista de modelo $^{3}$ e método ${ }^{4}$, marcando o início do desenvolvimento da solução.

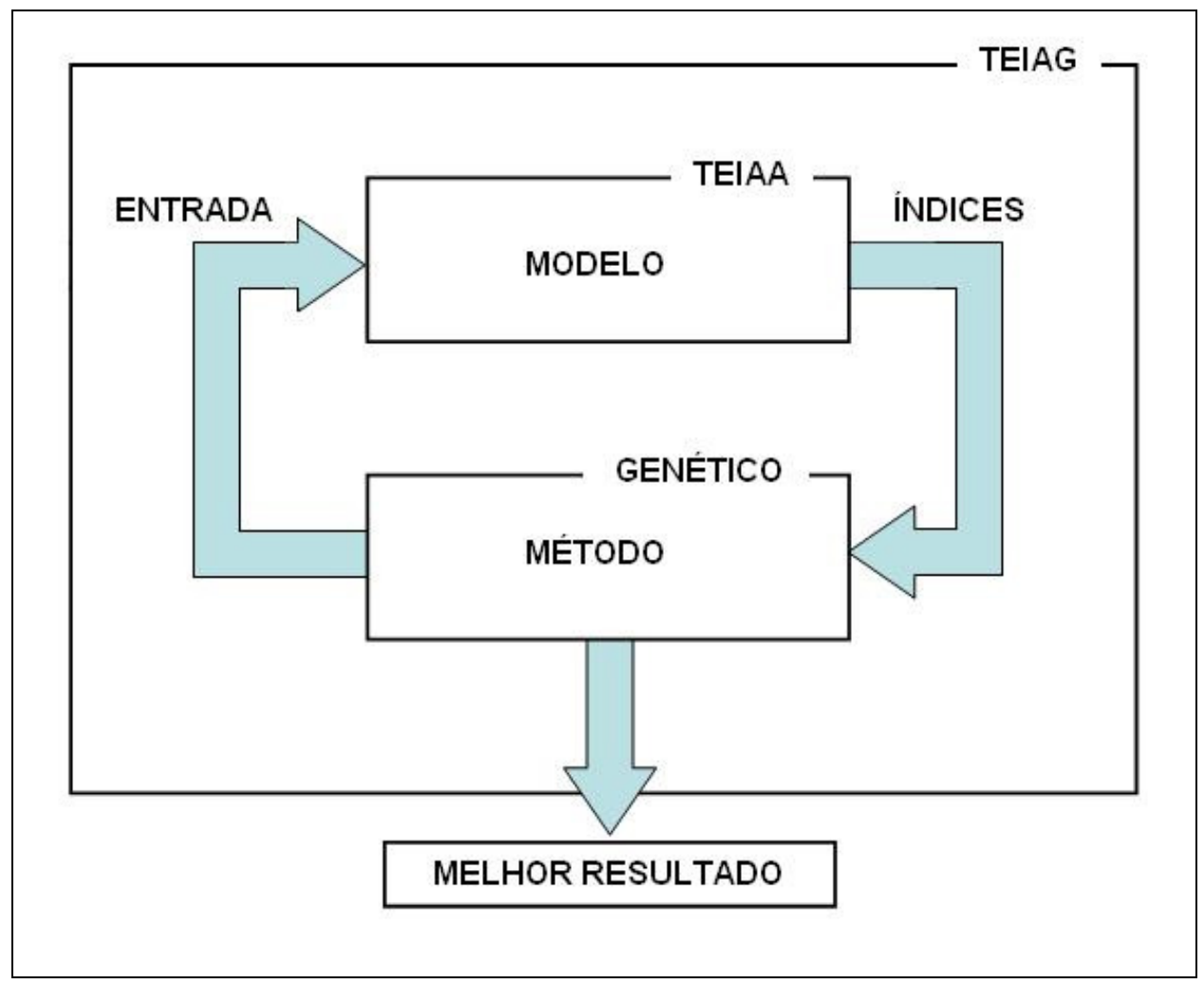

Figura 1.6 - Diagrama da localização dos programas TEIAA e TEIAG

Uma vez que os algoritmos tenham sido estudados, foi escolhido o Método de Árvore de Execução associado ao Algoritmo Genético, devido ao melhor desempenho apresentado. A primeira etapa do trabalho foi criar e desenvolver uma solução que representa um sistema elétrico genérico. Esta etapa seguiu o exemplo apresentado por Bishop (1997). Utilizou uma linguagem com as características de campo e

\footnotetext{
${ }^{3}$ Modelo: um modelo matemático é uma representação ou interpretação da realidade. Pode ser também interpretação de um fragmento de um sistema, segundo uma estrutura de conceitos mentais ou experimentais. Um modelo apresenta apenas uma visão ou cenário de um fragmento do todo.

${ }^{4}$ Método: a palavra método vem do grego méthodos (caminho para chegar a um fim). O método científico é um conjunto de regras básicas para desenvolver uma experiência, a fim de produzir novo conhecimento, bem como corrigir e integrar conhecimentos preexistentes.
} 
alocação de equipamentos existentes no mercado de distribuição brasileiro. Assim, uma das contribuições deste trabalho refere-se à representação de um circuito elétrico em forma de arquivo texto.

Com o programa TEIAA desenvolvido e considerando regras de alocação de equipamentos e parâmetros elétricos, calculam-se os índices de continuidade (DEC e FEC), buscando uma solução otimizada.

Nota-se, na Figura 1.6, que o programa TEIAA tem a função de representar o modelo a ser gerado. Este, por sua vez, foi utilizado como função a ser implementada no programa TEIAG. Testando as condições de contorno propostas por Bishop (1997), consolidou-se a aplicação desenvolvida, obtendo-se resultados semelhantes ao estudo de Bishop (1997). Com este núcleo de modelo, partiu-se para o desenvolvimento e implementação do AG.

Este processo envolveu regras de alocação de equipamentos, custos unitários, parâmetros elétricos associados, índices de continuidade e número de equipamentos, encontrando-se uma solução otimizada da distribuição dos componentes da rede de distribuição.

Este trabalho visa contribuir para o estudo do tema, implementando o cálculo dos índices de continuidade individuais DIC, FIC e DMIC. Além disso, utilizará uma tabela histórica de contingências, com ocorrências registradas posteriormente, emprego de chaves-de-manobra e chaves-de-proteção, de acordo às regras ditadas pela ANEEL [ANEEL № 24 (2000)]. Merece destaque a criação de uma linguagem de descrição do histórico de contingências, representando a sequência de eventos que o compõem e obtendo uma resposta do circuito para análise a posteriori. Essa iniciativa proporciona à concessionária visualizar a solução e adaptá-la à sua realidade. Foi criado também um programa aplicativo denominado CONTTEIA, incorporado ao pacote final, cuja finalidade é analisar as possibilidades de contingências descritas no arquivo.

Outra contribuição importante foi a criação de um banco de dados, que representa o inventário dos equipamentos disponíveis na concessionária. A partir de tais informações, é possível apresentar a melhor solução de circuitos, com os equipamentos disponíveis no estoque, de acordo com sua realidade econômica. Foi gerado um programa aplicativo INVENTTEIA, que utiliza o AG com as condições de contorno estabelecidas pelo mapa de estoque da concessionária. 


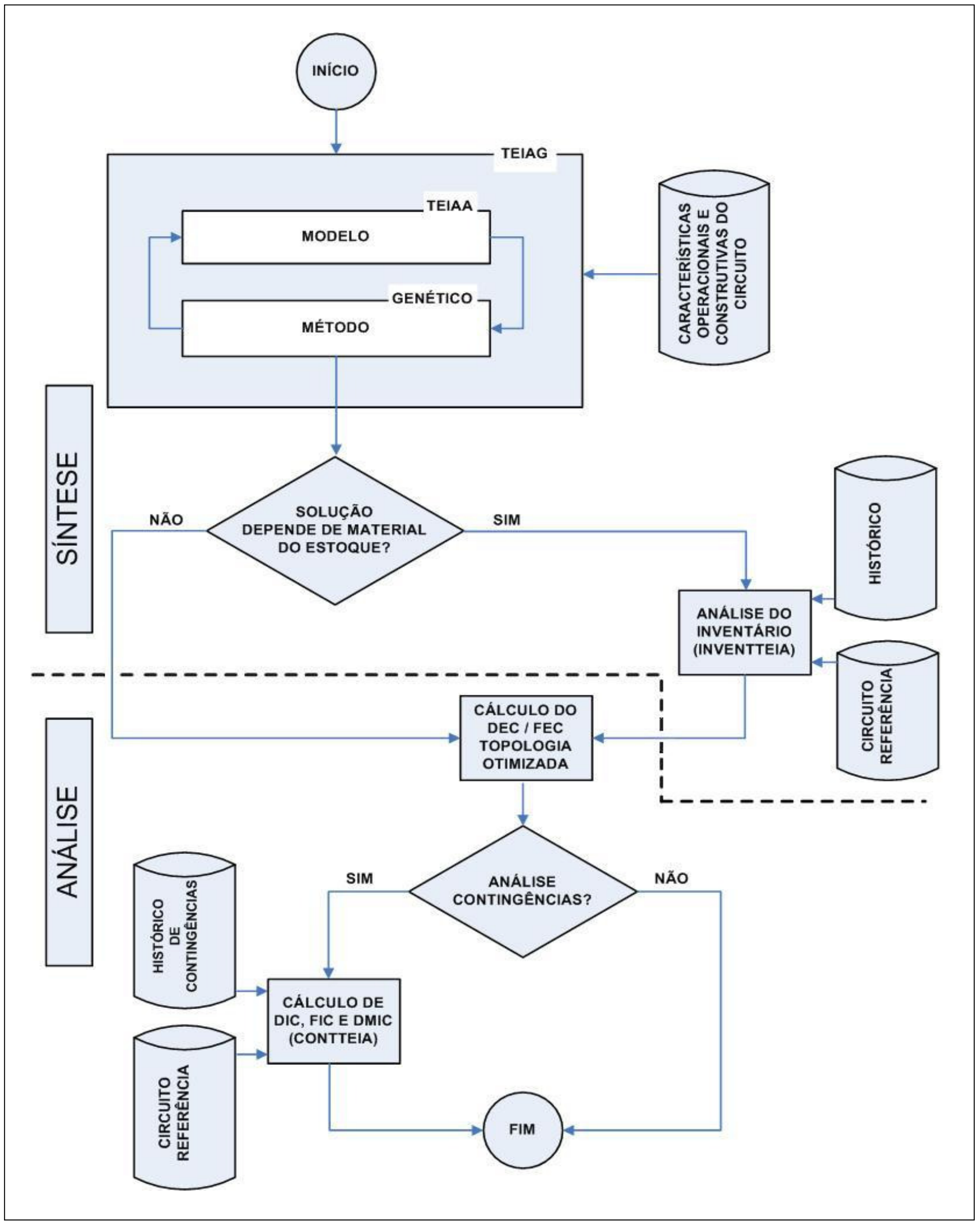

Figura 1.7 - Evolução do diagrama de localização dos programas TEIAA e TEIAG - Análise e Síntese 
Na Figura 1.7, vislumbram-se duas regiões distintas:

- Síntese: responsável pelas características operacionais e construtivas do circuito. O programa aplicativo TEIAG utiliza o TEIAA (modelo) e implementa a solução baseada no algoritmo genético (método).

O programa INVENTTEIA faz parte da síntese, usando as restrições impostas pelo inventário da concessionária. Ele busca criar uma solução otimizada com os equipamentos encontrados no estoque.

- Análise: verifica-se a topologia, efetuando o cálculo dos índices de continuidade DEC e FEC. Utiliza o histórico de contingências, objetivando o cálculo dos índices de continuidade DIC, FIC e DMIC, por meio do programa aplicativo CONTTEIA.

Verifica-se uma aplicação inovadora do uso do AG, como método para aplicação em soluções discretas de alocação de equipamentos, nas seguintes situações:

- aplicação de uma tabela de contingência de eventos e obtenção da resposta do sistema;

- uma solução AG otimizada, orientada por um fator de fitness. Este, por sua vez, baseia-se em custos e número de equipamentos;

- implementação de mudanças de regras de alocação de equipamentos, caso seja necessário, diretamente nos programas mencionados. A solução é adaptada a outros problemas de distribuição de energia elétrica;

- a análise do inventário da concessionária traz grandes vantagens de aplicação da solução: esta deve corresponder à realidade da concessionária, adequandose e baseando-se em cálculos realizáveis.

\subsection{Organização do trabalho}

Este estudo organiza-se em sete capítulos.

No Capítulo 2, é apresentado o modelo de rede de distribuição de energia elétrica. Parte-se da concepção atual de sistemas elétricos de potência até a localização do problema de alocação de dispositivos de proteção de energia elétrica. Discutem-se também os conceitos de qualidade de serviço/produto e aplicações no campo da energia elétrica. Este capítulo forma a base para os cálculos de indicadores de continuidade definidos pela ANEEL. Adicionalmente, apresenta as análises a posteriori e a priori, dentro de um cenário da distribuição de energia elétrica. 
O Capítulo 3 descreve os algoritmos genéticos como métodos de otimização de problemas em distribuição de energia elétrica. São discutidos os algoritmos evolutivos e suas derivações. Alguns exemplos de derivações são as técnicas de busca, o surgimento dos AGs como métodos inspirados na seleção natural, os passos de um AG canônico e a aplicação no trabalho.

No Capítulo 4, é discutida a metodologia utilizada para o desenvolvimento dos cálculos a todas as topologias da rede de distribuição de energia. O objetivo é calcular os valores de DEC e FEC, definidos em Bishop (1997), além de criar o programa TEIAA, utilizado como função no TEIAG.

O Capítulo 5 descreve a aplicação do AG junto à Árvore de Execução. Também analisa e dimensiona o processo de evolução dos programas desenvolvidos e de sua metodologia, abordando dos programas desenvolvidos: TEIAA, TEIAG, CONTTEIA e INVENTTEIA.

O Capítulo 6 apresenta as soluções de aplicação de cada programa. Inclui a análise das diferentes topologias, apresentadas no Capítulo 4, e os resultados alcançados.

O trabalho é finalizado no Capítulo 7. Apresentam-se as conclusões e considerações gerais, as suas contribuições e aplicações futuras das soluções desenvolvidas, com o intuito de serem aplicadas em concessionárias de energia elétrica. 
Capítulo 2

\section{Modelo de Rede de Distribuição de \\ Energia Elétrica}

\section{Modelo de Rede de Distribuição de Energia Elétrica}

Apresenta-se o modelo de rede de distribuição de energia elétrica, em que este estudo se baseou. Localiza-se o problema abordado, envolvendo os sistemas elétricos de potência.

\subsection{Sistemas elétricos}

Na concepção, segundo Jardini (1996), os sistemas elétricos de potência estão divididos em:

- geração: é o primeiro processo na entrega da eletricidade aos consumidores;

- transmissão: é o processo de transportar energia elétrica entre pontos. É realizado por linhas de transmissão de alta potência, geralmente, usando corrente alternada;

- subestação de energia elétrica: é uma instalação elétrica de alta potência, contendo equipamentos para transmissão, distribuição, proteção e controle de energia elétrica. Funciona como ponto de controle e transferência em um sistema de transmissão elétrica. Direciona e controla o fluxo energético, transformando os níveis de tensão e de energia elétrica ao consumidor final;

- sistemas de distribuição de consumidores finais: são os consumidores que usufruem da energia enviada pela concessionária.

No esquema da Figura 2.1, baseada em Jardini (1996), é possível observar essa disposição: 


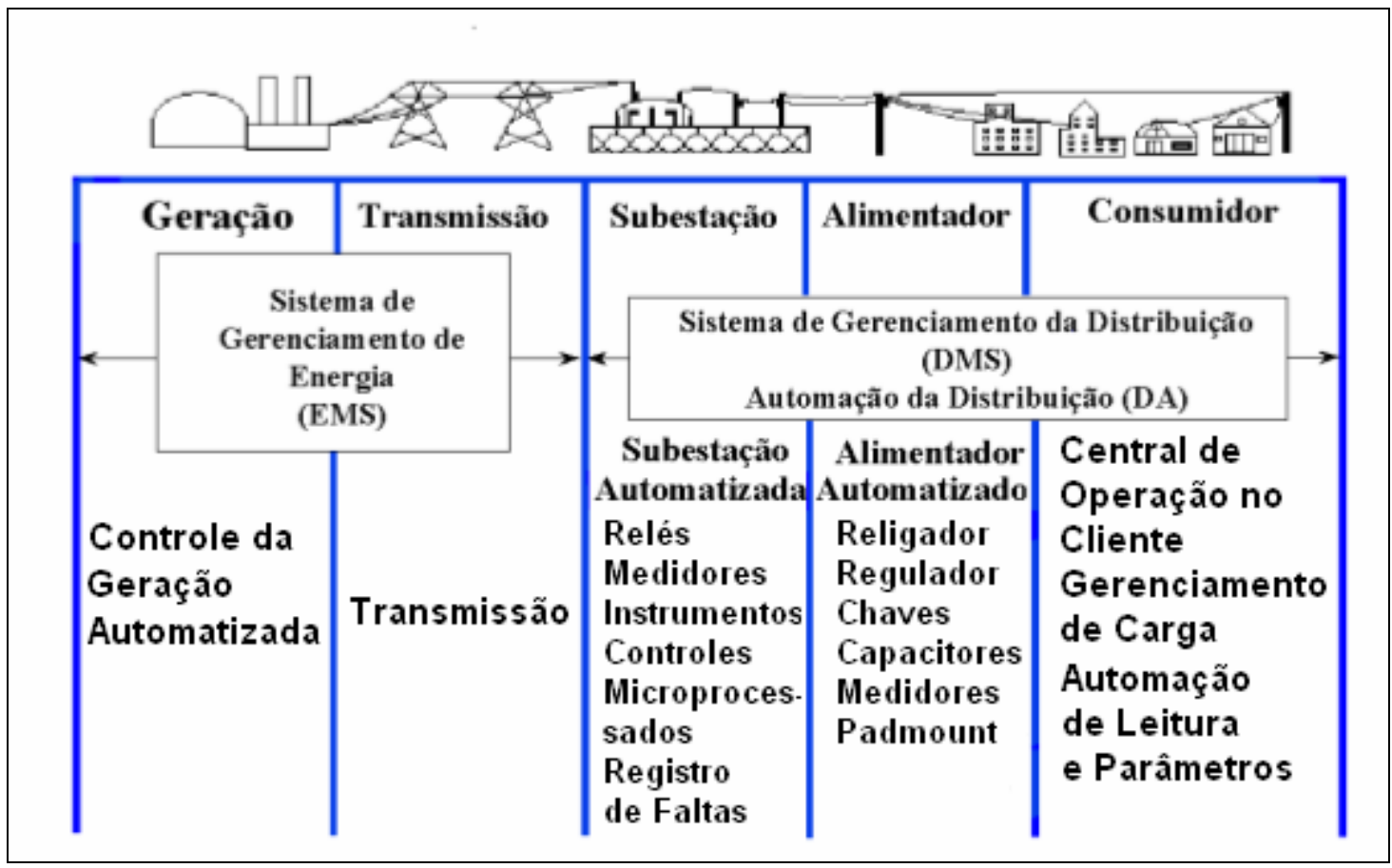

Figura 2.1 - Partes constituintes de um sistema elétrico

Na Figura 2.1, observa-se que a primeira divisão $\mathrm{EMS}^{5}$ engloba a geração de energia, a transmissão e parte da subestação de distribuição. A segunda DMS/DA ${ }^{6}$ abrange a subestação, o alimentador e o atendimento ao consumidor final [Jardini (1996) e Siqueira et al. (1988)].

Este trabalho considera a segunda divisão, utilizando um modelo de rede de distribuição de energia elétrica, no qual serão alocados dispositivos de proteção.

Segundo Kagan et al. (2005), o modelo de configuração de redes de distribuição de energia elétrica inclui os problemas de planejamento da operação: a reconfiguração de redes de distribuição e o planejamento de médio prazo de sistemas de distribuição.

Um estudo inicial consiste em apresentar como a medida da qualidade da energia elétrica, representada por seus índices de continuidade, pode afetar os consumidores finais e setores industriais, visualizados na Figura 2.1. As expectativas dos usuários precisam ser consideradas no estabelecimento de metas de qualidade, que podem variar de acordo à topologia da rede e à região geográfica envolvida.

\footnotetext{
${ }^{5}$ EMS - Sistema de Gerenciamento de Energia

${ }^{6}$ DMS - Sistema de Gerenciamento da Distribuição

DA - Automação da Distribuição
} 
É fundamental pontuar índices de desempenho, referenciados pela ANEEL [ANEEL № 24 (2000)], como índices de continuidade. Trata-se de um procedimento importante para possibilitar o controle da energia elétrica de forma objetiva. Conforme Kagan et al. (2005) e Westinghouse (1964), o fornecimento de energia elétrica deve obedecer a dois conceitos básicos:

- Qualidade de serviço: conhecida como continuidade de fornecimento, advém de interrupções no sistema elétrico. Estas provêm de falhas, que levam às chamadas "atividades de manutenção corretiva" e "atividades de manutenção programada ou preventiva". A qualidade de serviço, baseada nesses índices, é um dos núcleos do trabalho.

- Qualidade de produto: segundo Kagan et al. (2005), nessa abordagem, há a caracterização da forma de onda de tensão, no que se refere aos componentes de um sistema trifásico. Este perfil contempla os fenômenos de variação de frequência, as variações de tensão de longa e curta durações, as distorções harmônicas e desequilíbrios de tensão, de corrente e as flutuações de tensão. A qualidade de produto não é objeto de análise desta pesquisa.

É necessário apresentar os índices definidos pela ANEEL [ANEEL № 24 (2000)] e sua forma de cálculo [Kagan et al. (2005)], baseados nas seguintes avaliações:

- Avaliação a posteriori: determina os índices de continuidade, em função das ocorrências verificadas na rede de distribuição, após um determinado período.

$O$ desenvolvimento do CONTTEIA, programa que analisa um arquivo de contingências e retorna os valores de DIC, FIC e DMIC, utilizou a análise a posteriori. Nesta, a contabilização da qualidade do serviço, voltada tanto aos consumidores quanto ao sistema, é analisada sobre um intervalo de tempo, de acordo com as normas da concessionária de energia. A análise pode ser mensal, trimestral ou anual [Kagan et al. (2005)].

- Avaliação a priori: trata do cálculo de projeção dos indicadores de continuidade, quando se deseja realizar uma previsão de resposta do circuito. Tal procedimento baseou-se no desenvolvimento dos seguintes programas: TEIAA, responsável pelo cálculo dos índices de continuidade; TEIAG, que retorna um circuito de distribuição otimizado, baseado no AG; INVENTTEIA, que analisa o inventário da concessionária e adapta a melhor solução econômica, com auxílio do AG. Como não 
depende de histórico de contingências, o processo de desenvolvimento destes programas prioriza o processo de análise. Neste caso, foi feita uma estimativa da qualidade de energia, com base em parâmetros estatísticos, como: valores históricos de taxas de falhas dos equipamentos e tempo médio para atendimento de uma ocorrência na rede de distribuição [Kagan et al. (2005)]. A Tabela 2.1 resume as duas análises e a terminologia correlata.

Tabela 2.1 - Comparação entre estudos preditivo e corretivo

\begin{tabular}{|c|c|c|}
\hline Estudo & Antes da Falha & Após a Falha \\
\hline Análise & A priori & A posteriori \\
\hline Programas & $\begin{array}{c}\text { TEIAA } \\
\text { TEIAG } \\
\text { INVENTTEIA }\end{array}$ & CONTITEIA \\
\hline Entradas & $\begin{array}{c}\text { Dados Estatísticos } \\
\text { Valores Históricos } \\
\text { Tempos Médios }\end{array}$ & $\begin{array}{c}\text { Dados Reais } \\
\text { Veríodos de Tempo } \\
\text { Contingências }\end{array}$ \\
\hline Saídas & DEC & $\begin{array}{c}\text { DIC } \\
\text { FIC } \\
\text { DMIC }\end{array}$ \\
\hline
\end{tabular}

Observa-se que é possível calcular os índices de continuidade mencionados para as duas análises, antes e após as falhas. Outros índices também expressam o desempenho da rede no atendimento aos consumidores [Kagan et al. (2005)]. Neste trabalho foram calculados os índices indicados para a análise a priori e a posteriori, buscando a validação dos resultados, a partir do modelo inicial de [Bishop (1997)].

\subsection{Resposta da rede: análise a posteriori e a priori}

Foi tomado como base de estudo o circuito da Figura 2.2, oriundo do modelo apresentado em Bishop (1997). Neste, o circuito elétrico possui o alimentador de referência com valores de tensão e potência, um disjuntor na saída da subestação, as 
distâncias entre os nós do circuito, o número de consumidores nas laterais, os valores de tensão e a potência (carga) em cada trecho.

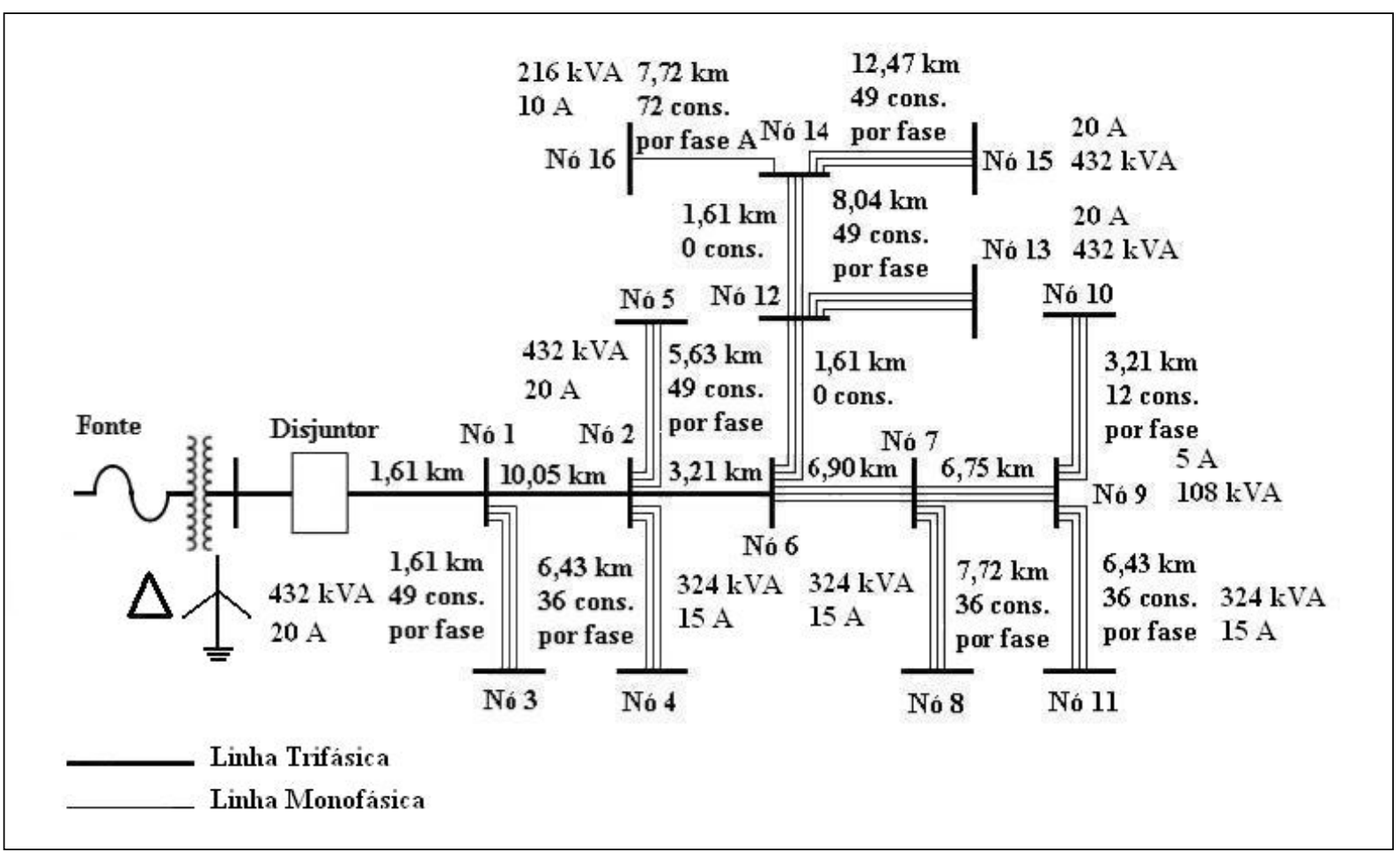

Figura 2.2 - Circuito modelo

O modelo de Bishop (1997) foi escolhido pelos motivos que seguem:

- número de consumidores envolvidos, que segundo o autor seriam consistentes com os resultados encontrados;

- obtenção da resposta do circuito de distribuição em relação aos índices de continuidade;

- valores típicos de reparo e restauração, baseados em índices de continuidade e divulgados pela ANEEL [ANEEL № 24 (2000) e Bishop (1997)];

- presença de diferentes tipos de linhas: $3 \phi$ e $1 \phi$;

- possibilidade de confrontar os dados (motivo principal), para validar os resultados obtidos nas simulações dos programas TEIAA, TEIAG, CONTITEIA E INVENTTEIA.

Foram considerados os mesmos parâmetros de Bishop (1997) para o cálculo dos índices de continuidade (dados estatísticos):

- número de falhas, por km de circuito, por ano: 0,1367;

- porcentagem de falhas permanentes: $20 \%$; 
- porcentagem de falhas temporárias: $80 \%$;

- tempo de restauração manual: 2 horas;

- tempo de reparo pela concessionária para linhas 3ф: 3 horas;

- tempo de reparo pela concessionária para linhas 1ф:2,5 horas.

Os valores dos parâmetros foram adotados devido à similaridade com a realidade brasileira. Porém, certas discrepâncias de tempo e filosofias podem ser encontradas. De qualquer forma, essas diferenças não invalidam o objetivo deste estudo: apresentar novas metodologias que podem ser implementadas para melhorar índices de continuidade em uma planta de distribuição de energia elétrica. $O$ procedimento deve ser realizado de acordo com as normas da ANEEL [ANEEL № 24 (2000)], cujas metas de DEC, FEC, DIC, FIC e DMIC devem obedecer a valores préfixados.

O circuito da Figura 2.2 baseia-se em Kagan et al. (2005), Bishop (1997) e Barros (1998), para estimar os indicadores DEC e FEC. Ele conta com informações que foram utilizadas para desenvolver os programas TEIAA e TEIAG:

- topologia e característica do alimentador primário;

- dispositivos de proteção e seccionamento disponíveis no alimentador;

- taxa de falhas dos trechos da rede;

- número de consumidores primários distribuídos pelas barras.

Com o intuito de adequar o trabalho ao padrão da ANEEL, alguns termos precisam ser padronizados.

Estabelece-se que:

- A taxa de falha de um dado equipamento da rede elétrica, para o caso dos trechos de rede, representa o número médio de falhas que ocorrem por ano e por unidade de comprimento do trecho, visando a uma manutenção corretiva.

- Falha temporária refere-se àquela que é sanada pelo restabelecimento do suprimento, pela manobra de uma chave religadora, seccionadora ou disjuntor de religamento. Não há necessidade de intervenção da equipe de manutenção [Kagan et al. (2005), Bishop (1997) e McCarthy et al. (1999)]. Há um caso que ilustra bem esse tipo de ocorrência na rede: os cabos de distribuição de energia elétrica podem entrar em contato comum ou à terra, em ocasiões de mau tempo (ventos) ou devido à presença de galhos de árvores posicionados sobre a linha energizada. Após instantes, retornam à posição original. A descrição deste cenário, em que a reenergiza- 
ção do sistema pode ser efetuada automaticamente, ilustra bem a falha temporária. Em sistemas de distribuição, esse tipo de defeito corresponde a $80 \%$ das incidências ocorridas na rede [Bishop (1997) e McCarthy et al. (1999)].

- As falhas permanentes representam um tipo de defeito que somente poderá ser corrigido pela intervenção da equipe de manutenção. Como mencionado [Kagan et al. (2005), Barros (1998), Bishop (1997) e McCarthy et al. (1999)], exemplificam esta categoria problemas com cruzetas, perfuração e destruição de um isolador de rua ou a quebra de um isolador ou ruptura de cabo de distribuição de energia elétrica. Trata-se de dificuldades que ocorrem devido a um acidente provocado por um veículo que causa danos físicos à rede de distribuição de energia, alterando a topologia da rede.

- A taxa de falha depende da avaliação estatística do comportamento de um dado instrumento ou conjunto de equipamentos durante um período estabelecido, sob condições em que a rede de distribuição esteja funcionando.

A análise a posteriori [Kagan et al. (2005)] permite ao responsável pelo projeto da rede de distribuição de energia elétrica estimar a qualidade de serviço de um dado sistema de distribuição. Essa estimativa pode ser usada como fator de tomada de decisão, quando da definição de um tipo de solução a ser implementada ou no momento de prever indicadores de continuidade.

A solução que leva aos cálculos dos índices da análise a posteriori (DIC, FIC e DMIC) e a priori (DEC e FEC) será apresentada no Capítulo 5, quando serão discutidos os programas desenvolvidos.

\subsection{Análise da qualidade de energia elétrica}

Com o intuito de melhorar a qualidade de serviço das empresas de distribuição, a ANEEL [ANEEL № 24 (2000)] enfatiza que as informações estatísticas têm se tornado ferramentas essenciais, ajudando as concessionárias a atingir suas metas de fornecimento de energia elétrica. Essas informações caracterizam-se pelo número de interrupções de energia por um período de tempo considerado e o número de consumidores envolvidos nessas interrupções.

Assim, os índices de continuidade fornecem informações históricas, as quais podem servir para projetar tendências de resposta do circuito e medir o seu desempenho face à solicitação de carga pelos consumidores. Estes índices fornecem uma 
diretriz do comportamento do sistema, em relação ao surgimento de falhas por consumidor durante um determinado período. Assim, criam um sistema de informações que contribui para a tomada de decisão em momentos críticos, garantindo a confiabilidade de energia elétrica fornecida ao consumidor final.

Os indicadores de continuidade são definidos pela ANEEL [ANEEL № 24 (2000)], segundo:

"A continuidade da distribuição da energia elétrica deverá ser supervisionada, avaliada e controlada por meio de indicadores que expressem os valores vinculados a conjuntos de unidades consumidoras e às unidades consumidoras individualmente consideradas".

Desse modo, o sistema deverá proporcionar máxima continuidade de fornecimento de energia a consumidores, de uma maneira econômica e simples [ANEEL № 24 (2000)].

A comparação entre diferentes configurações de sistemas de distribuição de energia elétrica baseia-se na análise de índices de continuidade. Estes traduzem como o sistema se comporta em relação ao fornecimento de energia e ao número de consumidores afetados.

Uma vez definidos, esses índices são analisados a partir de diferentes topologias. Com o uso de equipamentos de proteção, a partir dos resultados obtidos, é possível chegar a uma conclusão sobre qual solução é a que minimiza o tempo de interrupção de energia para os consumidores.

O emprego de índices de continuidade permite que se padronize a análise de sistemas de distribuição. Estes podem sofrer mudanças em suas topologias, seja por medidas técnicas, seja por necessidades de expansão futura.

Serão consideradas as seguintes definições [ANEEL № 24 (2000)]:

- Duração equivalente de interrupção por unidade consumidora (DEC): intervalo de tempo que, em média, no período de observação, em cada unidade consumidora do conjunto considerado ocorreu descontinuidade da distribuição de energia elétrica;

- Frequência equivalente de interrupção por unidade consumidora (FEC): número de interrupções ocorridas, em média, no período de observação, em cada unidade consumidora do conjunto considerado; 
- Duração de Interrupção Individual por Unidade Consumidora (DIC): intervalo de tempo que, no período de observação, em cada unidade consumidora ocorreu descontinuidade da distribuição de energia elétrica;

- Freqüência de Interrupção Individual por Unidade Consumidora (FIC): número de interrupções ocorridas, no período de observação, em cada unidade consumidora.

-Duração Máxima de Interrupção Contínua por Unidade Consumidora (DMIC): tempo máximo de interrupção contínua, da distribuição de energia elétrica, para uma unidade consumidora qualquer.

- Interrupção: descontinuidade do neutro ou da tensão disponível em qualquer uma das fases de um circuito elétrico que atende à unidade consumidora;

- Interrupção de longa duração: toda a interrupção do sistema elétrico com duração maior ou igual a 1 (um) minuto;

- Interrupção programada: interrupção antecedida de aviso prévio, por tempo preestabelecido, para fins de intervenção no sistema elétrico da concessionária;

- Interrupção de energia: interrupção deliberada no sistema elétrico da concessionária, sem possibilidade de programação e caracterizada pela urgência na execução de serviços;

- Metas de continuidade: padrões estabelecidos pela ANEEL para os indicadores de continuidade, a serem respeitados mensalmente, trimestralmente e anualmente, para períodos preestabelecidos;

- Padrão de continuidade: valor limite de um indicador de continuidade, aprovado pela ANEEL e utilizado para análise comparativa com os indicadores de continuidade apurados;

- Restabelecimento da continuidade da distribuição de energia elétrica: retorno do neutro e da tensão disponível em todas as fases, com permanência mínima de tempo igual a 1 (um) minuto, no ponto de entrega de energia elétrica da unidade consumidora.

\subsubsection{Indicadores de continuidade de conjunto}

De acordo com o artigo 6ํำ da resolução [ANEEL № 24 (2000)], as concessionárias deverão apurar, para todos os seus conjuntos de unidades consumidoras, os indicadores: 


$$
\begin{aligned}
& \mathrm{DEC}=\frac{1}{\mathrm{Cc}} \sum_{\mathrm{i}=1}^{\mathrm{k}} \mathrm{Ca}(\mathrm{i}) . \mathrm{T}(\mathrm{i}) \\
& \mathrm{FEC}=\frac{1}{\mathrm{Cc}} \sum_{\mathrm{i}=1}^{\mathrm{k}} \mathrm{Ca}(\mathrm{i})
\end{aligned}
$$

Onde:

DEC = Duração equivalente de interrupção por unidade consumidora, expressa em horas e centésimos de hora;

FEC = Frequência equivalente de interrupção por unidade consumidora, expressa em número de interrupções e centésimos do número de interrupções;

$\mathrm{Ca}$ (i) = Número de unidades consumidoras interrompidas em um evento (i), no período de apuração;

$\mathrm{T}(\mathrm{i})$ = Duração de cada evento (i), no período de apuração;

$\mathrm{i}$ = Índice de eventos ocorridos no sistema que provocam interrupções em uma ou mais unidades consumidoras;

k = Número máximo de eventos no período considerado;

$\mathrm{Cc}=$ Número total de unidades consumidoras, do conjunto considerado, no final do período de apuração.

\subsubsection{Indicadores de continuidade individual (por consumidor)}

A concessionária deverá informar os indicadores individuais discriminados ${ }^{7}$ :

$$
\begin{aligned}
& \mathrm{DIC}=\sum_{\mathrm{i}=1}^{\mathrm{n}} \mathrm{t}(\mathrm{i}) \\
& \mathrm{FIC}=\mathrm{N} \\
& \mathrm{DMIC}=\max _{\mathrm{i}=1, \ldots, \mathrm{N}}\left(\mathrm{t}_{\mathrm{i}}\right)
\end{aligned}
$$

Onde:

DIC = Duração das Interrupções por Unidade Consumidora considerada, expressa em horas e centésimos de hora;

FIC = Frequência de Interrupções por Unidade Consumidora considerada, expressa em número de interrupções;

DMIC = Duração Máxima das Interrupções por Unidade Consumidora considerada, expressa em horas e centésimos de hora;

\footnotetext{
${ }^{7}$ Redação dada pela Resolução ANEEL № 075, de 13.02.2003
} 
i = Índice de interrupções da unidade consumidora, no período de apuração, variando de $1 \mathrm{a} n$;

$\mathrm{n}=$ Número de consumidores.

$\mathrm{N}$ = Número de interrupções da unidade consumidora considerada, no período de apuração;

$t(i)=$ Tempo de duração da interrupção (i) da unidade consumidora considerada, no período de apuração;

$\mathrm{t}(\mathrm{i})_{\max }=$ Valor correspondente ao tempo da máxima duração de interrupção (i), no período de apuração verificado na unidade consumidora considerada, expresso em horas e centésimos de horas.

\subsection{Cenário da distribuição de energia elétrica}

No cenário de distribuição de energia elétrica, as concessionárias não garantem um fornecimento absolutamente contínuo de energia elétrica para seus clientes. Contudo, são responsáveis por um serviço confiável, refletindo os estados da tecnologia e realizando um balanço entre qualidade e custo para a entrega do produto final.

A análise de índices de continuidade é um fator a ser considerado entre os consumidores e a empresa fornecedora do serviço. Os mesmos níveis de continuidade podem ser vistos como aceitáveis pela concessionária e não-aceitáveis pelo consumidor final: dois consumidores podem ter diferentes opiniões sobre um mesmo serviço, apesar de conectados ao mesmo sistema.

Um determinado número de interrupções pode ser, por um lado, aceito por um consumidor residencial. Por outro, para um consumidor industrial, conectado ao mesmo circuito de distribuição, pode ser inaceitável.

Destaca-se que, mesmo para um grupo de consumidores, com características semelhantes, a percepção de serviço de qualidade tem mudado com os anos. Parte dessa mudança deve-se à melhoria do fornecimento de energia provindo das concessionárias. Outro motivo decorre do aumento da sofisticação dos consumidores e seus equipamentos, cuja dependência da disponibilidade do serviço elétrico é ininterrupta. 
A reação dos consumidores a falhas depende das circunstâncias. Eles podem aceitar ou tolerar a interrupção de um serviço, caso entendam que tal problema foi motivado por um fenômeno da natureza, que fuja ao controle da concessionária.

Desde a década de 1990 [Bishop (1997); McCarthy et al. (2000)], há uma cobrança muito forte em relação ao tipo de serviço fornecido pelas concessionárias. $O$ aumento da competição entre si as tem forçado a utilizar índices de continuidade para os usuários finais. Assim, nota-se uma evolução da simples análise qualitativa para uma análise quantitativa dos serviços prestados.

Com base em índices de continuidade que possam ser considerados confiáveis, o desenvolvimento tecnológico foca a redução de falhas permanentes [Bishop (1997) e Kagan et al. (2005)]. Este enfoque ocorre porque, sob o ponto de vista histórico e desde o surgimento de redes de distribuição de energia elétrica, os sistemas foram projetados para detectar e resolver problemas, de maneira a minimizar a probabilidade de danos à rede. Muitas vezes, essas dificuldades aconteciam devido às interrupções momentâneas, fazendo com que o fornecimento fosse restabelecido o mais rápido possível. Há duas décadas, a maioria dos equipamentos dos clientes residenciais não era afetada por esse tipo de interrupção, ou seja, um consumidor não se incomodava com um curto bloqueio de iluminação.

O conceito de utilização de cargas pelos clientes, com o passar dos anos, tem mudado, além de sua percepção e necessidades. Os equipamentos digitais microprocessados tornaram-se suscetíveis a interrupções momentâneas. Essas paradas de fornecimento podem levar à perda de dados computacionais, programação de eletrodomésticos com tecnologia digital, microondas, ajustes de produtos eletrônicos, dependentes de programação e munidos de memória volátil.

As interrupções momentâneas acabaram se tornando um dos principais motivos de reclamação por parte dos consumidores. Grande parte das concessionárias de energia elétrica registra informações sobre o número de falhas, sejam estas permanentes ou temporárias, tempo do sistema fora-do-ar e número de consumidores afetados. Essas informações podem ser associadas a cada circuito ou divisão operacional, para efeitos de comparação e tomada de decisão.

Com o intuito de fornecer dados para comparações relativas entre as companhias, foram desenvolvidos índices padronizados para registrar a qualidade e confiabilidade da entrega de energia elétrica. Esses índices podem ser usados para determinar o aumento ou diminuição de tendências ou verificar se o sistema atingiu os 
resultados operacionais esperados, dependendo da região e da topologia. Como exemplo, quanto maior e mais longo for o circuito na distribuição, serão maiores as chances de acidentes e falhas devido a contingências (raios, animais, veículos, árvores e outros). As zonas rurais estão sujeitas a um número mais elevado de interrupções, dentro do intervalo de um ano [Bishop et al. (2000)].

De acordo com Bishop (1997), a interrupção de dois minutos equivale a um período-padrão em plantas de distribuição de energia elétrica, podendo ser um valor razoável para regiões residenciais durante o dia. Porém, para áreas industriais, esse tempo não é aceitável. Destaca-se que a taxa de interrupção pode levar à escolha dos índices de continuidade, que dependem da natureza do sistema de distribuição.

As áreas rurais possuem um tratamento diferenciado das urbanas, com relação à ocorrência de falhas. Enquanto que, em sistemas com diferentes níveis de tensão, os índices podem variar em função do número de consumidores envolvidos. Não será foco deste estudo a análise das áreas rurais. A Tabela 2.2, baseada em Bishop (1997), mostra valores típicos para os índices.

Tabela 2.2 - Meta para índices DEC e FEC

\begin{tabular}{|c|c|l|}
\hline Índice & Tipo de Sistema & \multicolumn{1}{|c|}{ Meta } \\
\hline FEC & Urbano & 1 interrupção / ano \\
\hline FEC & Rural & 1,5 interrupção / ano \\
\hline DEC & Urbano & 1 hora interrupção / ano \\
\hline DEC & Rural & 1,5 hora interrupção / ano \\
\hline
\end{tabular}

Projetos adequados de circuitos de distribuição e o uso de dispositivos de proteção podem levar a uma melhoria significativa dos índices de continuidade, seja na existência de um cronograma para manutenções preditivas e preventivas, seja em um conjunto de ações corretivas. 
Capítulo 3

\section{Algoritmos Genéticos como Métodos de Otimização}

\section{Algoritmos Genéticos como Métodos de Otimização}

Este capítulo descreve o desenvolvimento dos algoritmos evolucionários e suas aplicações nas áreas correlatas ao tema do trabalho.

\subsection{Algoritmos evolucionários}

Os algoritmos evolucionários fazem parte de um campo de pesquisa relativamente novo quando empregados em soluções computacionais. Uma de suas primeiras manifestações formais, nesta área, ocorreu em 1991. A partir de então os pesquisadores têm se esforçado para simular aspectos da evolução natural e implementá-los em ambientes computacionais [Goldberg (1989) e Linden (2006)].

As técnicas que envolvem o tema são representadas pelos algoritmos genéticos, estratégias evolucionárias e programação evolutiva. Apresentam características comuns para conceitos como reprodução, variação aleatória, competição e seleção de indivíduos dentro de uma população.

\subsection{Otimização para processamento de sistemas de distribuição de energia elétrica}

Dentre várias técnicas utilizadas para os sistemas de distribuição de energia elétrica, no que se refere à locação de dispositivos de chaveamento, a evolução é um processo de otimização [Mayr (1988)] que pode identificar e propor soluções funcionais precisas. Trata-se de um percurso que envolve problemas específicos, sob uma perspectiva computacional.

O princípio de soluções baseadas no conceito de evolução torna-se viável quando pode ser descrito por algoritmos. Estes, quando implementados com esfor- 
ço computacional otimizado, buscam resolver problemas no campo da engenharia, utilizando as técnicas baseadas em estudo de gradiente de funções - a exemplo de Hill Climbing, Signal Annealing (Resfriamento Simulado) e Métodos de Pesquisas Aleatórias (sem hereditariedade). Essas técnicas são insatisfatórias quando aplicadas a problemas de otimização não-linear, especialmente com componentes estocásticos, temporais e caóticos [Michalewicz et al. (1997)].

Os algoritmos evolucionários são adotados em populações de estruturas, denominadas "indivíduos" ou "cromossomos", que se comportam de forma semelhante ao observado na evolução natural [Darwin (1859) e Goldberg (1989)].

Aplicam-se a estas estruturas os chamados "operadores genéticos", como a recombinação, a mutação e outros [Linden (2006)]. Neste contexto, cada novo indivíduo recebe uma nota ou avaliação, caracterizando um fator de qualidade, cuja interpretação está ligada ao conceito de sua adaptação ao meio ambiente. Este cálculo tem seus pesos definidos por regras, o que é uma característica representativa, quando se busca a solução de um problema.

Este fator de qualidade, também denominado "fator de fitness (ff)", é determinado pela adaptação do indivíduo, ao se deparar com situações presentes na natureza. Tal fator representa a diferenciação entre aqueles que competem para atingir suas metas de vida e a multiplicação de seus genes às próximas gerações. Assim, cada indivíduo, caracterizado por seu cromossomo, recebe uma nota de avaliação (fator de fitness) que é uma quantificação da sua qualidade. A partir deste ponto, serão aplicados os operadores genéticos diretamente no cromossomo, possibilitando que o indivíduo mais apto se sobressaia sobre os demais [Linden (2006)].

Segundo Linden (2006), Michalewicz et al. (1997) e Eiben et al. (2004), os operadores genéticos consistem de aproximações computacionais de processos de seleção encontrados na natureza.

A Tabela 3.1 ilustra a ligação entre um problema real a ser solucionado e a metáfora da evolução [Eiben (2002)]: 
Tabela 3.1 - Comparação, evolução e solução real de um problema

\begin{tabular}{|c|c|}
\hline Evolução & Solução do problema \\
\hline Meio ambiente & Problema \\
\hline Indivíduo & Solução candidata \\
\hline Boa forma & Qualidade \\
\hline
\end{tabular}

Observa-se que muitos componentes de um processo evolucionário são estocásticos (probabilísticos), tanto na fase inicial quanto na fase evolucionária. Os algoritmos evolucionários são soluções heurísticas ${ }^{8}$ [Eiben et al. (2004), Fogel (2002) e Linden (2006)]. São utilizados para resolver problemas cujos algoritmos são extraordinariamente lentos (problemas NP - completos ${ }^{9}$ ) ou incapazes de chegar a uma solução.

Uma visão geral de algoritmos evolucionários pode ser verificada pela figura 3.1[Eiben et al. (2004)].

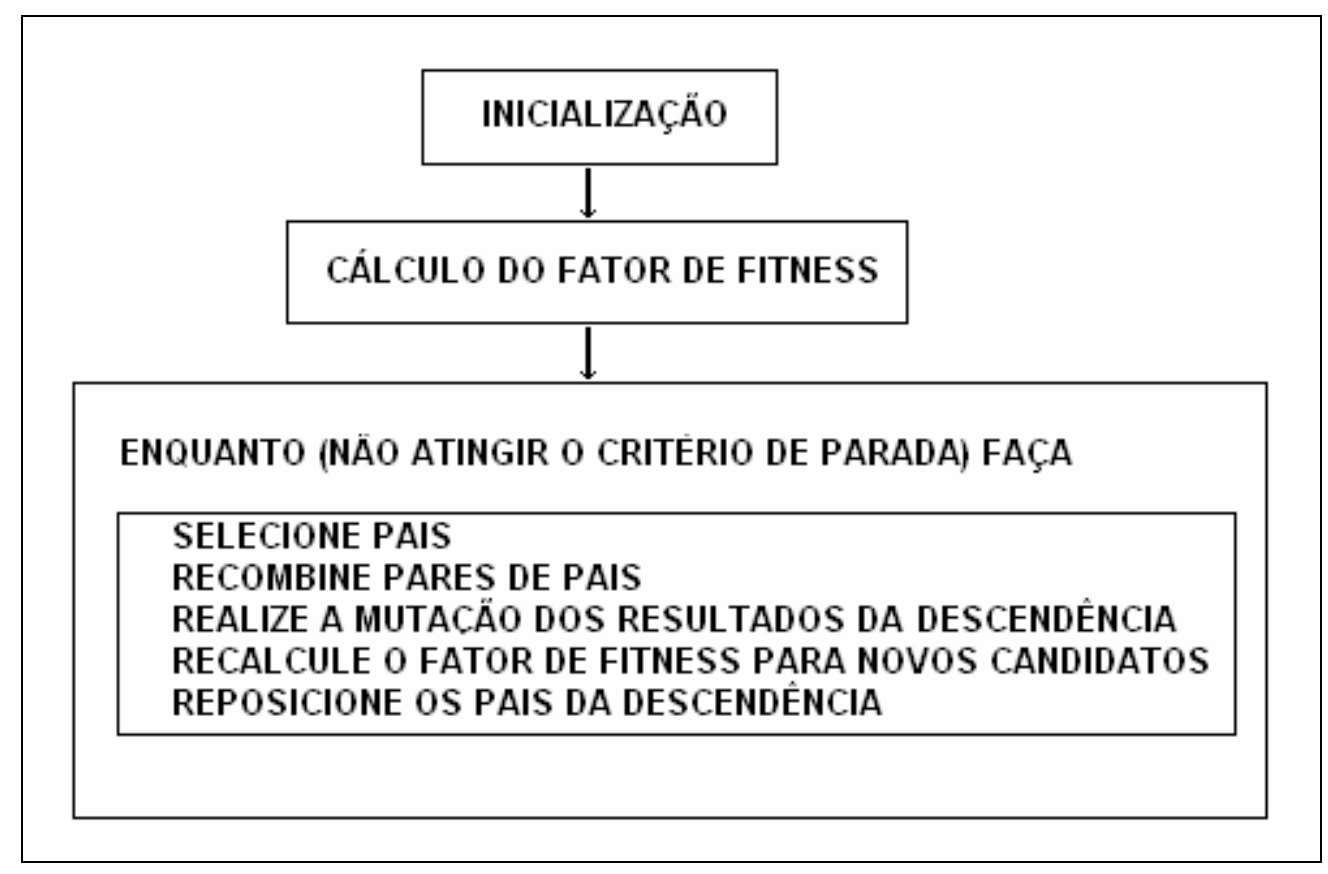

Figura 3.1 - Comportamento-padrão de algoritmos evolucionários

\footnotetext{
${ }^{8}$ Soluções heurísticas são algoritmos polinomiais que não têm garantia nenhuma sobre a qualidade da solução encontrada, mas que, usualmente, tendem a localizar a solução ótima ou se aproximar dela.

${ }^{9}$ Os problemas que apresentam possibilidade de tratamento também são comumente denominados "P" (Polinomiais), enquanto aqueles que não podem ser tratados são denominados "NP" (NãoPolinomiais).
} 
Os algoritmos evolucionários classificam-se como técnicas de busca [Linden (2006), Goldberg (1989) e Eiben et al. (2004)]. Pertencem à classe das "Técnicas Aleatórias Guiadas", pois usam informações do estado corrente para a busca da solução e determinação do próximo estado, embora tenham componentes aleatórios. Atuam, portanto, de maneira diferente dos métodos puramente aleatórios, porque a informação conhecida direciona a busca. Na Figura 3.2, é possível observar as técnicas de busca e seu caminho até os algoritmos genéticos:

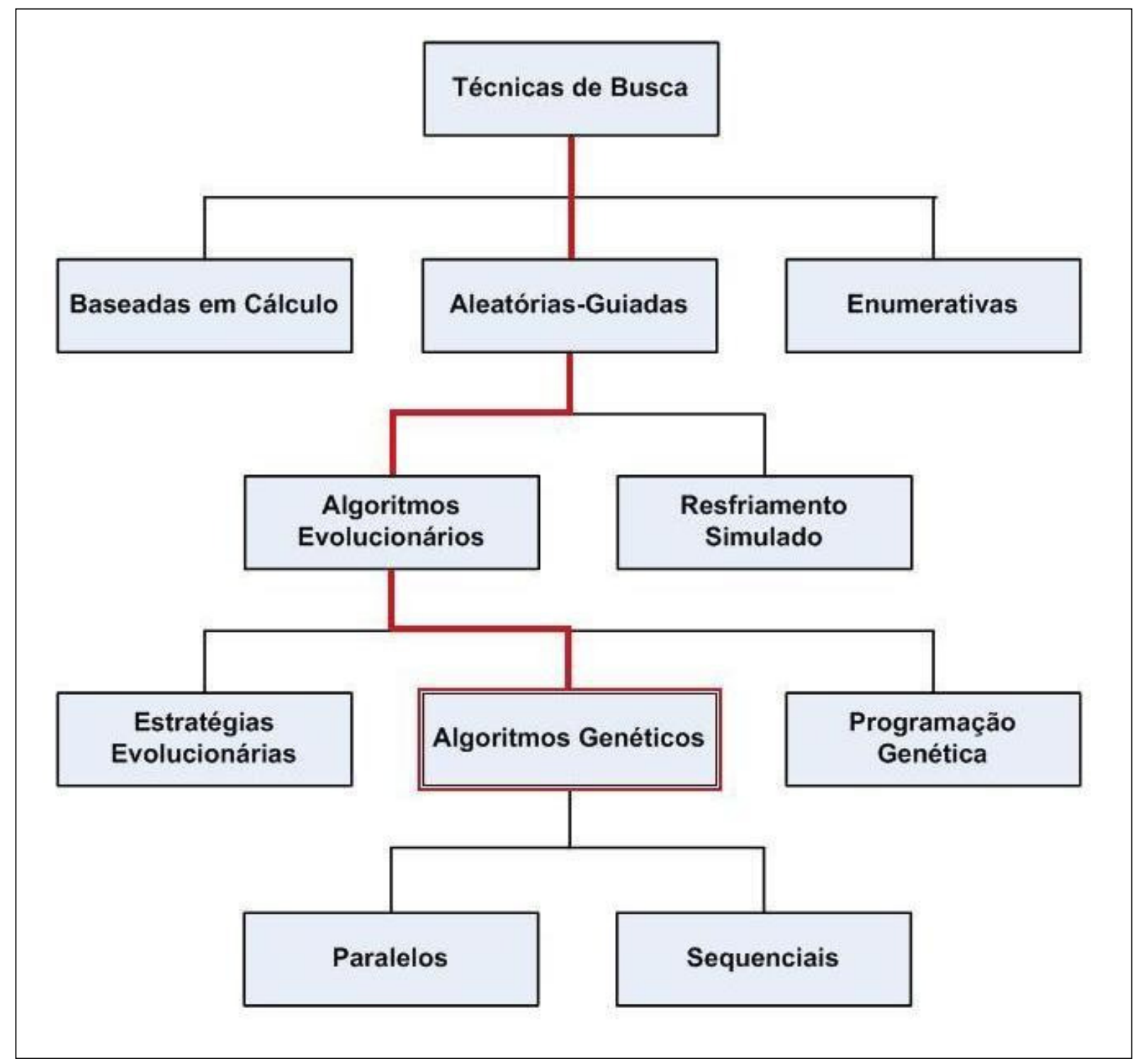

Figura 3.2 - Algoritmos evolucionários como técnicas de busca

\subsection{Surgimento e desenvolvimento dos algoritmos genéticos}

O estudo dos AGs se iniciou por volta de 1940, como concepção de solução, quando os pesquisadores começaram a realizar estudos baseados em fenômenos 
da natureza. Seu objetivo era alcançar o que se tornaria conhecido, hoje, como "inteligência artificial".

No começo da década de 1960, pesquisas com genes, guiadas pelos trabaIhos de Bledsoe (1961) e Bremermann (1962), sobrepuseram o uso da representação binária por aquela inteira e real. Assim, esses pesquisadores foram os precursores dos operadores de recombinação (crossover) [Linden (2006) e Goldberg (1989)].

Os estudos do referido período foram marcados pela tentativa de utilização de processos evolutivos para resolver problemas computacionais, desenvolvidos por Rechenberg $(1965)^{10}$. Um dos casos tratou dois indivíduos com cromossomos compostos de números reais. Um deles era o filho, gerado pela aplicação exclusiva do operador de mutação. Neste processo, a mutação era aplicada com base em uma distribuição gaussiana dos parâmetros. Este método foi usado com sucesso em problemas práticos, marcando o pioneirismo de aplicações de AGs.

Os trabalhos que se seguiram procuraram suprir lacunas dos resultados anteriores, instituindo conceitos de população e operadores como o crossover.

No início da década de 1970, John Holland começou a trabalhar com os chamados "Algoritmos Genéticos" [Holland (1975)], introduzindo o termo utilizado até hoje. Observando que as soluções desenvolvidas naquela época concentravam-se em codificações discretas, Holland propôs um modelo heurístico que levava em consideração a evolução das espécies e que podia ser expresso em uma linguagem computacional, voltado a problemas NP-completos. Em 1975, publicou seu livro, intitulado "Adaptation in Natural and Artificial Systems". Neste, realizou um estudo formal dos processos evolutivos, apresentando os algoritmos genéticos como uma metáfora, de maneira que pudesse estudar a adaptação e a evolução da realidade [Holland (1975)].

Sua pesquisa consistia em dois pontos:

- abstração e explicação do processo adaptativo de sistemas naturais;

- projeto de sistemas artificiais que conservassem os mecanismos relevantes da evolução natural.

Um dos pontos principais da pesquisa com algoritmos genéticos tem sido o conceito de robustez. Este envolve o balanço entre eficiência e eficácia, necessário para a sobrevivência e o desenvolvimento dos organismos em diferentes ambientes.

\footnotetext{
${ }^{10}$ Escritor alemão conhecido por seus estudos em princípios de evolução da biologia.
} 
Quando se deseja encontrar soluções envolvendo robustez em alto desempenho, pode-se utilizar exemplos encontrados na natureza.

Os sistemas artificiais, sendo mais robustos, levam a projetos de custos mais reduzidos, pois há maior probabilidade que a solução seja encontrada. Vale salientar que há muitas implicações envolvidas no conceito de robustez. Os projetistas de sistemas artificiais podem buscar soluções envolvendo software e hardware. Este processo abrange as áreas de engenharia de sistemas, sistemas computacionais ou área de negócios. Consideram-se robustez, eficiência e flexibilidade, inerentes aos sistemas biológicos, em que características como auto-reparo, orientação própria e capacidade de reprodução são regras constituídas.

Os Algoritmos Genéticos, como métodos inspirados no mecanismo de seleção natural e genética, combinam o desenvolvimento de formas apropriadas, por meio de séries de estruturas. O mecanismo inclui troca de informação, de maneira aleatória, para formar um algoritmo adaptativo. Em cada geração, um novo conjunto de indivíduos artificiais é criado, usando unidades de outro grupo mais antigo. Esse processo gera, frequentemente, indivíduos mais bem adaptados. Assim, de maneira eficiente, exploram-se informações históricas para buscar um novo conjunto de resultados, com ganho de desempenho.

Como técnicas heurísticas de otimização, os AGs se opõem aos métodos tradicionais do gradiente (Hill Climbing) e Simulated Annealing, que se baseiam na derivada de uma função, segundo mencionado no Capítulo 2 do trabalho. O objetivo é encontrar o seu valor máximo/mínimo, ficando restritos a valores locais, como exemplificado na Figura 1.3, localizada no Capítulo 1 deste estudo [Linden (2006) e Goldberg (1989)].

Os AGs não interrompem a busca quando encontram um ótimo local, pois não são métodos baseados em técnicas de gradiente [Goldberg (1989)], mas se comportam como a evolução natural [Koza (1994)], ou seja, continuam pesquisando soluções melhores do ponto de vista sistêmico. É feita, portanto, uma busca completa no espaço de soluções possíveis.

A pesquisa envolvendo soluções de AG é bastante ampla, abrangendo diversas áreas do conhecimento. 


\subsection{Aplicações com AGs}

É importante citar soluções como as propostas por Nara et al. (1992), cujos mecanismos do AG são extremamente simples, pois envolvem cópias e permutas parciais de strings, referindo-se a cromossomos. Essas soluções, normalmente, denotam a idéia de reprodução, entendida como cópia, em um processo no qual as strings são copiadas de acordo com sua função de fitness (ff). Isto significa que os cromossomos com elevado ff têm probabilidade maior de contribuir para a próxima geração de indivíduos, ou seja, os descendentes vão depender diretamente desse valor.

O crossover, que é considerado o operador principal, caracteriza-se por trocar partes do cromossomo entre os indivíduos. Este é executado após a reprodução, sendo dividido em duas etapas:

- Os membros de um novo cromossomo são alocados de modo aleatório;

- Cada par de cromossomos trabalha em conjunto com o novo cromossomo. Este é criado a partir dos elementos originais, permutando todos os caracteres.

Com respeito à mutação - que se revela um tema complexo, quando indicado na literatura -, Nara et al. (1992) a mencionam como uma "alteração aleatória" de um gene presente em um cromossomo. A mutação é necessária para suprir a perda de informação ou variedade genética que possa ocorrer no momento de recombinação de cromossomos. Assim, ela funcionaria como um elemento de proteção, contra perdas irreparáveis da qualidade da geração.

Miranda et al. (1994) tratam os AGs como métodos de busca e otimização baseados na evolução natural, sendo mencionados os três operadores canônicos: seleção, crossover e mutação. No referido trabalho, cada cromossomo representa uma possível solução para o problema a ser otimizado, e cada bit ou grupo de bits representa um valor para alguma variável do problema (gene). As soluções são classificadas como funções de validação. Estas retornam melhores valores ou fitness, gerando as melhores soluções.

Miranda et al. (1994) mencionam Grefenstette (1991) para se referir às inúmeras formas existentes de AGs. Citam, porém, a forma canônica do algoritmo, a qual trabalha com os três operadores mencionados, aplicados a cromossomos unidimensionais. O AG canônico possui um tamanho fixo. Nestas circunstâncias, a no- 
va geração se origina a partir da aplicação do operador genético, sendo alterada por crossover e mutação em suas descendências.

O operador chamado seleção é responsável pela criação de uma nova população, considerando indivíduos da geração anterior, classificados como os melhores. Evidentemente, também existirão cópias de alguns indivíduos com fatores de fitness inferiores, que serão descartados com o surgimento de novas gerações.

Segundo Miranda et al. (1994), o operador genético pode ser implementado de várias maneiras. Os autores utilizam o chamado "Torneio Estocástico", mencionado em Goldberg (1991). Neste, a cada vez que se quer selecionar um indivíduo para a reprodução, escolhem-se outros dois, de modo aleatório. O melhor, dentre os selecionados, é obtido com base em um valor de probabilidade fixa, da ordem de 80\%. Quanto ao crossover este é implementado de uma forma simplificada, selecionando um ponto aleatório do cromossomo e trocando-se os genes entre este ponto e o final do mesmo.

O último operador mencionado é a mutação. Implica em alterar um gene aleatoriamente em um indivíduo. Deve ser usado com cuidado, com baixa probabilidade, tipicamente da ordem de 0,1\%, segundo Miranda et al. (1994). Esses autores descrevem a mutação como um seguro de vida. Neste contexto, se acontecer que alguns bits ditos importantes se percam e, com eles, desapareçam também informações valiosas, a mutação pode trazê-los de volta. Verifica-se que uma taxa elevada de mutação pode ser prejudicial, conduzindo a valores completamente aleatórios e descaracterizando as gerações seguintes. Esta situação poderá acontecer independente da probabilidade do crossover [Goldberg (1989)], incluindo uma possível perda de cromossomos que já comprovaram ter tido sucesso ou fator de fitness elevado.

Billington et al. (1996) apresentam uma abordagem interessante sobre o posicionamento de chaves-de-manobra. $O$ estudo concentra-se em sistemas de distribuição radial, baseados em regras de alocação de equipamentos de proteção, com o objetivo de aumentar a confiabilidade.

Destaca-se o emprego de Lógica Fuzzy ${ }^{11}$ e de AGs para determinar o posicionamento de dispositivos de chaveamento, seleção do número e posicionamento

\footnotetext{
${ }^{11}$ Lógica difusa ou lógica fuzzy é uma extensão da lógica booleana que admite infinitos valores lógicos intermediários entre o FALSO(0) e o $\operatorname{VERDADEIRO(1),~bem~como~abrangendo~o~valor~médio~'TAL-~}$ VEZ' $(0,5)$.
} 
de chaves de manobra, dependendo de fatores como confiabilidade, tipo de consumidores conectados, variações de carga, manutenção e custos de instalação.

Um dos tópicos abordados, no contexto da Lógica Fuzzy e dos AGs, é o emprego do Simulated Annealing como técnica para resolver problemas de otimização combinatorial. É descrito o algoritmo baseado em cadeias de Markov ${ }^{12}$. Este representa uma sequência de amostras, em que o resultado de cada uma é a função da iteração anterior.

O trabalho de Vasconcelos et al. (2001) também merece destaque. Trata-se de um estudo comparativo entre o SGA - sigla que, traduzida para o português, equivale a Algoritmo Genético Simplificado -, o SSGA - da mesma maneira, Algoritmo Genético de Estado Estável - e o RGA, da mesma maneira, Algoritmo Genético Baseado em Substituição. Analisa-se o desempenho de cada método em relação aos operadores crossover, seleção e mutação. Também são analisadas as probabilidades do crossover e mutação, com e sem mudanças dinâmicas de seus valores, durante o processo de otimização. Descreve-se ainda o método da roleta e amostras determinísticas no operador seleção.

Vasconcelos et al. (2001) incluem em seu estudo o crossover, com diferentes "pontos de corte", e a mutação bit-por-bit: uma mutação por cromossomo e outra por indivíduo, ambas em posições aleatórias. Aborda-se a taxa de mutação fixa em 2,5\% para mutação bit-por-bit, sendo 50\% para uma mutação por cromossomo e $100 \%$ para uma mutação por indivíduo. Dessa forma, cada integrante tem mais que $50 \%$ de chance de ter um bit alterado pela operação. Finalmente, evidencia-se a questão do elitismo, tanto simples quanto global. Observa-se elitismo, na sua forma simples, e como o SGA trabalha com o procedimento. No caso, o melhor indivíduo na geração $k$ (o pai) é mantido na próxima geração $k+1$, se o filho tiver um desempenho inferior ao pai. Sem o elitismo, os melhores resultados podem ser perdidos durante as operações de seleção, mutação e crossover.

$\mathrm{Na}$ análise de Vasconcelos et al. (2001), o SGA, SSGA e RGA são iniciados com o elitismo simples. Para o elitismo global, cada indivíduo na população da geração $k+1$ pode substituir seu pai da geração $k$, se tiver um desempenho superior à-

\footnotetext{
${ }^{12}$ A cadeia de Markov é um caso particular de processo estocástico com estados discretos e que apresenta a propriedade Markoviana, chamada assim em homenagem ao matemático Andrei Andreyevich Markov. A definição desta propriedade, também chamada de memória markoviana, é que os estados anteriores são irrelevantes para a predição dos estados seguintes, desde que o estado atual seja conhecido.
} 
quele. Sob esta condição, a geração k+1 possui indivíduos melhores do que os da geração k.

Vasconcelos et al. (2001) enfatizam o estudo de probabilidades da adaptação dinâmica do crossover e mutação, verificando como as metas com probabilidades adaptativas são utilizadas para manter a diversidade genética na população e evitar que o AG se converta de maneira prematura para um mínimo local. Com o objetivo de medir a diversidade genética ( $g d m)$, foi utilizada a proporção entre o valor inferior e o valor máximo da função de fitness de cada geração, ou seja, $0 \leq \mathrm{gdm} \leq 1$.

Quando o valor de gdm se aproxima da unidade, o resultado indica que todos os indivíduos têm o mesmo código genético: eles representam o mesmo ponto na curva de otimização, caracterizando uma diversidade genética menor.

As probabilidades de mutação (pm) e crossover (pc), com a finalidade de evitar uma convergência prematura, precisam ser alteradas, para representar novas características genéticas e reduzir a perda de diversidade genética. Assim, a pm precisa ser aumentada e o pc reduzido. No outro caso, se gdm tender a zero, o resultado significa que existe uma diversidade genética exagerada, introduzida pela operação de mutação. Para evitar uma busca aleatória, pm precisa ser reduzida e pc aumentado.

Yeh et al. (1996) abordam um modelo do sistema de distribuição, utilizando o conceito de computação evolutiva. Primeiramente, é feito um breve descritivo sobre as tarefas, envolvendo topologia dos sistemas de distribuição, dificuldades encontradas na implementação da solução e as ferramentas desenvolvidas para a área. Em seguida, ressalta-se a nova abordagem proposta no planejamento da distribuição, visando à melhoria de desempenho dos operadores de planejamento (tarefas programadas) em conjunto com técnicas de conhecimento humano, heurística e evolução computacional. Yeh et al. (1996) afirmam que a otimização de um planejamento da distribuição complexo, normalmente, indica o seguinte quadro: vários pontos de máximos locais coexistem com máximos globais, caracterizando um problema NP (Não-Polinomial). Os referidos pesquisadores complementam sua abordagem com o emprego do AG. Citam Goldberg (1989) em problemas de otimização numérica e de paralelismo em soluções estocásticas, afirmando que os AGs são adequados para uso nessas situações. O AG é descrito como um processo que uti- 
liza os operadores reprodução, crossover e mutação, trabalhando em conjunto para a obtenção de suas gerações.

O fato de o AG transformar um problema espacial em um código genérico esquemático dispensa o uso de funções específicas e complexas ou algoritmos de "força bruta", presentes em outras soluções.

Yeh et al. (1996) realizaram suas simulações e obtiveram resultados finais baseados em 5000 gerações, com uma população de 350 indivíduos e taxa de probabilidade de mutação de 0,3\%.

Na mesma linha de Yeh et al. (1996), o trabalho de Brown et al. (1996) destaca os passos necessários para o projeto de um sistema de distribuição baseado em confiabilidade $\left(\mathrm{DFR}^{13}\right)$. Esse sistema é composto por definição, avaliação e otimização, propondo um critério de confiabilidade econômica e um método de avaliação analítica. Assim, com base nestes critérios, o AG vem auxiliar o posicionamento das chaves e dispositivos de proteção, minimizando o custo total da confiabilidade.

A solução DFR é aplicada a um circuito de distribuição com alimentador. A partir deste ponto, discutem-se os resultados relativos à confiabilidade e à aplicação do AG no processo. Analisam-se os custos totais e o ponto de custo ótimo em relação ao nível de confiabilidade.

\subsection{Algoritmos genéticos - diferenciação dos métodos tradicionais de busca de raízes}

Um dos critérios que levam os AGs a superar os algoritmos tradicionais é a robustez $^{14}$ [Goldberg (1989)]. Destacam-se, pelo menos, quatro características em que são diferentes dos procedimentos normais de otimização e procura:

- Trabalham com um conjunto de parâmetros codificados, não com parâmetros isolados;

- O resultado da pesquisa do AG provém de uma população de pontos e não de um ponto isolado;

- Usam funções objetivas, não derivadas ou outro conhecimento auxiliar;

- AGs usam regras de transição probabilísticas e não regras determinísticas;

\footnotetext{
${ }^{13}$ DFR - Sistema de Distribuição baseado em confiabilidade.

${ }^{14} \mathrm{Na}$ área computacional, uma solução é considerada robusta se continua a operar independente de entradas e de processamentos.
} 
- São "paralelizáveis", ou seja, mantêm uma população de soluções que podem ser avaliadas simultaneamente.

Embora os AGs tenham componentes aleatórios, utilizam a informação da população corrente para determinar o próximo estado da busca. Assim, não podem ser considerados totalmente aleatórios e não são afetados por descontinuidades na função, tampouco dependem da análise de derivadas para efetuar buscas.

\subsection{Metas de otimização}

O conceito de otimização busca descrever e atingir a melhor solução, uma vez que se saiba como medir e alterar o que é "bom" ou "ruim", ou seja, há a preocupação com o estudo quantitativo do ótimo e métodos para encontrá-lo. Esta é uma característica dos problemas NP-completos. Desta maneira, a busca da otimização procura incrementar o desempenho, por meio de um conjunto de soluções, incluindo pontos ótimos.

Observa-se que os procedimentos que julgam a otimização têm como foco principal a convergência da solução, muitas vezes, ignorando critérios que envolvam desempenho [Goldberg (1989)].

Os AGs utilizam um conjunto de parâmetros, provenientes de um problema otimizado, de maneira que estes sejam codificados como uma "palavra" (vetor unidimensional) de comprimento finito sobre um alfabeto finito.

Verifica-se que muitas técnicas de pesquisa precisam de informação auxiliar para funcionar adequadamente. Por exemplo, técnicas de gradiente necessitam derivadas (calculadas analiticamente ou numericamente). Objetiva-se encontrar um valor de máximo, em uma região espacial, ou procedimentos de pesquisa local que utilizam técnicas de otimização combinatória, necessitando de um conjunto de valores tabelados [Eiben et al. (2004) e Fogel (2002)].

Em contrapartida, os AGs não necessitam de um conjunto de informações auxiliares, trabalhando somente com valores de funções objetivas, associadas com vetores individuais. Ao contrário de outros métodos, usam regras de transição probabilísticas na orientação da pesquisa. Para profissionais familiarizados com métodos determinísticos, é estranho utilizar esse tipo de regra. O uso de probabilidade não sugere que o método seja simplesmente uma pesquisa aleatória, mas que use este tipo de solução como ferramenta para guiar uma pesquisa em regiões de espaço, onde se encontra a solução. Reunindo características específicas - como o uso 
de código otimizado, pesquisa de população e operadores genéticos definidos -, atende-se ao perfil de robustez do AG, revelando sua vantagem sobre outras técnicas.

\subsection{Funcionamento dos AGs}

Os AGs são métodos de pesquisa e otimização baseados na evolução natural [Goldberg (1989)]. Contêm uma população de bits (ou strings) que será transformada pelos três operadores genéticos: seleção, crossover e mutação.

Cada cromossomo representa uma possível solução para o problema a ser otimizado, e cada posição corresponde à contribuição de alguma variável do problema (gene). Essas soluções são classificadas como "funções de avaliação", retornando os melhores valores ou fitness [Miranda et al. (1994)].

Existem muitos tipos de AGs [Grefenstette (1991)], um dos mais tradicionais é o algoritmo genético canônico. Este se baseia no trabalho dos três operadores genéticos supracitados; é linear e pode ou não ser binário, com tamanho fixo para o cromossomo. A primeira geração tem seus elementos alocados aleatoriamente; a nova geração é criada a partir da atuação dos operadores. O uso desta técnica simplifica a formulação de problemas de otimização, possibilitando o ajuste de parâmetros e análise de problemas complexos que exijam um método robusto de solução [Oliveira et al. (2004), Leung et al. (2003), Goldberg (1989) e Hetem et al. (2007)]. A Figura 3.3 representa a sequência de funcionamento do AG utilizada no desenvolvimento das soluções deste trabalho.

A representação elétrica do circuito é feita por meio de um arquivo texto, que permite a entrada de parâmetros elétricos.

Uma vez definido o arquivo de entrada, é realizada a primeira geração, que consiste na criação de um número fixo de cromossomos. No trabalho, foram considerados 100 cromossomos por geração, valor este baseado em Hetem et al. (2007) e tomado como coerente para a formação da geração. 


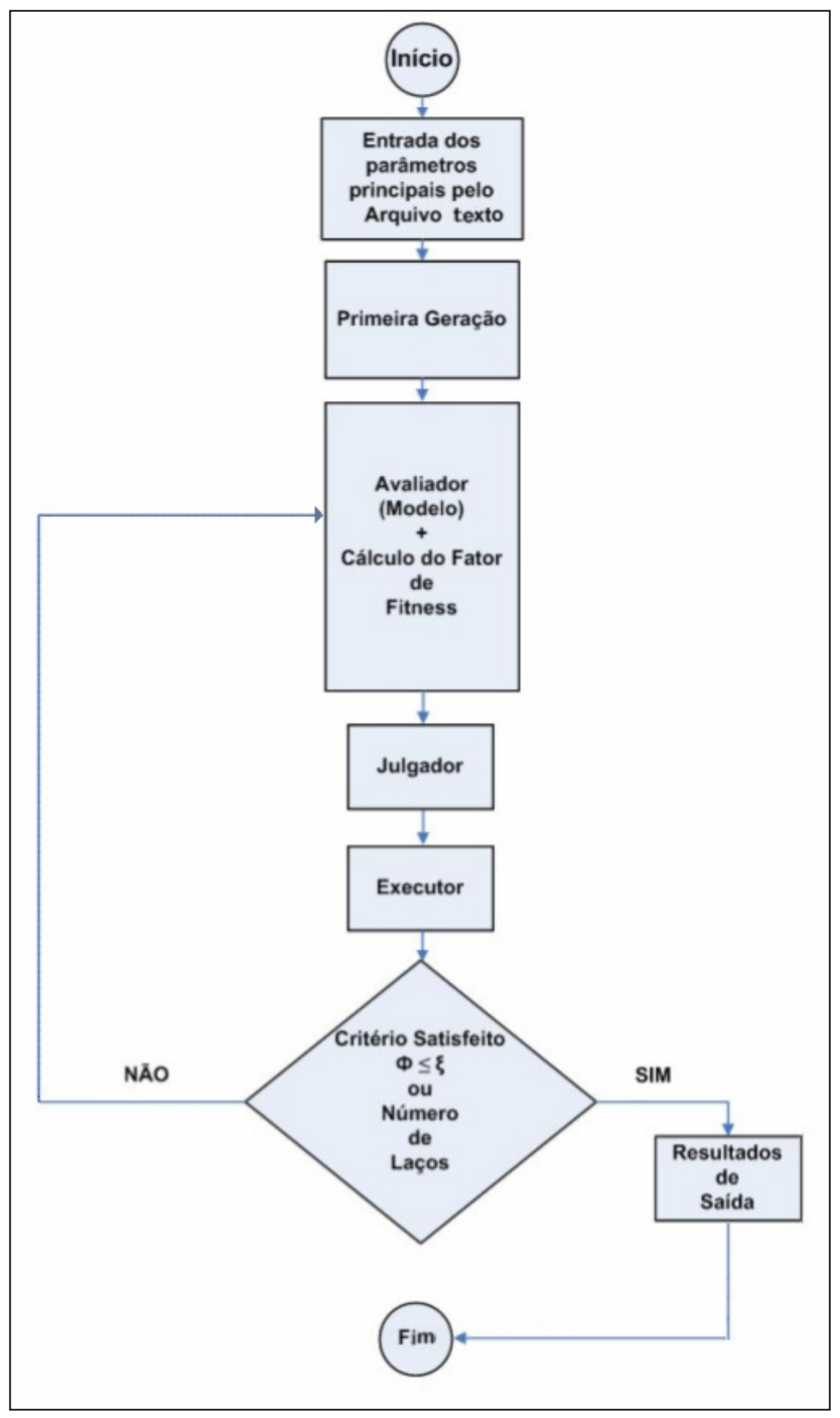

Figura 3.3 - Etapas do AG utilizado neste trabalho 


\subsubsection{Definição de parâmetros e primeira geração}

O arquivo texto que modela o circuito elétrico de referência é representado na Tabela 3.2 que contém parâmetros que serão utilizados na construção do circuito elétrico.

Tabela 3.2 - Entrada de parâmetros do circuito elétrico de referência

\begin{tabular}{|c|c|c|c|c|c|c|c|c|c|}
\hline TRECHO & ORIGEM & DESTINO & DISTANCIA & TIP0 DE LINHA & NUMERO DEFASES & CONSUMIDORES PORFASE & FALTASPOR KM & FATORDEFALTAS & EQUIPAMENTO \\
\hline 1 & G00 & N01 & 1,6093 & $\mathrm{~T}$ & 1 & 0 & 0,1367 & 1 & $\mathrm{R}$ \\
\hline 2 & N01 & N02 & 10,0581 & $T$ & 1 & 0 & 0,1367 & 1 & V \\
\hline 3 & N01 & $\mathrm{N} 03$ & 1,6093 & $M$ & 3 & 49 & 0,1367 & 1 & $F$ \\
\hline 4 & $\mathrm{~N} 02$ & N04 & 6,4372 & $M$ & 3 & 36 & 0,1367 & 1 & $F$ \\
\hline 5 & N02 & N05 & 5,6325 & $M$ & 3 & 49 & 0,1367 & 1 & $F$ \\
\hline 6 & N02 & N06 & 3,2186 & $T$ & 1 & 0 & 0,1367 & 1 & V \\
\hline 7 & N06 & N07 & 6,9199 & $M$ & 3 & 0 & 0,1367 & 1 & V \\
\hline 8 & N07 & N08 & 7,7246 & $M$ & 3 & 36 & 0,1367 & 1 & $F$ \\
\hline 9 & N07 & No9 & 6,759 & $M$ & 3 & 0 & 0,1367 & 1 & $V$ \\
\hline 10 & N09 & N10 & 3,2186 & $M$ & 3 & 12 & 0,1367 & 1 & $F$ \\
\hline 11 & Nog & N11 & 6,4372 & $M$ & 3 & 36 & 0,1367 & 1 & $F$ \\
\hline 12 & N06 & N12 & 1,6093 & $M$ & 3 & 0 & 0,1367 & 1 & V \\
\hline 13 & N12 & N13 & 8,0465 & $M$ & 3 & 49 & 0,1367 & 1 & $F$ \\
\hline 14 & N12 & N14 & 1,6093 & $M$ & 3 & 0 & 0,1367 & 1 & V \\
\hline 15 & N14 & N15 & 12,472 & $M$ & 3 & 49 & 0,1367 & 1 & $F$ \\
\hline 16 & N14 & N16 & 7,7246 & $M$ & 1 & 72 & 0,1367 & 1 & $F$ \\
\hline
\end{tabular}

Para a obtenção da primeira geração de indivíduos, é necessário definir a estrutura do cromossomo. Este é formado por uma sequência de genes, cujo tamanho varia de acordo com o circuito. Cada cromossomo representa uma solução em potencial para o problema a ser investigado.

No trabalho, o cromossomo foi alocado dinamicamente, com tamanho fixo, em função do número de nós do circuito, sendo representado pela Figura 3.4:

Alocação dinâmica de uma palavra (cromossomo)

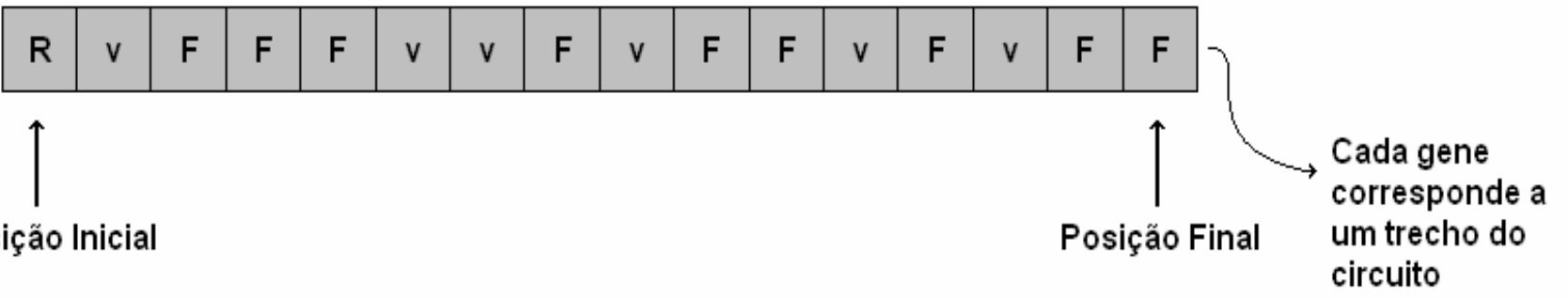

Figura 3.4 - Exemplo de cromossomo - alocação dinâmica de uma "palavra"

No cromossomo modelado, cada gene representa um trecho, de modo análogo a uma estrutura biológica. Cada um receberá um símbolo, que dependerá da alocação aleatória dos elementos: Disjuntor de Subestação (S), Religador (R), Fusível $(F)$ e trecho sem equipamento $(v)$. 
Podem ser utilizados outros elementos para o modelo, como no estudo das contingências, no caso das chaves de proteção, ou outro tipo de representação, em base binária [Miranda et al. (1994) e Brown et al. (1996)].

A primeira geração toma por base a entrada dos parâmetros, criando-se um conjunto aleatório de cromossomos $\left[\mathrm{S}_{1}, \mathrm{~S}_{2}, \ldots, \mathrm{S}_{\mathrm{n}}\right]$, como o exemplificado na Tabela 3.2. Assim, caracteriza-se a primeira geração de indivíduos (ilustrada na Tabela 3.3), ou seja, os elementos formadores dos cromossomos são alocados aleatoriamente. Neste ponto, o peso ff (fator de fitness) do cromossomo ainda não foi calculado.

Tabela 3.3 - Exemplo de primeira geração, com 10 indivíduos

\begin{tabular}{|c|c|c|}
\hline Número do Cromossomo & Peso (fator de fitness) & Cromossomos \\
\hline $000:$ & 0 & SvFFRRRFRRFFRFRF \\
\hline $001:$ & 0 & SRFRFvRRvRFRFFRR \\
\hline $002:$ & 0 & wRFRRvFFFRFRFRR \\
\hline $003:$ & 0 & wFFFRRFFFFFFRF \\
\hline $004:$ & 0 & SvRFRvFRRFRRRvRF \\
\hline $005:$ & 0 & wRFFvFRFRRRRRRF \\
\hline $006:$ & 0 & vRRRFvvFFRFvRRRR \\
\hline $007:$ & 0 & vRFRFRRFvFRvRRFF \\
\hline $008:$ & 0 & wRFFRRRvFRFRRRF \\
\hline $009:$ & 0 & vRFRFvRFvFRFRFFF \\
\hline $010:$ & 0 & SvRRRvFRvRRvFFRF \\
\hline
\end{tabular}

\subsubsection{Aplicação da função Avaliador e cálculo do fator de fitness}

O próximo passo, observado na Figura 3.3, é aplicar a função Avaliador. Esta, por sua vez, determina o fator de qualidade dos cromossomos, a partir de seus genes (elementos formadores), associando uma nota ao indivíduo. É o chamado "fator de fitness (ff)".

A função Avaliador somente julga a qualidade de cada indivíduo, sem adicionar qualquer tipo de informação a respeito das técnicas de resolução do problema em questão [Linden (2006)].

O fator de fitness deverá refletir o comportamento do circuito frente às variações de alocação dos equipamentos. Caso sejam alocados religadores em todos os trechos, os índices de continuidade DEC e FEC, por um lado, serão os menores 
possíveis, porém, a um elevado custo. Por outro, não alocar equipamento algum elevará os valores dos índices aos seus máximos, mas a custo zero.

Assim, é necessário alcançar o equilíbrio entre o número de equipamentos alocados (custo) e os índices de continuidade, portanto o fator de fitness (ff) deve ser escolhido para que seu comportamento se inverta, quando considerado cada um desses dois fatores, em separado. Essa informação será detalhada no Capítulo 5.

O comportamento esperado de ff é exemplificado pela Figura 3.5. Nota-se que o ponto de mínimo do fator de fitness não corresponde, necessariamente, ao ponto de cruzamento das duas outras funções.

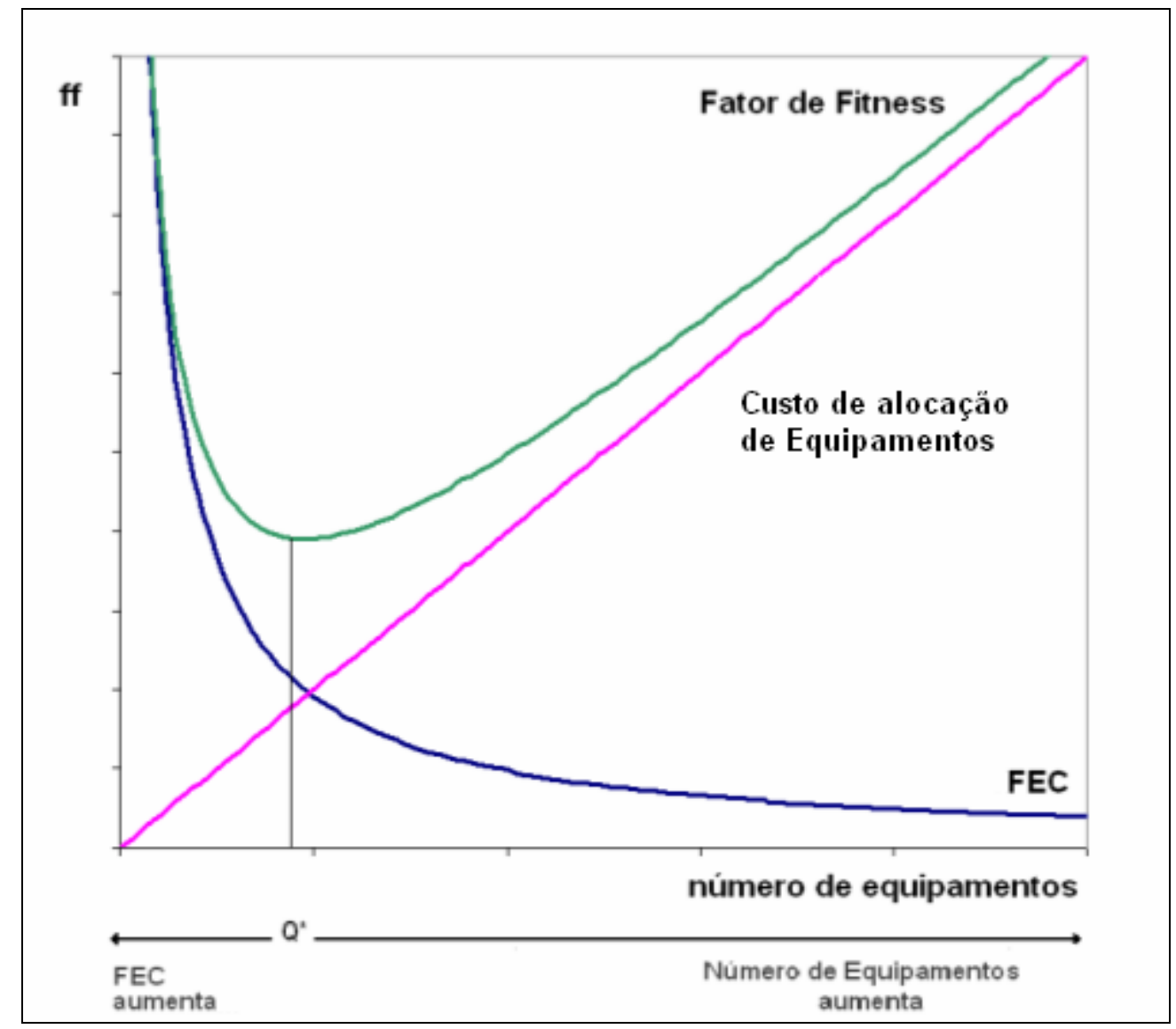

Figura 3.5 - Comportamento do ff

Observando a Figura 3.5, constata-se que a distribuição ff representa cada indivíduo, ou seja, cada conjunto de configuração de equipamentos alocados. Esse fato terá consequências diretas no cálculo do valor de FEC do circuito, no resultado e na solução ideal. Influenciará também no ponto de inflexão da curva, representada por $Q^{*}$. 


\subsubsection{Classificação dos cromossomos pela função Julgador}

A função Julgador utiliza o valor de ff para escolha dos operadores genéticos a serem aplicados aos indivíduos. É ela que auxilia a diferenciar os cromossomos. Calcula-se um "fator de fitness" que pontuará cada cromossomo, a partir de seus genes. Trata-se de um ponto crítico, pois a solução ótima depende diretamente de um fator de fitness coerente e condizente, que reflita a realidade do problema.

Ao trabalhar com a primeira geração de indivíduos e calcular o fator de fitness (que será detalhado no decorrer do Capítulo 5) para cada cromossomo (função Avaliador), obtém-se a pontuação de cada um. Tais dados, obtidos com seus respectivos fatores, indicam se um indivíduo representa uma boa solução [Kagan (1999) e Bentley et al. (2002)], conforme apresenta a Tabela 3.4.

Tabela 3.4 - Exemplo de primeira geração, após função Avaliadora sobre 10 indivíduos

\begin{tabular}{|c|c|c|}
\hline Número do Cromossomo & Peso (fator de fitness) & Cromossomos \\
\hline $000:$ & 35.0706 & SvFFRRvFFRFvFvRF \\
\hline $001:$ & 22.9298 & SRRRRvFRRFFvFvFF \\
\hline $002:$ & 243.753 & SRFFRRRRvFFFRFFR \\
\hline $003:$ & 22.2299 & SRFRFvRFRRFFFRFF \\
\hline $004:$ & 3407.88 & wFFRvFRvRFFRRFF \\
\hline $005:$ & 31.2362 & SvFFRvFFvFFvRvRR \\
\hline $006:$ & 24235.7 & wFFFRFFvRFFFFRF \\
\hline $007:$ & 87.4095 & vRFFFvRFRRFRFFRF \\
\hline $008:$ & 91.4312 & vRRRFRFFRFFRFvRR \\
\hline $009:$ & 14.2194 & vRFRFRvRRRRvRvFR \\
\hline $010:$ & 90.1582 & vRRRRRRFvRFFRvRF \\
\hline
\end{tabular}

A partir da criação do conjunto de indivíduos pontuados, a função Julgador classifica os cromossomos em ordem crescente, com base no fator de fitness. Ela aplica o operador genético correspondente, de acordo com percentuais definidos.

Foram considerados os operadores:

- Cópia: o indivíduo é o mesmo na geração seguinte;

- Crossover. o indivíduo é escolhido para alterar um número de genes (parâmetros) com outro, criando um novo elemento;

- Mutação: um dos genes deverá ser aleatoriamente alterado;

- Descarte: nenhum dos genes deve continuar nas próximas gerações. 
A escolha de cada ação é expressa pela variável $\Phi_{\mathrm{i}}$, que representa o operador que será associado a cada cromossomo.

\subsubsection{Criação da próxima geração pela função Executor}

O próximo passo é a evolução da geração atual $(k)$ para a próxima geração $(k+1)$. Esta etapa é alcançada por meio de um procedimento $\Gamma$ (o algoritmo genéti$c o)$, que considera as soluções e seu operador genético correspondente, determinado por $\Phi_{i}$.

Formalmente:

$$
\left[S_{1}, S_{2}, \ldots, S_{n}\right]_{k+1}=\Gamma\left[\left(S_{1}, \Phi_{1}\right),\left(S_{2}, \Phi_{2}\right), \ldots,\left(S_{n}, \Phi_{n}\right)\right]_{k}
$$

A equação (3.1) indica que "os indivíduos da próxima geração $(k+1)$ são obtidos pela aplicação de cada operador genético $\left(\Phi_{\mathrm{i}}\right)$ aos parâmetros $\left(\mathrm{S}_{\mathrm{i}}\right)$ " [Hetem et al. (2007)].

A função Executor cria a próxima geração aplicando os operadores genéticos correspondentes, de acordo com seus percentuais definidos. Após a conclusão desta fase, parte-se para a análise dos critérios de parada, que podem ser:

- Convergência de valores: os indivíduos - muito próximos uns dos outros começam a ter o mesmo valor de ff. Assim, pode-se definir um fator de erro ( $\xi$ ) absoluto para indicar precisão de trabalho;

- Número de laços ou número de gerações.

Uma vez satisfeito o critério de parada, informam-se os resultados de saída. Caso contrário, retorna-se à função Avaliador, que é reaplicada, e o algoritmo repete as ações descritas. 
Capítulo 4

\section{Metodologia para Obtenção de Índices de}

Continuidade

\section{Metodologia para Obtenção de Índices de Continuidade}

Este capítulo apresenta a metodologia para obtenção de índices de continuidade, os quais foram calculados a partir do circuito-base e apresentados no Capítulo 2.

Os modelos e os respectivos cálculos foram dispostos segundo a sequência de Bishop (1997) e Burian (2001). O objetivo foi apresentar a evolução das topologias utilizadas e implementadas no programa TEIAA.

\subsection{Cálculos em cada topologia do circuito elétrico}

Para o desenvolvimento das topologias do circuito elétrico, foi tomado como base um circuito de distribuição de energia elétrica [Bishop (1997) e Burian (2001)]. Os índices de continuidade, DEC e FEC, foram calculados em várias configurações de circuitos, contendo diferentes alocações de equipamentos de proteção.

A partir do circuito da Figura 2.2, foram calculados os índices de continuidade, de maneira recursiva ${ }^{15}$. Partiu-se do ramo mais distante e usou-se o alimentador principal como referência, baseado em uma estrutura de árvore.

Foram analisadas cinco topologias, com diferentes equipamentos de proteção, provenientes do modelo de Bishop (1997). Na medida em que elas evoluíam com o incremento de novas alocações de dispositivos em diferentes ramos do circuito - foram determinados os índices de continuidade DEC e FEC.

A topologia 1, representada pela Figura 4.1, baseou-se na definição de DEC e FEC, documentada em Bishop et al. (1999). Consideraram-se as regras de aloca-

\footnotetext{
${ }^{15} \mathrm{O}$ algoritmo recursivo envolve a definição de uma função que pode invocar a si própria.
} 
ção de equipamentos descritas no item 2.2. As fórmulas utilizadas para o cálculo dos índices de continuidade são descritas, de acordo com a topologia:

Frequência equivalente por consumidor - Topologia 1

$$
\mathrm{FEC}=\sum_{i=1}^{n}\left(\mathrm{CTT}_{\mathrm{i}}{ }^{*} I \mathrm{~F}_{\mathrm{i}}{ }^{*} N \mathrm{~F}_{\mathrm{i}}+\mathrm{CTM} \mathrm{M}_{\mathrm{i}}{ }^{*} \mathrm{~F}_{\mathrm{i}}\right)
$$

\section{Duração equivalente por consumidor - Topologia 1}

$$
\begin{aligned}
& \mathrm{DEC}=\sum_{\mathrm{i}=1}^{\mathrm{n}}\left(\mathrm{CTT}_{\mathrm{i}}{ }^{*} \mathrm{IF}_{\mathrm{i}}{ }^{*} \mathrm{TLG}_{\mathrm{i}}{ }^{*} \mathrm{PTFT}_{\mathrm{i}}+\mathrm{CTT}_{\mathrm{i}}{ }^{*} \mathrm{IF}_{\mathrm{i}}{ }^{*} \mathrm{TLT}_{\mathrm{i}}{ }^{*} \mathrm{PTFP} \mathrm{P}_{\mathrm{i}}+\right. \\
& +{ } \mathrm{CTM}_{i}{ }^{*} \mathrm{~F}_{\mathrm{i}}{ }^{*} \mathrm{RLG}_{\mathrm{i}}{ }^{*} \mathrm{PTFT}_{\mathrm{i}}{ }^{*} \mathrm{NF}_{\mathrm{i}}+\mathrm{CTM}_{\mathrm{i}}{ }^{*} \mathrm{IF}_{\mathrm{i}}{ }^{*} \mathrm{TLM}_{\mathrm{i}}{ }^{*} \mathrm{PTFP}_{\mathrm{i}}{ }^{*} N \mathrm{~F}_{\mathrm{i}} \text { ) }
\end{aligned}
$$

A topologia 2, representada pela Figura 4.3, incorpora a capacidade de religamento no disjuntor da subestação (função $79^{16}$ ). Considera-se que a porcentagem de falhas temporárias é "filtrada", restando somente as parcelas permanentes de $20 \%$.

Logo:

\section{Frequência equivalente por consumidor - Topologia 2}

$$
\mathrm{FEC}=\sum_{\mathrm{i}=1}^{\mathrm{n}}\left(\mathrm{CTT}_{\mathrm{i}}{ }^{*} \mathrm{IF}_{\mathrm{i}}{ }^{\star} \mathrm{PTFP} \mathrm{P}_{\mathrm{i}}+\mathrm{CTM}_{\mathrm{i}}{ }^{*} \mathrm{IF}_{\mathrm{i}}{ }^{*} \mathrm{PTFP}_{\mathrm{i}}{ }^{*} \mathrm{NF}_{\mathrm{i}}\right)
$$

\section{Duração equivalente por consumidor - Topologia 2}

$$
\mathrm{DEC}=\sum_{\mathrm{i}=1}^{n}\left(\mathrm{CTT}_{\mathrm{i}}{ }^{*} \mathrm{IF}_{\mathrm{i}}{ }^{*} \mathrm{TLT}_{\mathrm{i}}{ }^{*} \mathrm{PTFP} \mathrm{P}_{\mathrm{i}}+\mathrm{CTM}_{\mathrm{i}}{ }^{*} \mathrm{IF}_{\mathrm{i}}{ }^{*} \mathrm{TLM}_{\mathrm{i}}{ }^{*} \mathrm{PTFP}_{\mathrm{i}}{ }^{*} \mathrm{NF}_{\mathrm{i}}\right)
$$

A topologia 3, representada pela Figura 4.5, incorpora o elemento fusível. Adicionalmente, tem a capacidade de religamento no disjuntor da subestação, com curvas rápidas e lentas, responsáveis por sua atuação.

Assim, observam-se as contribuições relacionadas aos fusíveis:

- Contribuição I: Circuito sem fusíveis em falhas permanentes;

- Contribuição II: Circuito com fusíveis em falhas temporárias (compensação por não haver uma coordenação de proteção de sobrecorrente perfeita).

A composição dos índices de continuidade é feita da seguinte maneira:

Frequência equivalente por consumidor - Topologia 3

FEC=FEC_Contribl+FEC_Contribll

Onde,

\footnotetext{
${ }^{16}$ Função 79: realiza o ciclo de religamento utilizado em relés e religadores
} 
FEC_Contribl é a parcela de FEC devido à Contribuição I;

FEC_Contribll é a parcela de FEC devido à Contribuição II.

Para o trecho, sem fusíveis, em falhas permanentes:

FEC_Contribl $=\sum_{i=1}^{n}\left(C T T_{i}{ }^{*} F_{i}{ }^{*} P_{T F P}+C T M_{i}{ }^{*} F_{i}{ }^{*} P T F P_{i}{ }^{*} N F_{i}\right)$

Para o trecho, com fusível, em falhas temporárias:

FEC_Contribll $=\sum_{\mathrm{i}=1}^{\mathrm{n}}\left(\right.$ FatorFEC $\left._{\mathrm{i}}{ }^{*} \mathrm{NC}_{\mathrm{i}}{ }^{*} \mathrm{CTM}_{\mathrm{i}}{ }^{*} \mathrm{NF}_{\mathrm{i}}\right) / \sum_{\mathrm{i}=1}^{\mathrm{n}} \mathrm{NC}_{\mathrm{i}}$

Assim,

FatorFEC ${ }_{i}=\mathrm{IF}_{i}^{*} 0,2+\mathrm{IF}_{\mathrm{i}}^{\star} 0,8^{\star} 0.25$
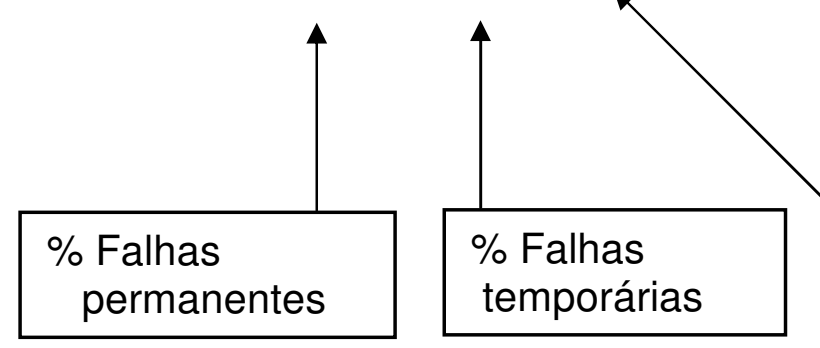

Fator de compensação

Logo:

O FatorFEC ${ }_{i}$ será igual à $\mathrm{IF}_{i}{ }^{*} 0,4$, para o caso de incidência de falhas de 0,1367/km, com base nas regras enunciadas.

\section{Duração equivalente por consumidor - Topologia 3}

DEC=DEC_Contribl+DEC_Contribll

Onde,

DEC_Contribl é a parcela de DEC devido à Contribuição I;

DEC_Contribll é a parcela de DEC devido à Contribuição II.

Para o trecho, sem fusíveis, em falhas permanentes:

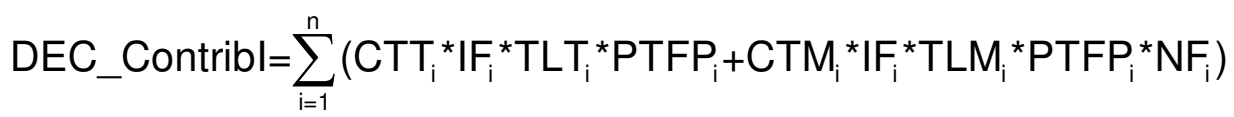

Para o trecho, com fusível, em falhas temporárias:

DEC_Contribll $=\sum_{i=1}^{n}\left(\right.$ FatorDEC $\left._{i}{ }^{*} \mathrm{NC}_{i}{ }^{*} \mathrm{CTM}_{\mathrm{i}}{ }^{*} \mathrm{NF}_{\mathrm{i}}\right) / \sum_{\mathrm{i}=1}^{\mathrm{n}} \mathrm{NC}_{\mathrm{i}}$ 
Assim,

FatorDEC $_{i}=$ IncidFalhas $_{i}{ }^{*} 0,2^{\star} 2+$ IncidFalhas $_{i}{ }^{*} 0,2^{\star} 2,5$

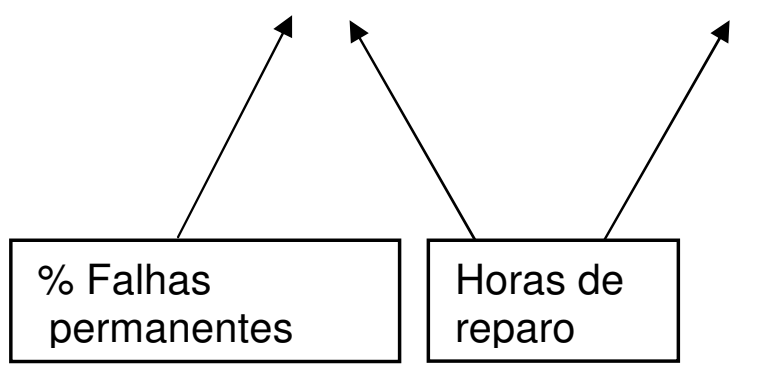

Logo:

O FatorDECi será igual à IncidFalhas ${ }_{i}^{*} 0,123$, para o caso de incidência de faIhas de $0,1367 / \mathrm{km}$, com base nas regras enunciadas.

A topologia 4, representada pela Figura 4.7, incorpora - além da capacidade de religamento no disjuntor da subestação com curva lenta - o elemento elo fusível e o religador trifásico no meio de linha.

Com a incorporação do religador R4, criaram-se zonas de proteção ilustradas na Figura 4.8.

Para o cálculo dos índices de continuidade, foram utilizadas as fórmulas apresentadas para a topologia 3, com a diferença de que não foi considerada a contribuição do ramo 1 - 3. Essa distinção deve-se à proximidade com o disjuntor da subestação, solução apresentada em Bishop (1997).

A topologia 5, representada pela Figura 4.10, seguiu as mesmas equações da topologia 4: empregou os conjuntos de religadores monofásicos, indicados como R5 e R7. Este fato faz com que o valor da contribuição dos valores de DEC e FEC, das zonas 3 e 4, seja dividido por 3, devido ao emprego de 3 religadores. Trata-se de um processo que corrobora a solução apresentada por Bishop (1997), Bishop et al. (1999) e McCarthy et al. (2000). 


\subsection{Topologia 1 - Circuito com disjuntor na subestação de energia elétrica} sem capacidade de religamento

O circuito-base para a topologia 1 é ilustrado na Tabela 4.1.

Tabela 4.1 - Representação da topologia 1 em arquivo de entrada

\begin{tabular}{|c|c|c|c|c|c|c|c|c|c|}
\hline TRECHO & ORIGEM & DESTINO & DISTÂNCIA & TIPO DE LINHA & NÚMERO DE FASES & CONSUMIDORES POR FASE & FALTAS POR KM & FATOR DE FALTAS & EQUIPAMENTO \\
\hline 1 & G0 & N1 & 1,6093 & $\mathrm{~T}$ & 1 & 0 & 0,1367 & 1 & V \\
\hline 2 & N1 & N2 & 10,0581 & $T$ & 1 & 0 & 0,1367 & 1 & $\mathrm{v}$ \\
\hline 3 & N1 & N3 & 1,6093 & $\mathrm{M}$ & 3 & 49 & 0,1367 & 1 & $\mathrm{v}$ \\
\hline 4 & N2 & N4 & 6,4372 & $\mathrm{M}$ & 3 & 36 & 0,1367 & 1 & $v$ \\
\hline 5 & N2 & N5 & 5,6325 & $M$ & 3 & 49 & 0,1367 & 1 & $v$ \\
\hline 6 & N2 & N6 & 3,2186 & $T$ & 1 & 0 & 0,1367 & 1 & $\mathrm{v}$ \\
\hline 7 & N6 & N7 & 6,9199 & $\mathrm{M}$ & 3 & 0 & 0,1367 & 1 & $v$ \\
\hline 8 & N7 & N8 & 7,7246 & $\mathrm{M}$ & 3 & 36 & 0,1367 & 1 & $v$ \\
\hline 9 & N7 & N9 & 6,759 & $\mathrm{M}$ & 3 & 0 & 0,1367 & 1 & $v$ \\
\hline 10 & N9 & N10 & 3,2186 & $\mathrm{M}$ & 3 & 12 & 0,1367 & 1 & v \\
\hline 11 & N9 & N11 & 6,4372 & $\mathrm{M}$ & 3 & 36 & 0,1367 & 1 & $v$ \\
\hline 12 & N6 & $\mathrm{N} 12$ & 1,6093 & $\mathrm{M}$ & 3 & 0 & 0,1367 & 1 & v \\
\hline 13 & N12 & N13 & 8,0465 & $\mathrm{M}$ & 3 & 49 & 0,1367 & 1 & $v$ \\
\hline 14 & N12 & N14 & 1,6093 & $\mathrm{M}$ & 3 & 0 & 0,1367 & 1 & v \\
\hline 15 & N14 & N15 & 12,472 & $\mathrm{M}$ & 3 & 49 & 0,1367 & 1 & $v$ \\
\hline 16 & N14 & N16 & 7,7246 & $M$ & 1 & 72 & 0,1367 & 1 & $\mathrm{v}$ \\
\hline
\end{tabular}

O circuito da Figura 4.1 foi modelado com um disjuntor sem capacidade de religamento na subestação de energia:

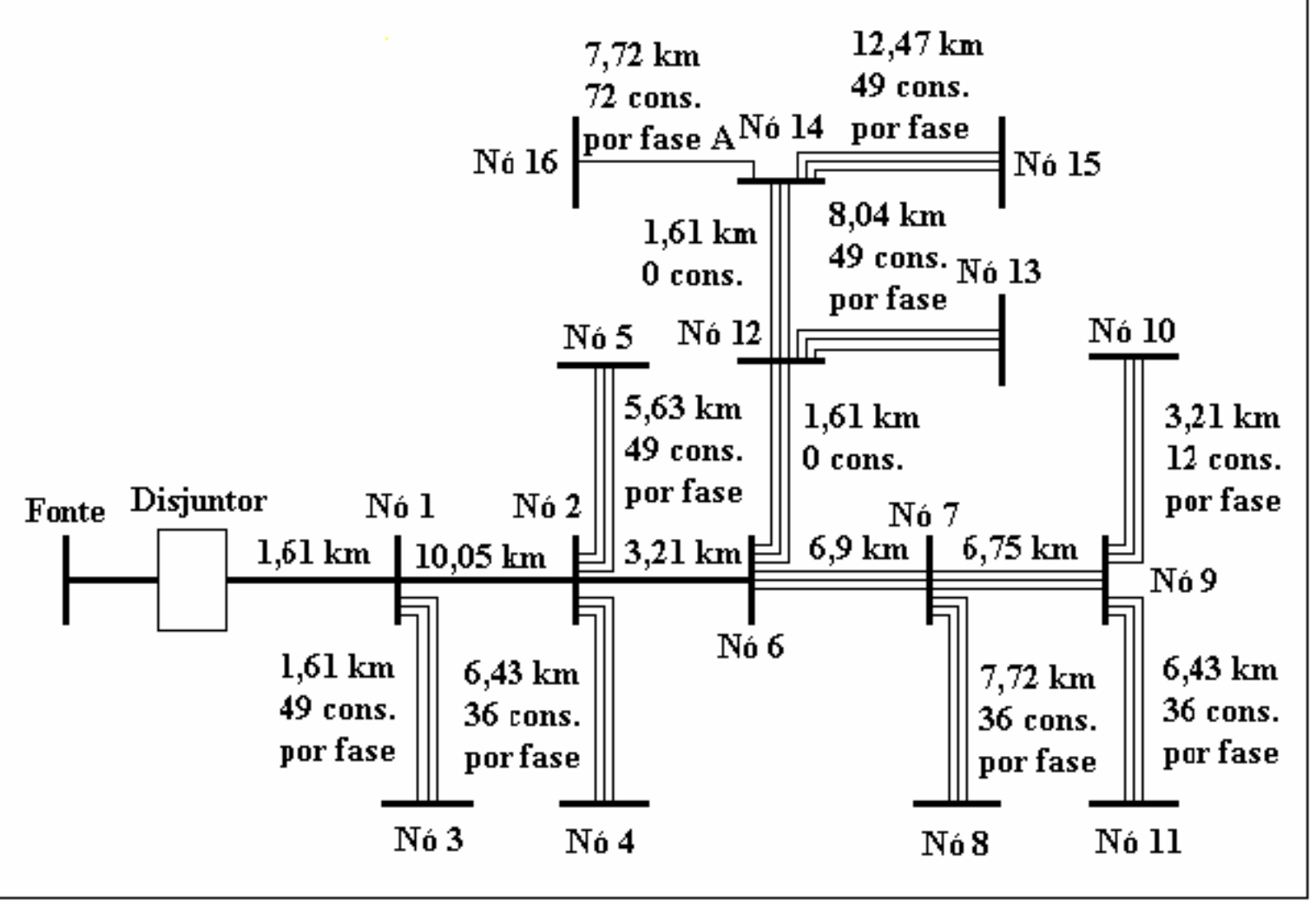

Figura 4.1 - Circuito com disjuntor na subestação 
Observa-se que:

- Nesta situação, qualquer ocorrência de falha no circuito (permanente ou temporária) resulta em uma interrupção de fornecimento de energia elétrica, envolvendo todos os consumidores, até que o disjuntor seja rearmado.

- Com base nas informações relativas ao circuito [Bishop (1997)], constrói-se a Tabela 4.2. Esta mostra os valores de DEC, baseados na Figura 2.2 (Capítulo 2), do circuito de distribuição de energia elétrica.

Tabela 4.2 - Valores de DEC do circuito

\begin{tabular}{|c|c|c|c|c|c|c|}
\hline $\begin{array}{l}\frac{0}{0} \\
0 \\
0 \\
0\end{array}$ & 을 을 & 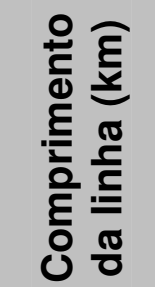 & 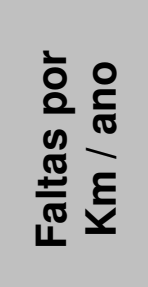 & 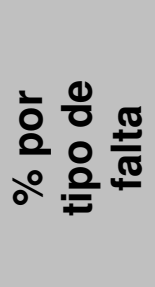 & 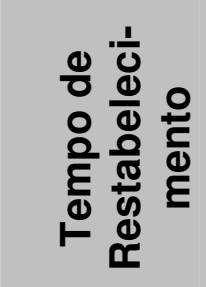 & 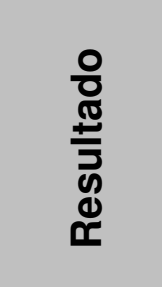 \\
\hline Temporária & $3 \varnothing$ & 14,89 & 0,1367 & 0,8 & 2 horas & 3,2567 \\
\hline $\begin{array}{l}\text { Permanen- } \\
\text { te }\end{array}$ & $3 \varnothing$ & 14,89 & 0,1367 & 0,2 & 3 horas & 1,2213 \\
\hline Temporária & $1 \varnothing$ & 213,24 & 0,1367 & 0,8 & 2 horas & 46,6398 \\
\hline $\begin{array}{l}\text { Permanen- } \\
\text { te }\end{array}$ & $1 \varnothing$ & 213,24 & 0,1367 & 0,2 & 2,5 horas & 14,5749 \\
\hline & & & & & Total & 65,6927 \\
\hline
\end{tabular}

\subsubsection{Considerações gerais da topologia 1}

Com base na Tabela 4.2, observa-se que:

- O FEC é resultado do produto do comprimento total do circuito, em km, pela taxa de incidência de falhas por km;

- O circuito modelado possui 14,89 km de linhas trifásicas e 213,24 km de linhas monofásicas;

- A incidência é de 0,1367 falhas por km / ano, levando a um total de 31,1731 falhas por ano, distribuídas ao longo do circuito, cujos cálculos foram baseados na equação (4.1) e (4.2);

- O DEC obtido resulta do fato de que falhas permanentes necessitam de um tempo maior para serem reparadas. De acordo com o modelo adotado, foram assumidas 2,5 horas, para linhas monofásicas, e 3 horas, para linhas trifásicas. Em caso de falhas temporárias, é necessária a presença da equipe de manutenção. Esta deverá fazer uma verificação rápida, para saber se houve algum tipo de dano, an- 
tes que a linha possa ser novamente energizada. Para tanto, destinam-se 2 horas à realização da tarefa, independente do tipo de linha;

- Assume-se que $80 \%$ das falhas são temporárias [Bishop (1997)]. Outras referências fazem menção a taxas menores, como Kagan et al. (2005), que admitem $70 \%$.

Devido à ausência de um equipamento de proteção com capacidade de religamento, realiza-se diretamente o cálculo do DEC. Tal situação induz que qualquer tipo de falha seja permanente. Portanto, ocasiona a desenergização dos trechos que alimentam os consumidores.

No programa TEIAA, a função recursiva que calcula os índices DEC e FEC foi desenvolvida de acordo com a Figura A.1, no Anexo A.

\subsubsection{Resultados obtidos da topologia 1}

Baseado na equação (4.1), o valor de FEC é 31,1731 interrupções de energia elétrica por consumidor.

De modo análogo, baseado na equação (4.2), o valor de DEC é 65,6927 horas de interrupção por consumidor .

As concessionárias de energia adotam diferentes tipos de configuração elétrica. Uma dessas configurações posiciona o disjuntor da subestação junto a um dispositivo, o que promove um disparo rápido e um religamento temporizado. Essas características podem ser encontradas em dispositivos de interrupção com controladores microprocessados [Cooper (1990) e Westinghouse (1964)].

Com a simulação feita pelo programa TEIAA, foram obtidos os valores dos índices de continuidade DEC e FEC, cuja topologia 1 está representada na Figura 4.2 . 


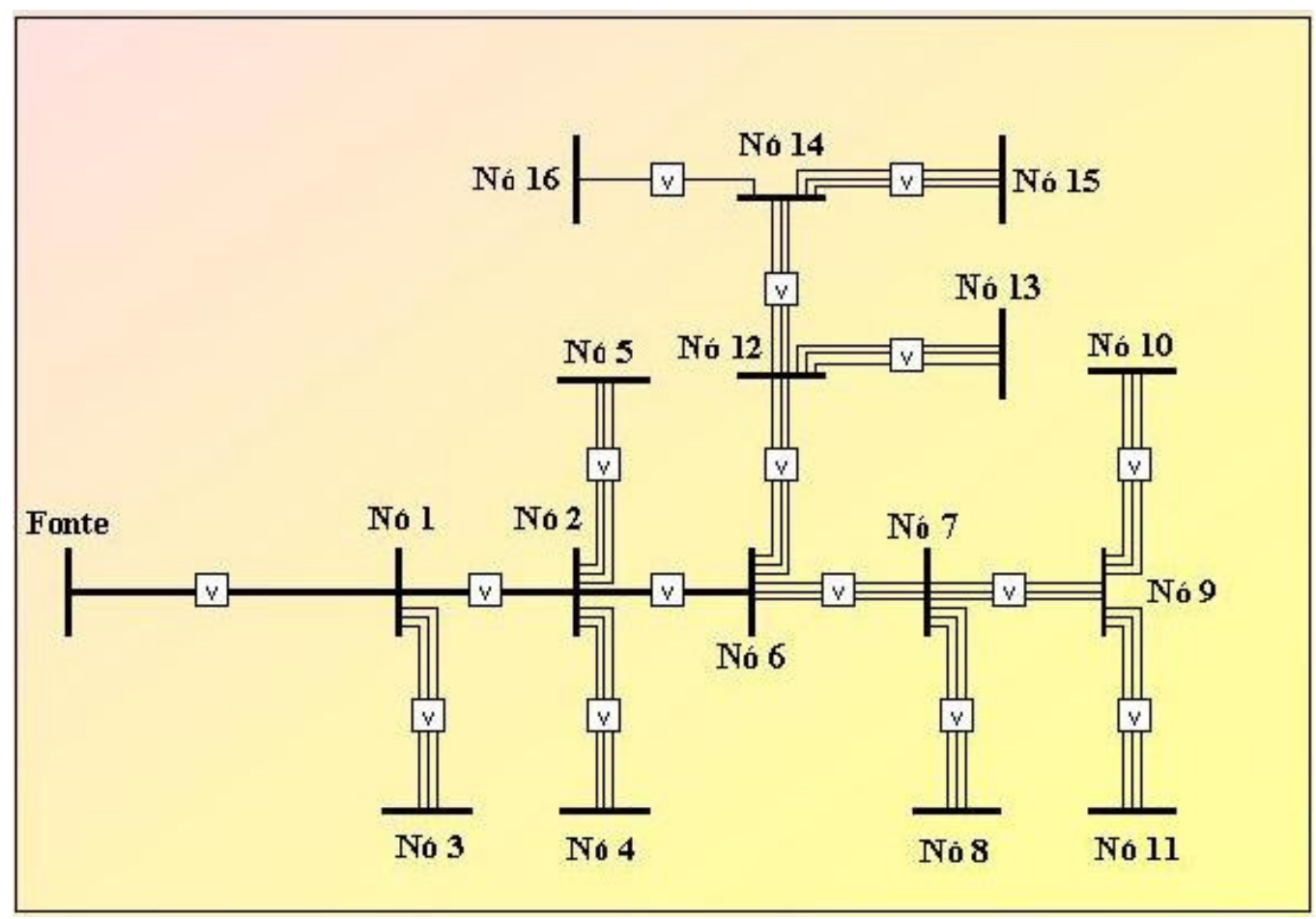

Figura 4.2 - Topologia 1 obtida da simulação realizada pelo programa TEIAA

A partir da simulação, constrói-se a Tabela 4.3. Esta apresenta os valores parciais de FEC e DEC, de acordo com o número de consumidores, com o nó-base de cada cálculo e com o trecho de circuito elétrico considerado. A obtenção desses valores baseou-se em um algoritmo recursivo. Nota-se que houve a convergência dos valores de FEC para 31,17263 interrupções de energia elétrica por consumidor e DEC para 65,66602 horas de interrupção por consumidor, indicados na tabela 4.3. 
Tabela 4.3 - Cálculo dos índices DEC e FEC para a topologia 1

\begin{tabular}{|c|c|c|c|c|c|c|}
\hline Nós/Trechos & Percentual & Eq. montante & FEC e Equip. & DEC e FEC & DEC e Cons. & Consumidores \\
\hline N4 & (n) & $p s=1$ & eqmontante $=y$ & $\mathrm{FEC}=0$ & $\mathrm{DEC}=\quad 0$ & ncons $=0$ \\
\hline$N 2->N 4$ & $p s=1$ & eqmontante $=\mathrm{v}$ & $\mathrm{FEC}=2.639896$ & $\mathrm{DEC}=5.543781$ & ncons $=108$ & \\
\hline N5 & (n) & $p s=1$ & eqmontante $=v$ & $\mathrm{FEC}=\quad 0$ & $\mathrm{DEC}=\quad 0$ & ncons $=0$ \\
\hline$N 2->N 5$ & $p s=1$ & eqmontante $=\mathrm{v}$ & $\mathrm{FEC}=2.309888$ & $\mathrm{DEC}=4.850766$ & ncons $=255$ & \\
\hline N8 & (n) & $p s=1$ & eqmontante $=\gamma$ & $\mathrm{FEC}=\quad 0$ & $D E C=\quad 0$ & ncons $=0$ \\
\hline$N 7->N 8$ & $\mathrm{ps}=1$ & eqmontante $=v$ & $\mathrm{FEC}=3.167859$ & $\mathrm{DEC}=6.652503$ & ncons $=108$ & \\
\hline N10 & (n) & $p s=1$ & eqmontante $=\mathrm{v}$ & $\mathrm{FEC}=\quad 0$ & $\mathrm{DEC}=\quad 0$ & ncons $=0$ \\
\hline$N 9->N 10$ & $\mathrm{ps}=1$ & eqmontante $=\mathrm{v}$ & $\mathrm{FEC}=1.319948$ & $\mathrm{DEC}=2.771891$ & ncons $=36$ & \\
\hline N11 & (n) & $\mathrm{ps}=1$ & eqmontante $=\mathrm{y}$ & $\mathrm{FEC}=\quad 0$ & $\mathrm{DEC}=\quad 0$ & ncons $=0$ \\
\hline N9->N11 & $\mathrm{ps}=1$ & eqmontante $=\mathrm{v}$ & $\mathrm{FEC}=2.639896$ & $\mathrm{DEC}=5.543781$ & ncons $=144$ & \\
\hline N9 & (n) & $\mathrm{ps}=1$ & eqmontante $=\mathrm{v}$ & $\mathrm{FEC}=3.959844$ & $\mathrm{DEC}=8.315672$ & ncons $=144$ \\
\hline N7->N9 & $\mathrm{ps}=1$ & eqmontante $=\mathrm{v}$ & $\mathrm{FEC}=2.771866$ & $\mathrm{DEC}=5.820919$ & ncons $=252$ & \\
\hline N7 & (n) & $p s=1$ & eqmontante $=\mathrm{y}$ & $\mathrm{FEC}=9.899569$ & $\mathrm{DEC}=20.78909$ & ncons $=252$ \\
\hline$N 6->N 7$ & $\mathrm{ps}=1$ & eqmontante $=v$ & $\mathrm{FEC}=2.837851$ & $\mathrm{DEC}=5.959488$ & ncons $=252$ & \\
\hline N13 & (n) & $\mathrm{ps}=1$ & eqmontante $=\mathrm{v}$ & $\mathrm{FEC}=\quad 0$ & $\mathrm{DEC}=\quad 0$ & ncons $=0$ \\
\hline N12->N13 & $\mathrm{ps}=1$ & eqmontante $=v$ & $\mathrm{FEC}=3.29987$ & $\mathrm{DEC}=6.929726$ & ncons $=147$ & \\
\hline N15 & (n) & $\mathrm{ps}=1$ & eqmontante $=\mathrm{v}$ & $\mathrm{FEC}=\quad 0$ & $\mathrm{DEC}=\quad 0$ & ncons $=0$ \\
\hline N14->N15 & $p s=1$ & eqmontante $=v$ & $\mathrm{FEC}=5.114768$ & $\mathrm{DEC}=10.74101$ & ncons $=147$ & \\
\hline N16 & (n) & $p s=1$ & eqmontante $=v$ & $\mathrm{FEC}=\quad 0$ & $\mathrm{DEC}=0$ & ncons $=0$ \\
\hline$N 14->N 16$ & $\mathrm{ps}=1$ & eqmontante $=\mathrm{v}$ & $\mathrm{FEC}=1.055953$ & $\mathrm{DEC}=2.217501$ & ncons $=219$ & \\
\hline N14 & (n) & $p s=1$ & eqmontante $=\mathrm{v}$ & $\mathrm{FEC}=6.17072$ & $\mathrm{DEC}=12.95851$ & ncons $=219$ \\
\hline N12->N14 & $\mathrm{ps}=1$ & eqmontante $=v$ & $\mathrm{FEC}=0.659974$ & $\mathrm{DEC}=1.385945$ & ncons $=366$ & \\
\hline $\mathrm{N} 12$ & (n) & $\mathrm{ps}=1$ & eqmontante $=v$ & $\mathrm{FEC}=10.13056$ & $\mathrm{DEC}=21.27419$ & ncons $=366$ \\
\hline $\mathrm{N} 6->\mathrm{N} 12$ & $\mathrm{ps}=1$ & eqmontante $=v$ & $\mathrm{FEC}=0.659974$ & $\mathrm{DEC}=1.385945$ & ncons $=618$ & \\
\hline N6 & (n) & $p s=1$ & eqmontante $=\mathrm{v}$ & $\mathrm{FEC}=23.52796$ & $\mathrm{DEC}=49.40871$ & ncons $=618$ \\
\hline N2->N6 & $\mathrm{ps}=1$ & eqmontante $=v$ & $\mathrm{FEC}=0.4399827$ & $\mathrm{DEC}=0.9679618$ & ncons $=873$ & \\
\hline N2 & (n) & $p s=1$ & eqmontante $=v$ & $\mathrm{FEC}=28.91772$ & $\mathrm{DEC}=60.77122$ & ncons $=873$ \\
\hline$N 1->N 2$ & $\mathrm{ps}=1$ & eqmontante $=\mathrm{v}$ & $\mathrm{FEC}=1.374942$ & $\mathrm{DEC}=3.024873$ & ncons $=873$ & \\
\hline N3 & (n) & $p s=1$ & eqmontante $=\mathrm{v}$ & $\mathrm{FEC}=\quad 0$ & DEC $=\quad 0$ & ncons $=0$ \\
\hline$N 1->N 3$ & $p s=1$ & eqmontante $=v$ & $\mathrm{FEC}=0.659974$ & $\mathrm{DEC}=1.385945$ & ncons $=1020$ & \\
\hline N1 & (n) & $p s=1$ & eqmontante $=\mathrm{v}$ & $\mathrm{FEC}=30.95264$ & $\mathrm{DEC}=65.18204$ & ncons $=1020$ \\
\hline G0->N1 & $\mathrm{ps}=1$ & eqmontante $=v$ & $\mathrm{FEC}=0.2199913$ & $\mathrm{DEC}=0.4839809$ & ncons $=1020$ & \\
\hline GO & (n) & $p s=1$ & eqmontante $=y$ & $\mathrm{FEC}=31.17263$ & $\mathrm{DEC}=65.66602$ & ncons $=1020$ \\
\hline
\end{tabular}

\subsection{Topologia 2 - Circuito com disjuntor na subestação de energia elétrica, com capacidade de religamento}

As características funcionais do circuito que representa a topologia 2 são representadas na Tabela 4.4. 
Tabela 4.4 - Representação da topologia 2 em arquivo de entrada

\begin{tabular}{|c|c|c|c|c|c|c|c|c|c|}
\hline TRECHO & ORIGEM & DESTINO & DISTÁNCIA & TIPO DE LINHA & NÚMERO DE FASES & CONSUMIDORES POR FASE & FALTAS POR KM & FATOR DE FALTAS & EQUIPAMENTO \\
\hline 1 & GOO & N01 & 1,6093 & $\mathrm{~T}$ & 1 & 0 & \begin{tabular}{|l}
0,1367 \\
\end{tabular} & 1 & $S$ \\
\hline 2 & N01 & $\mathrm{N} 02$ & 10,0581 & $\mathrm{~T}$ & 1 & 0 & 0,1367 & 1 & $\mathrm{v}$ \\
\hline 3 & N01 & N03 & 1,6093 & $\mathrm{M}$ & 3 & 49 & 0,1367 & 1 & $\mathrm{v}$ \\
\hline 4 & $\mathrm{~N} 02$ & N04 & 6,4372 & $\mathrm{M}$ & 3 & 36 & 0,1367 & 1 & $\mathrm{v}$ \\
\hline 5 & N02 & N05 & 5,6325 & $\mathrm{M}$ & 3 & 49 & 0,1367 & 1 & $\mathrm{v}$ \\
\hline 6 & N02 & N06 & 3,2186 & $\mathrm{~T}$ & 1 & 0 & 0,1367 & 1 & $\mathrm{v}$ \\
\hline 7 & N06 & N07 & 6,9199 & $\mathrm{M}$ & 3 & 0 & 0,1367 & 1 & $\mathrm{v}$ \\
\hline 8 & N07 & N08 & 7,7246 & $\mathrm{M}$ & 3 & 36 & 0,1367 & 1 & $\mathrm{v}$ \\
\hline 9 & N07 & N09 & 6,759 & $\mathrm{M}$ & 3 & 0 & 0,1367 & 1 & $v$ \\
\hline 10 & N09 & N10 & 3,2186 & $\mathrm{M}$ & 3 & 12 & 0,1367 & 1 & $v$ \\
\hline 11 & N09 & N11 & 6,4372 & $\mathrm{M}$ & 3 & 36 & 0,1367 & 1 & $v$ \\
\hline 12 & N06 & $\mathrm{N} 12$ & 1,6093 & $\mathrm{M}$ & 3 & 0 & 0,1367 & 1 & $\mathrm{v}$ \\
\hline 13 & $\mathrm{~N} 12$ & N13 & 8,0465 & $\mathrm{M}$ & 3 & 49 & 0,1367 & 1 & $v$ \\
\hline 14 & $\mathrm{~N} 12$ & N14 & 1,6093 & $\mathrm{M}$ & 3 & 0 & 0,1367 & 1 & $v$ \\
\hline 15 & N14 & N15 & 12,472 & $\mathrm{M}$ & 3 & 49 & 0,1367 & 1 & $v$ \\
\hline 16 & $\mathrm{~N} 14$ & N16 & 7,7246 & $\mathrm{M}$ & 1 & 72 & 0,1367 & 1 & $\forall$ \\
\hline
\end{tabular}

O circuito da Figura 4.3 foi modelado com um dispositivo que possui capacidade de religamento na subestação de energia, associado ao disjuntor da subestação.

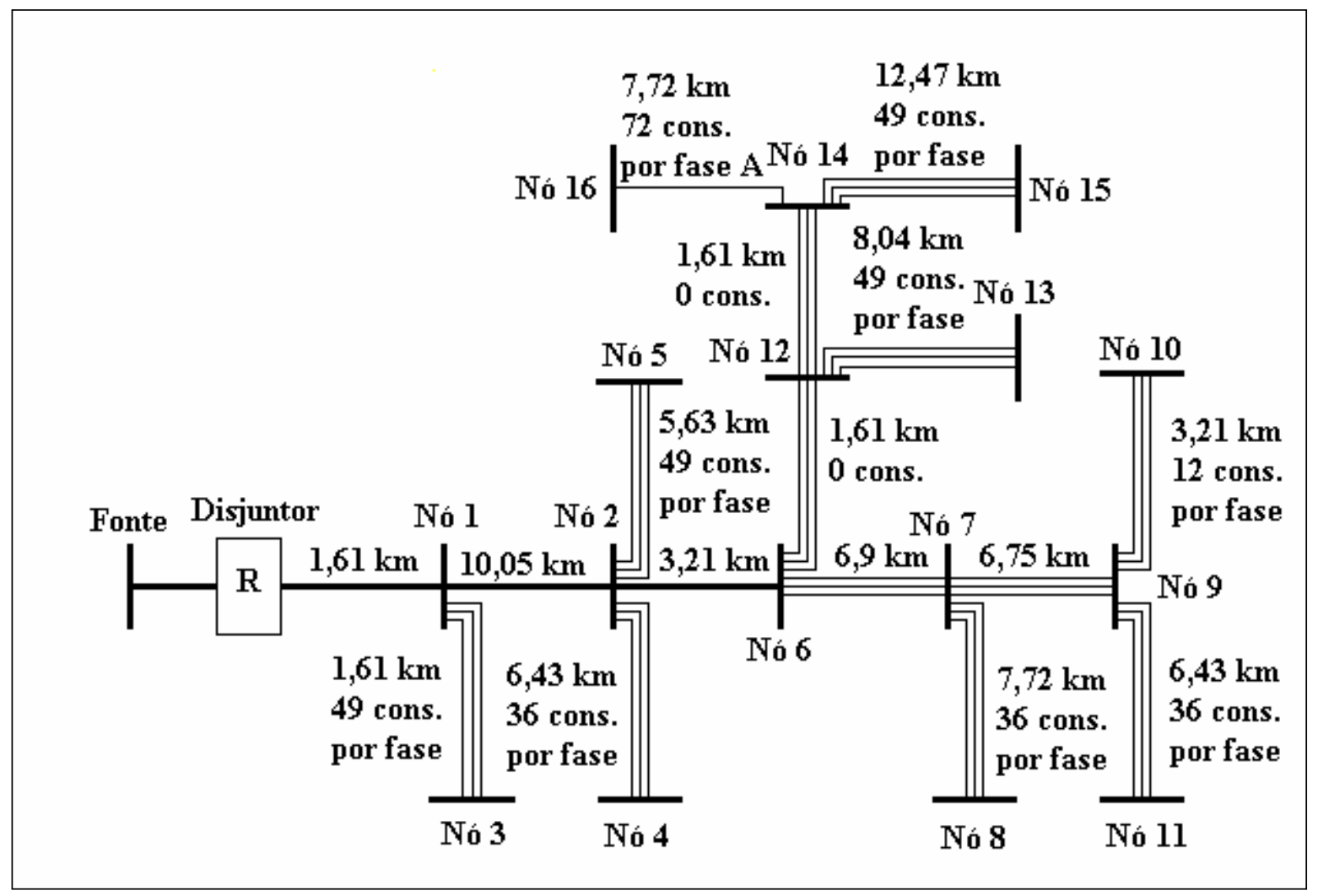

Figura 4.3 - Circuito com religamento no disjuntor da subestação

Para qualquer ocorrência de falha temporária no circuito, o disjuntor com características de religador incorporadas (função 79 - ciclo de religamento) será sensibilizado de acordo com a sua programação e ajustes internos. Ele deve entrar em ciclo de religamento, visando manter o fornecimento de energia elétrica. Desta maneira, as falhas temporárias não irão causar a interrupção do processo, pois serão 
filtradas pelo religador. Este, por sua vez, incorpora o religamento ao seu controle, seja ele processado ou não.

Conforme os parâmetros elétricos baseados em Bishop (1997), obtém-se a Tabela 4.5, a qual expõe os valores de DEC do circuito de distribuição de energia elétrica.

Tabela 4.5 - Valores de DEC do circuito com disjuntor na subestação munido de capacidade de religamento

\begin{tabular}{|c|c|c|c|c|c|c|}
\hline 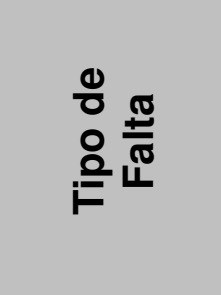 & 을를 돌 & 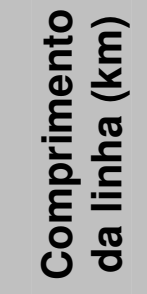 & 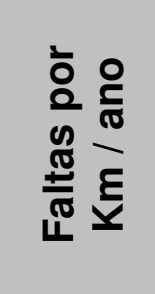 & 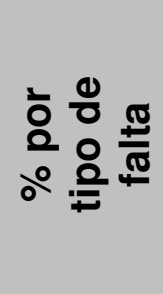 & 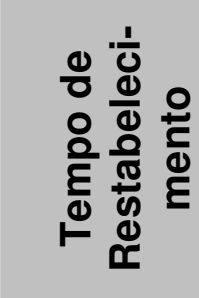 & $\begin{array}{l}\frac{0}{0} \\
\frac{\mathbb{T}}{ \pm} \\
\frac{0}{d} \\
\mathbb{1}\end{array}$ \\
\hline $\begin{array}{c}\text { Permanen- } \\
\text { te }\end{array}$ & $3 \varnothing$ & 14,89 & 0,1367 & 0,2 & 3 horas & 1,2213 \\
\hline $\begin{array}{c}\text { Permanen- } \\
\text { te }\end{array}$ & $1 \varnothing$ & 213,24 & 0,1367 & 0,2 & 2,5 horas & 14,5749 \\
\hline
\end{tabular}

\subsubsection{Resultados obtidos da topologia 2}

Baseado na equação (4.3), o valor de FEC é 6,2346 interrupções de energia elétrica por consumidor.

De modo análogo, baseado na equação (4.4), o valor de DEC é 15,7962 horas de interrupção por consumidor .

Analisando o circuito da figura 4.3 e as informações contidas na Tabela 4.5, conclui-se que:

- O valor do FEC caiu $80 \%$ devido à "filtragem" das falhas temporárias, somente restando $20 \%$ dos valores relativos às falhas permanentes;

- O índice DEC considerou somente as falhas permanentes.

Com a simulação feita pelo programa TEIAA, foram obtidos os valores dos índices de continuidade DEC e FEC, cuja topologia 2 está representada na Figura 4.4 . 


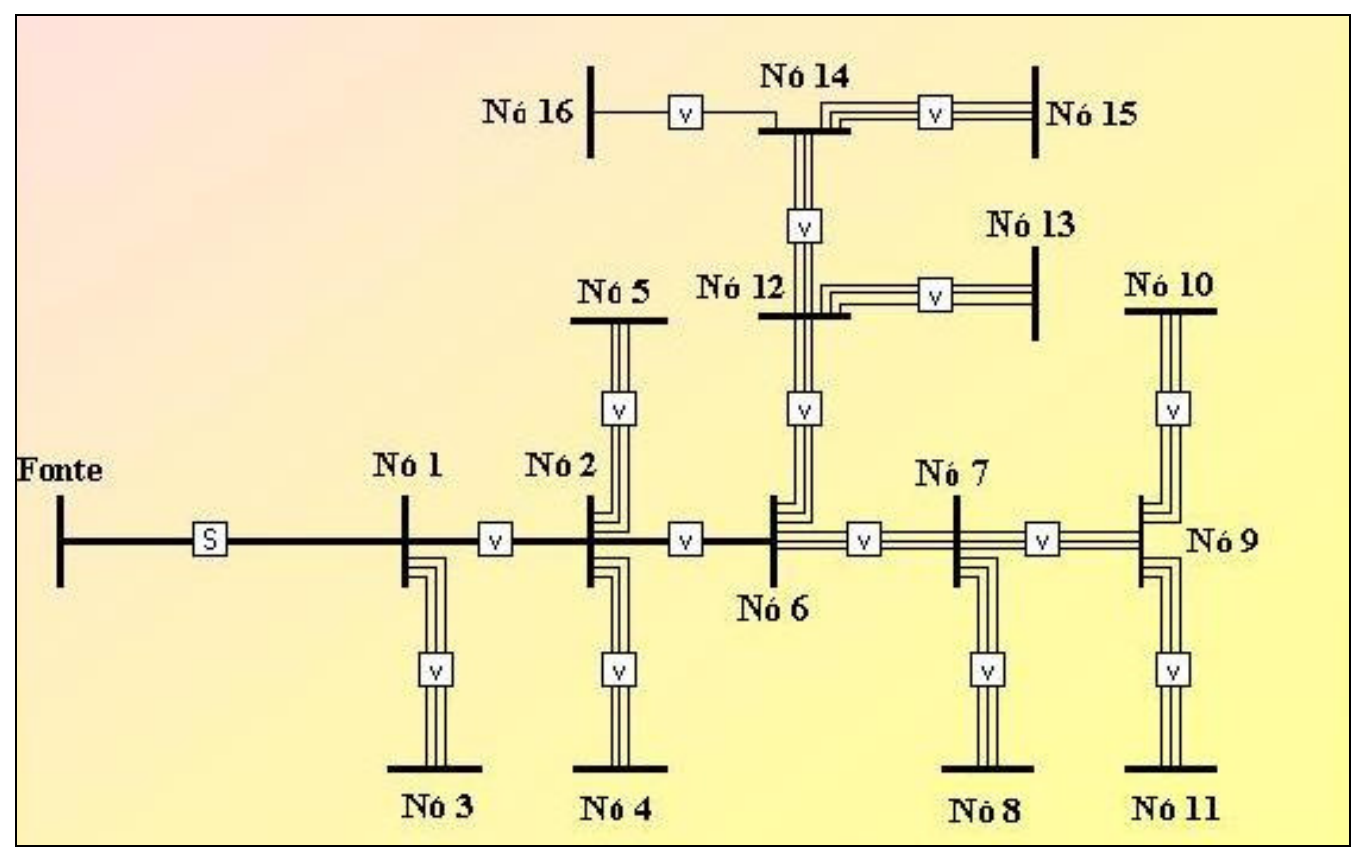

Figura 4.4 - Topologia 2 obtida da simulação realizada pelo programa TEIAA

Tabela 4.6:

Como resultado da simulação realizada pelo programa TEIAA, obteve-se a

Tabela 4.6 - Cálculo dos índices DEC e FEC para topologia 2

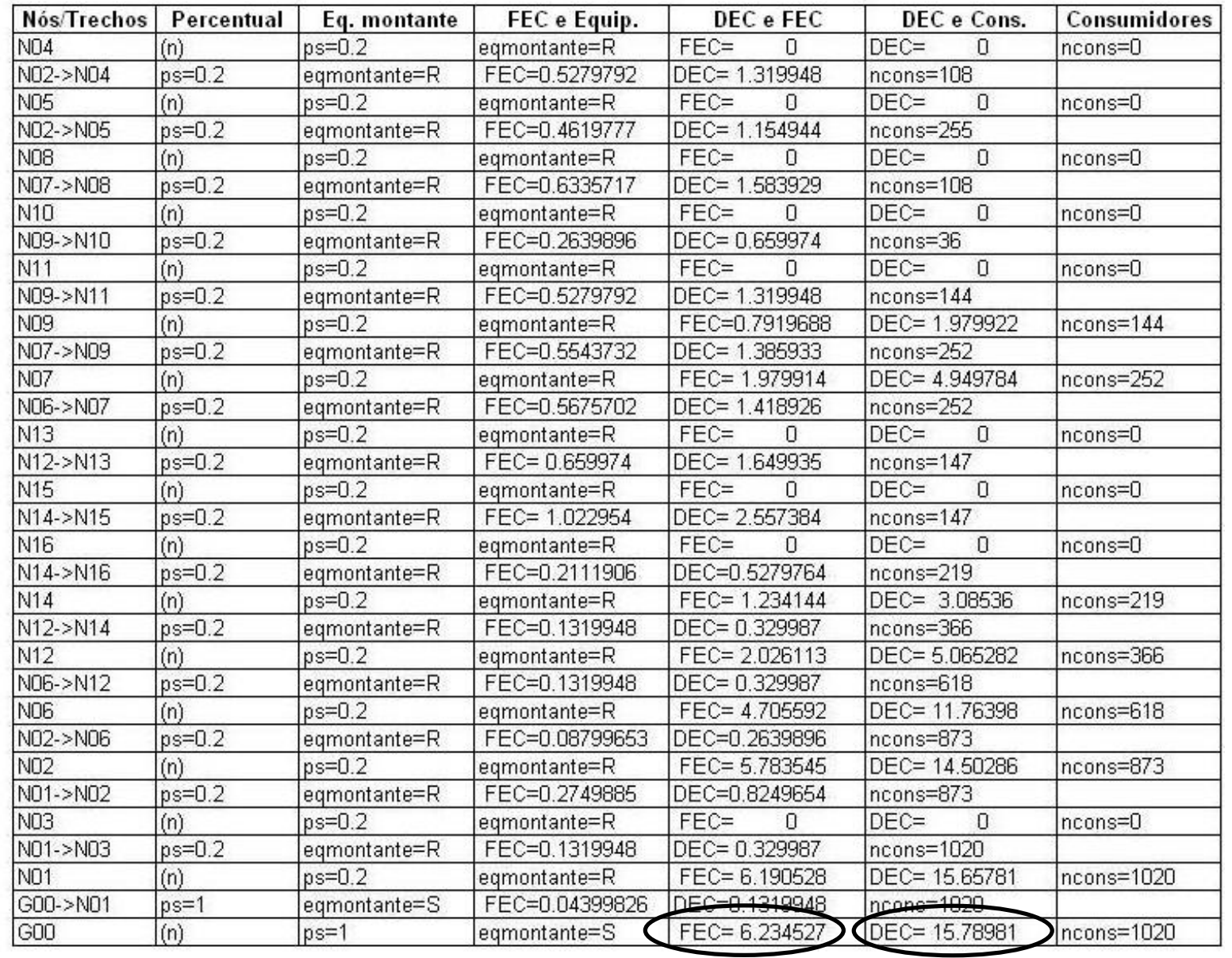


Na Tabela 4.6, observa-se que houve a convergência dos valores de FEC para 6,234527 interrupções de energia elétrica por consumidor e DEC para 15,78981 horas de interrupção por consumidor. Assim, verifica-se uma queda destes índices em relação à topologia 1 .

\subsection{Topologia 3 - Circuito protegido com fusíveis nos ramais, em relação ao} alimentador principal e disjuntor, na subestação de energia elétrica, dotado de capacidade de religamento com curva de atuação rápida e lenta

O circuito elétrico, representado pela Figura 4.5, possui os ramos laterais ligados ao alimentador principal, por meio de fusíveis. Estes deverão atuar em coordenação com o disjuntor, presente na subestação de energia elétrica e munido de capacidade de religamento.

As características funcionais do circuito que representa a topologia 3 são ilustradas na Tabela 4.7.

Tabela 4.7 - Representação da topologia 3 em arquivo de entrada

\begin{tabular}{|c|c|c|c|c|c|c|c|c|c|}
\hline TRECHO & ORIGEM & $\overline{\text { DESTINO }}$ & DISTANCIA & TIPO DELINHA & NUMERO DEFASES & CONSUMIDORES PORFASE & FALTAS POR KM & FATORDEFALTAS & EQUIPAMENTO \\
\hline 1 & G00 & N01 & 1,6093 & $\mathrm{~T}$ & 1 & 0 & 0,1367 & 1 & $\mathrm{R}$ \\
\hline 2 & N01 & $\mathrm{N} 02$ & 10,0581 & $T$ & 1 & 0 & 0,1367 & 1 & $v$ \\
\hline 3 & N01 & $\mathrm{N} 03$ & 1,6093 & $M$ & 3 & 49 & 0,1367 & 1 & $F$ \\
\hline 4 & N02 & N04 & 6,4372 & M & 3 & 36 & 0,1367 & 1 & $\mathrm{~F}$ \\
\hline 5 & N02 & N05 & 5,6325 & $M$ & 3 & 49 & 0,1367 & 1 & $\mathrm{~F}$ \\
\hline 6 & N02 & N06 & 3,2186 & $T$ & 1 & 0 & 0,1367 & 1 & V \\
\hline 7 & N06 & N07 & 6,9199 & M & 3 & 0 & 0,1367 & 1 & V \\
\hline 8 & N07 & N08 & 7,7246 & $M$ & 3 & 36 & 0,1367 & 1 & $F$ \\
\hline 9 & N07 & N09 & 6,759 & $M$ & 3 & 0 & 0,1367 & 1 & V \\
\hline 11 & N09 & N11 & 6,4372 & $M$ & 3 & 36 & 0,1367 & 1 & $F$ \\
\hline 12 & N06 & N12 & 1,6093 & $M$ & 3 & 0 & 0,1367 & 1 & V \\
\hline 13 & N12 & N13 & 8,0465 & $M$ & 3 & 49 & 0,1367 & 1 & $F$ \\
\hline 14 & N12 & N14 & 1,6093 & $M$ & 3 & 0 & 0,1367 & 1 & V \\
\hline 15 & N14 & N15 & 12,472 & $M$ & 3 & 49 & 0,1367 & 1 & $F$ \\
\hline 16 & N14 & N16 & 7,7246 & $M$ & 1 & 72 & 0,1367 & 1 & $F$ \\
\hline
\end{tabular}

No circuito elétrico da Figura 4.5, os fusíveis devem ser capazes de interromper falhas nos ramos laterais antes que - na possibilidade de falhas permanentes o dispositivo religador, presente na subestação, entre em ciclo de religamento. Para falhas temporárias, o religador atuará como um filtro. 


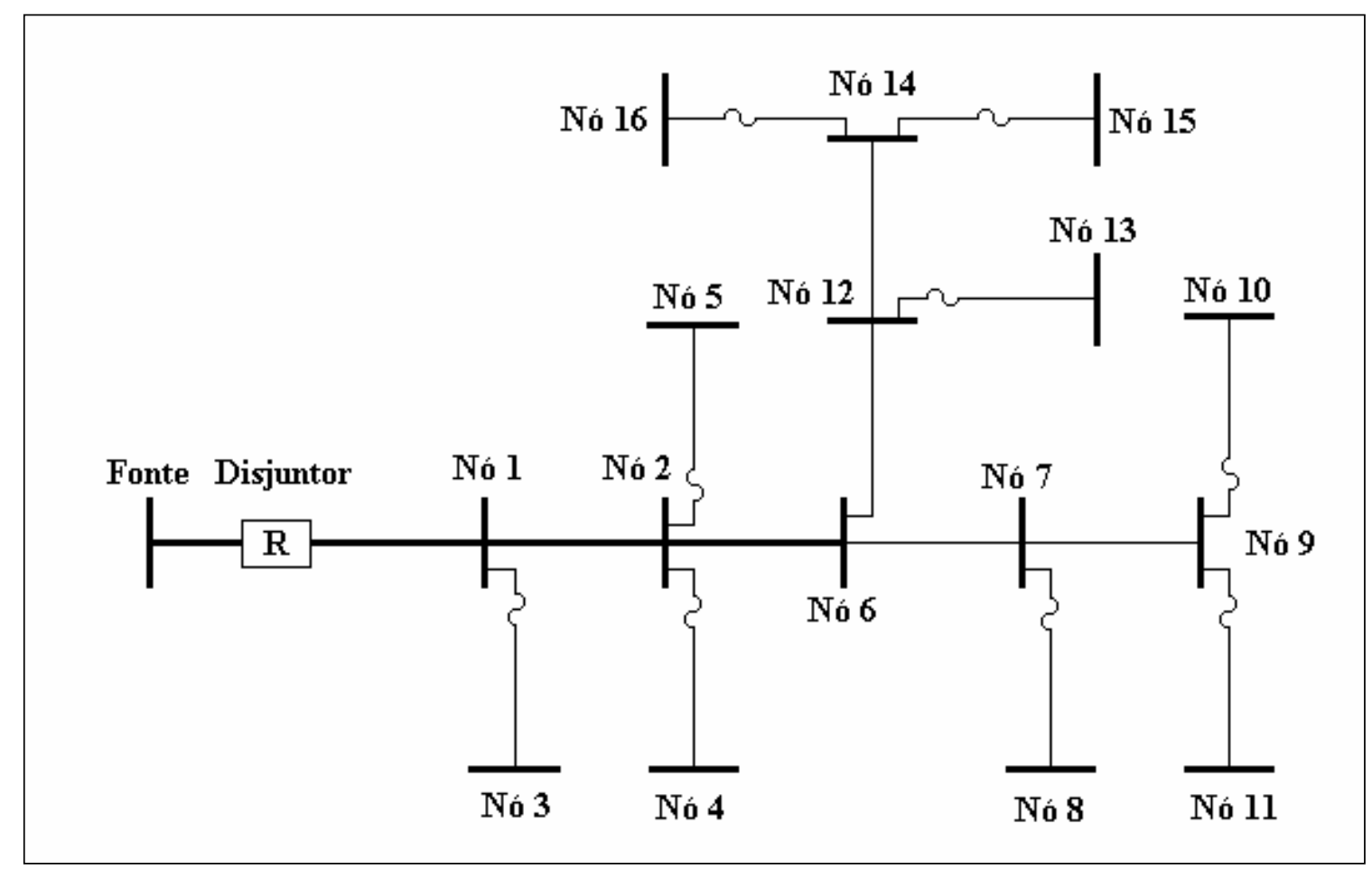

Figura 4.5 - Circuito com religamento no disjuntor da subestação em coordenação com fusíveis nas laterais do circuito elétrico

\subsubsection{Considerações gerais da topologia 3}

Observa-se que nem sempre a coordenação entre um dispositivo munido de característica de religamento - presente na subestação, com fusíveis nos ramos laterais do alimentador principal - gera uma coordenação perfeita. Para tanto, é necessário considerar um índice de $25 \%$ de atuação dos fusíveis a falhas temporárias, aproximando o modelo da realidade.

Esta solução utiliza um disjuntor de subestação trifásico equipado com curvas tempo x corrente. Estas são programadas com disparo rápido e capacidade de religamento, incorporando-se à característica de proteção de sobrecorrente (função $50 / 51)^{17}$. Pode-se utilizar um religador com controle eletrônico ou microprocessado, regulado e programado para uma sequência de disparos rápidos. O religador - de acordo com o estudo de coordenação - apresenta curvas lentas e intervalo apropriado de religamento entre elas.

Com o aperfeiçoamento da programação dos equipamentos de proteção, é possível atingir uma coordenação sofisticada, principalmente, no que se refere a e-

\footnotetext{
${ }^{17}$ Função 50/51: proteção de sobrecorrente
} 
quipamentos munidos de controles microprocessados. O emprego de fusíveis em série pode ser coordenado apropriadamente, de maneira que somente o fusível mais próximo da falha atue.

O disjuntor da subestação precisa coordenar-se com os fusíveis, para permitir o disparo rápido e eliminar as falhas temporárias nos ramos laterais antes que os fusíveis atuem. Após os disparos rápidos, o fusível deverá interromper as falhas ocorridas nas laterais antes que o disjuntor da subestação (ou religador) opere na curva lenta.

A aplicação de fusíveis nos ramos laterais de um alimentador principal resultará na diminuição dos valores dos índices de continuidade. Esse resultado levará a um número limitado de consumidores, cujo fornecimento de energia elétrica será interrompido devido a falhas permanentes.

Este estudo entende que a coordenação religador-fusível $75 \%$ das falhas temporárias, ocorridas nas laterais, irá proporcionar uma sobrevida ao fusível. Isto dependerá de cada tipo de ramo: de acordo com a magnitude das correntes, das curvas de coordenação do fusível e do dispositivo de proteção à montante. Destacase que tais especificações não serão contempladas nas topologias estudadas.

\subsubsection{Resultados obtidos da topologia 3}

Com base nos parâmetros elétricos do circuito da Figura 4.5, obtém-se a Tabela 4.8 .

Tabela 4.8 - Circuito com fusíveis nas laterais e elemento com característica de religador na subestação

\begin{tabular}{|c|c|c|c|c|c|c|}
\hline 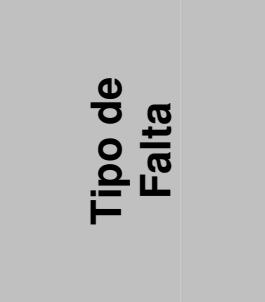 & 으ㄹㅗㅡㄹ & 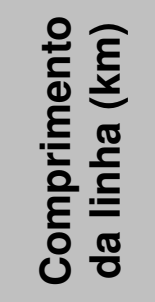 & 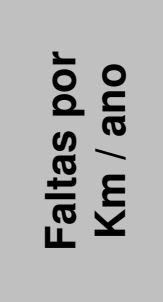 & 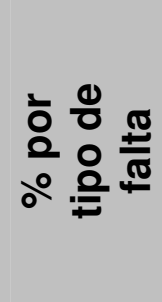 & $\frac{\bar{\Phi}}{\frac{2}{D}}$ & 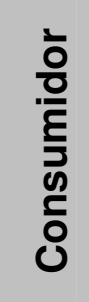 \\
\hline $\begin{array}{l}\text { Permamen- } \\
\text { te }\end{array}$ & $3 \varnothing$ & 14,89 & 0,1367 & 0,2 & Não & Não \\
\hline $\begin{array}{l}\text { Permamen- } \\
\text { te }\end{array}$ & $1 \varnothing$ & 50,69 & 0,1367 & 0,2 & Não & Não \\
\hline $\begin{array}{l}\text { Temporária / } \\
\text { Permanente }\end{array}$ & $1 \varnothing$ & 162,46 & 0,0548 & 0,2 & Sim & Sim \\
\hline
\end{tabular}


Os índices de continuidade foram calculados notando que o valor do FEC considera duas contribuições, baseadas nas equações (4.5), (4.6) e (4.7):

- Contribuição I: Circuito sem fusíveis em falhas permanentes;

- Contribuição II: Circuito com fusíveis em falhas temporárias (compensação por não haver uma coordenação de proteção de sobrecorrente perfeita).

A Tabela 4.9 indica o valor da contribuição em cada área que compõe o cálculo dos índices de continuidade, os quais baseiam-se nas equações apresentadas no item 4.1.

Tabela 4.9 - Distribuição dos elementos de proteção no circuito da topologia 3

\begin{tabular}{|c|c|c|c|c|c|c|c|}
\hline 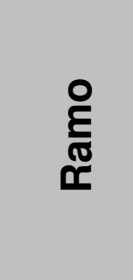 & $\stackrel{\overline{9}}{\overline{9}}^{\overline{1}}$ & 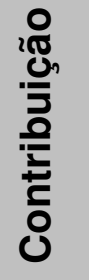 & 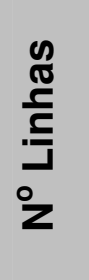 & 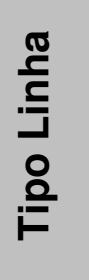 & 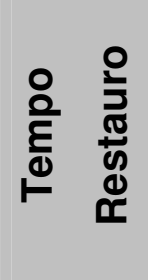 & 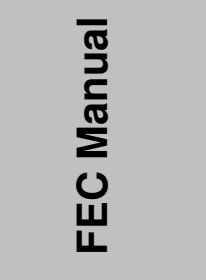 & 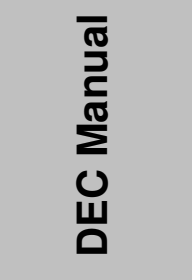 \\
\hline $\mathrm{R}_{9-11}$ & $F$ & $\mathrm{Cll}$ & $3 \mathrm{~L}$ & 10 & -- & 0,037400 & 0,083835 \\
\hline$R_{9-10}$ & $F$ & Cll & $3 \mathrm{~L}$ & 10 & -- & 0,006200 & 0,013970 \\
\hline $\mathrm{R}_{7-9}$ & NF & $\mathrm{Cl}$ & $3 \mathrm{~L}$ & $1 \varnothing$ & 2,5 & 0,553635 & 1,384090 \\
\hline $\mathrm{R}_{7-8}$ & $\mathrm{~F}$ & Cll & $3 \mathrm{~L}$ & $1 \varnothing$ & -- & 0,044821 & 0,100600 \\
\hline $\mathrm{R}_{6-7}$ & NF & $\mathrm{Cl}$ & $3 \mathrm{~L}$ & $1 \varnothing$ & 2,5 & 0,565938 & 1,414850 \\
\hline $\mathrm{R}_{6-12}$ & NF & $\mathrm{Cl}$ & $3 \mathrm{~L}$ & 10 & 2,5 & 0,131995 & 0,329990 \\
\hline $\mathrm{R}_{12-13}$ & $\mathrm{~F}$ & $\mathrm{Cll}$ & $3 \mathrm{~L}$ & $1 \varnothing$ & -- & 0,063500 & 0,142640 \\
\hline $\mathrm{R}_{12-14}$ & NF & $\mathrm{Cl}$ & $3 \mathrm{~L}$ & 10 & 2,5 & 0,131995 & 0,329990 \\
\hline$R_{14-15}$ & $F$ & $\mathrm{Cll}$ & $3 \mathrm{~L}$ & 10 & -- & 0,098500 & 0,221090 \\
\hline$R_{14-16}$ & $F$ & Cll & $1 \mathrm{~L}$ & 10 & -- & 0,029900 & 0,067070 \\
\hline $\mathrm{R}_{2-6}$ & $\mathrm{NF}$ & $\mathrm{Cl}$ & $1 \mathrm{~L}$ & $3 \varnothing$ & 3 & 0,087761 & 0,263280 \\
\hline $\mathrm{R}_{2-5}$ & $\mathrm{~F}$ & Cll & $3 \mathrm{~L}$ & $1 \varnothing$ & -- & 0,044500 & 0,099840 \\
\hline $\mathrm{R}_{2-4}$ & $\mathrm{~F}$ & Cll & $3 \mathrm{~L}$ & $1 \varnothing$ & -- & 0,037400 & 0,083840 \\
\hline $\mathrm{R}_{1-2}$ & $\mathrm{NF}$ & $\mathrm{Cl}$ & $1 \mathrm{~L}$ & $3 \varnothing$ & 3 & 0,274767 & 0,824300 \\
\hline $\mathrm{R}_{1-3}$ & $\mathrm{~F}$ & $\mathrm{Cll}$ & $3 \mathrm{~L}$ & $1 \varnothing$ & -- & 0,012700 & 0,028530 \\
\hline $\mathrm{R}_{\mathrm{G}-1}$ & $\mathrm{NF}$ & $\mathrm{Cl}$ & $1 \mathrm{~L}$ & $3 \varnothing$ & 3 & 0,043998 & 0,131990 \\
\hline
\end{tabular}

O cálculo dos índices de continuidade, para a topologia 3, considerou que 0 valor do FEC é resultado da soma dos FECs parciais em cada setor do circuito elé- 
trico. O FEC depende da soma da Contribuição I com a Contribuição II, e estas são obtidas a partir das equações (4.6) e (4.7), respectivamente. Assim, obtém-se o FEC igual a 2,165010 interrupções de energia elétrica por consumidor.

É necessário considerar, para cada trecho, o ajuste na taxa de falhas, devido ao emprego dos fusíveis:

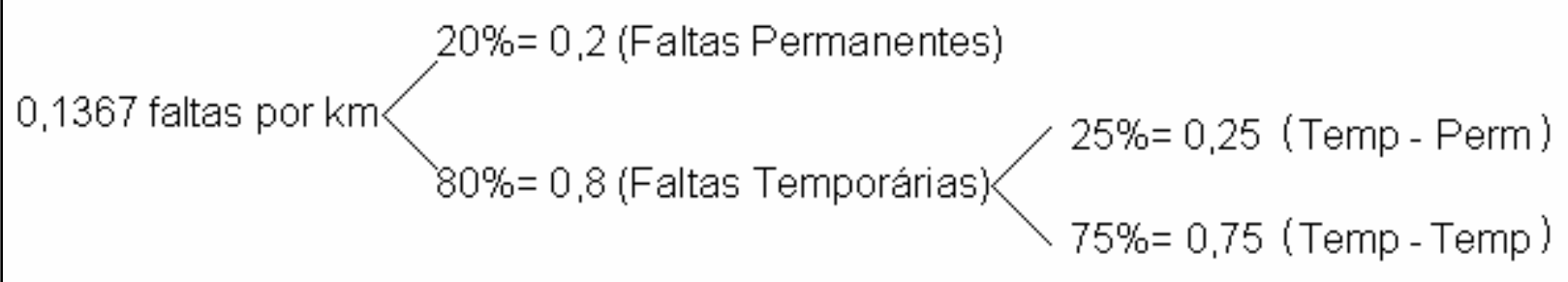

Substituem-se os valores percentuais:

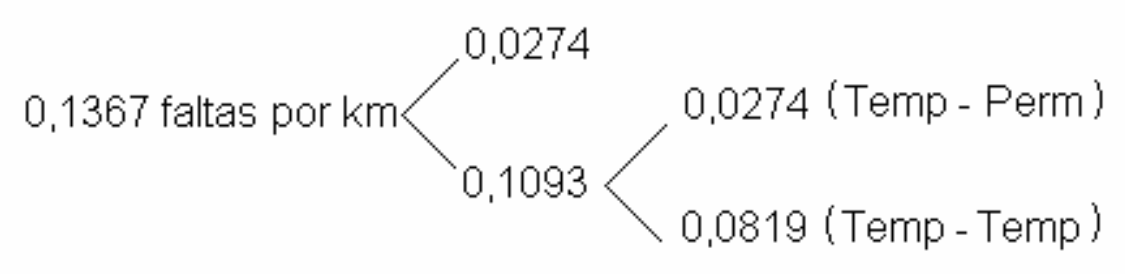

Desse modo, a taxa de falhas, devido ao emprego de fusíveis nas laterais do alimentador principal, é igual a 0,0548 interrupções por km.

Analogamente, o cálculo do DEC considera que uma falha permanente na lateral do circuito requer 2,50 horas para reparo:

ContribI_Fus=Taxa de Falhas*\% de Faltas Permanentes*

*Horas_de_Reparo_Perman

Com base na equação (4.13), a Contribl_Fus é igual a 0,0683.

De modo análogo, uma falha temporária na lateral, que leve à queima de um fusível, requer 2 horas para reparo.

Contribll_Fus=Taxa de Falhas*\% Faltas Permanentes*

$$
\text { *Horas_de_Reparo_Temp }
$$

Com base na equação (4.14), a Contribll_Fus é igual a 0,0547.

Este fato influencia na taxa de interrupção, devido ao emprego dos fusíveis nas laterais do circuito, que considera a soma das duas contribuições. No caso particular, com base nos valores utilizados, obteve-se uma taxa de 0,1230 interrupções por km. 
O cálculo dos índices de continuidade observou que o valor do FEC considera duas contribuições, baseadas nas equações (4.5), (4.6) e (4.7):

- Contribuição I: Circuito sem fusíveis em falhas permanentes;

- Contribuição II: Circuito com fusíveis em falhas temporárias (compensação por não haver uma coordenação de proteção de sobrecorrente perfeita).

O cálculo dos índices de continuidade, para a topologia 3, entendeu que o valor do DEC é resultado da soma dos DECs parciais, em cada ramo do circuito elétrico.

O DEC depende da soma da Contribuição I com a Contribuição II, e estas são obtidas a partir das equações (4.8), (4.9) e (4.10), respectivamente. Assim, obtém-se o DEC igual a 5,519905 horas de interrupção por consumidor.

Com a simulação feita pelo programa TEIAA, foram obtidos os valores dos índices de continuidade DEC e FEC, cuja topologia 3 é ilustrada na Figura 4.6.

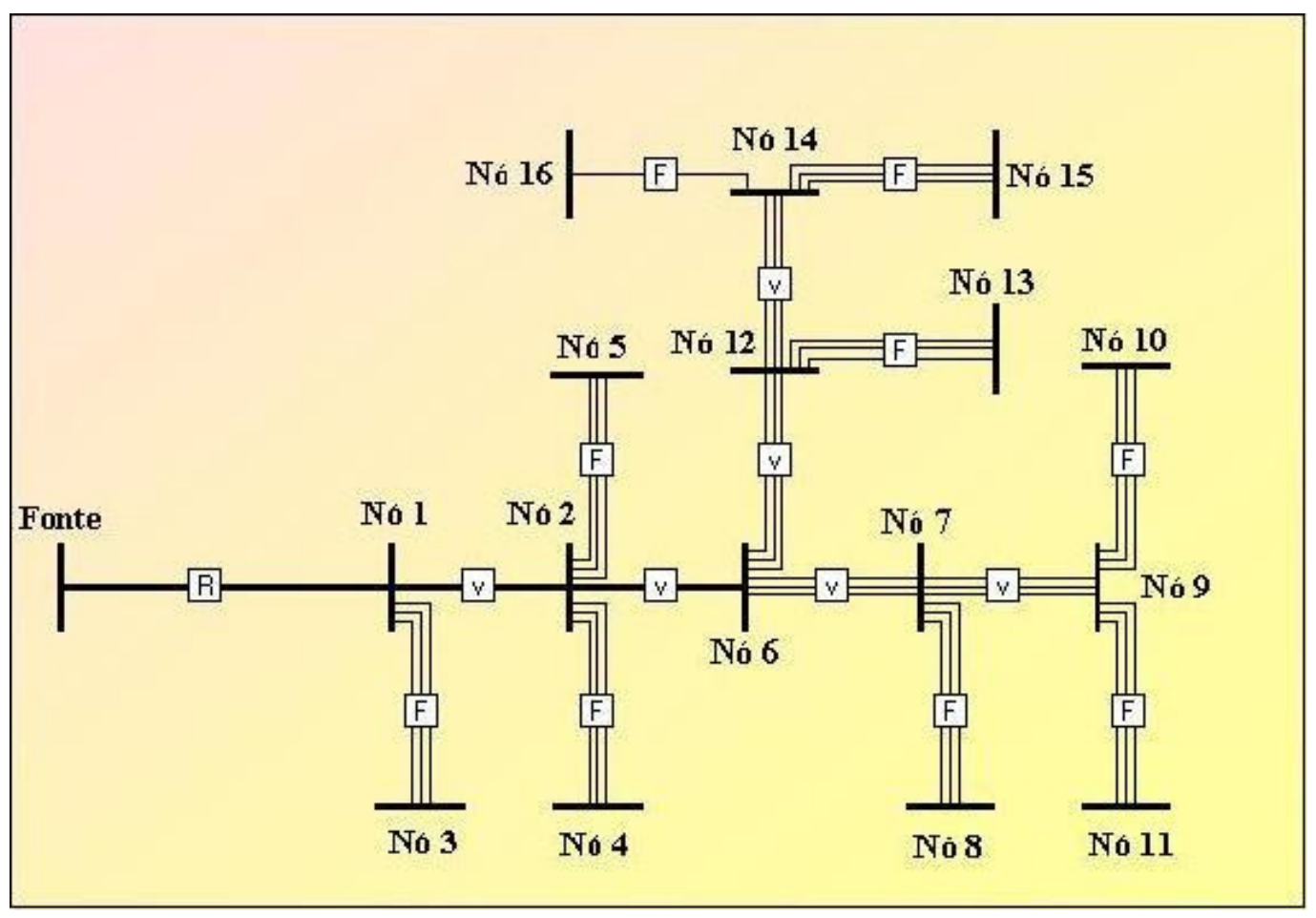

Figura 4.6 - Topologia 3 obtida da simulação realizada pelo programa TEIAA

A simulação realizada pelo programa TEIAA resultou na Tabela 4.10. 
Tabela 4.10 - Cálculo dos índices DEC e FEC para a topologia 3

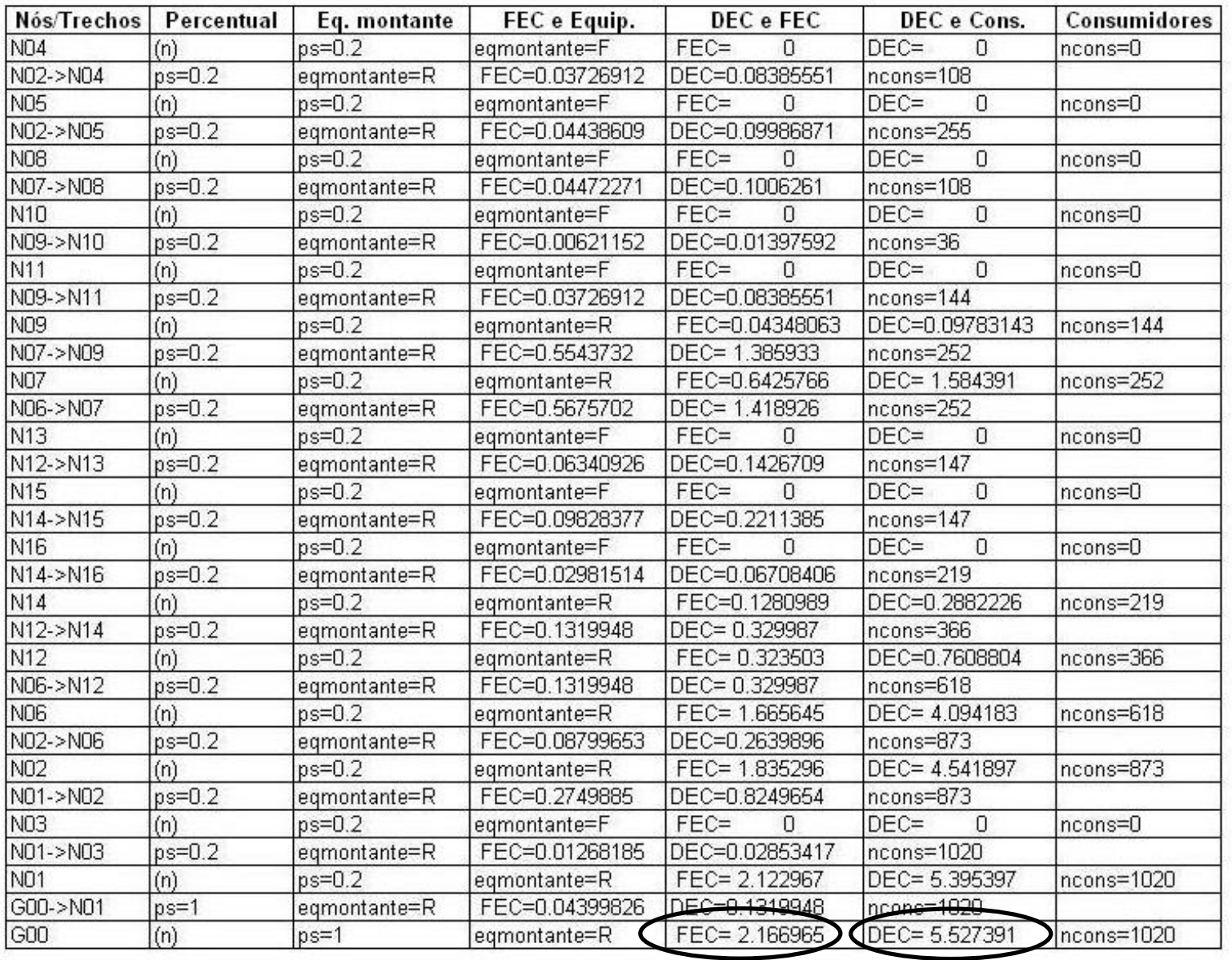

$\mathrm{Na}$ Tabela 4.10, observa-se que houve a convergência dos valores de FEC para 2,166965 interrupções de energia elétrica por consumidor e DEC para 5,527391 horas de interrupção por consumidor.

O FEC sofreu uma redução significativa de seu valor anterior, devido à aplicação dos fusíveis nos ramos laterais e à atuação das curvas rápidas e lentas do dispositivo de proteção da subestação. Este realiza a proteção do elemento fusível, presente nos ramos laterais, imediatamente à sua frente, atuando em falhas permanentes.

Outra contribuição para a redução do FEC provém das falhas nos fusíveis laterais. Nesses trechos, os ramos são submetidos a 0,1367 falhas/km por ano, cujos índices caem a $20 \%$ (devido às falhas permanentes). No entanto, admite-se que a proteção de sobrecorrente não pode "salvar" todos os fusíveis em todas as falhas temporárias. Para cada quilômetro de linha, considera-se 0,1367 falha/km por ano, com $80 \%$ de falhas temporárias e $25 \%$ de taxa de fusíveis queimados em falhas temporárias, porcentagens baseadas em Bishop (1997) e Kagan et al. (2005). Des- 
sa maneira, chega-se a valores de índices de continuidade menores do que os calculados para a topologia 2.

Calcula-se como a duração da interrupção de energia pode influenciar no processo em questão. Esse cálculo envolve a consolidação das falhas em cada seção do circuito, além do tempo de reparo ou restauração, associados a cada trecho do alimentador principal.

A presença de fusíveis instalados nas laterais do circuito e o uso de operações em curvas rápidas e lentas do dispositivo de proteção da subestação resultam em informações estocásticas sobre as interrupções permanentes, considerando valores típicos esperados. As operações em curvas rápidas e lentas ocorrem em apagões momentâneos, e os elementos religadores (trabalhando em coordenação com os fusíveis) tentam restabelecer o serviço de fornecimento de energia elétrica.

Constata-se que o elemento de proteção, na subestação - caso seja considerado um religador -, é somente um dispositivo que tem a característica religamento incorporada. No entanto, o circuito inteiro pode ser interrompido por uma falha, em qualquer ponto, tanto no alimentador principal quanto nas laterais.

\subsection{Topologia 4 - Circuito protegido com fusíveis nos ramais, em relação ao} alimentador principal e disjuntor, na subestação de energia elétrica, dotado de capacidade de religamento, com curva de atuação lenta e religador trifásico no meio da linha de distribuição

A Tabela 4.11 descreve as características funcionais do circuito que representa a topologia 4 .

Tabela 4.11 - Representação do modelo 4 em arquivo de entrada

\begin{tabular}{|c|c|c|c|c|c|c|c|c|c|}
\hline TRECHO & ORIGEM & DESTINO & DISTÂNCIA & TIPO DE LINHA & NÚMERO DE FASES & CONSUMIDORES POR FASE & FALTAS POR KM & FATOR DE FALTAS & EQUIPAMENT 0 \\
\hline 1 & G00 & N01 & 1,6093 & $\mathrm{~T}$ & 1 & 0 & 0,1367 & 1 & $S$ \\
\hline 2 & N01 & N02 & 10,0581 & $T$ & 1 & 0 & 0,1367 & 1 & $\mathrm{R}$ \\
\hline 3 & N01 & N03 & 1,6093 & M & 3 & 49 & 0,1367 & 1 & $\mathrm{~F}$ \\
\hline 4 & $\mathrm{~N} 02$ & N04 & 6,4372 & $\mathrm{M}$ & 3 & 36 & 0,1367 & 1 & $\mathrm{~F}$ \\
\hline 5 & $\mathrm{NO2}$ & N05 & 5,6325 & $\mathrm{M}$ & 3 & 49 & 0,1367 & 1 & $\mathrm{~F}$ \\
\hline 6 & $\mathrm{NO2}$ & N06 & 3,2186 & $T$ & 1 & 0 & 0,1367 & 1 & $\mathrm{v}$ \\
\hline 7 & N06 & N07 & 6,9199 & $\mathrm{M}$ & 3 & 0 & 0,1367 & 1 & $\mathrm{v}$ \\
\hline 8 & N07 & N08 & 7,7246 & $\mathrm{M}$ & 3 & 36 & 0,1367 & 1 & $F$ \\
\hline 10 & N09 & N10 & 3,2186 & $M$ & 3 & 12 & 0,1367 & 1 & $\mathrm{~F}$ \\
\hline 11 & N09 & N11 & 6,4372 & $\mathrm{M}$ & 3 & 36 & 0,1367 & 1 & $F$ \\
\hline 12 & N06 & N12 & 1,6093 & $\mathrm{M}$ & 3 & 0 & 0,1367 & 1 & v \\
\hline 13 & N12 & N13 & 8,0465 & $\mathrm{M}$ & 3 & 49 & 0,1367 & 1 & $F$ \\
\hline 14 & N12 & N14 & 1,6093 & $M$ & 3 & 0 & 0,1367 & 1 & v \\
\hline 15 & N14 & N15 & 12,472 & $\mathrm{M}$ & 3 & 49 & 0,1367 & 1 & $F$ \\
\hline 16 & N14 & N16 & 7,7246 & $M$ & 1 & 72 & 0,1367 & 1 & $F$ \\
\hline
\end{tabular}


O circuito para análise baseia-se na Figura 4.7.

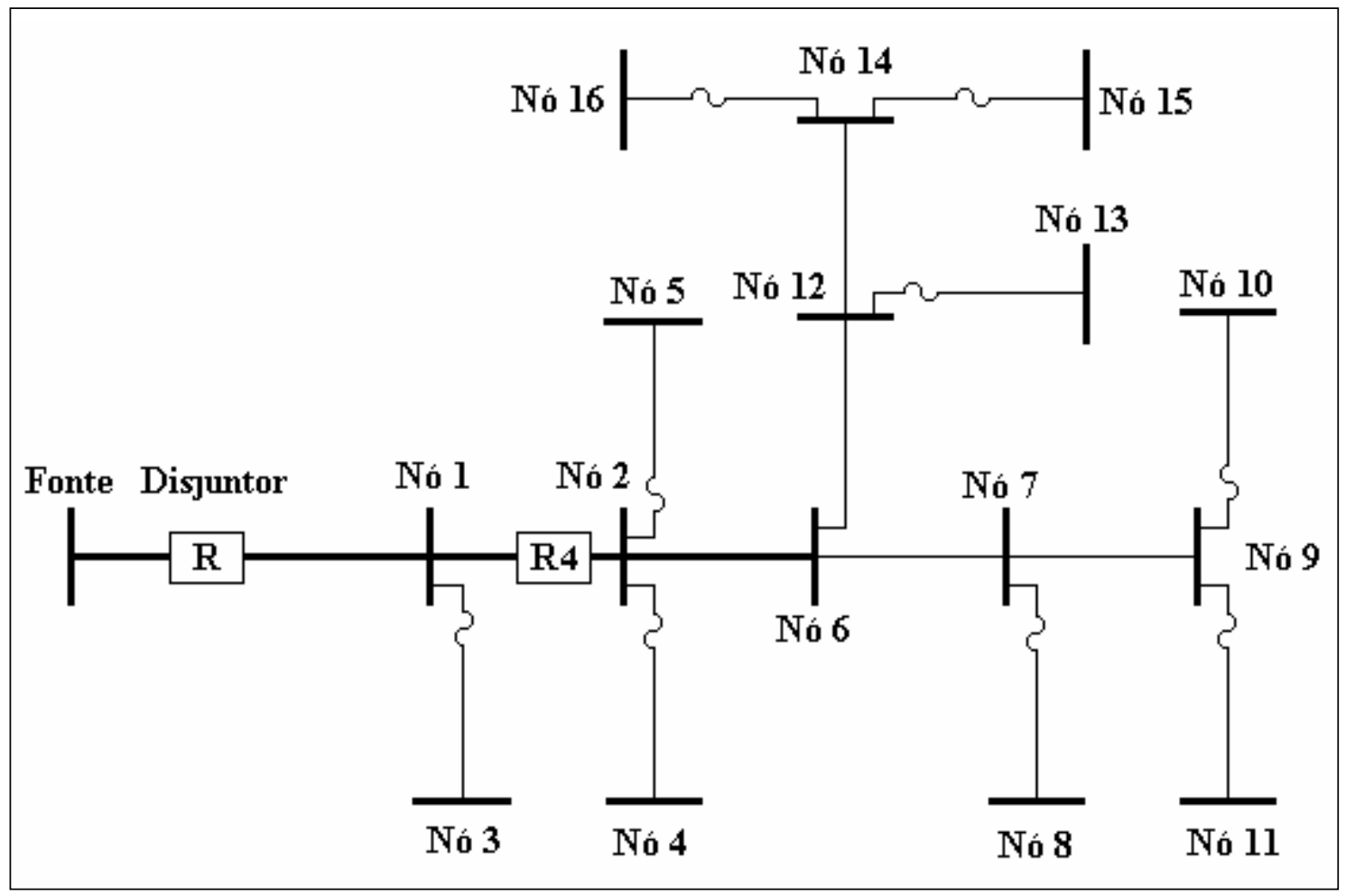

Figura 4.7 - Circuito com religador de meio de linha para a representação da topologia 4

Constatam-se chamadas dos consumidores em relação a apagões momentâneos, provenientes do religamento de equipamentos de proteção de sobrecorrente. Com base nessas reclamações, muitas concessionárias têm removido a função de disparo rápido. Essa iniciativa reduz os índices temporários, desde que falhas nas laterais resultem em queima de fusíveis antes que o dispositivo de proteção da subestação opere. Assim, ocorre uma consequente diminuição no religamento do dispositivo da subestação, levando-o a atuar somente em seções do alimentador principal que não estão protegidas por fusíveis.

\subsubsection{Considerações gerais da topologia 4}

No circuito da Figura 4.7, um religador trifásico, representado por R4, é alocado no alimentador principal. Nesta topologia, a responsabilidade do controle de falhas temporárias é retirada do dispositivo de proteção da subestação e encaminha-se para o religador de meio-de-linha, minimizando as consequências de "apagões momentâneos" na seção do alimentador principal. No circuito da Figura 4.8, o religador deverá fornecer uma proteção de $75 \%$ para o fusível, na ocorrência de fa- 
Ihas temporárias, em qualquer fusível lateral dentro de sua zona de proteção [Bishop et al. (1996)].

O fusível lateral, servido pelo alimentador principal e protegido pelo equipamento de proteção da subestação, não deverá ser salvo, em caso de ocorrência de falhas temporárias. Isso acontece porque o religamento atua em curvas lentas, além do fato de que falhas temporárias não são esperadas no alimentador principal.

Para prover o cálculo dos índices de continuidade, o circuito foi dividido em zonas, de acordo com a região de atuação do dispositivo de proteção:

- Zona 1: região à jusante do elemento com capacidade de religamento na subestação $(\mathrm{R})$;

- Zona 2: região à jusante do religador R4.

Na Figura 4.8, é possível visualizar as duas zonas de proteção.

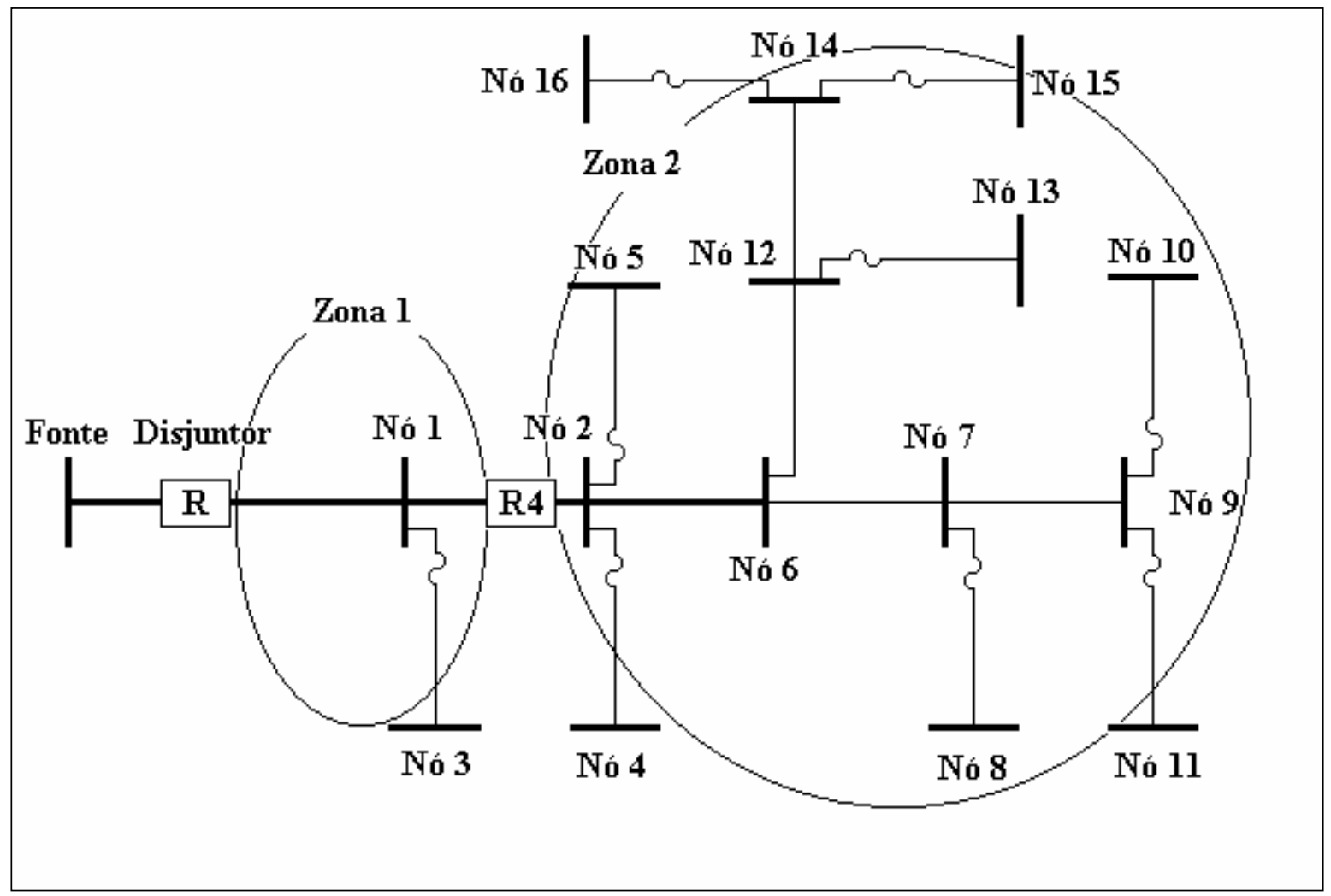

Figura 4.8 - Circuito com religador de meio de linha e zonas de proteção

\subsubsection{Resultados obtidos da topologia 4}

Com base na topologia 4 modelada, representada pelo circuito da Figura 4.8, obtém-se a Tabela 4.12. Esta apresenta o valor da contribuição, em cada ramo, compondo o cálculo dos índices de continuidade, os quais baseiam-se nas equações apresentadas no item 4.1. 
Tabela 4.12 - Distribuição dos elementos de proteção no circuito da topologia 4

\begin{tabular}{|c|c|c|c|c|c|c|c|}
\hline 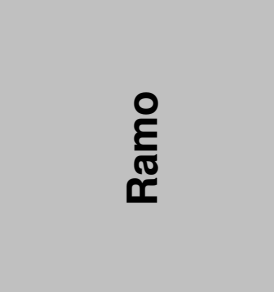 & 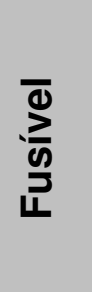 & 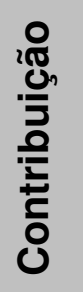 & 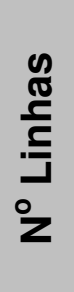 & 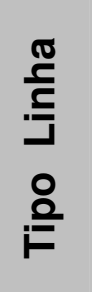 & 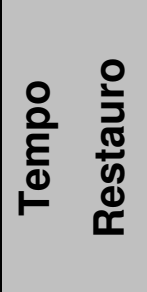 & 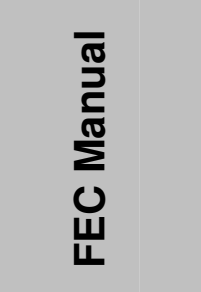 & 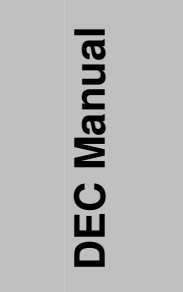 \\
\hline $\mathrm{R}_{9-11}$ & $F$ & CII & $3 \mathrm{~L}$ & $1 \varnothing$ & -- & 0,037400 & 0,083835 \\
\hline$R_{9-10}$ & $\mathrm{~F}$ & CII & $3 \mathrm{~L}$ & $1 \varnothing$ & -- & 0,006200 & 0,013970 \\
\hline $\mathrm{R}_{7-9}$ & NF & $\mathrm{Cl}$ & $3 \mathrm{~L}$ & $1 \varnothing$ & 2,5 & 0,553635 & 1,384090 \\
\hline $\mathrm{R}_{7-8}$ & $\mathrm{~F}$ & CII & $3 \mathrm{~L}$ & $1 \varnothing$ & -- & 0,044821 & 0,100600 \\
\hline $\mathrm{R}_{6-7}$ & $\mathrm{NF}$ & $\mathrm{Cl}$ & $3 \mathrm{~L}$ & $1 \varnothing$ & 2,5 & 0,565938 & 1,414850 \\
\hline$R_{6-12}$ & $\mathrm{NF}$ & $\mathrm{Cl}$ & $3 \mathrm{~L}$ & $1 \varnothing$ & 2,5 & 0,131995 & 0,329990 \\
\hline $\mathrm{R}_{12-13}$ & $F$ & CII & $3 \mathrm{~L}$ & $1 \varnothing$ & -- & 0,063500 & 0,142640 \\
\hline $\mathrm{R}_{12-14}$ & $\mathrm{NF}$ & $\mathrm{Cl}$ & $3 \mathrm{~L}$ & $1 \varnothing$ & 2,5 & 0,131995 & 0,329990 \\
\hline $\mathrm{R}_{14-15}$ & $\mathrm{~F}$ & $\mathrm{Cll}$ & $3 \mathrm{~L}$ & $1 \varnothing$ & -- & 0,098500 & 0,221090 \\
\hline$R_{14-16}$ & $\mathrm{~F}$ & Cll & $1 \mathrm{~L}$ & $1 \varnothing$ & -- & 0,029900 & 0,067070 \\
\hline $\mathrm{R}_{2-6}$ & NF & $\mathrm{Cl}$ & $1 \mathrm{~L}$ & $3 \varnothing$ & 3 & 0,087761 & 0,263280 \\
\hline $\mathrm{R}_{2-5}$ & $F$ & $\mathrm{Cll}$ & $3 \mathrm{~L}$ & $1 \varnothing$ & -- & 0,044500 & 0,099840 \\
\hline $\mathrm{R}_{2-4}$ & $\mathrm{~F}$ & Cll & $3 \mathrm{~L}$ & $1 \varnothing$ & -- & 0,037400 & 0,083840 \\
\hline $\mathrm{R}_{1-2} 1^{0}$ trecho & $\mathrm{NF}$ & $\mathrm{Cl}$ & $1 \mathrm{~L}$ & $3 \varnothing$ & 3 & 0,137490 & 0,412487 \\
\hline $\mathrm{R}_{1-2} 2^{\circ}$ trecho & $\mathrm{NF}$ & $\mathrm{Cl}$ & $1 \mathrm{~L}$ & $3 \varnothing$ & 3 & 0,137490 & 0,412487 \\
\hline $\mathrm{R}_{1-3}$ & $\mathrm{~F}$ & CII & $3 \mathrm{~L}$ & $1 \varnothing$ & -- & 0,000000 & 0,000000 \\
\hline $\mathrm{R}_{\mathrm{G}-1}$ & $\mathrm{NF}$ & $\mathrm{Cl}$ & $1 \mathrm{~L}$ & $3 \varnothing$ & 3 & 0,043998 & 0,131990 \\
\hline
\end{tabular}

O cálculo do FEC baseou-se nas equações (4.5), (4.6) e (4.7). Seu valor total é resultado da soma dos FECs parciais em cada ramo do circuito elétrico, considerando-se a contribuição de cada zona de proteção. Assim, obtém-se o valor de FEC igual a 2,152529 interrupções de energia elétrica por consumidor.

De modo análogo, o cálculo do DEC baseou-se nas equações (4.8), (4.9) (4.10). Seu valor total é resultado da soma dos DECs parciais em cada ramo do circuito elétrico, considerando-se a contribuição de cada zona de proteção. Assim, obtém-se o valor de DEC igual a 5,492049 horas de interrupção por consumidor. 
Com a simulação feita pelo programa TEIAA, foram obtidos os valores dos índices de continuidade DEC e FEC, cuja topologia 4 está representada na Figura 4.9.

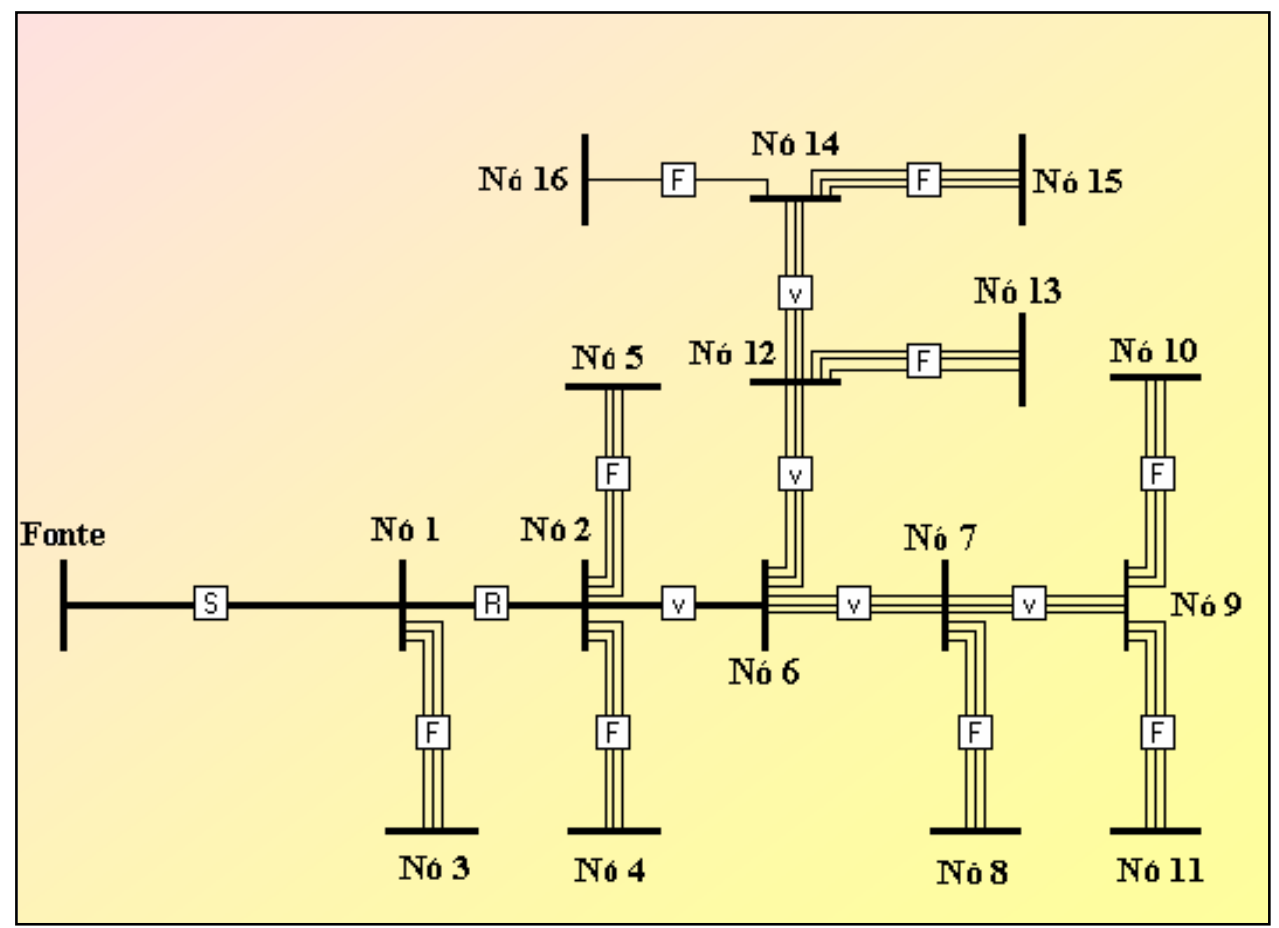

Figura 4.9 - Topologia 4 obtida da simulação realizada pelo programa TEIAA

Como resultado da simulação realizada pelo programa TEIAA, obteve-se a Tabela 4.13, onde se observa que houve a convergência dos valores de FEC para 2,154283 interrupções de energia elétrica por consumidor e DEC para 5,498857 horas de interrupção por consumidor, indicando um decréscimo dos índices de continuidade.

O religador considerado na topologia deve incluir curvas rápidas e lentas na programação de seu controle microprocessado, cuidando para que haja a proteção do fusível, no caso das falhas consideradas. 
Tabela 4.13 - Cálculo dos índices DEC e FEC para topologia 4

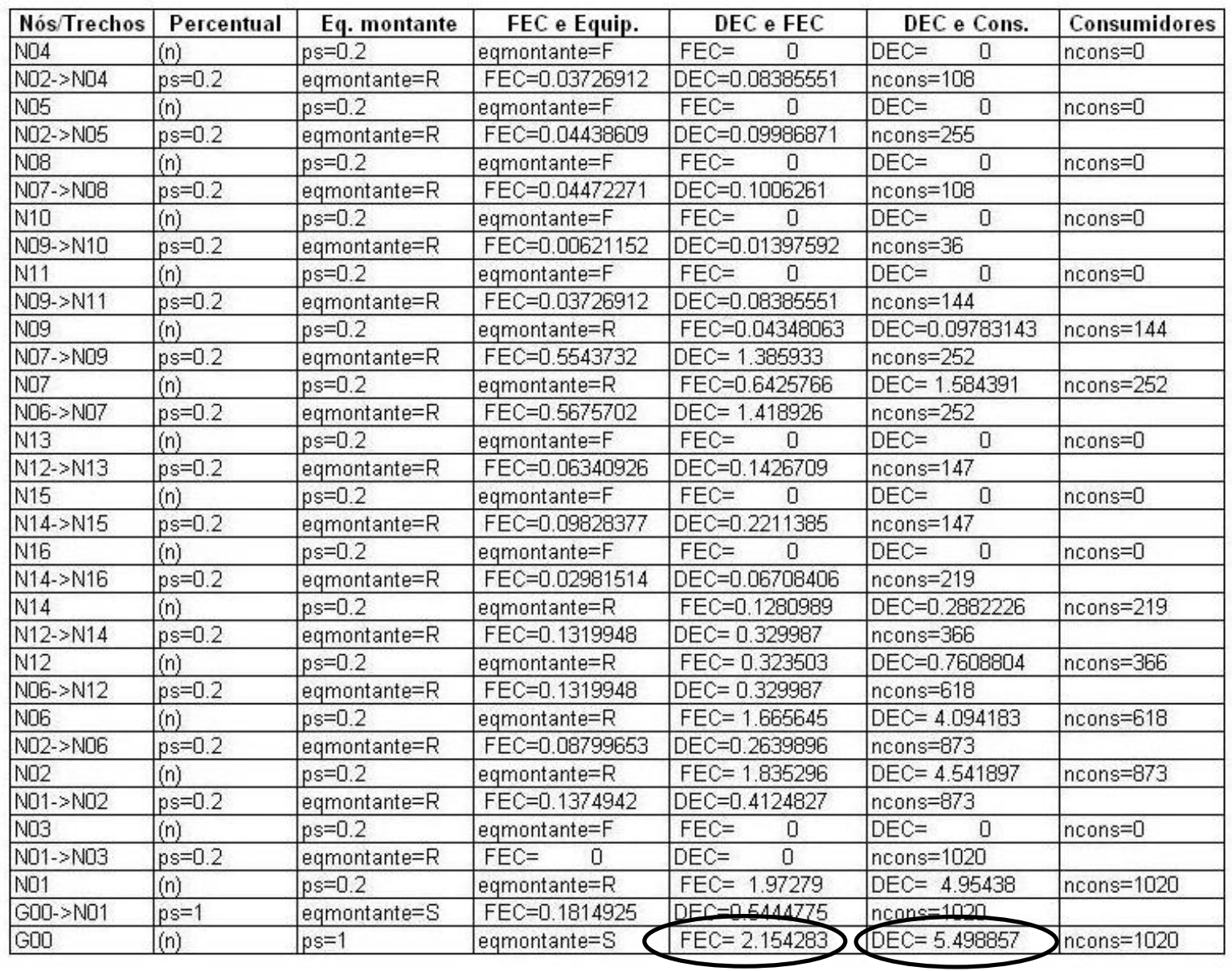

\subsection{Topologia 5 - Circuito protegido com fusíveis nos ramais, em relação ao} alimentador principal e disjuntor na subestação de energia elétrica, com capacidade de religamento, com curva de atuação lenta, religador trifásico no meio da linha de distribuição e religadores monofásicos distribuídos pelos circuitos monofásicos

A Tabela 4.14 indica as características funcionais do circuito que representa a topologia 5. 
Tabela 4.14 - Representação da topologia 5 em arquivo de entrada

\begin{tabular}{|c|c|c|c|c|c|c|c|c|c|}
\hline TRECHO & ORIGEM & DESTINO & DISTÁNCIA & TIPO DE LINHA & NÚMERO DE FASES & CONSUMIDORES POR FASE & FALTAS POR KM & FATOR DE FALTAS & EQUIPAMENTO \\
\hline 1 & G00 & N01 & 1,6093 & \begin{tabular}{|c|}
$T$ \\
\end{tabular} & \begin{tabular}{|c|}
1 \\
\end{tabular} & $\begin{array}{c}0 \\
0\end{array}$ & \begin{tabular}{|l|}
0,1367 \\
\end{tabular} & 1 & 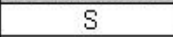 \\
\hline 2 & N01 & N02 & 10,0581 & $T$ & 1 & 0 & 0,1367 & 1 & $\mathrm{R}$ \\
\hline 3 & N01 & N03 & 1,6093 & $\mathrm{M}$ & 3 & 49 & 0,1367 & 1 & $\mathrm{~F}$ \\
\hline 4 & N02 & N04 & 6,4372 & $\mathrm{M}$ & 3 & 36 & 0,1367 & 1 & $\mathrm{~F}$ \\
\hline 5 & N02 & N05 & 5,6325 & $\mathrm{M}$ & 3 & 49 & 0,1367 & 1 & $\mathrm{~F}$ \\
\hline 6 & N02 & N06 & 3,2186 & $T$ & 1 & 0 & 0,1367 & 1 & $\mathrm{v}$ \\
\hline 7 & N06 & N07 & 6,9199 & $\mathrm{M}$ & 3 & 0 & 0,1367 & 1 & $\mathrm{R}$ \\
\hline 8 & N07 & N08 & 7,7246 & $\mathrm{M}$ & 3 & 36 & 0,1367 & 1 & $\mathrm{~F}$ \\
\hline 9 & N07 & N09 & 6,759 & $\mathrm{M}$ & 3 & 0 & 0,1367 & 1 & 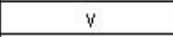 \\
\hline 10 & N09 & N10 & 3,2186 & $\mathrm{M}$ & 3 & 12 & 0,1367 & 1 & $F$ \\
\hline 11 & N09 & N11 & 6,4372 & $\mathrm{M}$ & 3 & 36 & 0,1367 & 1 & $F$ \\
\hline 12 & N06 & $\mathrm{N} 12$ & 1,6093 & $\mathrm{M}$ & 3 & 0 & 0,1367 & 1 & $\mathrm{R}$ \\
\hline 13 & $\mathrm{~N} 12$ & N13 & 8,0465 & $\mathrm{M}$ & 3 & 49 & 0,1367 & 1 & $F$ \\
\hline 14 & $\mathrm{~N} 12$ & N14 & 1,6093 & $\mathrm{M}$ & 3 & 0 & 0,1367 & 1 & $v$ \\
\hline 15 & N14 & N15 & 12,472 & $\mathrm{M}$ & 3 & 49 & 0,1367 & 1 & $F$ \\
\hline 16 & N14 & N16 & 7,7246 & $\mathrm{M}$ & 1 & 72 & 0,1367 & 1 & $F$ \\
\hline
\end{tabular}

O circuito para análise baseia-se na Figura 4.10.

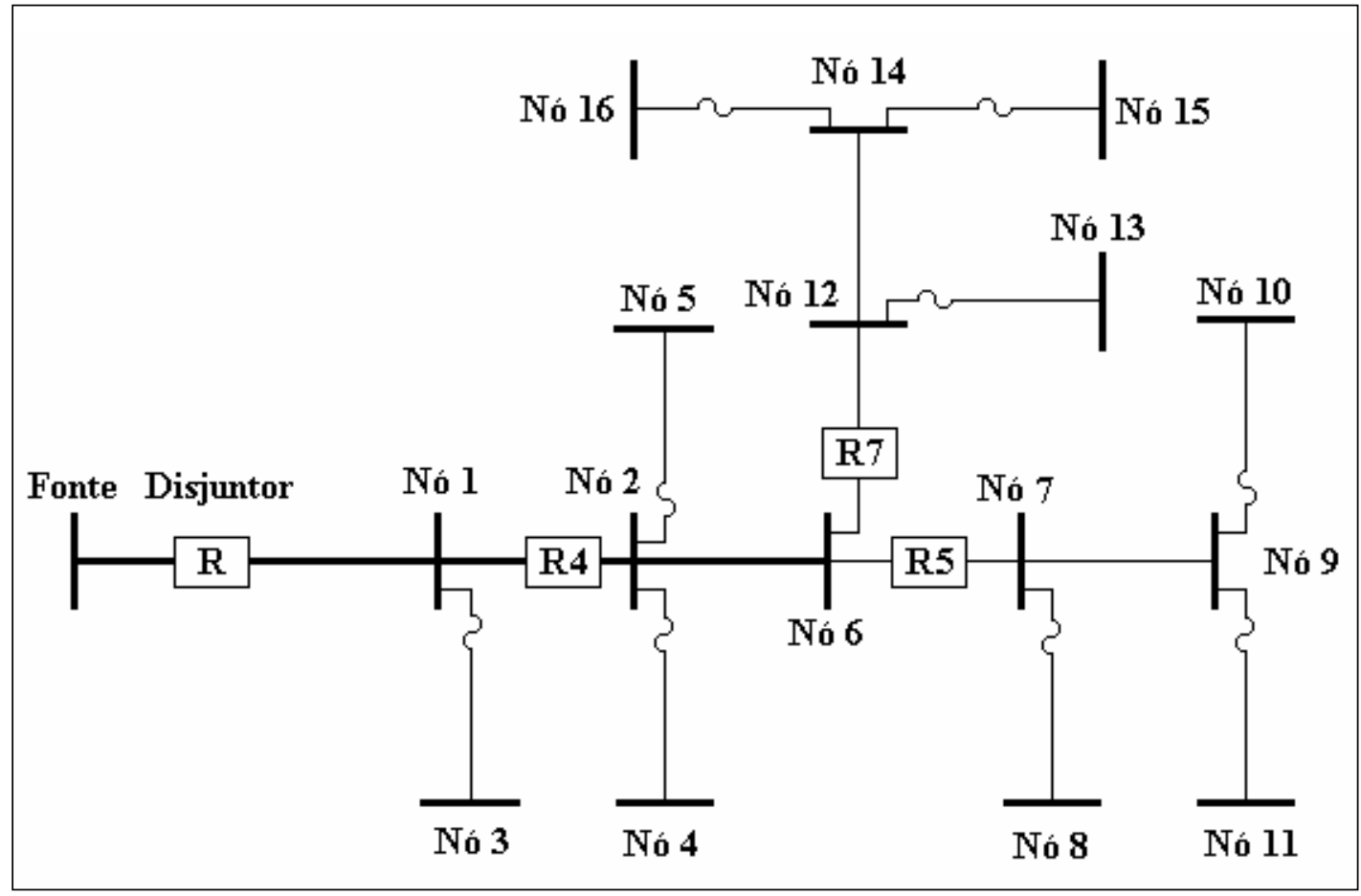

Figura 4.10 - Circuito com religadores distribuídos pelo circuito

Com o objetivo de otimizar a confiabilidade no fornecimento de energia elétrica e responder às interrupções permanentes, costuma-se instalar religadores monofásicos. Estes são munidos de controles eletrônicos ou microprocessados em pontos de bifurcação ou pontos críticos do circuito resultante. 


\subsubsection{Considerações gerais da topologia 5}

Os religadores R5 e R7, visualizados na Figura 4.11, associam-se ao religador trifásico R4. Eles estão programados com uma sequência de disparo que permite coordenar suas operações de falha à jusante, evitando a operação de R4.

Esta operação pode ser realizada desde que R4 esteja programado com curva de operação rápida, fornecendo proteção aos fusíveis contra falhas temporárias em seus ramos laterais e na bifurcação do nó 2.

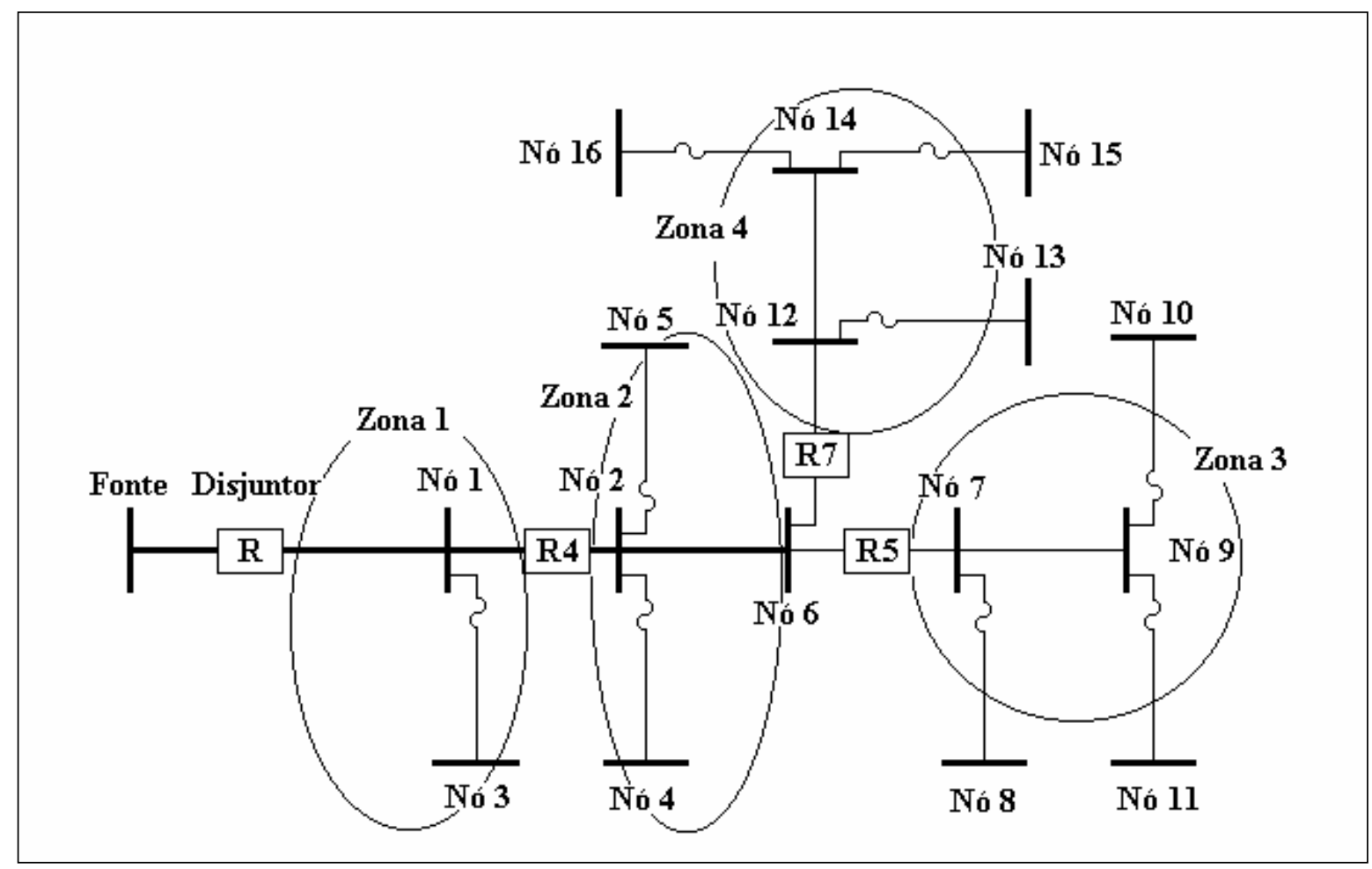

Figura 4.11 - Circuito com religador de meio de linha, religadores espalhados e suas zonas de proteção

A instalação de religadores adicionais, como R5 e R7, permite seccionalizar o alimentador principal em zonas de proteção, quando falhas permanentes ocorrerem. Para facilitar o cálculo dos índices de continuidade, o circuito foi dividido de acordo com a região de atuação do dispositivo de proteção:

- Zona 1: região à jusante do dispositivo, com característica de religamento na subestação $(\mathrm{R})$ até à montante do religador $\mathrm{R} 4$;

- Zona 2: região à jusante do religador $\mathrm{R} 4$ até à montante dos religadores R5 e R7;

- Zona 3: região à jusante do religador R5;

- Zona 4: região à jusante do religador R7. 
Dessa forma, no circuito da Figura 4.11, observa-se que o religador R4 é equipado com ajustes de curvas rápidas, bem como de curvas lentas. Assim, em caso de falhas temporárias ocorridas nas laterais do circuito, os fusíveis terão proteção na zona de R4.

\subsubsection{Resultados obtidos da topologia 5}

Com base na topologia 5 modelada, obtém-se a Tabela 4.15, com o valor de contribuição, em cada ramo, compondo o cálculo dos índices de continuidade. Estes baseiam-se nas equações apresentadas no item 4.1.

Tabela 4.15 - Distribuição dos elementos de proteção no circuito da topologia 5

\begin{tabular}{|c|c|c|c|c|c|c|c|}
\hline $\begin{array}{l}\stackrel{O}{E} \\
\underset{\mathbb{N}}{\simeq}\end{array}$ & 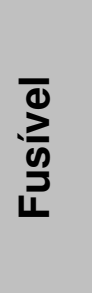 & 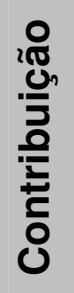 & 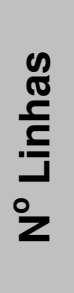 & 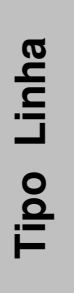 & 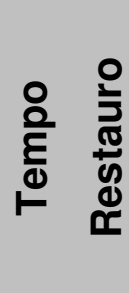 & 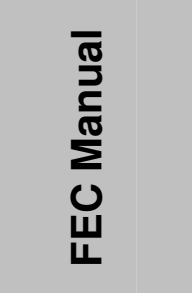 & 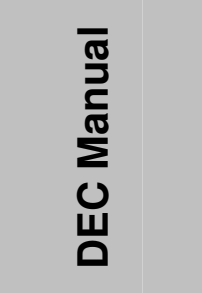 \\
\hline$R_{9-11}$ & $\mathrm{~F}$ & $\mathrm{Cll}$ & $3 \mathrm{~L}$ & $1 \varnothing$ & -- & 0,037400 & 0,083835 \\
\hline$R_{9-10}$ & $F$ & $\mathrm{Cll}$ & $3 \mathrm{~L}$ & $1 \varnothing$ & -- & 0,006200 & 0,013970 \\
\hline $\mathrm{R}_{7-9}$ & $\mathrm{NF}$ & $\mathrm{Cl}$ & $3 \mathrm{~L}$ & $1 \varnothing$ & 2,5 & 0,553635 & 1,384090 \\
\hline $\mathrm{R}_{7-8}$ & $\mathrm{~F}$ & $\mathrm{Cll}$ & $3 \mathrm{~L}$ & $1 \varnothing$ & -- & 0,044821 & 0,100600 \\
\hline $\mathrm{R}_{6-7}$ & NF & $\mathrm{Cl}$ & $3 \mathrm{~L}$ & $1 \varnothing$ & 2,5 & 1,414850 & 1,414850 \\
\hline $\mathrm{R}_{6-12}$ & NF & $\mathrm{Cl}$ & $3 \mathrm{~L}$ & $1 \varnothing$ & 2,5 & 0,131995 & 0,329990 \\
\hline $\mathrm{R}_{12-13}$ & $\mathrm{~F}$ & Cll & $3 \mathrm{~L}$ & $1 \varnothing$ & -- & 0,063500 & 0,142640 \\
\hline $\mathrm{R}_{12-14}$ & $\mathrm{NF}$ & $\mathrm{Cl}$ & $3 \mathrm{~L}$ & $1 \varnothing$ & 2,5 & 0,131995 & 0,329990 \\
\hline $\mathrm{R}_{14-15}$ & $\mathrm{~F}$ & CII & $3 \mathrm{~L}$ & $1 \varnothing$ & -- & 0,098500 & 0,221090 \\
\hline $\mathrm{R}_{14-16}$ & $\mathrm{~F}$ & Cll & $1 \mathrm{~L}$ & $1 \varnothing$ & -- & 0,029900 & 0,067070 \\
\hline $\mathrm{R}_{2-6}$ & $\mathrm{NF}$ & $\mathrm{Cl}$ & $1 \mathrm{~L}$ & $3 \varnothing$ & 3 & 0,087761 & 0,263280 \\
\hline $\mathrm{R}_{2-5}$ & $\mathrm{~F}$ & CII & $3 \mathrm{~L}$ & 10 & -- & 0,044500 & 0,099840 \\
\hline $\mathrm{R}_{2-4}$ & $\mathrm{~F}$ & $\mathrm{Cll}$ & $3 \mathrm{~L}$ & $1 \varnothing$ & -- & 0,037400 & 0,083840 \\
\hline $\mathrm{R}_{1-2} 1^{\circ}$ trecho & NF & $\mathrm{Cl}$ & $1 \mathrm{~L}$ & $3 \varnothing$ & 3 & 0,137490 & 0,412487 \\
\hline $\mathrm{R}_{1-2} 2^{\circ}$ trecho & $\mathrm{NF}$ & $\mathrm{Cl}$ & $1 \mathrm{~L}$ & $3 \varnothing$ & 3 & 0,137490 & 0,412487 \\
\hline $\mathrm{R}_{1-3}$ & $F$ & Cll & $3 L$ & 10 & -- & 0,000000 & 0,000000 \\
\hline $\mathrm{R}_{\mathrm{G}-1}$ & $\mathrm{NF}$ & $\mathrm{Cl}$ & $1 \mathrm{~L}$ & $3 \varnothing$ & 3 & 0,043998 & 0,131990 \\
\hline
\end{tabular}


O cálculo do FEC baseou-se nas equações (4.5), (4.6) e (4.7). Seu valor total é resultado da soma dos FECs parciais em cada ramo do circuito elétrico, considerando-se a contribuição de cada zona de proteção. Dessa maneira, obtém-se o valor de FEC igual a 1,043267 interrupções de energia elétrica por consumidor.

De modo análogo, o cálculo do DEC baseou-se nas equações (4.8), (4.9) (4.10). Seu valor total é resultado da soma dos DECs parciais em cada ramo do circuito elétrico, considerando-se a contribuição de cada zona de proteção. Assim, obtém-se o valor de DEC igual a 2,766632 horas de interrupção por consumidor.

Com a simulação feita pelo programa TEIAA, foram obtidos os valores dos índices de continuidade DEC e FEC, cuja topologia 5 é representada na Figura 4.12.

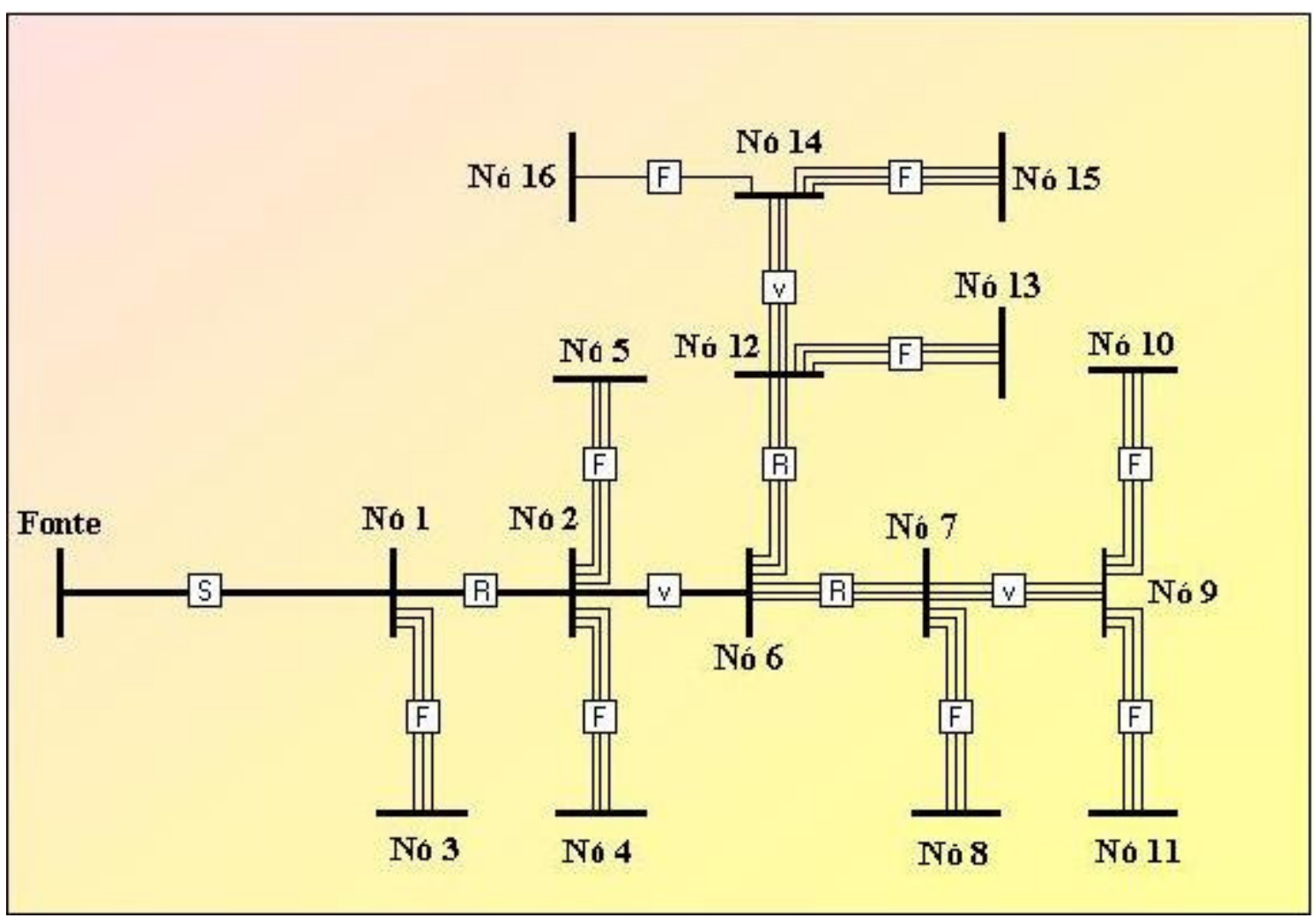

Figura 4.12 - Topologia 5 obtida da simulação realizada pelo programa TEIAA

Como resultado da simulação realizada pelo programa TEIAA, obteve-se a Tabela 4.16: 
Tabela 4.16 - Cálculo dos índices DEC e FEC para a topologia 5

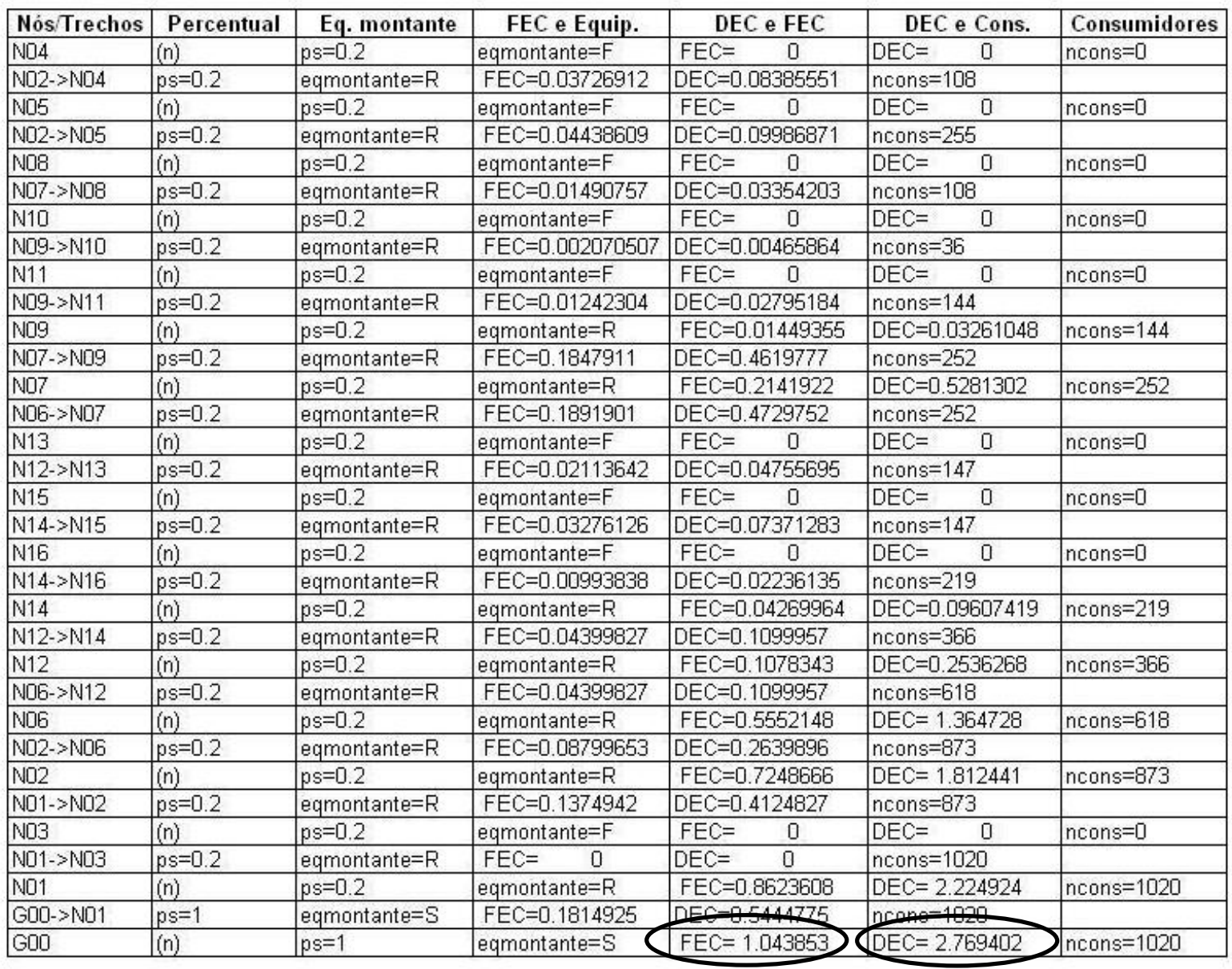

Os resultados indicam a diminuição dos índices DEC e FEC. Consideram o alimentador seccionado em pequenos segmentos, caso ocorram interrupções permanentes.

Nesta situação, a adição de religadores que permitam realizar uma coordenação entre si, principalmente quando munidos de controles microprocessados, aumenta as possibilidades de configuração e manobras. Este cenário proporciona aos consumidores uma redução das interrupções temporárias ao longo do alimentador. As falhas que ocorrem no final dos ramos laterais são eliminadas pelos religadores, não sendo necessário interromper o fornecimento de energia.

$\mathrm{Na}$ tabela 4.16, observa-se que houve a convergência dos valores de FEC para 1,043853 interrupções de energia elétrica por consumidor e DEC para 2,769402 horas de interrupção por consumidor indicando a diminuição dos índices DEC e FEC, considerando o alimentador seccionado em pequenos segmentos, no caso de ocorrer interrupções permanentes. 


\subsection{Conclusões parciais}

Através da metodologia desenvolvida, durante as topologias analisadas, observou-se uma diminuição dos índices de continuidade na medida em que os equipamentos de proteção eram posicionados no circuito, chegando-se ao valor e a solução proposta por [Bishop (1997)], como uma das melhores.

$\mathrm{Na}$ topologia 5 analisada, a adição de religadores que permitam realizar uma coordenação entre si, principalmente quando munidos de controles microprocessados, aumenta as possibilidades de reconfigurações de circuitos e manobras, levando a uma redução das interrupções temporárias para os consumidores ao longo do alimentador. As falhas que ocorrem no final dos ramos laterais são eliminadas pelos religadores, não sendo necessário interromper o fornecimento de energia.

A tabela 4.17, faz um resumo das topologias analisadas através da metodologia desenvolvida e compara os valores dos índices de continuidade, de acordo com cada topologia e suas características circuitais. Os resultados foram obtidos a partir do programa TEIAA.

Tabela 4.17 - Valores de DEC e FEC obtidos das topologias analisadas

\begin{tabular}{|c|c|c|c|c|c|}
\hline $\begin{array}{c}\text { Topo- } \\
\text { logias }\end{array}$ & $\begin{array}{c}\text { Caracteristicas } \\
\text { Circuitais }\end{array}$ & FEC & $\begin{array}{c}\text { Valores } \\
\text { \% } \\
\text { de FEC }\end{array}$ & DEC & $\begin{array}{c}\text { Valores } \\
\% \\
\text { de DEC }\end{array}$ \\
\hline 1 & $\begin{array}{c}\text { Disjuntor na subestação } \\
\text { sem capacidade de religa- } \\
\text { mento }\end{array}$ & 31,17 &.-- & 65,66 & - \\
\hline 2 & $\begin{array}{c}\text { Disjuntor na subestação } \\
\text { com capacidade de religa- } \\
\text { mento }\end{array}$ & 6,23 & 20 & 15,78 & 24,05 \\
\hline 3 & $\begin{array}{c}\text { Fusiveis laterais e } \\
\text { Disjuntor na subestação } \\
\text { com capacidade de religa- } \\
\text { mento }\end{array}$ & 2,16 & 6,95 & 5,52 & 8,41 \\
\hline 4 & $\begin{array}{c}\text { Fusiveis laterais, } \\
\text { Disjuntor na subestação } \\
\text { com capacidade de religa- } \\
\text { mento e Religador trifásico }\end{array}$ & 2,15 & 6,91 & 5,49 & 4,21 \\
\hline 5 & $\begin{array}{c}\text { Fusiveis laterais, } \\
\text { Disjuntor na subestação } \\
\text { com capacidade de religa- } \\
\text { mento e Religador } \\
\text { monofásicos }\end{array}$ & 1,04 & 3,35 & 2,76 & \\
\hline
\end{tabular}

Obs: valores \% de FEC e DEC em relação à Topologia 1 
Capítulo 5

\section{Aplicação de Algoritmos Genéticos para Análise e Dimensionamen- to da Proteção de Sistemas de Distribuição de Energia Elétrica}

\section{Aplicação de Algoritmos Genéticos para Análise e Dimensiona- mento da Proteção de Sistemas de Distribuição de Energia Elé- trica}

Neste capítulo, é desenvolvida a metodologia relacionada à criação dos programas e às aplicações envolvendo o AG, a partir do modelo de Bishop (1997).

\subsection{Metodologia de software utilizada}

Para o desenvolvimento da pesquisa, utilizou-se o ciclo de vida clássico ou o modelo em cascata. Este propõe uma abordagem sistêmica sequencial para o desenvolvimento das soluções propostas. Inicia-se desde a etapa de sistema, progredindo, por meio da análise, para o projeto, a codificação, o teste e a manutenção dessas soluções. Tal modelo apresentou eficácia superior em relação a outros, principalmente, durante a implementação.

Baseando-se em Pressman (2002) e Sommerville (2007), é possível analisar cada etapa, de acordo com a Figura 5.1. 


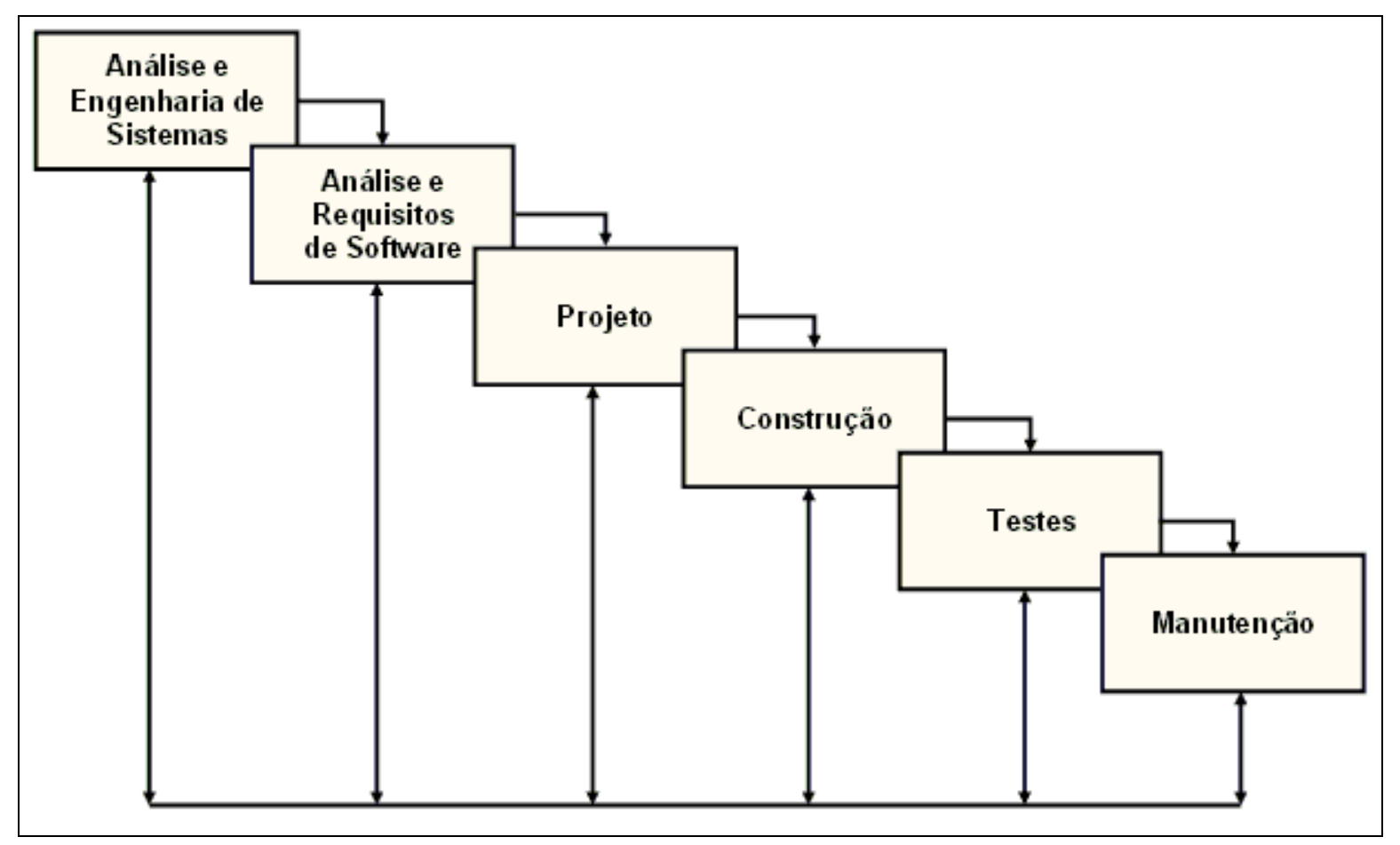

Figura 5.1 - Modelo em cascata

\subsubsection{Análise e engenharia de sistemas}

Esta etapa inicia-se com a análise das soluções de software, considerando os seguintes aspectos:

- tratamento direto do problema de alocação dos equipamentos de distribuição de energia elétrica. Para tanto, calculam-se os índices de continuidade, número de equipamentos, unidades e custo relacionados;

- análise de uma tabela de contingências. O objetivo é verificar o comportamento do circuito elétrico mediante os eventos indicados;

- busca de uma solução otimizada (melhor solução com os equipamentos de proteção alocados), a partir de um arquivo de entrada que represente o estoque de equipamentos da concessionária. 


\subsubsection{Análise e requisitos de software}

Esta etapa aborda as propostas de funções, o comportamento esperado, o desempenho e a interface das soluções. Objetivando facilitar a compreensão dos dados, optou-se por documentar o desenvolvimento desse processo (Anexo A).

Assim, consideraram-se os seguintes aspectos:

- entradas: utilizaram-se arquivos de entrada, codificando a topologia do circuito elétrico e a leitura da tabela de contingências;

- saídas: obtiveram-se os valores de DEC, FEC, DIC, FIC, DMIC, número de equipamentos e custo total;

- levantamento de requisitos de todos os elementos do sistema e sua respectiva alocação nos programas. Desse modo, promoveu-se sua interação com outros elementos em uma base de dados: para tal propósito, este trabalho utilizou os arquivos de entrada.

\subsubsection{Projeto}

O projeto de software baseia-se em um processo de múltiplos passos, que engloba quatro atributos de programa [Pressman (2002) e Sommerville (2007)]:

- estrutura de dados;

- arquitetura do software;

- representações da interface;

- detalhes procedimentais (algoritmos).

Segundo Pressman (2002), o processo relativo ao projeto traduz os requisitos para uma representação de software. A representação pode ser avaliada quanto à qualidade, antes que a codificação tenha início, tornando-se, após a documentação, parte da configuração do software.

Nesta etapa, foram escolhidas as ferramentas a serem utilizadas durante a construção. Com relação à linguagem de programação para o desenvolvimento das soluções, optou-se pela linguagem $\mathrm{C}_{++}$, devido às suas características funcionais [Barros et al. (2003)]:

- orientação a objeto: permite projetar aplicações sob a ótica do encapsulamento, da hereditariedade e do polimorfismo; 
- portabilidade: é possível compilar o código, na maioria dos sistemas operacionais existentes, sem necessidade de um número elevado de alterações;

- o código gerado é otimizado.

Para o ambiente de desenvolvimento dos programas, foi escolhido um compilador-padrão $\mathrm{C}++$. Este possui um Ambiente de Desenvolvimento Integrado relacionado aos programas para uso no ambiente Windows ${ }^{\circledR}$. Sua interface é apresentada na Figura 5.2.

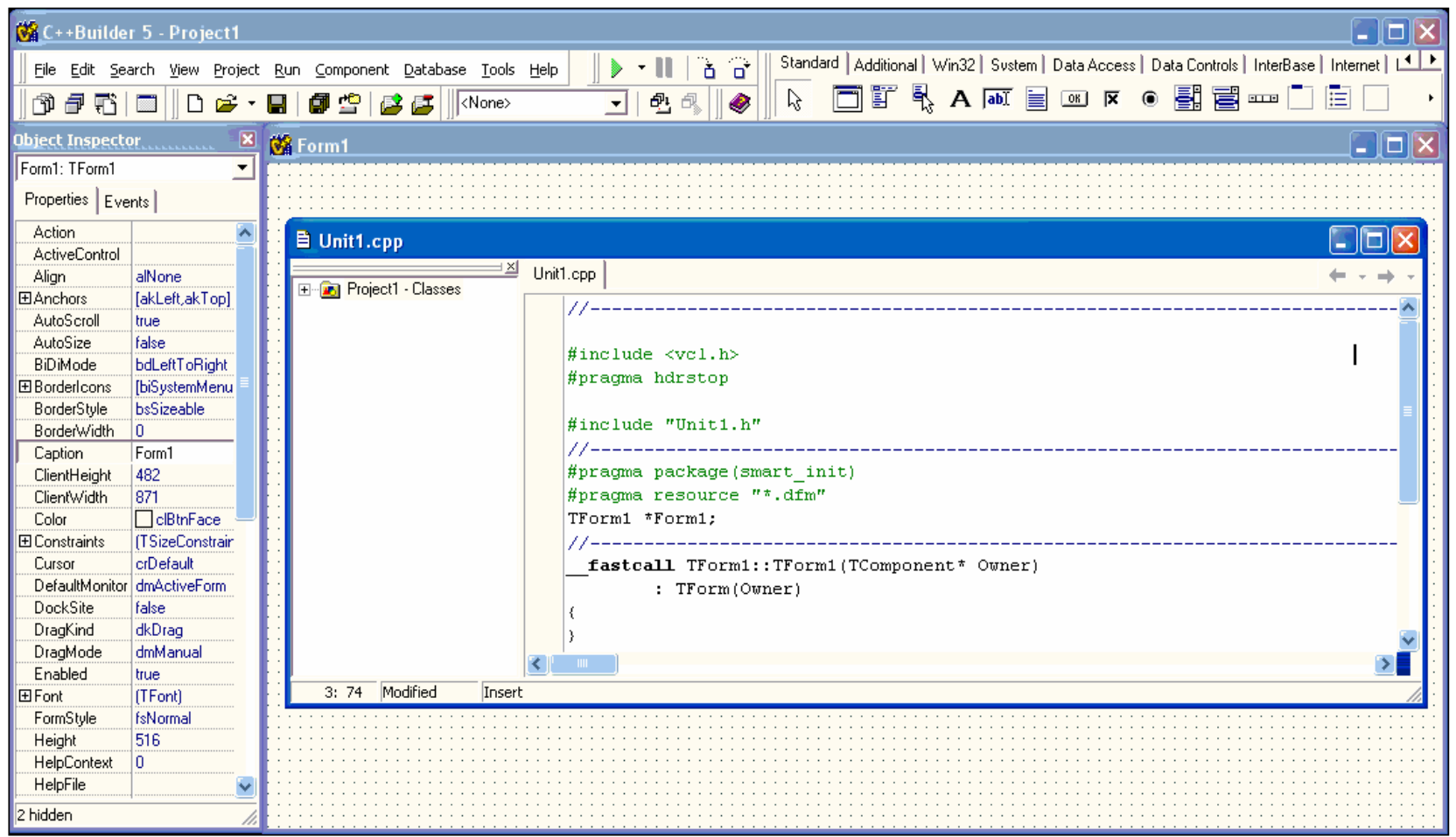

Figura 5.2 - Ambiente de desenvolvimento do compilador $C_{++}$Builder

A estrutura de um Projeto no $\mathrm{C}_{+}+$Builder é formada por um conjunto de arquivos, conforme indica a Figura 5.3 [Barros et al. (2003)]. 


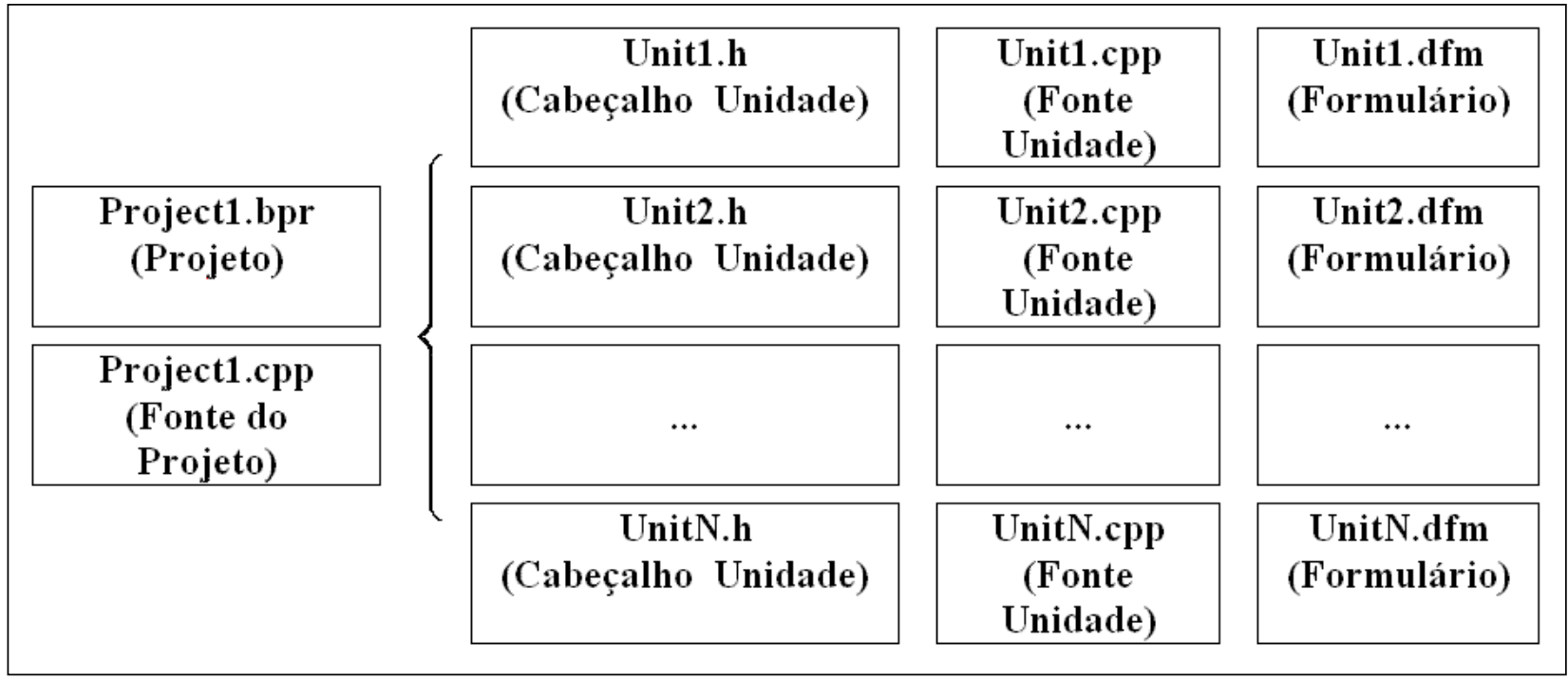

Figura 5.3 - Organização de arquivos no compilador C++ Builder

Cada extensão de arquivo tem um significado:

- .bpr: Builder Project;

- .cpp: C Plus Plus;

- .h: Header;

- .dfm: Delphi Form (a linguagem $\mathrm{C}++$ usa o mesmo padrão de formulários do ambiente Delphi).

Quanto ao desenvolvimento dos algoritmos, utilizaram-se as regras descritas em Bishop et al. (1995) e ANEEL № 24 (2000). Tais regras foram extraídas da metodologia desenvolvida no Capítulo 4 deste estudo. A solução do AG baseou-se em Hetem et al. (2007), no Capítulo 3.

\subsubsection{Construção das soluções}

Uma vez estabelecido o projeto, a construção das soluções desenvolveu-se com a geração de um código, em que se traduziram as premissas estabelecidas no projeto.

Desta etapa, resultaram os programas:

- TEIAA: cria um modelo simbólico da topologia de um circuito elétrico implementado com esforço computacional otimizado. Contém as informações elétricas provindas de um arquivo de entrada. Como resultado, obtêm-se os valores numéricos dos índices de continuidade DEC e FEC, conforme Bishop et al. (1995) e Burian (2001). 


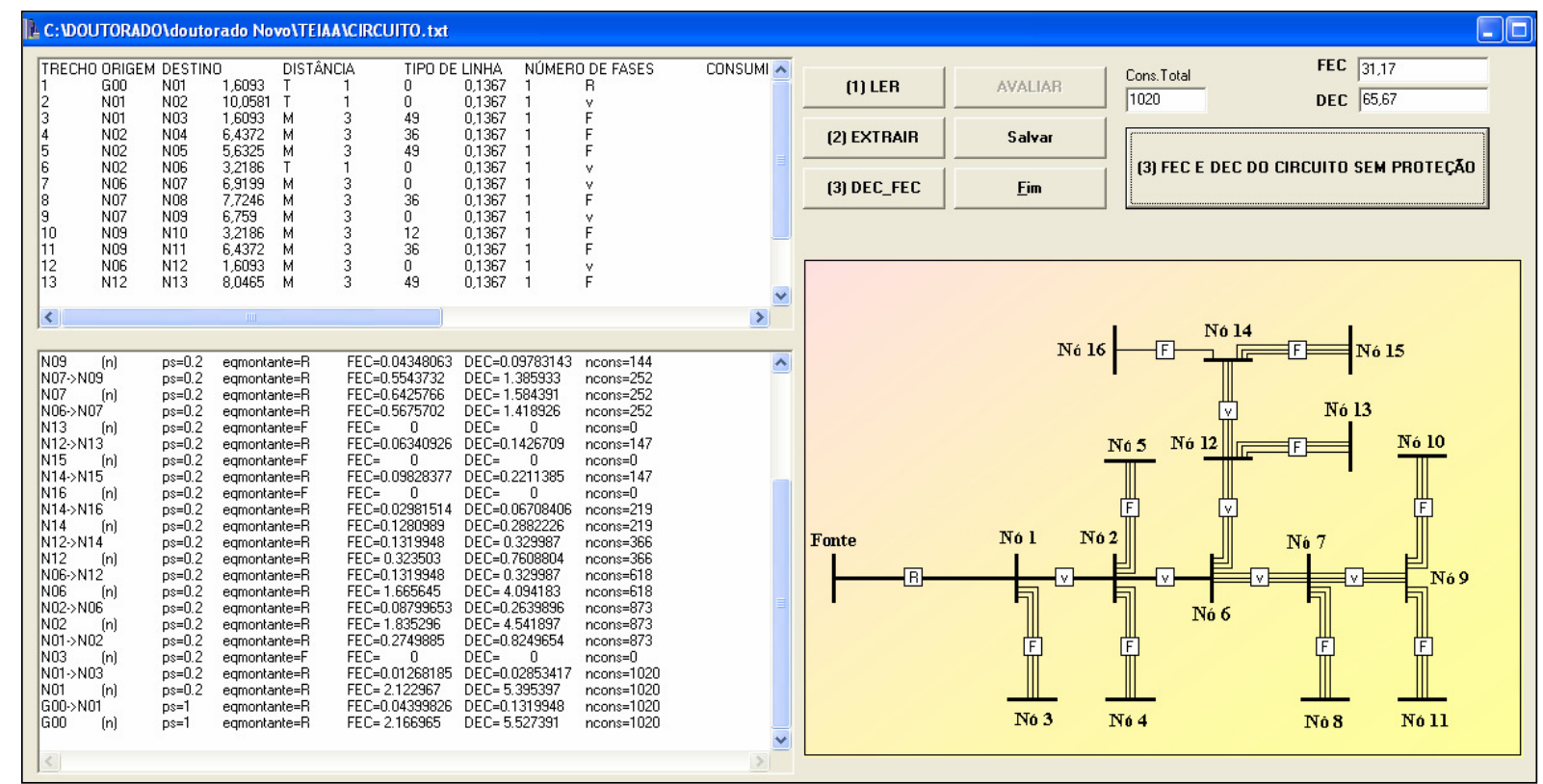

Figura 5.4 - Tela do programa TEIAA

- TEIAG: incorpora o programa TEIAA e aplica o método AG. Como resultado, obtém-se a alocação otimizada de equipamentos de distribuição, retornando:

I. representação gráfica do circuito otimizado;

II. número e total de dispositivos utilizados;

III. valores dos índices DEC e FEC do circuito otimizado;

IV. gráfico de tendências que indica a evolução dos valores do fator de fitness nas gerações;

V. arquivo com as alterações de configuração do circuito elétrico;

VI. gráfico de evolução;

VII. arquivo texto com as informações geradas pelo AG.

A Figura 5.5 expõe um exemplo de tela do programa TEIAG. 


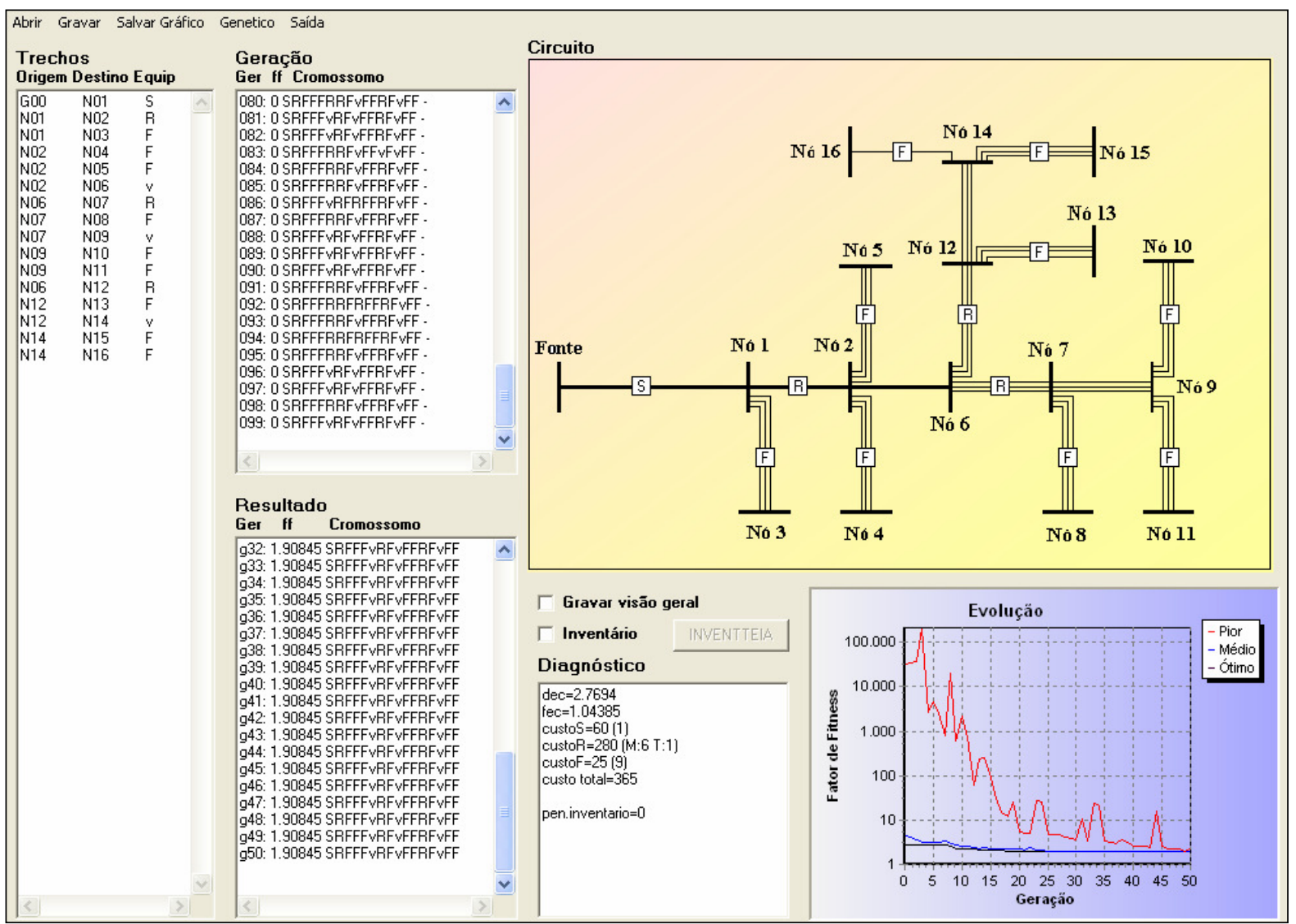

Figura 5.5 - Tela do programa TEIAG

- CONTTEIA: para este programa, criou-se uma linguagem de descrição do histórico de contingências, a qual pode representar a sequência de eventos que compõem uma contingência e sua solução. Assim, é possível conhecer o comportamento do circuito em uma análise a posteriori. Essa possibilidade proporciona uma visualização detalhada da resposta do circuito à contingência.

O programa CONTTEIA necessita de dois arquivos de entrada:

I. circuito a ser analisado;

II. histórico das contingências.

O CONTTEIA simula as ocorrências de cada contingência, podendo ser analisadas passo a passo ou de uma única vez. Chega-se aos valores de DIC, FIC e DMIC, por meio de uma análise a posteriori. Dessa maneira, observa-se o comportamento das chaves de operação e proteção alocadas. 


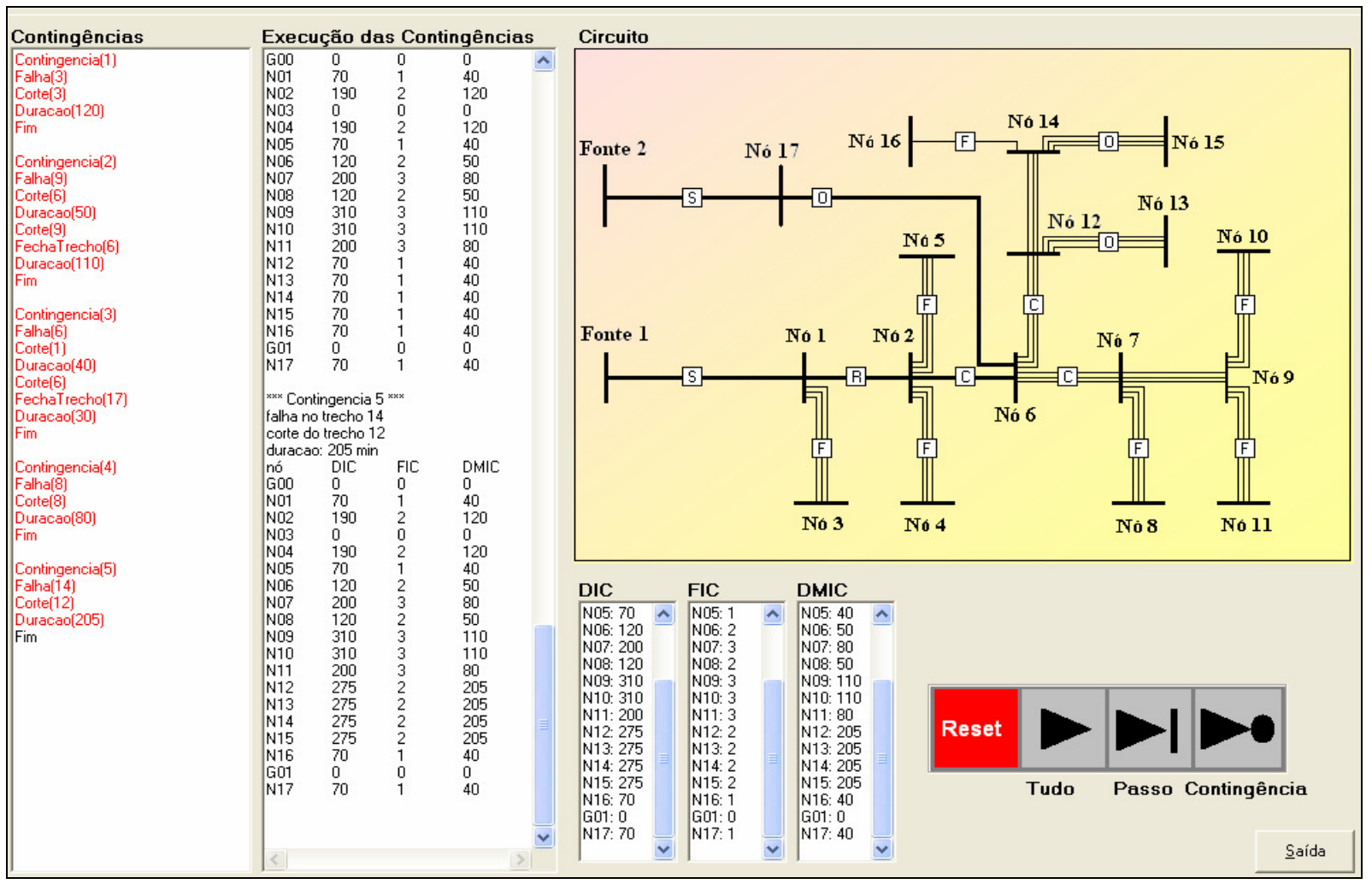

Figura 5.6 - Tela do programa CONTTEIA

- INVENTTEIA: programa que utiliza um banco de dados com as quantidades de equipamentos de proteção disponíveis no estoque da concessionária. A partir destas informações, encontra-se uma solução circuital otimizada, com base nos equipamentos disponíveis e de acordo com a análise do inventário.

A solução otimizada que provém do programa TEIAG tem como finalidade a comparação do ponto de ótimo com a solução real. Esse processo fornece uma referência à concessionária quanto à alocação dos dispositivos de proteção e à tomada de decisão (Figura 5.7). 


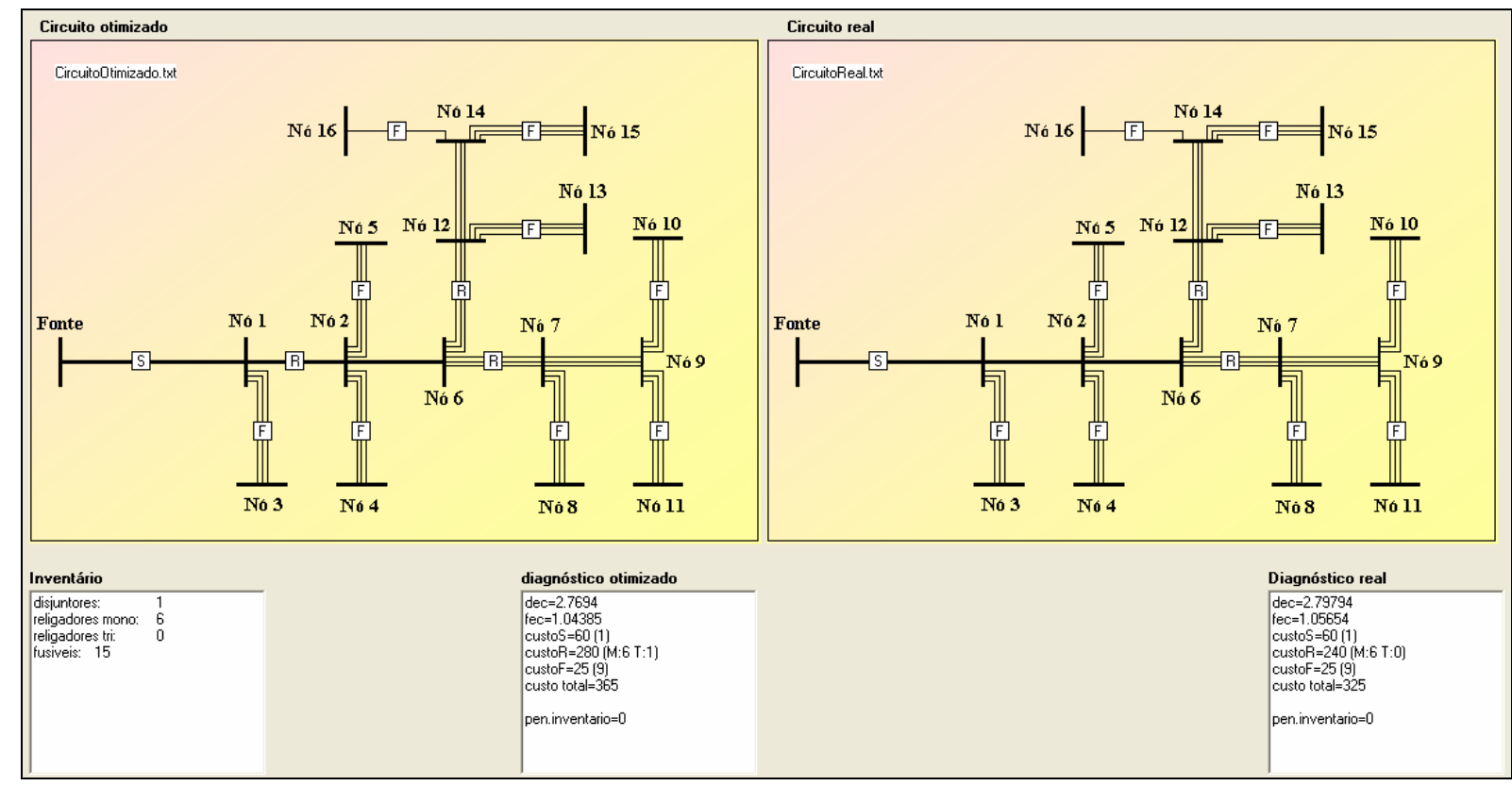

Figura 5.7 - Tela do programa INVENTTEIA

\subsubsection{Testes}

Conforme a metodologia de desenvolvimento de software adotada, os testes de programa iniciaram-se durante a geração do código, focando os aspectos lógicos e garantindo que todos os comandos fossem testados. Os testes evidenciaram possíveis erros, de maneira que as entradas definidas produzissem resultados condizentes. Verificou-se a operabilidade das funções comuns, muitas vezes, utilizadas entre os programas e a estabilidade quanto ao aspecto funcional.

Realizaram-se os testes baseados em Pressman (2002), Sommerville (2007) e Delamaro et al. (2007):

- Teste de Caixa-branca (aplicado no início do processo): método de teste em que se procura garantir que todos os caminhos lógicos, independentes dos módulos, tenham sido exercitados, pelo menos, uma vez. Busca-se ainda exercitar todas as decisões lógicas em seus aspectos verdadeiro e falso, além de executar todos os ciclos nos seus limites e dentro de seus intervalos operacionais e estruturas de dados internos.

- Teste de Caixa-Preta (aplicado durante os últimos estágios), conforme Pressman (2002): tem como foco os requisitos funcionais do software, permitindo testar conjuntos de condições de entrada que irão exercitar plenamente os requisitos funcionais do programa. Trata-se de uma abordagem complementar às técnicas da caixa-branca. Podem-se encontrar as seguintes falhas: funções incorretas ou o- 
mitidas; erros de interface; erros de estruturas de dados ou de acesso à base de dados externa; erros de comportamento ou desempenho; erros de iniciação e término.

\subsubsection{Manutenção}

Conforme previsto [Pressman (2002)], os programas sofrem alterações durante as etapas de desenvolvimento. A necessidade de modificações ocorre quando erros são encontrados ou o software precisa ser adaptado para acomodar mudanças no ambiente externo. As alterações também são pertinentes quando se necessitam melhorias funcionais ou de desempenho. O processo de manutenção da solução reaplicou cada uma das fases precedentes a um programa existente, em vez de criar um novo.

Nos programas desenvolvidos, realizaram-se dois tipos de manutenções corretivas:

- corretiva: houve alteração do programa para corrigir defeitos;

- aperfeiçoamento: na medida em que o software estava sendo utilizado, foram propostas funções adicionais que trouxeram benefícios. Este tipo de manutenção aprimora o software, além dos requisitos funcionais originais [Pressman (2002)].

\subsection{Estrutura dos arquivos de entrada}

$\mathrm{O}$ arquivo de entrada, representado pela Tabela 5.1, baseou-se nas características indicadas em Bishop (1997) e Bishop et al. (1995). Ele foi simplificado para que pudesse ser usado junto aos algoritmos apresentados neste trabalho. A escolha do formato texto foi motivada pela facilidade de se encontrarem os chamados Editores Simples. Estes foram localizados em praticamente todas as plataformas disponíveis no mercado, facilitando a entrada de dados pelo programa e o modelamento do circuito elétrico. 
Tabela 5.1 - Exemplo de representação da topologia 1 por arquivo de entrada

\begin{tabular}{|c|c|c|c|c|c|c|c|c|c|}
\hline TRECHO & ORIGEM & DESTINO & DISTÁNCIA & TIPO DE LINHA & NÚMERO DE FASES & CONSUMIDORES POR FASE & FALTAS POR KM & FATOR DE FALTAS & EQUIPAMENTO \\
\hline 1 & G0 & N1 & 1,6093 & $\mathrm{~T}$ & 1 & 0 & 0,1367 & 1 & $v$ \\
\hline 2 & N1 & N2 & 10,0581 & $T$ & 1 & 0 & 0,1367 & 1 & $v$ \\
\hline 3 & N1 & N3 & 1,6093 & $M$ & 3 & 49 & 0,1367 & 1 & v \\
\hline 4 & N2 & N4 & 6,4372 & $\mathrm{M}$ & 3 & 36 & 0,1367 & 1 & $\mathrm{v}$ \\
\hline 5 & N2 & N5 & 5,6325 & $\mathrm{M}$ & 3 & 49 & 0,1367 & 1 & $\mathrm{v}$ \\
\hline 6 & N2 & N6 & 3,2186 & $T$ & 1 & 0 & 0,1367 & 1 & v \\
\hline 7 & N6 & N7 & 6,9199 & $M$ & 3 & 0 & 0,1367 & 1 & $v$ \\
\hline 8 & N7 & N8 & 7,7246 & $M$ & 3 & 36 & 0,1367 & 1 & $v$ \\
\hline 9 & N7 & N9 & 6,759 & $M$ & 3 & 0 & 0,1367 & 1 & v \\
\hline 10 & N9 & N10 & 3,2186 & $M$ & 3 & 12 & 0,1367 & 1 & v \\
\hline 11 & N9 & N11 & 6,4372 & $\mathrm{M}$ & 3 & 36 & 0,1367 & 1 & $\mathrm{v}$ \\
\hline 12 & N6 & N12 & 1,6093 & $M$ & 3 & 0 & 0,1367 & 1 & v \\
\hline 13 & N12 & N13 & 8,0465 & $M$ & 3 & 49 & 0,1367 & 1 & v \\
\hline 14 & N12 & N14 & 1,6093 & $M$ & 3 & 0 & 0,1367 & 1 & V \\
\hline 15 & N14 & N15 & 12,472 & $M$ & 3 & 49 & 0,1367 & 1 & v \\
\hline 16 & N14 & N16 & 7,7246 & $M$ & 1 & 72 & 0,1367 & 1 & $v$ \\
\hline
\end{tabular}

Informações disponíveis no arquivo de entrada:

- identificação do trecho;

- nó origem;

- nó destino;

- distância entre nós;

- tipo de linha - Trifásica (T) ou Monofásica (M);

- número de fases por trecho;

- consumidores, por fase, nos trechos;

- falhas por km;

- fator de faltas (flag de controle interno do programa);

- equipamento.

\subsection{Construção e aplicação do AG}

O AG foi implementado e utilizado nos programas TEIAG e INVENTTEIA. Considerando que sua nomenclatura poderia gerar dúvidas, devido às características peculiares do seu formalismo, apresentou-se uma descrição dos termos utilizados.

Para o desenvolvimento de um modelo de um circuito de distribuição de energia elétrica, com equipamentos de proteção alocados e aplicação do conceito de $A G$, definem-se os seguintes termos:

- gene - representa um equipamento alocado em uma determinada posição do circuito de distribuição de energia elétrica. Um parâmetro (por exemplo, um religador alocado) corresponde a este gene; já uma mudança aleatória pode caracterizar uma mutação; 
- cromossomo - é uma palavra composta por um conjunto de genes, em que cada posição, ao longo da palavra, corresponde a um trecho do circuito;

- indivíduo - solução completa com os equipamentos (genes) alocados no cromossomo, associada a duas variáveis adicionais. Uma delas é o fator de fitness (ff), que indica um índice de qualidade do cromossomo. A outra variável de controle é o $\Phi$ (o operador genético), que será utilizado pelo Julgador, para a criação da próxima geração de indivíduos;

- geração - conjunto de todos os indivíduos (ou todas as soluções) presentes em uma iteração do método.

Tabela 5.2 - Nomenclatura do AG

\begin{tabular}{|c|l|}
\hline Terminologia do AG & \multicolumn{1}{c|}{ Modelo } \\
\hline Gene & $\begin{array}{l}\text { O equipamento a ser alocado em um determi- } \\
\text { nado trecho }\end{array}$ \\
\hline Cromossomo & $\begin{array}{l}\text { Todos os equipamentos alocados para um dado } \\
\text { circuito }\end{array}$ \\
\hline Indivíduo & $\begin{array}{l}\text { Uma solução completa (equipamentos aloca- } \\
\text { dos, } S_{i}, \text { resultado da função de avaliação, ff e o } \\
\text { operador genético a ser aplicado, } \Phi)\end{array}$ \\
\hline Geração & $\begin{array}{l}\text { Conjunto de todos os indivíduos atualmente ati- } \\
\text { vos }\end{array}$ \\
\hline
\end{tabular}

Para implementar o AG, é necessário criar uma estrutura que armazene gerações completas de indivíduos, que possa classificá-los e, posteriormente, reproduzi-los.

Optou-se por uma matriz de ponteiros dinamicamente alocados, em função do número de trechos (Figura A.5, no Anexo A). Suas principais estruturas para manipular os dados foram listas ligadas ${ }^{18}$, contendo as soluções (conjunto de parâmetros, nível de adaptação $\left(\mathrm{ff}_{\mathrm{i}}\right)$ e operadores genéticos $\left.\left(\Phi_{\mathrm{i}}\right)\right)$ expressas por:

$S_{i}=\left[\left(E_{1}, E_{2, \ldots} E_{n}\right), f_{i}, \Phi_{i}\right]$

Onde:

- $S_{i}$ representa i-ésima solução da geração corrente;

\footnotetext{
${ }^{18}$ Uma lista ligada ou lista encadeada é uma estrutura de dados linear e dinâmica. Ela é composta por células que apontam para o próximo elemento da lista.
} 
- $E_{n}$ é o n-ésimo gene no cromossomo;

- $\mathrm{ff}_{\mathrm{i}}$ é o valor do fator de fitness do i-ésimo indivíduo;

- $\Phi_{i}$ é o operador genético a ser aplicado ao i-ésimo indivíduo.

O AG analisa cada indivíduo da geração atual (g) e cria novos deles para a próxima geração $(g+1)$. $O$ procedimento $\Gamma$ (gama), que corresponde ao algoritmo genético (AG), analisa cada solução / indivíduo e considera que seu operador genético executa um passo evolutivo.

Formalmente:

$\left[S_{1}, S_{2}, \ldots, S_{n}\right]_{g+1}=\Gamma\left[\left(S_{1}, \Phi_{1}\right),\left(S_{2}, \Phi_{2}\right), \ldots,\left(S_{n}, \Phi_{n}\right)\right]_{g}$

A equação 5.2 expressa que "os indivíduos da próxima geração serão obtidos através do operador $\Gamma$ ao aplicar os operadores genéticos à geração atual" [Hetem et al. (2007), Goldberg (1989) e Holland (1975)].

De acordo com Goldberg (1989), o código se inicia com a criação da primeira geração, em que todos os parâmetros são aleatoriamente escolhidos dentro de uma faixa permitida [Hetem et al. (2007)].

Escolhe-se, então, o vetor $E_{j}$ do cromossomo $S_{i}$, que obedeça à função:

$\left.E_{j}\right|^{s_{i}} \leftarrow \omega \in[$ ['S', 'R', 'F', 'v']

Onde:

- $\omega$ (ômega) é a representação de um equipamento a ser alocado no trecho considerado, sendo implementada na função CHOOSE (Figura A.7, do Anexo A). Assim, os símbolos representam, respectivamente: Disjuntor da Subestação (S), Religador (R), Fusível (F) e "ausência de equipamento" (v).

\subsubsection{Estrutura do cromossomo}

A topologia do circuito elétrico, representada por meio de um cromossomo, é fundamental para a implementação do AG. Trata-se de uma forma otimizada de se obter uma codificação que possa ser implementada em uma ambiente computacional.

A apresentação do mapa conceitual da memória de um computador é baseada na Figura 5.8. 


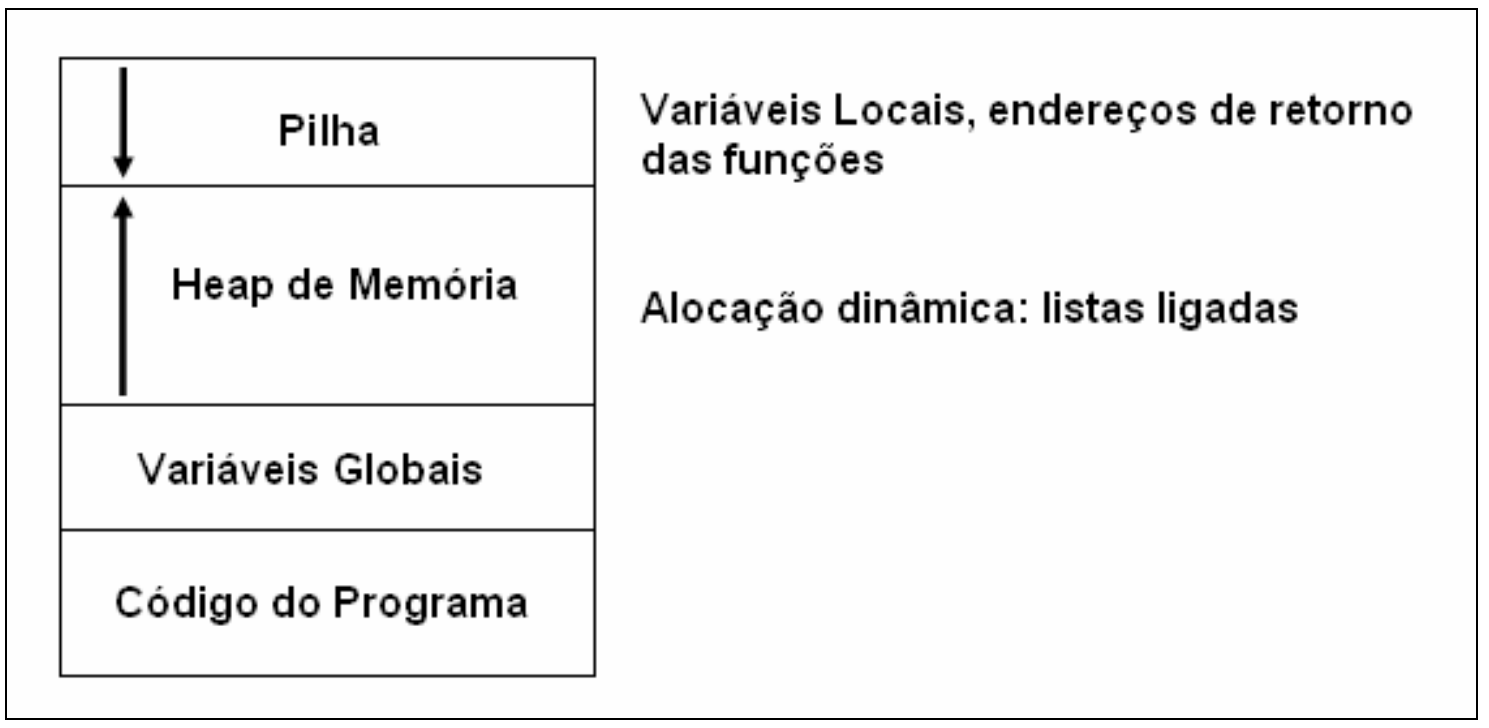

Figura 5.8 - Mapa conceitual das estruturas alocadas dinamicamente

$\mathrm{Na}$ possibilidade de se obter uma imagem da memória do computador no momento do uso das listas ligadas, a visualização seria exibida como na Figura 5.9.

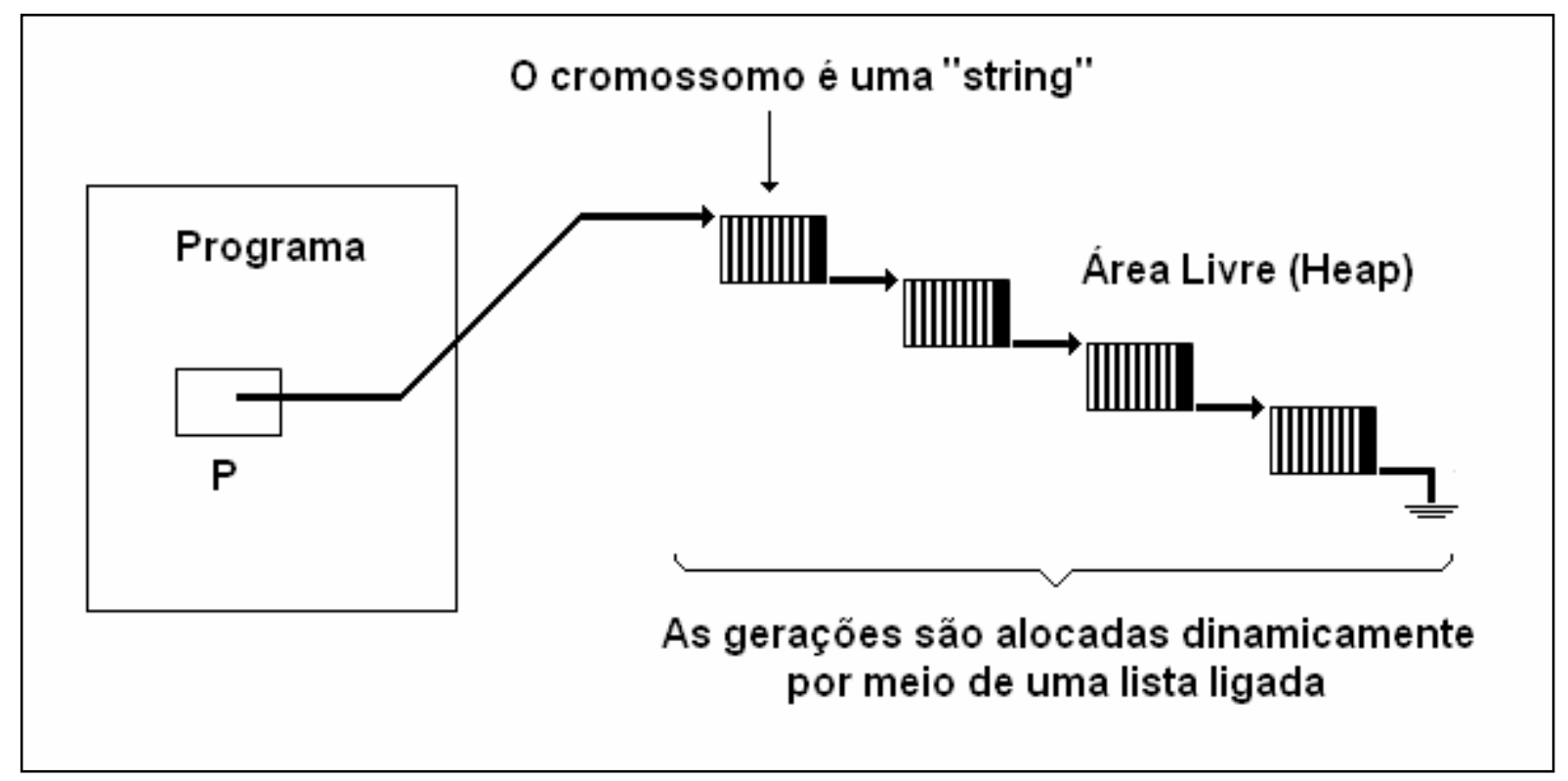

Figura 5.9 - Exemplo de cromossomo alocado

Após cada alocação, o ponteiro estará apontando para o primeiro byte do conjunto de bytes de memória livre alocado no heap de memória.

O AG implementado nos programas TEIAG e INVENTTEIA indica que o cromossomo original compõe-se de uma palavra (string). Seu comprimento será função do número de nós do circuito. Cada caractere correspondente à alocação de um equipamento de proteção. Cada família de cromossomos, que representa a gera- 
ção, será alocada dinamicamente por meio de uma lista ligada, sendo descartadas as gerações anteriores.

\subsubsection{Primeira geração}

A geração dos cromossomos baseou-se na alocação dos dispositivos de proteção, localizados nos trechos do circuito. Orientou-se também por regras de alocação de equipamentos, baseadas em Bishop et al. (1997).

A estrutura de dados da primeira geração é gerada pela função apresentada na Figura A.6, do Anexo A.

Para cada trecho do circuito elétrico, escolhe-se uma representação de elemento, de maneira aleatória, com base na função CHOOSE (Figura A.7, do Anexo A). Em seguida, é preciso averiguar se o dispositivo escolhido atende às regras de alocação de equipamentos de proteção, para sistemas de distribuição de energia elétrica [Bishop (1997) e Kagan et al. (2005)].

As referidas regras podem ser identificadas nos itens que seguem:

a) o religador de subestação pode ser alocado apenas no trecho raiz;

b) não é permitida a alocação de fusível no trecho raiz;

c) não é permitida alocação de religador no trecho raiz;

d) o trecho folha (terminal) deve ter, obrigatoriamente, um equipamento de proteção;

e) não é permitido alocar fusíveis em trechos com linhas trifásicas (opcional).

Uma geração é composta por um certo número de indivíduos (100 cromossomos), formados aleatoriamente e representados na Figura 5.10. Nesta, os cromossomos são compostos por uma sequência de $n$ caracteres, em que $n$ é igual ao número de trechos do circuito elétrico. Cada posição é a representação de um equipamento de proteção. 


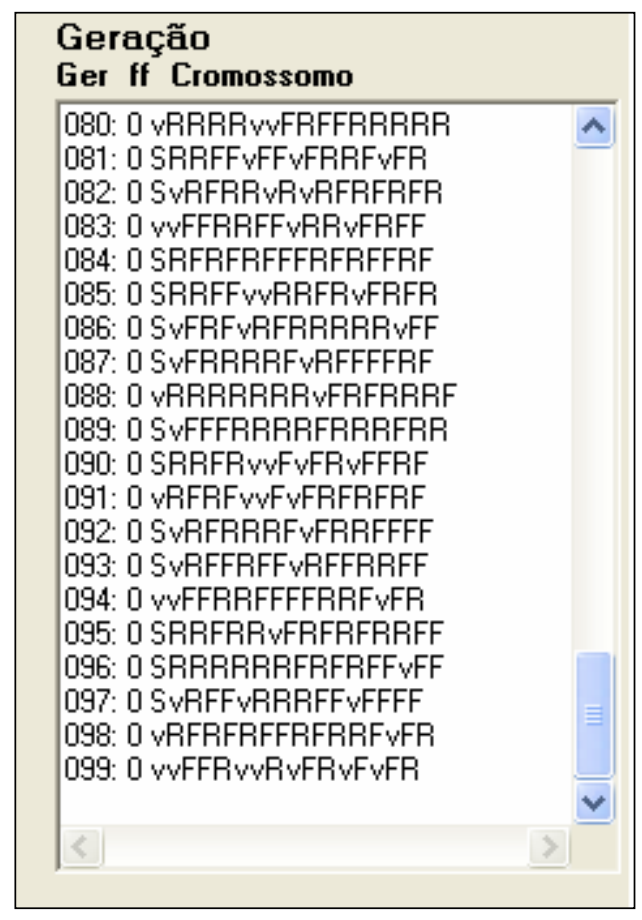

Figura 5.10 - Primeira geração

Após criar cada cromossomo, chega-se à Tabela 5.3, com os cromossomos da primeira geração. Os dados apresentados são resultado de uma execução do programa TEIAG.

Tabela 5.3 - Cromossomo com equipamentos alocados - Primeira Geração

\begin{tabular}{|c|l|l|}
\hline Indivíduo & ff & $\Phi_{\text {i }}$ \\
\hline vRFFRRFFFRFRvRR & 0 & \\
\hline SRFRFvvRvFRFFvRF & 0 & \\
\hline vvFRRvvRvRFvRFRR & 0 & \\
\hline SvFRRvFFRRFvRvFR & 0 & \\
\hline vvRRFRRFFRRFFvFR & 0 & \\
\hline vRFRRvRRvRRvRRFF & 0 & \\
\hline vvRRRRvFvFFvRFRR & 0 & \\
\hline vvRRFRvFvFRvFvRF & 0 & \\
\hline vRFFFRRRFFRRRvRF & 0 & \\
\hline SvFFRRvRRFRvRvRR & 0 & \\
\hline SvFRFvFRvRFRFRFR & 0 & \\
\hline SvFFRRFFvRRRFRFF & 0 & \\
\hline vRFFRRvFvFRvFRFR & 0 & \\
\hline vvFFRvRFFRRvRFRF & 0 & \\
\hline vvFRRRvRRRFRFFFR & 0 & \\
\hline vRRRRvvRRRRFRvRR & 0 & \\
\hline vRRRRRvFvFRFFvRF & 0 & \\
\hline vRFRFRFRFRRFFvFR & 0 & \\
\hline SvFFRRRRvFRvRvFR & 0 & \\
\hline vvFRRRFFRFFFFFF & 0 & \\
\hline
\end{tabular}

\begin{tabular}{|c|l|l|}
\hline Indivíduo & $\mathrm{ff}$ & $\boldsymbol{\Phi}_{\mathrm{i}}$ \\
\hline vvFRFvvFRFRFRFR & 0 & \\
\hline SRRFRvvFvFRvRvFF & 0 & \\
\hline vvRFFRvRFRFvFRRF & 0 & \\
\hline SvFFFvFFRRFRFvRR & 0 & \\
\hline vvFRRvRFFFRFFvFF & 0 & \\
\hline SRRFFRRFRFFvFRRF & 0 & \\
\hline vvRRFvFFFRRvFvFR & 0 & \\
\hline vvRRFRFRvRRFRRFF & 0 & \\
\hline SRRRRRvFRFRRRvFR & 0 & \\
\hline vvRFFvFFvRRvRFRR & 0 & \\
\hline vvFFFvFFFFRFFRRF & 0 & \\
\hline SvFFRvRRFFFFRFFR & 0 & \\
\hline SvRRFRvFFRRFFvRF & 0 & \\
\hline vRFRRRvFFRvRFRR & 0 & \\
\hline vRFRFvvRRFFRFRRR & 0 & \\
\hline vvFRFRFRFRRRRvRR & 0 & \\
\hline vvRRRvFRvFRvFRFF & 0 & \\
\hline SvRRFRvFvFRRFvRF & 0 & \\
\hline vRRRFRvRvFFFFvFR & 0 & \\
\hline SvFRRRvFvFFvRRR & 0 & \\
\hline
\end{tabular}




\begin{tabular}{|c|l|l|}
\hline Indivíduo & ff & $\Phi_{\mathrm{i}}$ \\
\hline vvRFRRRRFFRFvF & 0 & \\
\hline vRRRRRRRRFFFRF & 0 & \\
\hline vvFRFRvFvRRFRFF & 0 & \\
\hline vRRFRRFFRRRvRvFR & 0 & \\
\hline vRRFFvRFRFRRRFF & 0 & \\
\hline vRRRRvRRRFFFRRRR & 0 & \\
\hline vRFFRvvFFRFRFFF & 0 & \\
\hline SvFRFvFRFRFvRvRR & 0 & \\
\hline SvRFRvvFFRRvFRRF & 0 & \\
\hline SvRFRRFFFRRvFFFR & 0 & \\
\hline vRFRFRvFFRRRRvFF & 0 & \\
\hline vRFFFvFRFFRRFRFR & 0 & \\
\hline vRFFFvRRRFFRRFF & 0 & \\
\hline vRRRFvFFRRRvFvFF & 0 & \\
\hline vvRFFvRRRFFFRFRF & 0 & \\
\hline SvRFRvvRRRFFFvFR & 0 & \\
\hline SRRRRRRRRRFRFvFR & 0 & \\
\hline SRFFRvvFvRFFRFFR & 0 & \\
\hline vvFFRvRFRFRRRvRR & 0 & \\
\hline vvRFRvRFRRFvFRFR & 0 & \\
\hline SvFFRRFRRFFRRvFR & 0 & \\
\hline vvRRFRvFFFFFRRR & 0 & \\
\hline vvFFRvvRRFRFRRR & 0 & \\
\hline vvFRFRRFFFFvRFRR & 0 & \\
\hline SvFRRRRRFRFRRRFR & 0 & \\
\hline SRFRFRvFRFRvRFRF & 0 & \\
\hline SvRFRvRRRRRvRRFR & 0 & \\
\hline vRFRFvRRRFRFFvRF & 0 & \\
\hline vRFRRRvRFFRFFvFR & 0 & \\
\hline vvFFRvvFvRRRRFFR & 0 & \\
\hline
\end{tabular}

\begin{tabular}{|c|l|l|}
\hline Indivíduo & ff & $\boldsymbol{\Phi}_{\mathrm{i}}$ \\
\hline vRFFFviFRFFFR & 0 & \\
\hline SvFFRvRFFFFrvFR & 0 & \\
\hline vvFFFvRRFFRFvRR & 0 & \\
\hline vvFRFvvRRRRRRFR & 0 & \\
\hline SvRRRvFRFFRFFRF & 0 & \\
\hline SRFRRRRRvRFFRvRR & 0 & \\
\hline vvFFFRvRvFFvFFF & 0 & \\
\hline SvFFRRvRRRRvFFFR & 0 & \\
\hline vvRRRRFFvFRvFFR & 0 & \\
\hline SvFRRvRRRRRvFFF & 0 & \\
\hline SRRRFRFRRFFRFFRF & 0 & \\
\hline SvFFRRFFvFFRRFR & 0 & \\
\hline vvFRFvRRRFRFFvFF & 0 & \\
\hline SRRRRvFFRRFRRRF & 0 & \\
\hline SvRFFRFFvFFFRFRR & 0 & \\
\hline SvFFRvvFFFRFFFFR & 0 & \\
\hline vRFFRRvRFRRvFRRF & 0 & \\
\hline vRFFFRFRFRFvRFRR & 0 & \\
\hline vvRRRRFRvRFRRvRR & 0 & \\
\hline vvFRFRRRvFRRFRFR & 0 & \\
\hline SvFFFRFFRFRvFvRR & 0 & \\
\hline SRFFFvvRvRFFFvRF & 0 & \\
\hline vRRRRvRFRRRFRRF & 0 & \\
\hline SRFRFvRFRRFRFvRF & 0 & \\
\hline vvFFRRFRvFRRRvRF & 0 & \\
\hline SvFFRvRRFFFFFvRR & 0 & \\
\hline SRRFRRvRRFRvRFRF & 0 & \\
\hline SvRFRvFFRFFFFvFR & 0 & \\
\hline SvRFFRvFvRRFRRR & 0 & \\
\hline SvFFRvRFFFRvFvFF & 0 & \\
\hline
\end{tabular}

\subsubsection{Fator de fitness}

O objetivo deste trabalho é encontrar uma configuração equilibrada entre os valores de DEC e FEC e o custo de alocação de equipamentos. Assim, é pertinente tecer as considerações que seguem, acerca da implementação dos programas.

A interpretação de um cromossomo segue a sequência estabelecida pelos nós / trechos do circuito. Tal fato exige um procedimento recursivo, pois resultados à jusante de um nó podem influenciar nos cálculos dos índices de continuidade associados. 
À medida que o circuito é percorrido, calculam-se dois componentes relevantes do fator de fitness (ff):

- df, que é o componente FEC do ff;

- ct, o custo total, referenciado no trabalho, é o custo total de material, que é a função do custo direto do religador (custoR), custo do disjuntor da subestação (custoS) e do custo do fusível (custoF). Consideram-se os valores dos dispositivos que são colocados diretamente no local do sistema.

Formalmente:

$$
\mathrm{df}=\text { fator } * \sum_{i=1}^{n}\left(\text { FEC } C_{i}\right)
$$

Como opção é possível introduzir o índice DEC normalizado, como uma componente para o cálculo de df. Observou-se que a introdução dessa componente não altera o circuito otimizado que leva aos mesmos valores de DEC e FEC originais, confirmando a robustez do método utilizado.

$\mathrm{ct}=\kappa_{\mathrm{C}} \sum_{i=1}^{n}\left(\right.$ Custos $_{i}+$ CustoF $_{i}+$ CustoR $\left._{i}\right)$

O fator de fitness (ff) de um indivíduo é dado por:

$\mathrm{ff}=\mathrm{df}+\mathrm{ct}+\beta$

Onde,

- $K_{\mathrm{C}}$ é o fator de custo, e $\beta$ é a função do inventário (item 5.5).

- n é o número de ramos do circuito.

O fator de custo é um coeficiente, cuja função é "normalizar unidades". Sua finalidade é garantir que o comportamento do ff seja semelhante ao apresentado na Figura 3.5 (Capítulo 3). Dessa maneira, nos casos de excesso ou ausência de equipamentos (FEC ótimo ou custo ótimo), o ff deve assumir valores elevados. Este comportamento não é facilmente obtido, pois, enquanto o índice de continuidade FEC apresenta ordem de grandeza de unidades, o custo dos equipamentos enquadra-se na ordem de centenas de milhares.

Para a obtenção do $\kappa_{\mathbb{C}}$, foram realizadas simulações até atingir um número de pontos no espaço df versus custo total, a fim de que se definisse a região de sua 
distribuição discreta. Essa distribuição pode ser caracterizada por uma curva, cuja construção será descrita a seguir.

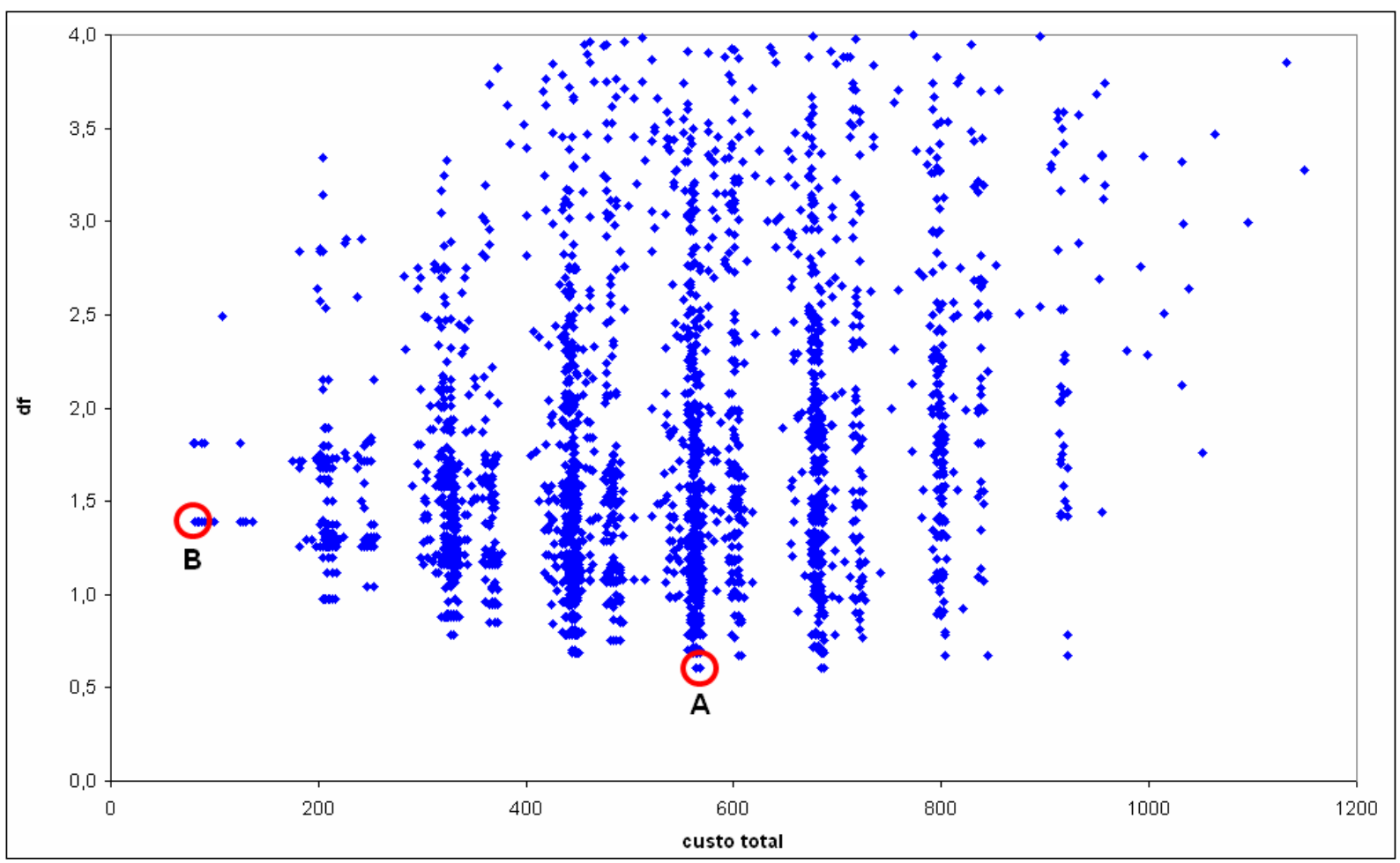

Figura 5.11 - df em função do custo total

Na Figura 5.11, destacam-se dois pontos notáveis: maior custo total para o menor df (A) e o maior df para o menor custo total (B).

A partir desses dois pontos definidos, constrói-se uma função interpoladora do tipo:

$\mathrm{df}=\alpha$ custo $^{-\beta}$

Onde $\alpha$ e $\beta$ são obtidos por intermédio do método de mínimos quadrados [Burian et al. (2007)]. Esta função deve conter os pontos de mínimo df das distribuições verticais de custos, observadas entre os pontos (A) e (B). A partir da construção desta curva, obteve-se o gráfico representado na Figura 5.12.

A função interpoladora obtida resultou em:

df $=9,5542$ custo $^{-0,4326}$

Esta curva é a fronteira entre as regiões onde podem ou não ser encontradas soluções df versus custo total, não sendo necessária para os cálculos seguintes. 


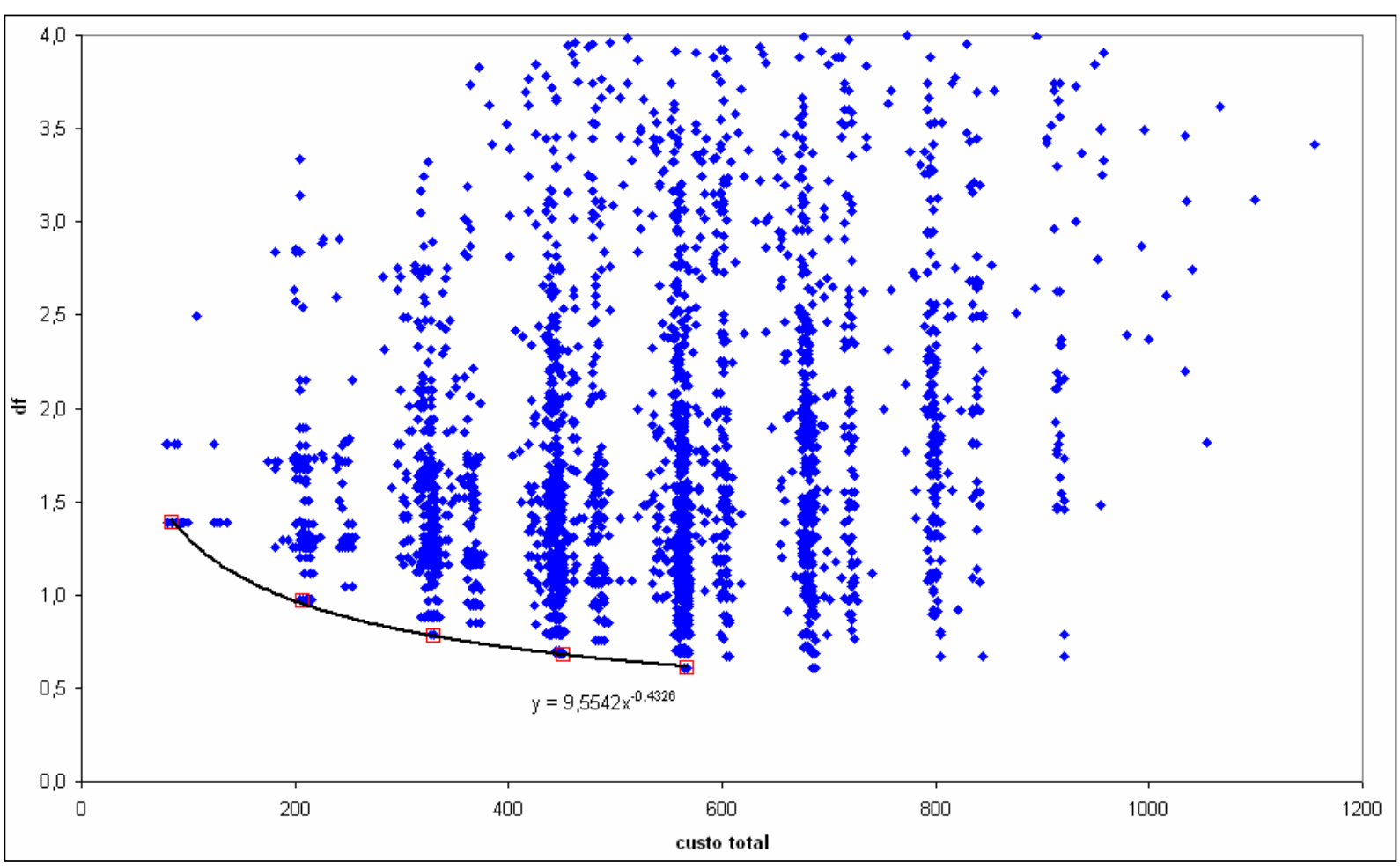

Figura 5.12 - Pontos do gráfico da Figura 5.11, com a função interpoladora e a identificação dos pontos com menor df, por distribuição vertical de custo total

Sabe-se que ct corresponde a uma função linear do custo total, baseado na equação (5.5), e que, para custo total igual a zero, ct se anula. Desse modo, é necessário apenas mais um ponto para obter a reta definida em (5.5). Esta função retornará o valor do fator de custo $\kappa_{\mathrm{C}}$.

Elege-se o ponto $(A)$, da Figura 5.11, como a intersecção entre a função interpoladora e a reta da equação (5.5). Tal escolha justifica-se pelo fato de que esse ponto representa o início conhecido do comportamento assintótico da função interpoladora (equação 5.8). Caso haja um número maior de pontos gerados, não se espera alteração deste valor, pois foram esgotadas as possibilidades da distribuição discreta dos equipamentos do circuito

Uma representação da função interpoladora completa e da reta ct versus custo total é visualizada na Figura 5.13. 


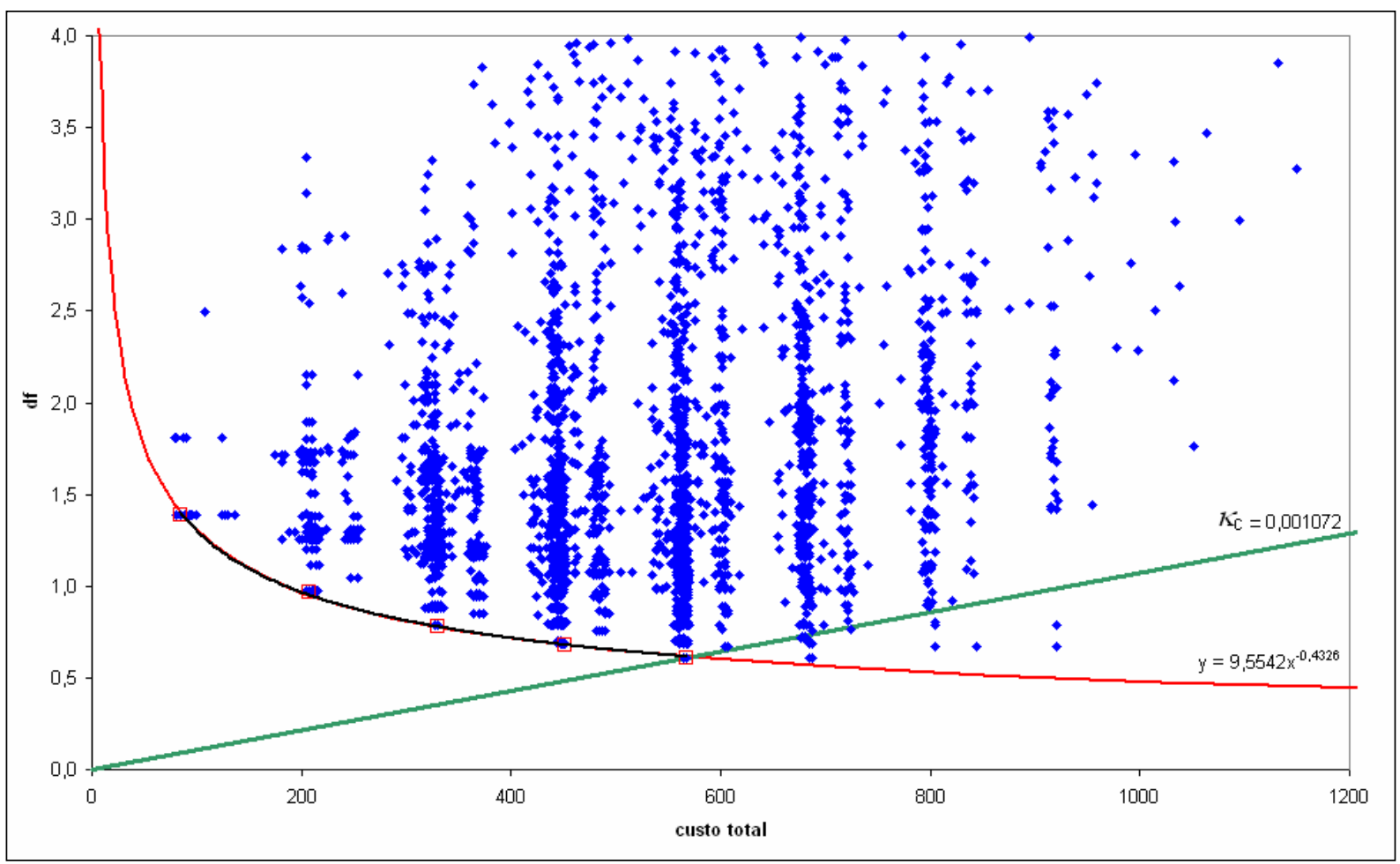

Figura 5.13 - Expansão do domínio da função interpoladora sobreposta à reta ct $=\kappa_{\mathrm{c}}^{\star}$ (custo total)

O resultado aponta como estimativa para $\kappa_{\mathrm{C}}$ o valor de 0,001072 , que é obtido numericamente a partir da coeficiente angular da reta $\mathrm{ct}=\boldsymbol{K}_{\mathrm{C}}{ }^{*}$ (Custo total).

Da equação 5.6 ao fator $\beta$, é imposto o valor zero, quando o programa for o TEIAG, o qual busca a solução otimizada geral. O programa INVENTTEIA atribui diferentes valores para este fator, levando em conta o estoque de equipamentos presentes no inventário da concessionária.

\subsubsection{Avaliador}

A função Avaliador utiliza as rotinas do programa TEIAA para calcular os valores de DEC e FEC de cada indivíduo e fornece ao AG um parâmetro para a determinação da qualidade de cada cromossomo, o fator de fitness (ff). 


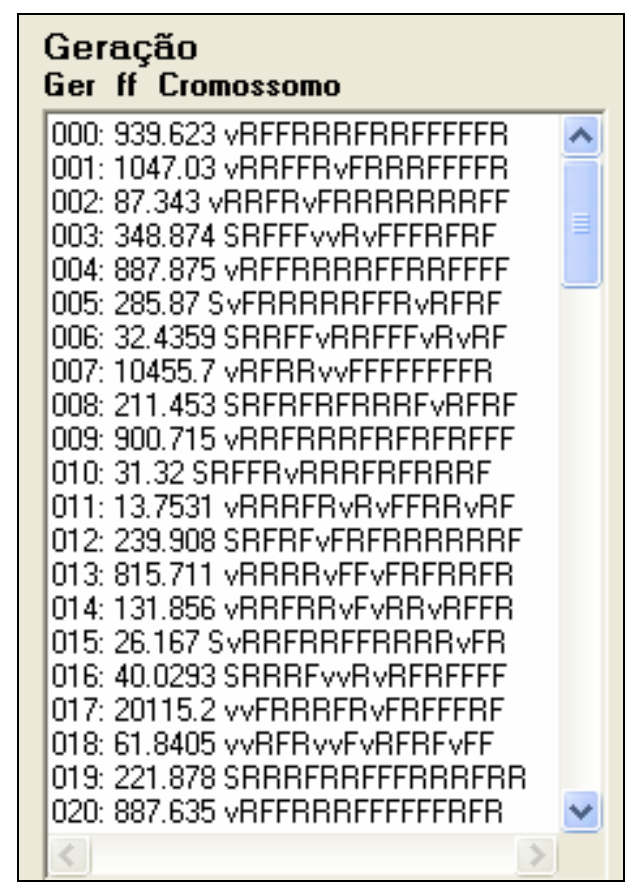

Figura 5.14 - Exemplo de cromossomos com fator de fitness

Segundo Linden (2006), o AG pode ser usado para descobrir o ponto de máximo de toda e qualquer função de $n$ variáveis, sem nenhuma alteração das estruturas de dados e procedimentos adotados. A Tabela 5.4 apresenta uma geração de cromossomos com seus respectivos fatores de fitness.

Tabela 5.4 - Cromossomo com equipamentos alocados e fator de fitness

\begin{tabular}{|c|c|c|}
\hline Indivíduo & $\mathrm{ff}$ & Фi \\
\hline vRFFRRFFFFRFRvR & 7546,03 & \\
\hline SRFRFvvRvFRFFvRF & 40,5285 & \\
\hline vvFRRvvRvRFvRFRR & 683,876 & \\
\hline SvFRRvFFRRFvRvFR & 30,3874 & \\
\hline vvRRFRRFFRRFFvFR & 2229,72 & \\
\hline vRFRRvRRvRRvRRFF & 12,0635 & \\
\hline vvRRRRvFvFFvRFRR & 247,179 & \\
\hline vvRRFRvFvFRvFvRF & 28,0441 & \\
\hline vRFFFRRRFFRRRvRF & 104,274 & \\
\hline SvFFRRvRRFRvRvRR & 4,97981 & \\
\hline SvFRFvFRvRFRFRFR & 19,1759 & \\
\hline SvFFRRFFvRRRFRFF & 15,2217 & \\
\hline vRFFRRvFvFRvFRFR & 13,4428 & \\
\hline vvFFRvRFFRRvRFRF & 4122,6 & \\
\hline vvFRRRvRRRFRFFFR & 237,452 & \\
\hline vRRRRvvRRRRFRvRR & 116,088 & \\
\hline vRRRRRvFvFRFFvRF & 121,534 & \\
\hline vRFRFRFRFRRFFvFR & 7886,14 & \\
\hline
\end{tabular}

\begin{tabular}{|c|c|c|}
\hline Indivíduo & $\mathrm{ff}$ & $\Phi \mathrm{i}$ \\
\hline vvFRFvvFRFFRFRFR & 49,4218 & \\
\hline SRRFRvvFvFRvRvFF & 4,63326 & \\
\hline vvRFFRvRFRFvFRRF & 279,299 & \\
\hline SvFFFvFFRRFRFvRR & 23,7177 & \\
\hline vvFRRvRFFFRFFvFF & 3124,89 & \\
\hline SRRFFRRFRFFvFRRF & 2,75359 & \\
\hline vvRRFvFFFRRvFvFR & 6348,49 & \\
\hline vvRRFRFRvRRFRRFF & 2122,21 & \\
\hline SRRRRRvFRFRRRvFR & 4,13604 & \\
\hline vvRFFvFFvRRvRFRR & 4553,41 & \\
\hline vvFFFvFFFFRFFRRF & 37717,9 & \\
\hline SvFFRvRRFFFFRFFR & 2134,37 & \\
\hline SvRRFRvFFRRFFvRF & 256,886 & \\
\hline vRFRRRvFRFRvRFRR & 124,019 & \\
\hline vRFRFvvRRFFRFRRR & 12,8989 & \\
\hline vvFRFRFRFRRRRvRR & 2455,35 & \\
\hline vvRRRvFRvFRvFRFF & 426,123 & \\
\hline SvRRFRvFvFRRFvRF & 4,43001 & \\
\hline & &
\end{tabular}




\begin{tabular}{|c|c|c|}
\hline Indivíduo & ff & Фi \\
\hline SvFFRRRRvFRvRvFR & 3,88005 & \\
\hline vvFRRRFFRFFFFFR & 20409,7 & \\
\hline vvRFRRRRFFRRFvR & 238,53 & \\
\hline vRRRRRRRRFFFRRF & 93,4191 & \\
\hline vvFRFRvFvRRFRFFF & 2692,46 & \\
\hline vRRFRRFFRRRvRvFR & 103,642 & \\
\hline vRRFFvRFRFRRRFFR & 92,5474 & \\
\hline vRRRRvRRRFFFRRR & 111,369 & \\
\hline vRFFRvvFFRRFRFFF & 9731,22 & \\
\hline SvFRFvFRFRFvRvRR & 311,969 & \\
\hline SvRFRvvFFRRvFRRF & 33,3835 & \\
\hline SvRFRRFFFRRvFFF & 1862,64 & \\
\hline vRFRFRvFFRRRRvFF & 105,646 & \\
\hline vRFFFvFRFFRRFRFR & 800,429 & \\
\hline vRFFFvRRRFFRRFF & 98,3168 & \\
\hline vRRRFvFFRRRvFvFF & 92,5623 & \\
\hline vvRFFvRRRFFFRFRF & 3453,85 & \\
\hline SvRFRvvRRRFFFvFR & 33,9619 & \\
\hline SRRRRRRRRRFRFvFR & 3,28358 & \\
\hline SRFFRvvFvRFRFFR & 363,976 & \\
\hline vvFFRvRFRFRRRvRR & 34,2825 & \\
\hline vvRFRvRFRRFvFRFR & 43,7436 & \\
\hline SvFFRRFRRFFRRvFR & 21,7799 & \\
\hline vvRRFRvFFFFFRRRR & 2519,15 & \\
\hline vvFFRvvRRFRFRRRF & 487,063 & \\
\hline vvFRFRRFFFFvRFRR & 2363,69 & \\
\hline SvFRRRRRFRFRRRFR & 31,0363 & \\
\hline SRFRFRvFRFRvRFRF & 36,1618 & \\
\hline SvRFRvRRRRRvRRFR & 3,82877 & \\
\hline vRFRFvRRRFRFFvRF & 102,5 & \\
\hline vRFRRRvRFFRFFvFR & 1097,15 & \\
\hline vvFFRvvFvRRRRFFR & 608,7 & \\
\hline & & \\
\hline
\end{tabular}

\begin{tabular}{|c|c|c|}
\hline Indivíduo & ff & $\Phi \mathrm{i}$ \\
\hline vRRRFRvRvFFFFvF & 120,687 & \\
\hline SvFRRRvFvFFvRRRR & 5,18182 & \\
\hline vRFFFvvRFRFFFRF & 1095,79 & \\
\hline SvFFRvRFFFFvRvFR & 29,2215 & \\
\hline vvFFFvRRFFRFRvRR & 3441,89 & \\
\hline vvFRFvvRRRRRRFRF & 476,091 & \\
\hline SvRRRvFRFFRFFRRF & 2243,44 & \\
\hline SRFRRRRRvRFFRvRR & 27,3085 & \\
\hline vvFFFRvRvFFvFFFF & 294,435 & \\
\hline SvFFRRvRRRRvFFFR & 38,5879 & \\
\hline vvRRRRFFvFRvFFRF & 2014,61 & \\
\hline SvFRRvRRRRRvFFFF & 34,4484 & \\
\hline SRRRFRFRRFFRFFRF & 150,398 & \\
\hline SvFFRRFFvFFRRRFR & 22,7296 & \\
\hline vvFRFvRRRFRFFvFF & 350,111 & \\
\hline SRRRRvFFRRFRRvRF & 28,725 & \\
\hline SvRFFRFFvFFFRFRR & 1305,64 & \\
\hline SvFFRvvFFFRFFFFR & 2573,86 & \\
\hline vRFFRRvRFRRvFRRF & 118,905 & \\
\hline vRFFFRFRFRFvRFRR & 8284,96 & \\
\hline vvRRRRFRvRFRRvRR & 222,595 & \\
\hline vvFRFRRRvFRRFRFR & 25,3394 & \\
\hline SvFFFRFFRFRvFvRR & 28,8522 & \\
\hline SRFFFvvRvRFFFvRF & 37,0132 & \\
\hline vRRRRvRFRRRFRRFF & 95,2882 & \\
\hline SRFRFvRFRRFRFvRF & 2,85235 & \\
\hline vvFFRRFRvFRRRvRF & 241,225 & \\
\hline SvFFRvRRFFFFFvRR & 209,657 & \\
\hline SRRFRRvRRFRvRFRF & 39,4119 & \\
\hline SvRFRvFFRFFFFvFR & 163,086 & \\
\hline SvRFFRvFvRRFRRRR & 45,2672 & \\
\hline SvFFRvRFFFRvFvFF & 23,1888 & \\
\hline
\end{tabular}

\subsubsection{Operadores genéticos}

Os operadores genéticos considerados são apresentados na Tabela 5.5. Nesta, a coluna que indica a porcentagem de cada operação (\% na Geração) baseia-se em Hetem et al. (2007), Flake (1998), Goldberg (1989) e Rojas et al. (2008). 
Tabela 5.5 - Descrição dos operadores genéticos utilizados

\begin{tabular}{|c|c|c|}
\hline Operador & Símbolo $\left(\Phi_{\mathbf{i}}\right)$ & $\%$ na Geração \\
\hline Cópia & $\mathrm{e}$ & 5 \\
\hline $\begin{array}{c}\text { Crossover } \\
\text { (Recombinação) }\end{array}$ & $\mathrm{c}$ & 89 \\
\hline Mutação & $\mathrm{x}$ & 1 \\
\hline Descarte & $\mathrm{k}$ & 5 \\
\hline
\end{tabular}

Cada operador genético é descrito funcionalmente:

\section{- Cópia}

Os indivíduos relacionados a este operador são replicados sem alterações para a próxima geração, conforme indica a Figura 5.15 [Hetem et al. (2007), Flake (1998) e Goldberg (1989)].

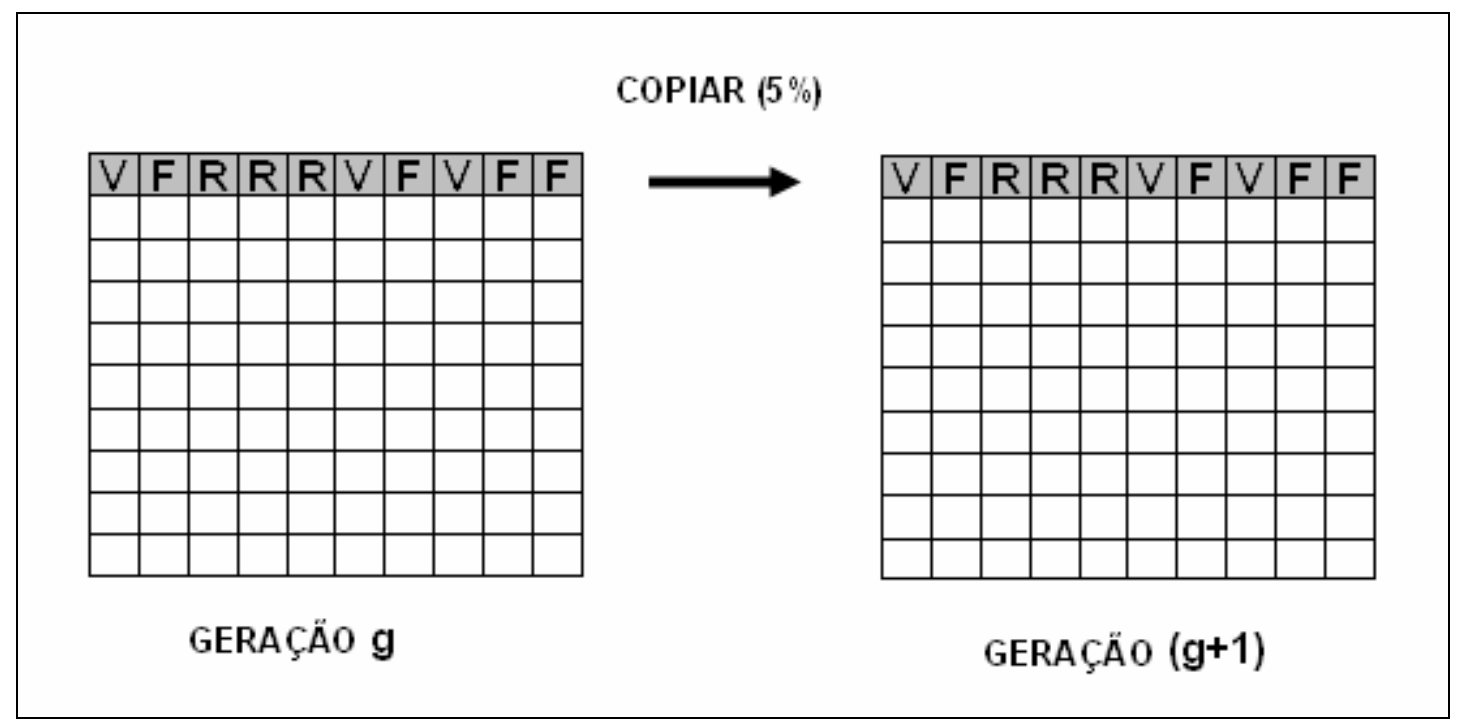

Figura 5.15 - Operador cópia

Formalmente:

$$
\Phi_{i}={ }^{\prime} e^{\prime} \rightarrow S_{i, g+1}=S_{i, g}
$$

Onde, i é um indivíduo e g sua geração.

A equação 5.9 indica que os indivíduos da geração g, relacionados ao operador cópia, serão reproduzidos sem alteração, para uso na próxima geração. Foi adotada uma taxa de $5 \%$ da geração g para este operador. 


\section{- Crossover}

A implementação do operador crossover utilizado no programa TEIAG baseia-se no modelo indicado em Linden (2006) e Flake (1998). Os indivíduos relacionados com este operador terão seus genes combinados com os de outro indivíduo. Assim, poderão gerar um novo cromossomo, baseado na combinação de genes herdados.

Formalmente:

$$
\Phi_{\mathrm{i}=} \mathbf{c}^{\prime} \rightarrow \mathrm{S}_{\mathrm{i}, \mathrm{g}+1}=\mathrm{S}_{\mathrm{i}, \mathrm{g}} \odot \mathrm{S}_{\mathrm{j}, \mathrm{g}}
$$

Onde $\mathrm{j} \neq \mathrm{i}$ e $\odot$ é o operador que executa a escolha de genes, aleatoriamente, de um "pai" e uma "mãe". Entende-se que i e j são indicadores de diferentes indivíduos e que g indica a geração.

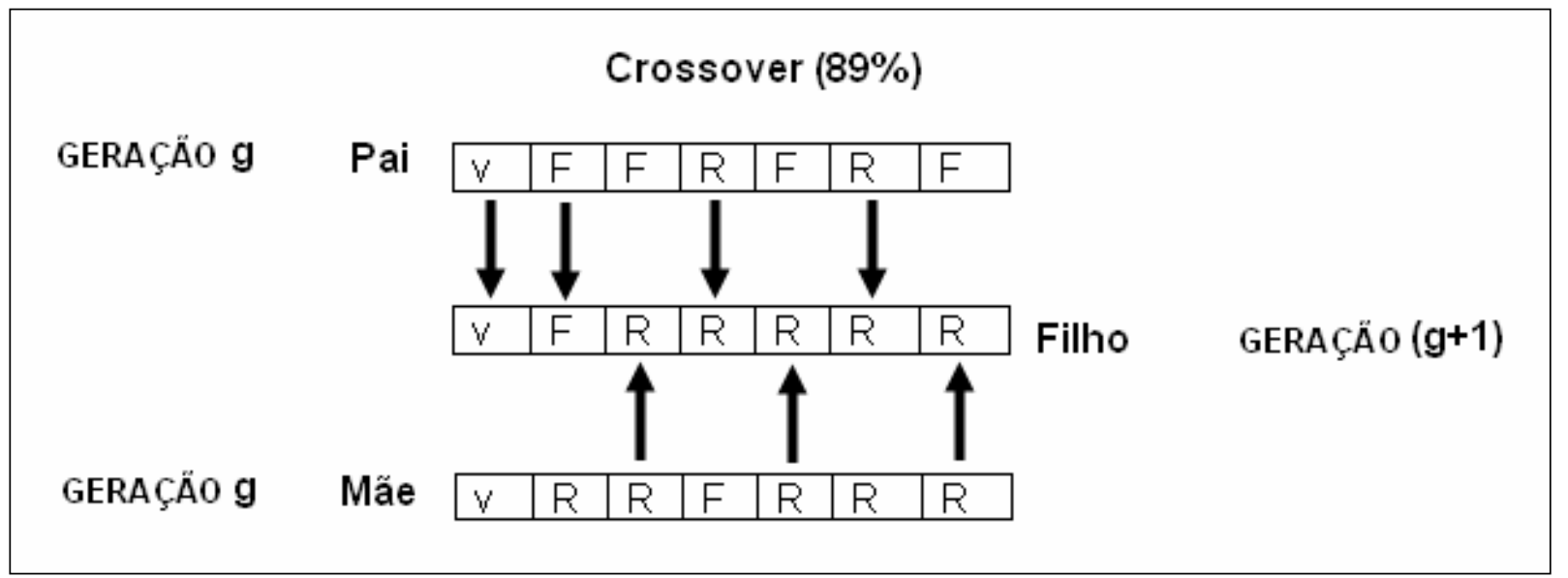

Figura 5.16 - Operador crossover

Uma vez determinado o operador crossover para um indivíduo, escolhe-se aleatoriamente outro indivíduo, cujo operador não seja k e que não seja ele próprio. Eles serão denominados "pai" e "mãe". O novo cromossomo será gerado sequencialmente (uma posição por vez), com a escolha de um gene do pai ou o correspondente da mãe, casualmente. Esse esquema de "crossover puro" é descrito em Goldberg (1989). Trata-se de uma variação do "crossover uniforme", como descrito em Linden (2006) e Goldberg (1989).

Como exemplo, considere os indivíduos:

- $S_{\mathrm{a}}$ representados por $\left[\left(E_{1}, E_{2, \ldots} E_{n}\right),\left(f_{a}, \Phi_{a}=^{\prime} c^{\prime}\right)\right]$

E,

- $S_{b}$ representados por $\left[\left(E_{1}, E_{2}, \ldots E_{n}\right),\left(f f_{b}, \Phi_{b} \neq^{\prime} k^{\prime}\right)\right]$

Os indivíduos resultantes da operação $\mathrm{S}_{\mathrm{a}} \odot \mathrm{S}_{\mathrm{b}}$ serão representados por $\mathrm{S}_{\mathrm{c}}$. 
Onde:

- $S_{c}$ é o conjunto de indivíduos $\left[\left(E_{1}, E_{2}, \ldots E_{n}\right),(-,-)\right]$.

\section{- Mutação}

Neste operador, há a reprodução do individuo original, exceto pela mudança aleatória de um de seus genes. Para tanto, utiliza-se a mesma função CHOOSE, referenciada na construção da primeira geração. Essa função é aplicada em apenas um gene, escolhido aleatoriamente dentro do cromossomo.

Formalmente:

$$
\Phi_{\mathrm{i}}=\mathbf{X}^{\prime} \rightarrow \mathrm{S}_{\mathrm{i}, \mathrm{g}+1}=\mathrm{S}_{\mathrm{i}, \mathrm{g}} ; \mathrm{E}_{\mathrm{y}}=\boldsymbol{\omega} \text {, sendo } 0<\mathrm{y} \leq \mathrm{n}
$$

Onde y é uma posição casual dentro do cromossomo que identifica o gene a ser alterado. Tal informação é ilustrada na Figura 5.17 [Holland (1975), Koza (1994), Goldberg (1989) e Flake (1998)].

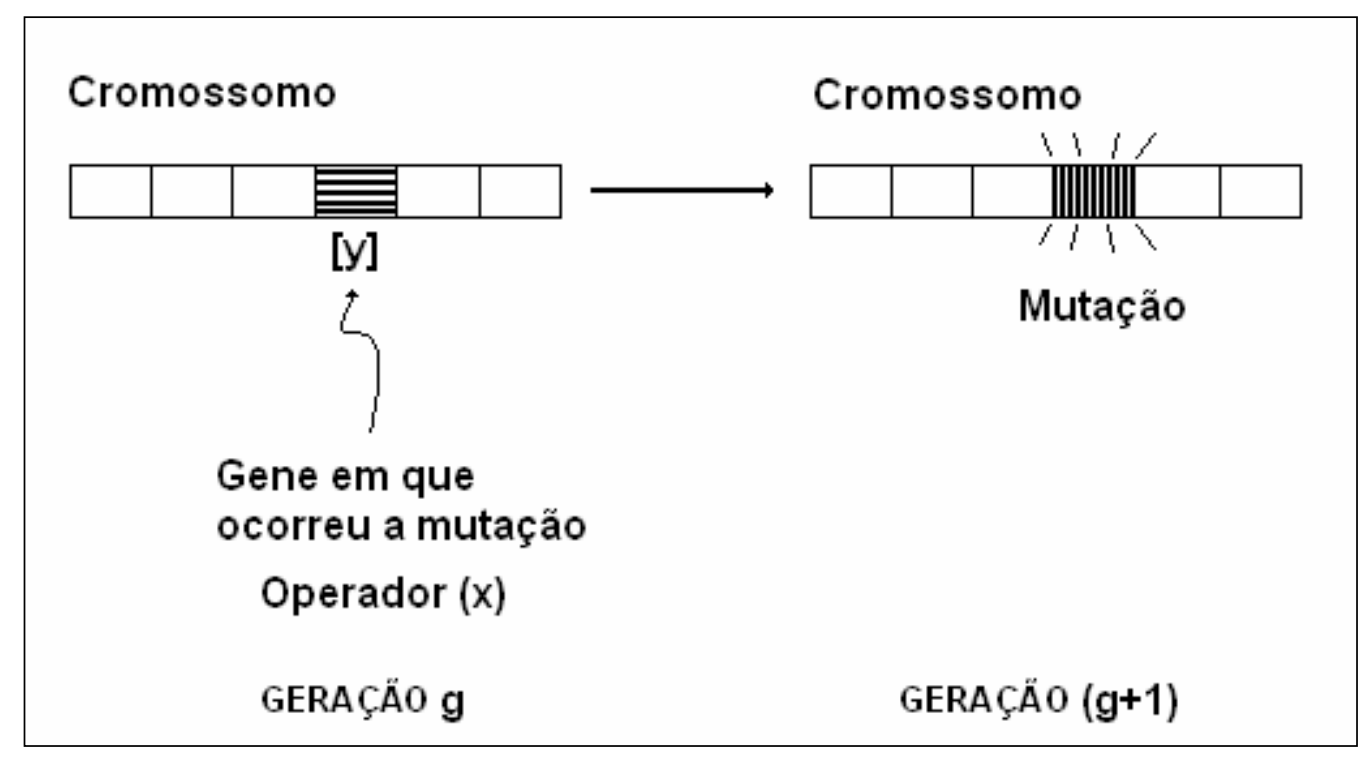

Figura 5.17 - Operador mutação

\section{- Descarte}

Os indivíduos selecionados por este operador não farão parte da próxima geração, pois serão descartados, conforme indica a Figura 5.18 [Mishra et al. (2007), Hetem et al. (2007), Flake (1998) e Goldberg (1989)].

Formalmente:

$$
\Phi_{\mathrm{i}=} \mathbf{\prime}^{\prime} \mathbf{k}^{\prime} \rightarrow \mathbf{S}_{\mathrm{i}, \mathrm{g}} \notin \mathbf{P}_{\mathrm{g}+1}
$$

Onde $P_{g+1}$ é a $(g+1)$-ésima geração. 


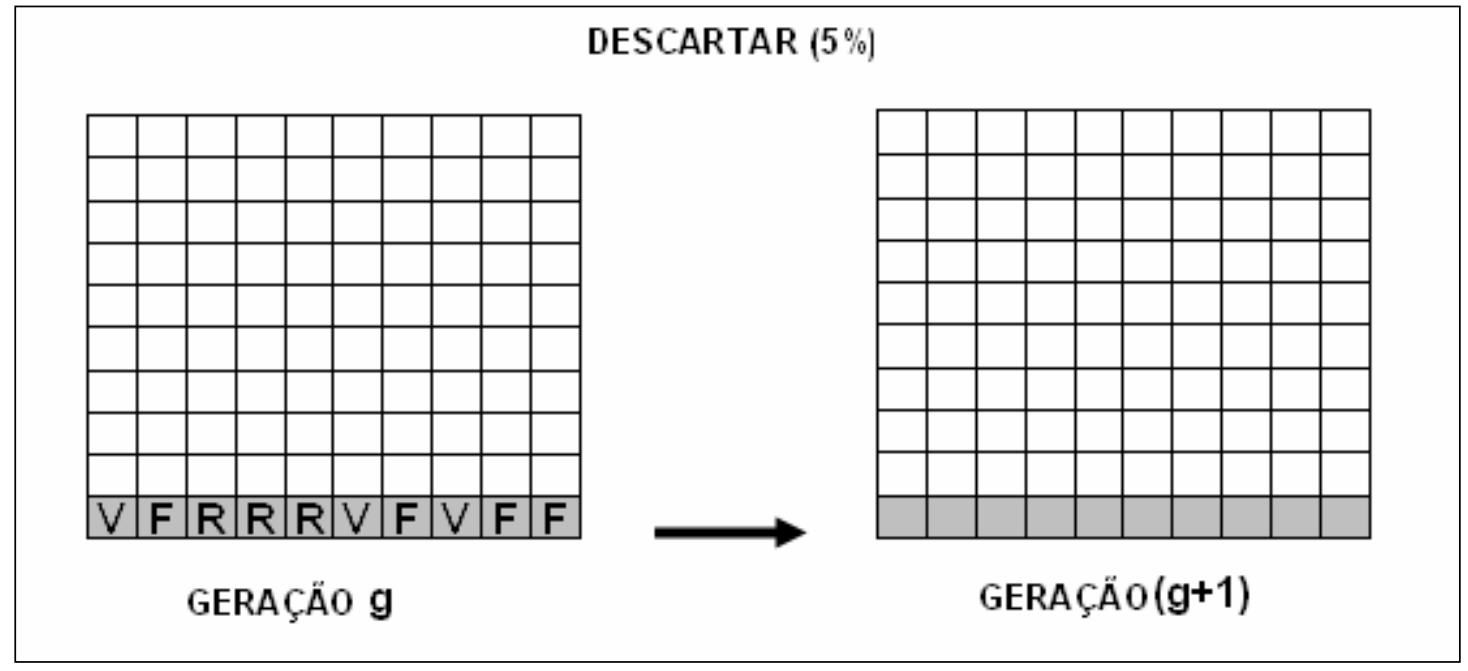

Figura 5.18 - Operador descarte

\subsubsection{Julgador}

A função Julgador classifica os cromossomos em ordem crescente, considerando o fator de fitness (Figura A.9, do Anexo A).

Uma vez que os cromossomos estejam ordenados em ordem crescente de ff, associa-se a cada um deles o operador genético correspondente.

\begin{tabular}{|c|c|c|}
\hline \multicolumn{3}{|c|}{$\begin{array}{l}\text { Geração } \\
\text { Ger ff Cromossomo }\end{array}$} \\
\hline \multicolumn{3}{|c|}{ 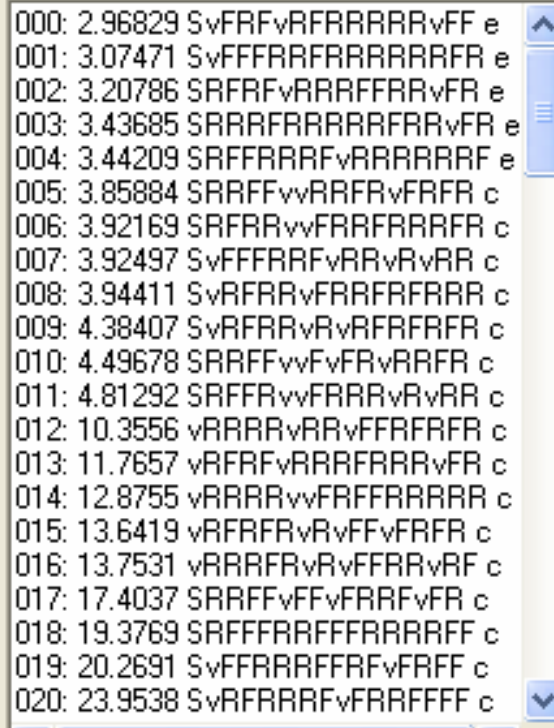 } \\
\hline$<$ & $>$ & \\
\hline
\end{tabular}

Figura 5.19 - Exemplo de cromossomos com operadores genéticos alocados

O operador genético baseia-se nas regras definidas para o AG e seus percentuais, de acordo com a Tabela 5.6 [Koza (1994), Bentley (2002) e Cormen et al. (2002)], sendo que o melhor indívíduo é aquele com o menor ff. 
Tabela 5.6 - Equipamentos alocados, fator de fitness e operadores genéticos - mutação $(x)$ em destaque

\begin{tabular}{|c|c|c|}
\hline Indivíduo & ff & $\Phi_{\mathrm{i}}$ \\
\hline RRFFRRFRFFvFRRF e & 2,75359 & e \\
\hline RFRFvRFRRFRFvRF e & 2,85235 & e \\
\hline RRRRRRRRRFRFvFR e & 3,28358 & e \\
\hline vRFRvRRRRRvRRFR e & 3,82877 & e \\
\hline vFFRRRRvFRvRvFR e & 3,88005 & e \\
\hline RRRRRvFRFRRRvFR c & 4,13604 & c \\
\hline vRRFRvFvFRRFvRF c & 4,43001 & c \\
\hline RRFRvvFvFRvRvFF c & 4,63326 & c \\
\hline vFFRRvRRFRvRvRR c & 4,97981 & c \\
\hline vFRRRvFvFFvRRRR c & 5,18182 & c \\
\hline RFRRvRRvRRvRRFF c & 12,0635 & c \\
\hline RFRFvvRRFFRFRRR c & 12,8989 & c \\
\hline RFFRRvFvFRvFRFR c & 13,4428 & c \\
\hline vFFRRFFvRRRFRFF c & 15,2217 & $\mathbf{c}$ \\
\hline vFRFvFRvRFRFRFR c & 19,1759 & c \\
\hline vFFRRFRRFFRRvFR c & 21,7799 & $\mathbf{c}$ \\
\hline vFFRRFFvFFRRRFR c & 22,7296 & c \\
\hline vFFRvRFFFRvFvFF c & 23,1888 & c \\
\hline vFFFvFFRRFRFvRR c & 23,7177 & c \\
\hline vFRFRRRvFRRFRFR c & 25,3394 & c \\
\hline RFRRRRRvRFFRvRR c & 27,3085 & c \\
\hline vRRFRvFvFRvFvRF c & 28,0441 & c \\
\hline RRRRvFFRRFRRvRF $x$ & 28,725 & $x$ \\
\hline vFFFRFFRFRvFvRR c & 28,8522 & c \\
\hline vFFRvRFFFFvRvFR c & 29,2215 & c \\
\hline vFRRvFFRRFvRvFR c & 30,3874 & c \\
\hline vFRRRRRFRFRRRFR c & 31,0363 & c \\
\hline vRFRvvFFRRvFRRF c & 33,3835 & c \\
\hline vRFRvvRRRFFFvFR c & 33,9619 & $\mathbf{c}$ \\
\hline vFFRvRFRFRRRvRR c & 34,2825 & c \\
\hline vFRRvRRRRRvFFFF c & 34,4484 & c \\
\hline RFRFRvFRFRvRFRF c & 36,1618 & c \\
\hline RFFFvvRvRFFFvRF c & 37,0132 & $\mathbf{c}$ \\
\hline vFFRRvRRRRvFFFR c & 38,5879 & c \\
\hline RRFRRvRRFRvRFRF c & 39,4119 & c \\
\hline RFRFvvRvFRFFvRF c & 40,5285 & c \\
\hline vRFRvRFRRFvFRFR c & 43,7436 & c \\
\hline vRFFRvFvRRFRRRR c & 45,2672 & c \\
\hline vFRFvvFRFFRFRFR c & 49,4218 & c \\
\hline RRFFvRFRFRRRFFR c & 92,5474 & c \\
\hline RRRFvFFRRRvFvFF c & 92,5623 & c \\
\hline RRRRRRRRFFFRRFF c & 93,4191 & c \\
\hline RRRRvRFRRRFRRFF c & 95,2882 & c \\
\hline RFFFvRRRFFRRFFF c & 98,3168 & c \\
\hline
\end{tabular}

\begin{tabular}{|c|c|c|}
\hline Indivíduo & ff & $\Phi_{\mathrm{i}}$ \\
\hline RFFRRvRFRRvFRRF c & 118,905 & c \\
\hline RRRFRvRvFFFFvFR c & 120,687 & c \\
\hline RRRRRvFvFRFFvRF c & 121,534 & c \\
\hline RFRRRvFRFRvRFRR c & 124,019 & $\mathbf{c}$ \\
\hline RRRFRFRRFFRFFRF c & 150,398 & c \\
\hline vRFRvFFRFFFFvFR c & 163,086 & c \\
\hline vFFRvRRFFFFFvRR c & 209,657 & $\mathbf{c}$ \\
\hline vRRRRFRvRFRRvRR c & 222,595 & $\mathbf{c}$ \\
\hline vFRRRvRRRFRFFFR c & 237,452 & $\mathbf{c}$ \\
\hline vRFRRRRFFRRFvFR c & 238,53 & $\mathbf{c}$ \\
\hline vFFRRFRvFRRRvRF c & 241,225 & c \\
\hline vRRRRvFvFFvRFRR c & 247,179 & c \\
\hline vRRFRvFFRRFFvRF c & 256,886 & c \\
\hline vRFFRvRFRFvFRRF c & 279,299 & c \\
\hline vFFFRvRvFFvFFFF c & 294,435 & c \\
\hline vFRFvFRFRFvRvRR c & 311,969 & $\mathbf{c}$ \\
\hline vFRFvRRRFRFFvFF c & 350,111 & c \\
\hline RFFRvvFvRFFRFFR c & 363,976 & c \\
\hline vRRRvFRvFRvFRFF c & 426,123 & $\mathbf{c}$ \\
\hline vFRFvvRRRRRRFRF c & 476,091 & c \\
\hline vFFRvvRRFRFRRRF c & 487,063 & $\mathbf{c}$ \\
\hline vFFRvvFvRRRRFFR c & $608,7 \mathrm{v}$ & $\mathbf{c}$ \\
\hline vFRRvvRvRFvRFRR c & 683,876 & $\mathbf{c}$ \\
\hline RFFFvFRFFRRFRFR c & 800,429 & $\mathbf{c}$ \\
\hline RFFFvvRFRFFFRRF c & 1095,79 & c \\
\hline RFRRRvRFFRFFvFR c & 1097,15 & $\mathbf{c}$ \\
\hline vRFFRFFvFFFRFRR c & 1305,64 & c \\
\hline vRFRRFFFRRvFFFR c & 1862,64 & c \\
\hline vRRRRFFvFRvFFRF c & 2014,61 & $\mathbf{c}$ \\
\hline vRRFRFRvRRFRRFF c & 2122,21 & c \\
\hline vFFRvRRFFFFRFFR c & 2134,37 & $\mathbf{c}$ \\
\hline vRRFRRFFRRFFvFR c & 2229,72 & c \\
\hline vRRRvFRFFRFFRRF c & 2243,44 & c \\
\hline vFRFRRFFFFvRFRR c & 2363,69 & $\mathbf{c}$ \\
\hline vFRFRFRFRRRRvRR c & 2455,35 & c \\
\hline vRRFRvFFFFFRRRR c & 2519,15 & $\mathbf{c}$ \\
\hline vFFRvvFFFRFFFFR c & 2573,86 & c \\
\hline vFRFRvFvRRFRFFF c & 2692,46 & $\mathbf{c}$ \\
\hline vFRRvRFFFRFFvFF c & 3124,89 & $\mathbf{c}$ \\
\hline vFFFvRRFFRFRvRR c & 3441,89 & c \\
\hline vRFFvRRRFFFRFRF c & 3453,85 & $\mathbf{c}$ \\
\hline vFFRvRFFRRvRFRF c & 4122,6 & $\mathbf{c}$ \\
\hline vRFFvFFvRRvRFRR c & 4553,41 & c \\
\hline vRRFvFFFRRvFvFR c & 6348,49 & c \\
\hline
\end{tabular}




\begin{tabular}{|c|c|c|}
\hline Indivíduo & ff & $\Phi_{\mathrm{i}}$ \\
\hline RFRFvRRRFRFFvRF c & $102,5 \mathrm{v}$ & $\mathrm{c}$ \\
\hline RRFRRFFRRRvRvFR c & 103,642 & $\mathrm{c}$ \\
\hline RFFFRRRFFRRRvRF c & 104,274 & $\mathrm{c}$ \\
\hline RFRFRvFFRRRRvFF c & 105,646 & $\mathrm{c}$ \\
\hline RRRRvRRRFFFRRRR c & 111,369 & $\mathrm{c}$ \\
\hline RRRRvvRRRRFRvRR c & 116,088 & $\mathrm{c}$ \\
\hline
\end{tabular}

\begin{tabular}{|c|c|c|}
\hline Indivíduo & ff & $\Phi_{\mathrm{i}}$ \\
\hline RFFRRFFFFRFRvRR c & 7546,03 & $\mathrm{c}$ \\
\hline RFRFRFRFRRFFvFR k & 7886,14 & k \\
\hline RFFFRFRFRFvRFRR k & 8284,96 & k \\
\hline RFFRvvFFRRFRFFF k & 9731,22 & k \\
\hline vFRRRFFRFFFFFFR k & 20409,7 & k \\
\hline vFFFvFFFFRFFRRF k & 37717,9 & k \\
\hline
\end{tabular}

A Tabela 5.6 contém exemplos de cromossomos com seus respectivos fatores de fitness e os operadores genéticos associados. Destaca-se o indivíduo que sofrerá mutação.

A equação 5.13 representa formalmente a escolha do operador genético:

$$
\Phi_{i}=\left\{\begin{array}{l}
\text { 'e' se } i \leq N^{*} f_{e} \\
\text { 'c' se } N^{*} f_{e}<i \leq N^{*} f_{c} \\
\text { 'x' para } N^{\star} f_{x} \text { indivíduos com } N^{\star} f_{e}<i \leq N^{\star} f_{c} \\
\text { 'k' se } i \geq N^{*}\left(1-f_{k}\right)
\end{array}\right.
$$

Onde,

- i é o índice do indivíduo;

- $\mathrm{N}$ é o número total de cromossomos.

Os parâmetros de controle do método foram adotados conforme:

- $\mathrm{f}_{\mathrm{e}}=5 \%$ - fração a ser copiada para a próxima geração;

- $\mathrm{f}_{\mathrm{c}}=89 \%$ - fração candidata a crossover,

- $\mathrm{f}_{\mathrm{x}}=1 \%$ - fração de mutações;

- $\mathrm{f}_{\mathrm{k}}=5 \%$ - fração a ser descartada.

De acordo com a filosofia do método AG, sempre existe a convergência. Afirma-se também que a eficiência pode ser otimizada mediante alterações do conjunto de parâmetros de controle. Os valores adotados para os operadores baseiamse em Hetem et al. (2007), Flake (1998) e Goldberg (1989). 


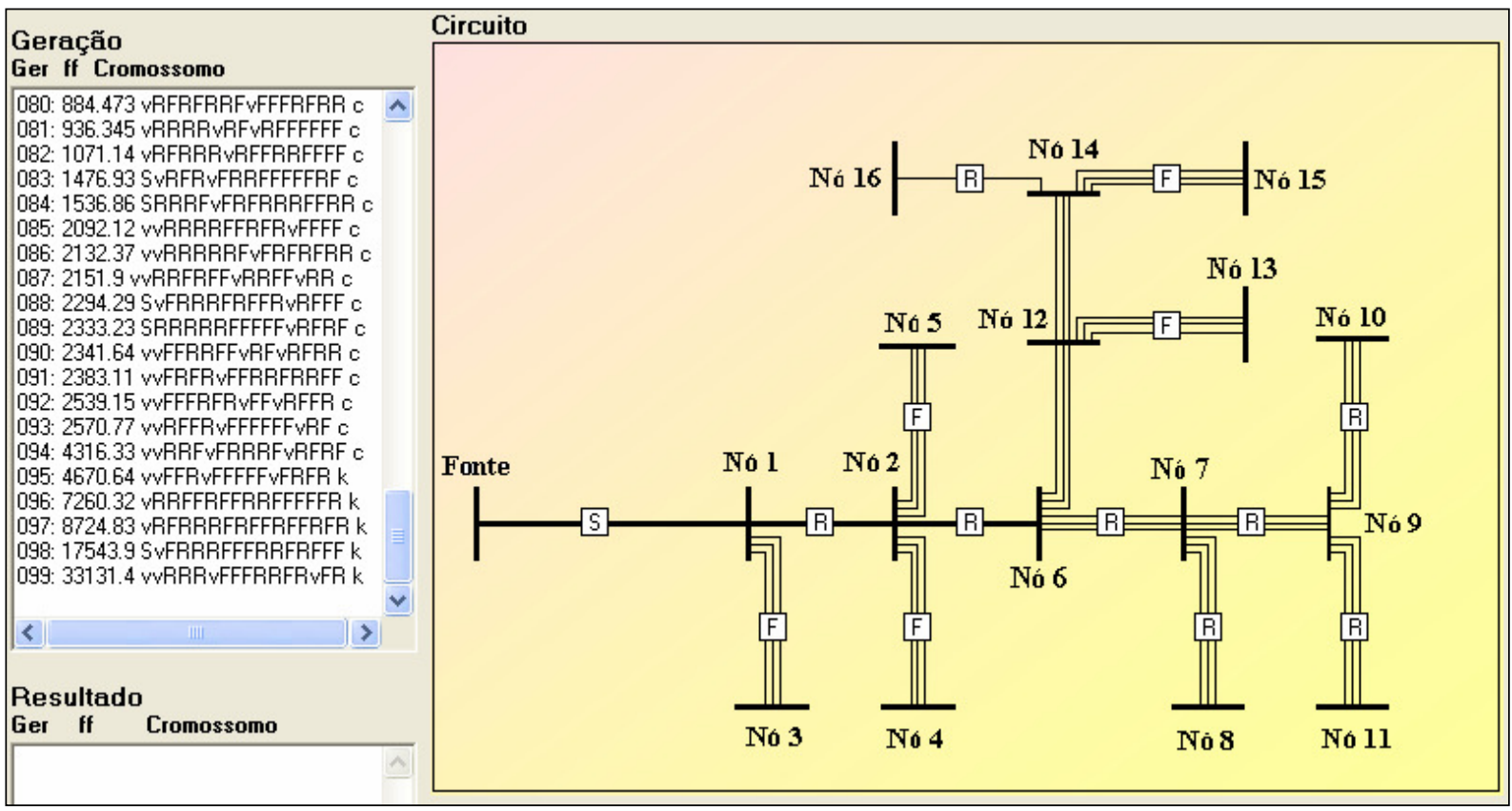

Figura 5.20 - Função Julgador: alocação de equipamentos de acordo com o melhor indivíduo

\subsubsection{Executor}

A próxima geração será criada a partir dos indivíduos atuais e da aplicação dos operadores genéticos determinados pela função Julgador. Esta ação é realizada pelo função Executor:

I - Os indivíduos marcados com o operador "cópia" serão reproduzidos, sem nenhuma alteração, para a próxima geração;

II - O operador crossover combina, aleatoriamente, os parâmetros de dois diferentes indivíduos;

III - Caso o operador seja mutação, um dos genes do indivíduo é alterado casualmente;

IV - Os indivíduos aos quais foram atribuídos o operador descarte não serão considerados para a geração seguinte.

Completando-se uma nova geração, o programa repete os passos descritos. O método continua criando novas gerações até que a condição final otimizada seja alcançada (veja Figura 3.3, no Capítulo 3 deste estudo).

O programa TEIAG realiza automaticamente um conjunto definido de iterações completas. 


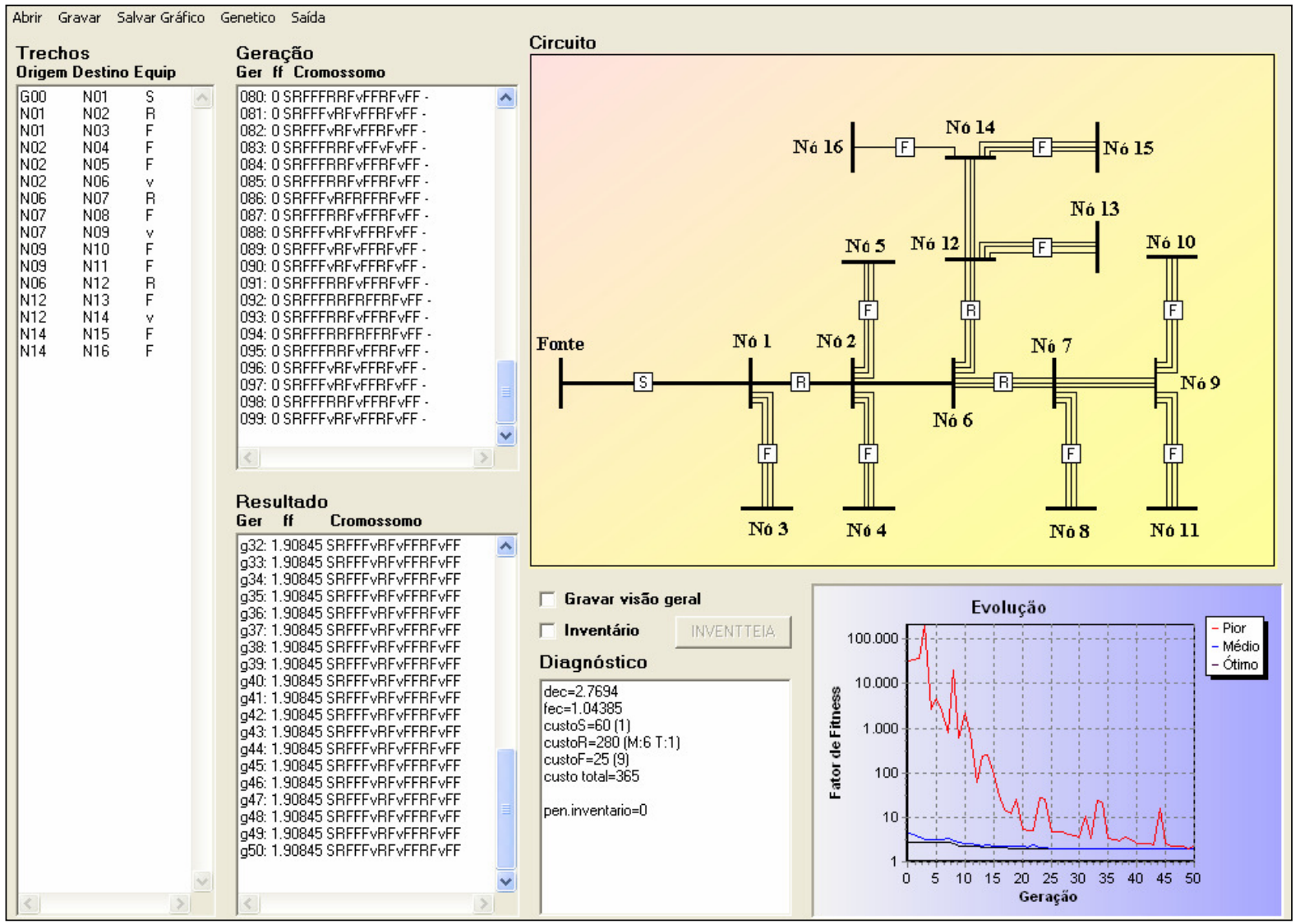

Figura 5.21 - Tela do programa TEIAG após um conjunto definido de iterações completas

Os campos apresentados para análise são:

- Resultado;

- Circuito;

- Diagnóstico;

- Evolução.

O campo Resultado apresenta os melhores indivíduos de cada geração (Tabela 5.7).

Tabela 5.7 - Melhor indivíduo ao longo de 50 gerações

\begin{tabular}{|c|c|c|}
\hline Geração & Fator de Fitness & Cromossomo \\
\hline g1: & 2,57207 & SvFFFvRFRFRRFRFR \\
\hline g2: & 2,57207 & SvFFFvRFRFRRFRFR \\
\hline g3: & 2,57207 & SvFFFvRFRFRRFRFR \\
\hline g4: & 2,57207 & SvFFFvRFRFRRFRFR \\
\hline g5: & 2,57207 & SvFFFvRFRFRRFRFR \\
\hline g6: & 2,57207 & SvFFFvRFRFRRFRFR \\
\hline g7: & 2,57207 & SvFFFvRFRFRRFRFR \\
\hline g8: & 2,35994 & SvRFFRRFvRFvFRFF \\
\hline g9: & 2,13805 & SRRFFRRFvRFRFRFF \\
\hline g10: & 2,13805 & SRRFFRRFvRFRFRFF \\
\hline g11: & 2,13805 & SRRFFRRFvRFRFRFF \\
\hline g12: & 2,13805 & SRRFFRRFvRFRFRFF \\
\hline g13: & 2,13805 & SRRFFRRFvRFRFRFF \\
\hline g14: & 2,12741 & SvFFRvRFRFFRFvFF \\
\hline g15: & 1,90845 & SRFFFvRFvFFRFvFF \\
\hline g16: & 1,90845 & SRFFFvRFvFFRFvFF \\
\hline
\end{tabular}




\begin{tabular}{|c|c|c|}
\hline Geração & Fator de Fitness & Cromossomo \\
\hline g17: & 1,90845 & SRFFFvRFvFFRFvFF \\
\hline g18: & 1,90845 & SRFFFvRFvFFRFvFF \\
\hline g19: & 1,90845 & SRFFFvRFvFFRFvFF \\
\hline g20: & 1,90845 & SRFFFvRFvFFRFvF \\
\hline g21: & 1,90845 & SRFFFvRFvFFRFvFF \\
\hline g22: & 1,90845 & SRFFFvRFvFFRFvFF \\
\hline g23: & 1,90845 & SRFFFvRFvFFRFvFF \\
\hline g24: & 1,90845 & SRFFFvRFvFFRFvFF \\
\hline g25: & 1,90845 & SRFFFvRFvFFRFvFF \\
\hline g26: & 1,90845 & SRFFFvRFvFFRFvFF \\
\hline g27: & 1,90845 & SRFFFvRFvFRFvFF \\
\hline g28: & 1,90845 & SRFFFvRFvFFRFvFF \\
\hline g29: & 1,90845 & SRFFFvRFvFFRFvFF \\
\hline g30: & 1,90845 & SRFFFvRFvFFRFvFF \\
\hline g31: & 1,90845 & SRFFFvRFvFFRFvFF \\
\hline g32: & 1,90845 & SRFFFvRFvFFRFvFF \\
\hline g33: & 1,90845 & SRFFFvRFvFFRFvFF \\
\hline g34: & 1,90845 & SRFFFvRFvFFRFvFF \\
\hline g35: & 1,90845 & SRFFFvRFvFRFvFF \\
\hline g36: & 1,90845 & SRFFFvRFvFFRFvFF \\
\hline g37: & 1,90845 & SRFFFvRFvFFRFvFF \\
\hline g38: & 1,90845 & SRFFFvRFvFFRFvFF \\
\hline g39: & 1,90845 & SRFFFvRFvFFRFvFF \\
\hline g40: & 1,90845 & SRFFFvRFvFFRFvFF \\
\hline g41: & 1,90845 & SRFFFvRFvFFRFvFF \\
\hline g42: & 1,90845 & SRFFFvRFvFFRFvFF \\
\hline g43: & 1,90845 & SRFFFvRFvFFRFvFF \\
\hline g44: & 1,90845 & SRFFFvRFvFRFvFF \\
\hline g45: & 1,90845 & SRFFFvRFvFFRFvFF \\
\hline g46: & 1,90845 & SRFFFvRFvFFRFvFF \\
\hline g47: & 1,90845 & SRFFFvRFvFFRFvFF \\
\hline g48: & 1,90845 & SRFFFvRFvFFRFvFF \\
\hline g49: & 1,90845 & SRFFFvRFvFFRFvFF \\
\hline g50: & 1,90845 & SRFFFvRFvFFRFvFF \\
\hline & & \\
\hline
\end{tabular}

A Tabela 5.7 revela que o cromossomo apresentado em g50 corresponde ao melhor indivíduo entre as gerações. O campo Circuito apresenta a configuração de alocação de equipamentos do melhor indivíduo da última geração. Consideram-se as regras de alocação de equipamentos, identificadas no capítulo 4 deste trabalho, e o custo.

Dessa forma, chega-se ao circuito representado na Figura 5.22. 


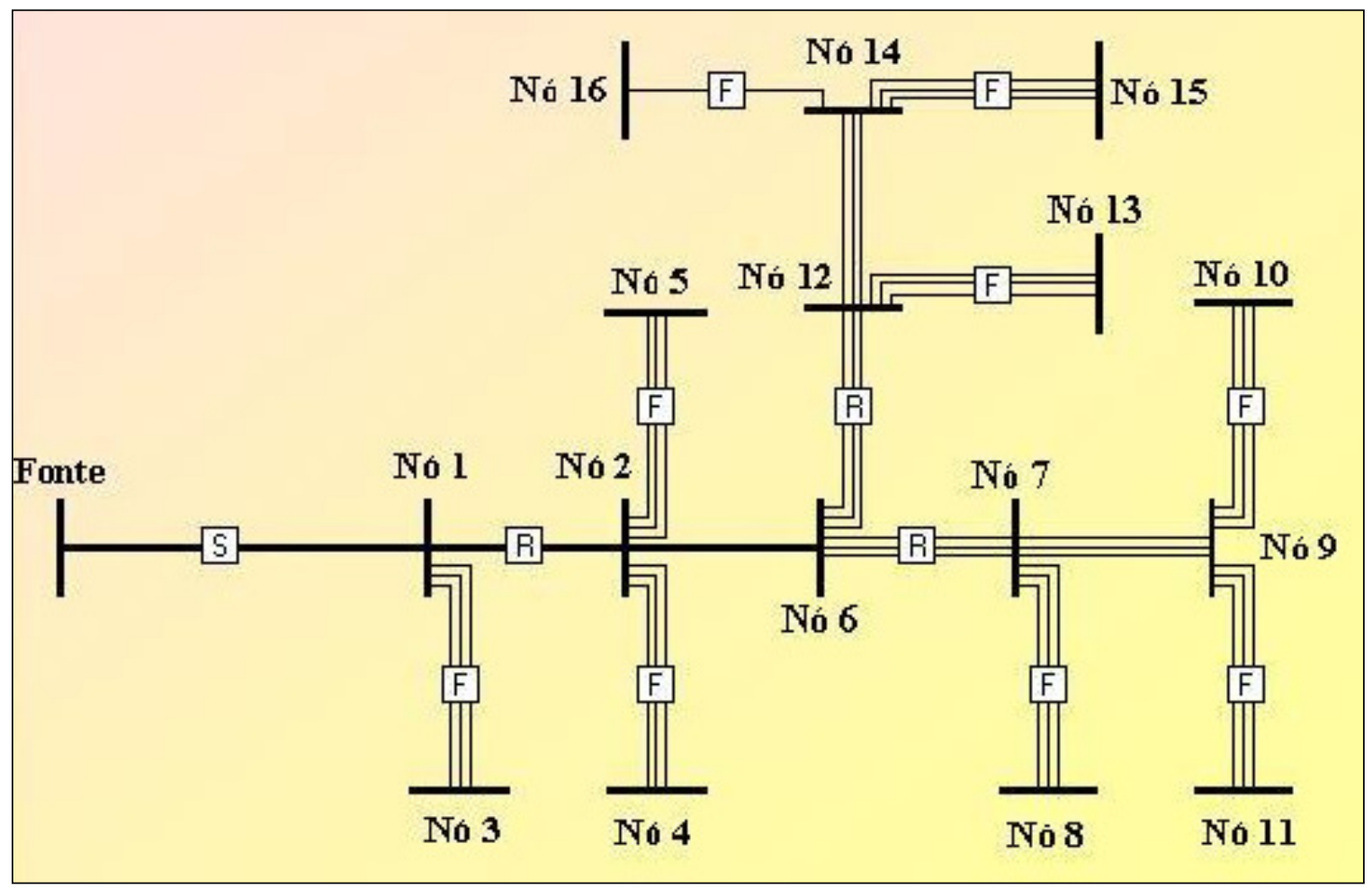

Figura 5.22 - Circuito com a solução otimizada

O campo Diagnóstico apresenta os valores de DEC, FEC, CustoS (Disjuntor da Subestação), CustoR (Religador), CustoF (Fusível), Custo Total da solução final e uma informação de penalidade, que será utilizada pelo programa INVENTTEIA (Figura 5.23).

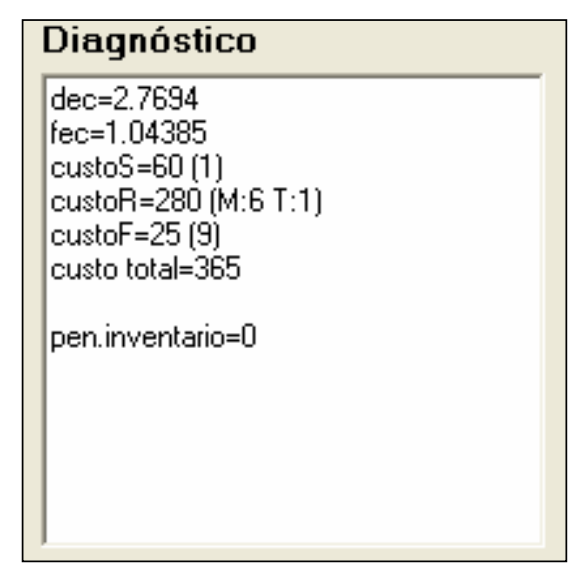

Figura 5.23 - Campo Diagnóstico

O campo Evolução, na Figura 5.24, representa graficamente a variação do ff ao longo das gerações. Os "máximos locais", na linha do pior indivíduo, correspondem a mutações inapropriadas para a geração vigente. 


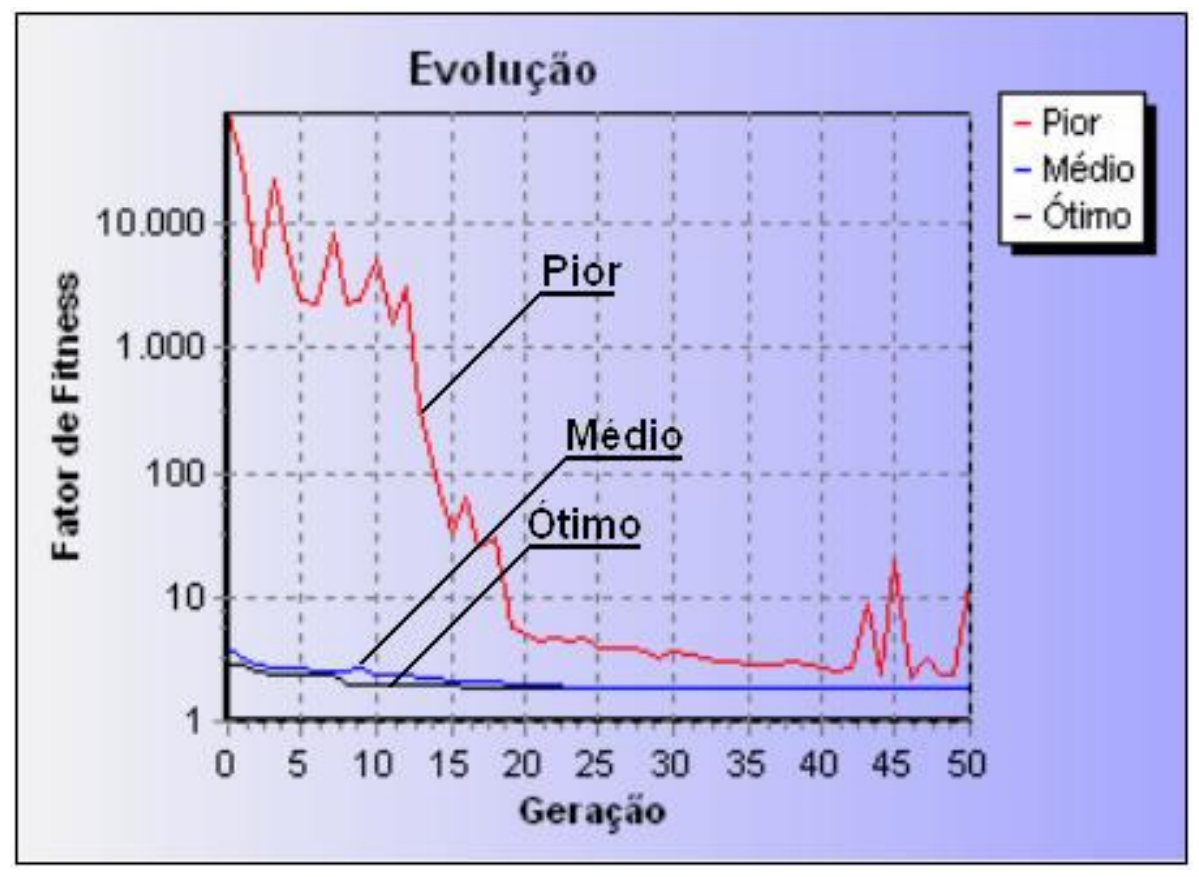

Figura 5.24 - Campo Evolução

Um detalhe de determinada região deste gráfico (Figura 5.24) foi representado na Figura 5.25.

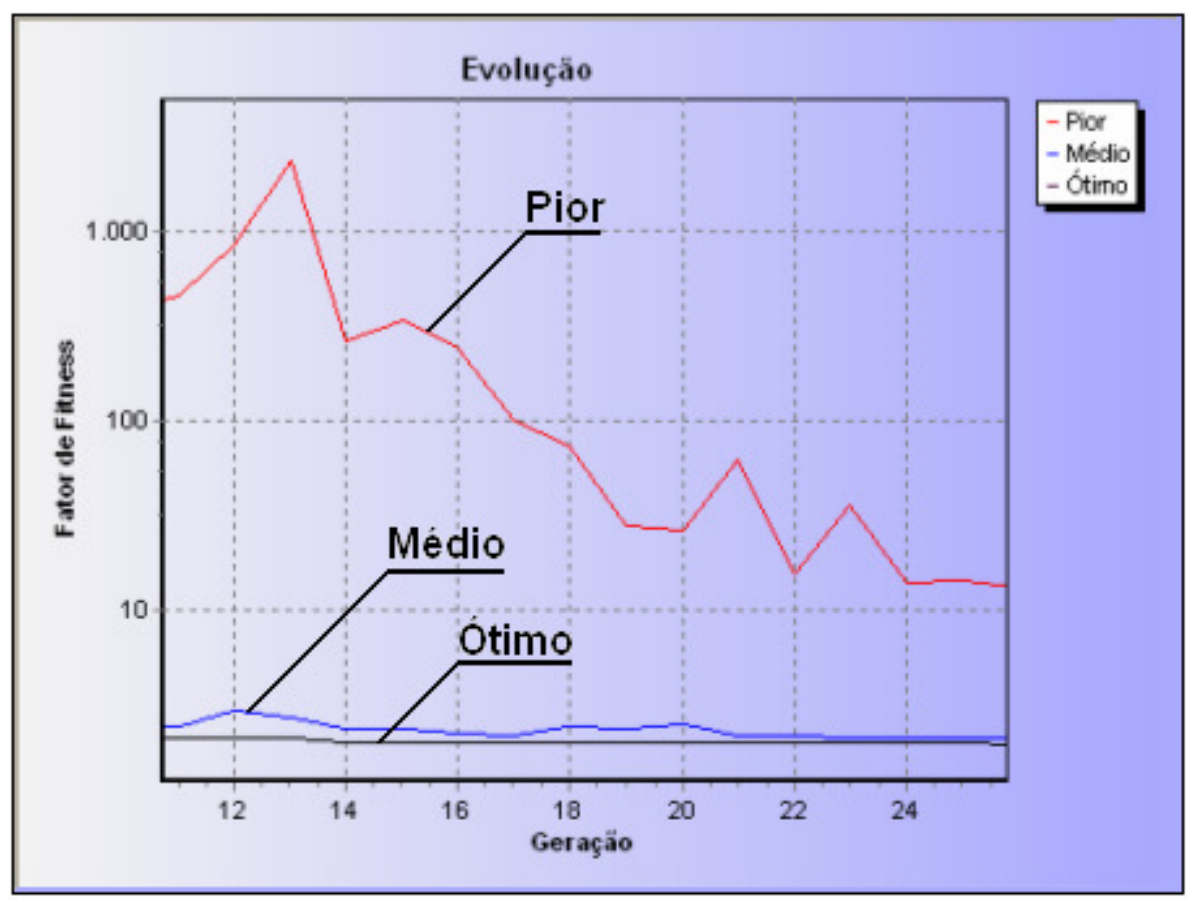

Figura 5.25 - Extrato de uma sequência evolutiva gerada pelo programa TEIAG

O modelo de representação da Figura 5.24 também foi adotado por Mishra et al. (2007) - Figura 3, Capítulo 3 do presente estudo - e Billington et al. (1996) - Figura 5, Capítulo 5. 


\subsubsection{Critérios de parada das iterações}

Existem dois critérios de parada das interações:

- número de iterações;

- precisão.

Os critérios podem ser definidos e configurados, de acordo com o problema a ser analisado, ocorrendo a mudança de parâmetros diretamente no aplicativo.

O programa TEIAG pode funcionar com os dois critérios; é capaz de processar informações até atingir um valor preestabelecido. Este é definido pela precisão ou por um número fixo de gerações, como foi mencionado.

\subsection{Programa CONTITEIA}

O programa CONTTEIA lê um arquivo com o histórico das contingências relativas ao circuito, ou seja, com todas as ocorrências registradas (Figura 5.26).

A linguagem utilizada para descrever o histórico das contingências oferece os seguintes comandos:

- Contingência (identificador): indica o número da contingência;

- Falha (trecho): interrompe o trecho com uma chave-de-manobra "Normalmente Aberta" e sinaliza "O" (OPEN) no circuito (Figura 5.27). Expressa o evento ocorrido no trecho;

- Corte (trecho): indica corte de um trecho, após a falha;

- Duração (minutos): informa o tempo de duração do estágio corrente da contingência, calcula o DIC, FIC e DMIC para todos os nós e atualiza as informações de tela;

- Fecha-trecho (trecho): fecha o circuito no trecho indicado, sinaliza equipamento de proteção com "C" (CLOSE) e atualiza as informações de tela;

- Fim: finaliza a contingência corrente. 


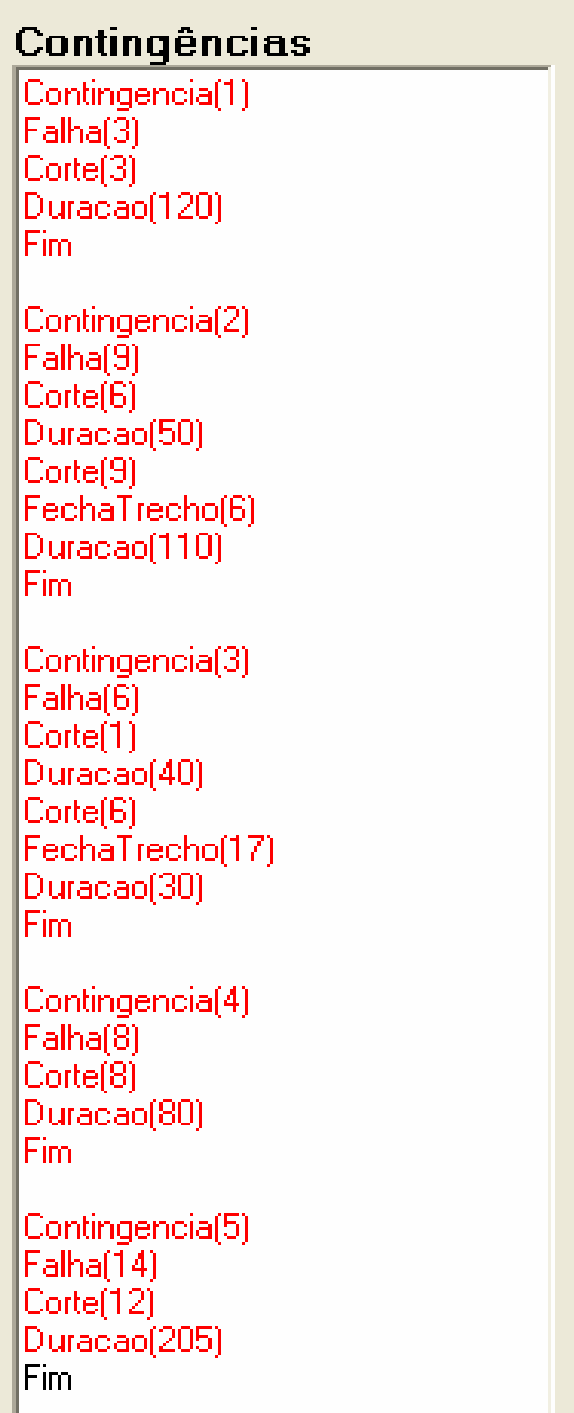

Figura 5.26 - Arquivo de entrada com histórico de contingências

No programa CONTITEIA existe um menu para percorrer o arquivo de contingências até se obterem os índices DIC, FIC e DMIC.

\subsubsection{Aplicação - CONTITEIA}

Lido o arquivo com as informações dos dispositivos alocados, representa-se o circuito, de acordo com a Figura 5.27. 


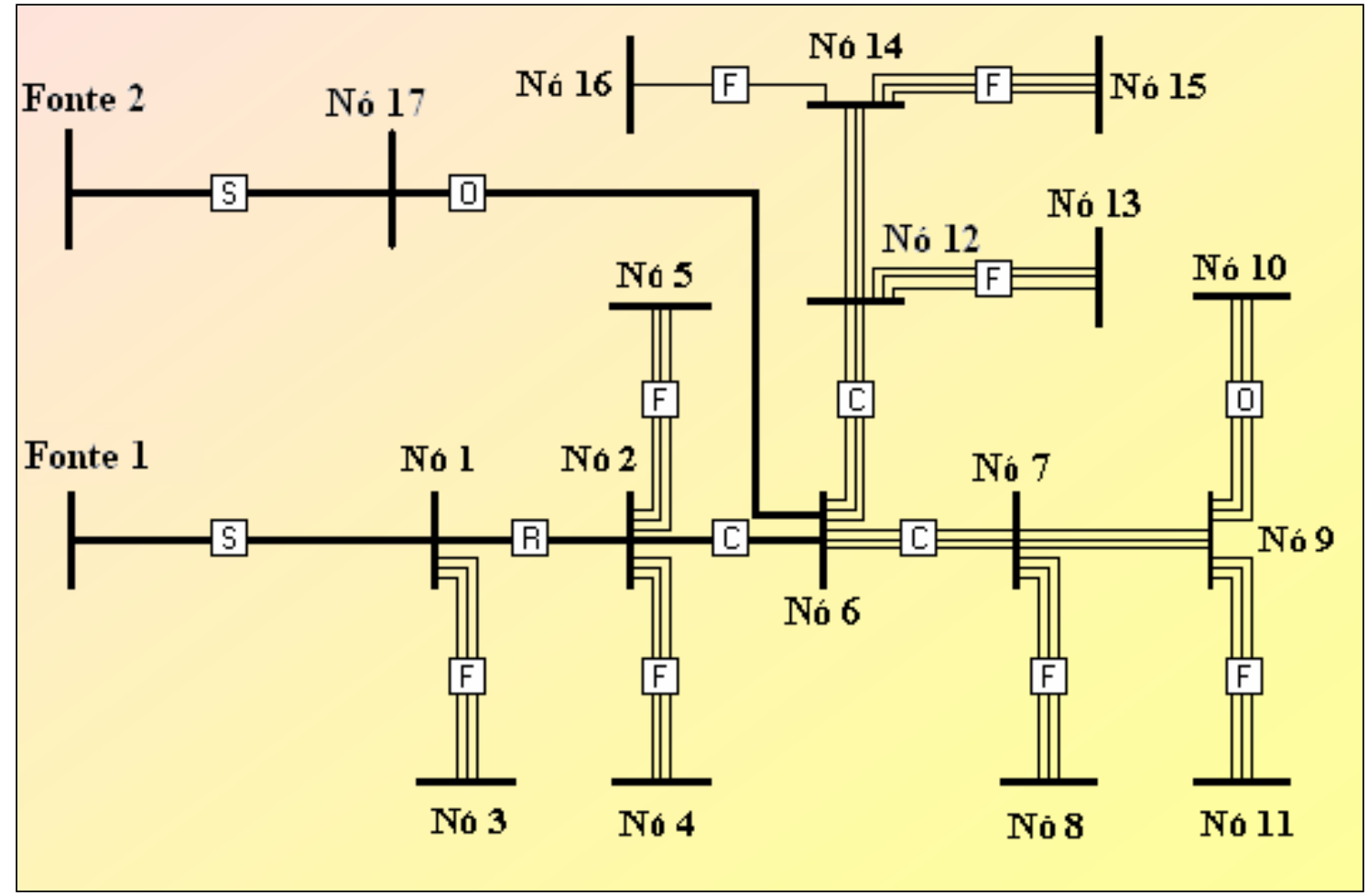

Figura 5.27 - Circuito para análise de contingências

No circuito da Figura 5.27, observa-se alguns dispositivos indicados por "C" . Eles representam chaves-de-manobra (normalmente fechadas) ou chaves-deseccionamento (NC). Há ainda outros dispositivos simbolizados por "O", representando chaves-de-seccionamento (NO). Estas podem servir como chaves-de-socorro (NO), conforme Kagan et al. (2005).

Na Figura 5.28, a chave entre os nós 6 e 17 possibilita a energização do circuito, ou parte dele, pela fonte 2. A presença dessas chaves garante que as duas fontes não entrem em contato (curto-circuito).

$\mathrm{Na}$ medida em que o programa executa o arquivo de contingências, comandos referentes a cada item do histórico são realizados. Na Figura 5.28, o programa realizou alguns comandos, indicados na cor vermelha. 


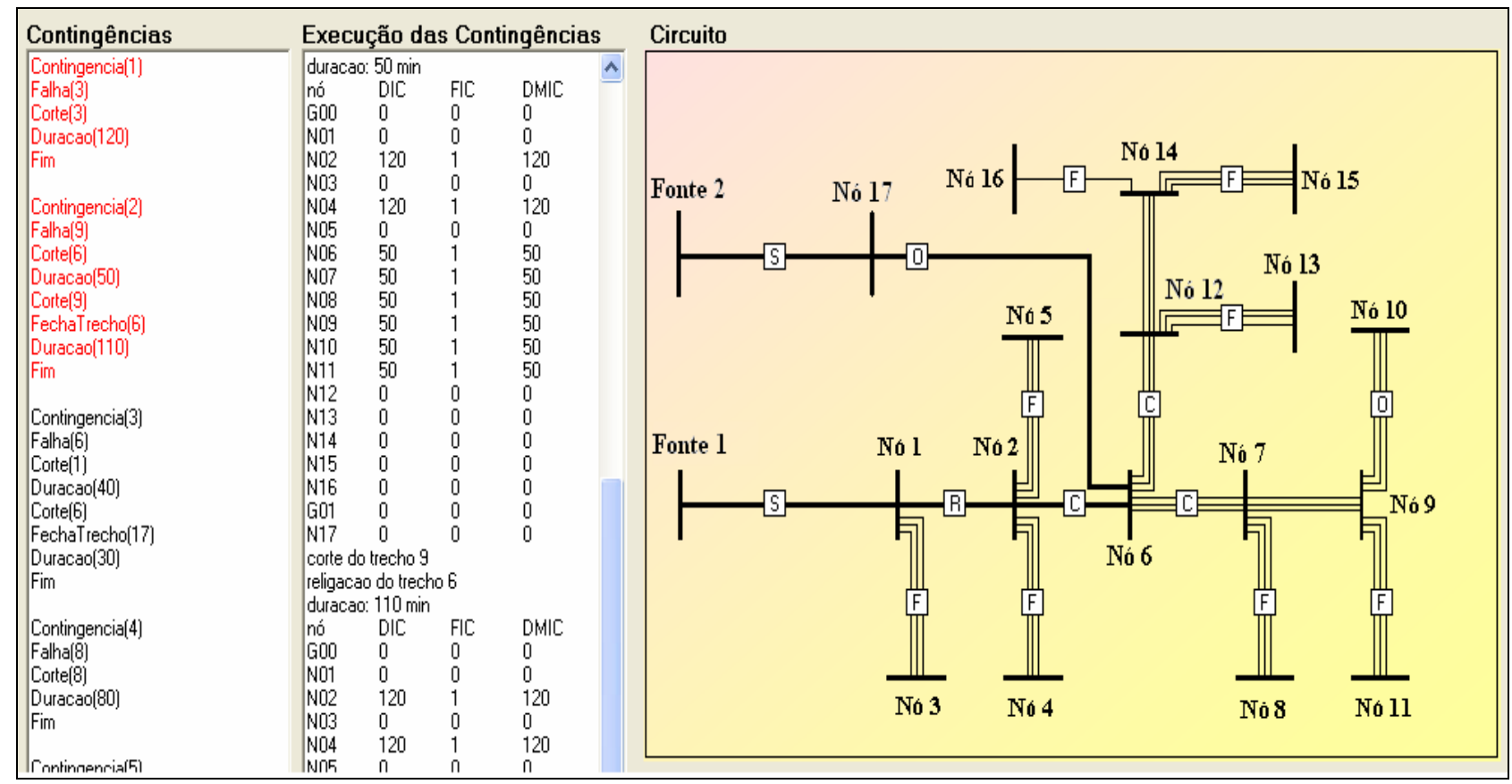

Figura 5.28 - Programa CONTTEIA após a análise de duas contingências

Após o acionamento do botão Passo, o circuito indica as alterações que refletem o ocorrido. Verifica-se que o dispositivo entre os nós 1 e 2 e a chave-demanobra entre os nós 6 e 7 se abrirão (Figura 5.29), isolando a falta.

Na Figura 5.29, observa-se o circuito com os equipamentos de proteção alocados e os valores de DIC, FIC e DMIC. Estes são calculados de acordo com as regras discutidas no capítulo 2 deste estudo.

O dispositivo entre os nós 1 e 2 continua aberto, assim como a chave-deproteção entre os nós 6 e 7. A chave entre os nós 6 e 17 mudou de estado, mudou de estado (de aberto para fechado), passando a alimentar o circuito pela fonte 2 . Destaca-se, na Figura 5.29, o estado da chave-de-proteção. 


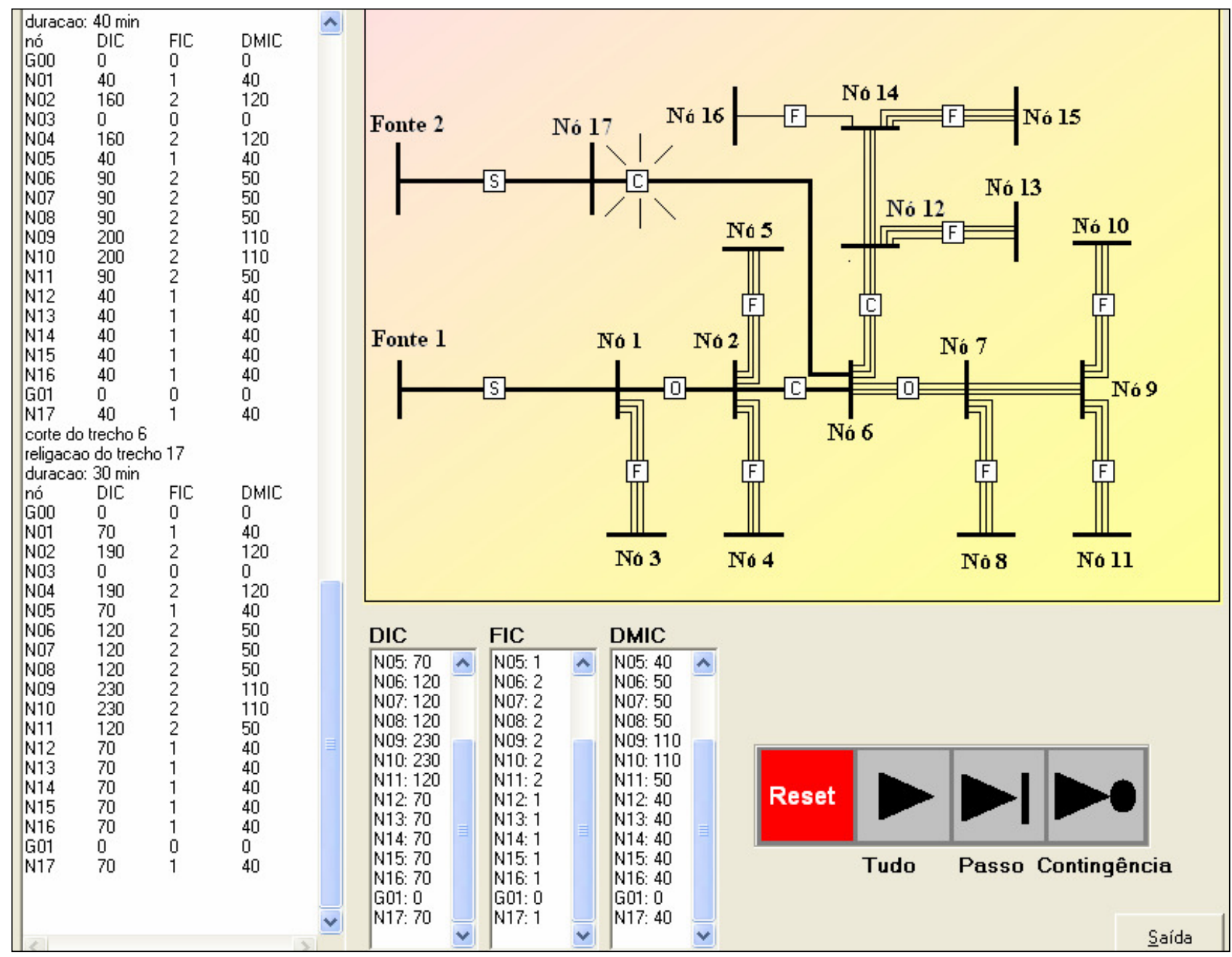

Figura 5.29 - Estado do circuito e índices resultantes do programa CONTTEIA

\subsection{Programa INVENTTEIA}

O programa INVENTTEIA possui dois campos para apresentação de circuitos: o primeiro destina-se ao circuito otimizado, resultante do programa TEIAG, e possui um setor que indica o número de equipamentos do estoque da concessionária; o segundo informa o diagnóstico de um circuito otimizado (Figura 5.30). 


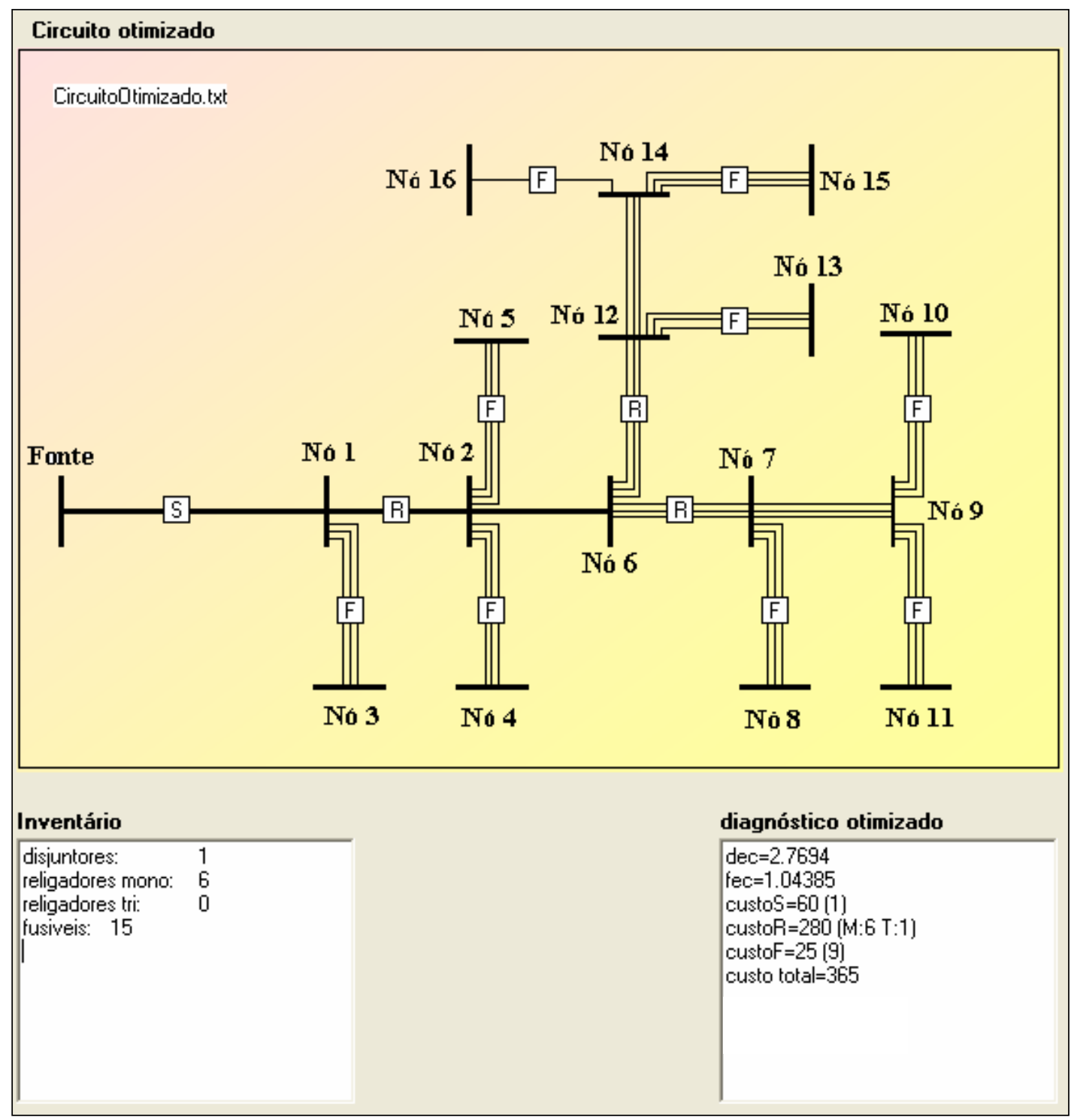

Figura 5.30 - Circuito otimizado e diagnóstico - Programa INVENTTEIA

O outro campo, ilustrado na Figura 5.31, representa o circuito resultante da análise do programa INVENTTEIA e o diagnóstico de um circuito real.

O programa INVENTTEIA obtém um circuito otimizado que considera o número de equipamentos estabelecido. Para tanto, atribui-se ao fator $\beta$, da expressão 5.6, uma parcela correspondente a uma "penalidade" para cada equipamento que exceda o estabelecido no inventário. No programa TEIAG, observa-se que $\beta=0$. 


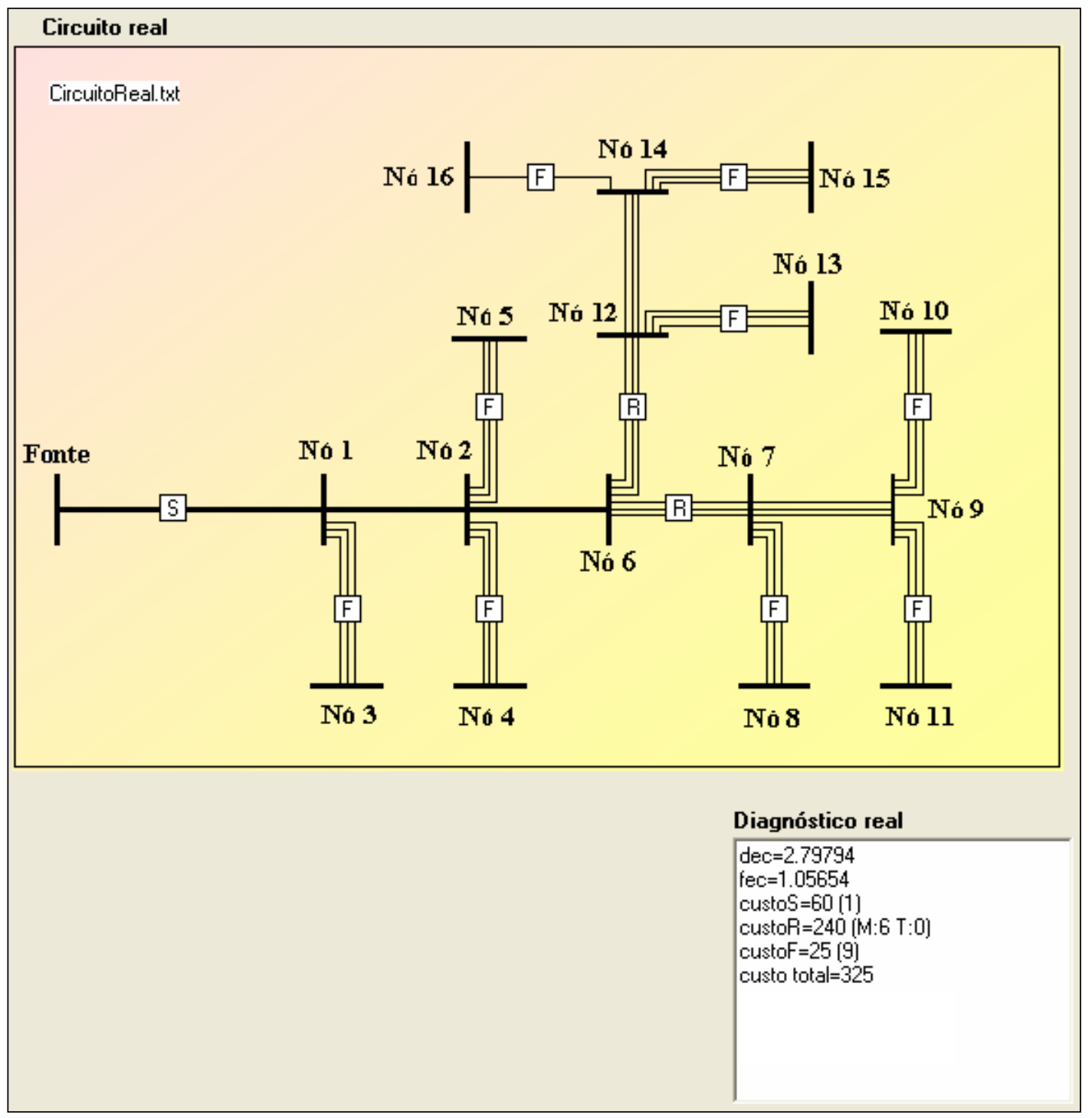

Figura 5.31 - Circuito e diagnóstico reais - Programa INVENTTEIA

\subsection{Conclusões parciais}

Neste capítulo, foi discutida a metodologia usada no desenvolvimento das soluções, baseando-se no modelo em cascata, sendo descrito cada módulo do protótipo de software utilizado.

Após a análise dos módulos, iniciou-se a construção das soluções, pela análise do AG. Foi discutida a solução de armazenamento de cromossomos, adotandose ponteiros. Abordaram-se ainda as etapas do algoritmo, a nomenclatura utilizada e a resposta de seu comportamento durante as simulações.

Detalhou-se o item referente ao fator de fitness, com a finalidade de identificar claramente qual a contribuição deste trabalho para o campo de estudo em questão. Foi desenvolvida uma metodologia para se calcularem os componentes de ff. 
Ao longo deste capítulo, desenvolveram-se soluções, em meio às especificidades do AG. Neste contexto, explorou-se um percurso desde o descritivo das aplicações e formalismo matemático até a sua convergência, de acordo com as topologias de rede de distribuição de energia elétrica apresentadas no capítulo 4. Descreveram-se ainda os programas CONTITEIA, com um exemplo de aplicação sobre um histórico de contingências, e INVENTTEIA, que realiza uma análise sobre o inventário de uma concessionária de energia elétrica. 
Capítulo 6

\section{Análise dos Resultados}

\section{Análise dos Resultados}

\subsection{Considerações gerais}

Este trabalho apresentou o desenvolvimento e a aplicação da modelagem de um problema de alocação de dispositivos de proteção. Seu objetivo foi otimizar os índices de continuidade em um sistema de distribuição de energia elétrica, proposto inicialmente por Bishop (1997). Para tal, foram desenvolvidos quatro programas aplicativos.

A análise desses programas - e de seus resultados - é objeto de discussão deste capítulo.

\subsection{Análise das topologias simuladas no programa TEIAA (modelos)}

A Tabela 6.1 resulta da análise das topologias do Capítulo 4 e de suas configurações. De acordo com a Tabela 6.1, as topologias iniciais apresentam valores de índices de continuidade elevados, devido à inexistência de dispositivos de proteção no circuito. Na medida em que aqueles são incorporados, os valores dos índices de continuidade diminuem. Inicialmente, esse fenômeno se deve à filtragem de falhas temporárias. Posteriormente, conforme as topologias se alteram, com a inclusão dos equipamentos de proteção, os índices de continuidade diminuem. Finalmente, entre as topologias 4 e 5, com a inclusão de religadores na área central do circuito, ocorre novamente uma queda significativa dos índices de continuidade. Observa-se na tabela 6.1 a queda dos valores dos índices de continuidade, DEC e FEC, em termos percentuais. As figuras 6.1, 6.2, 6.3 e 6.4 apresentam o comportamento dos índices com as topologias analisadas. 
Tabela 6.1 - Valores de DEC e FEC obtidos das topologias analisadas

\begin{tabular}{|c|c|c|c|c|}
\hline $\begin{array}{c}\text { Topo- } \\
\text { logias }\end{array}$ & FEC & $\begin{array}{c}\text { Valores } \\
\% \\
\text { de FEC }\end{array}$ & DEC & $\begin{array}{c}\text { Valores } \\
\% \\
\text { de DEC }\end{array}$ \\
\hline 1 & 31,17 & $-\cdots--$ & 65,66 & $\cdots$ \\
\hline 2 & 6,23 & 20 & 15,78 & 24,05 \\
\hline 3 & 2,16 & 6,95 & 5,52 & 8,41 \\
\hline 4 & 2,15 & 6,91 & 5,49 & 8,37 \\
\hline 5 & 1,04 & 3,35 & 2,76 & 4,21 \\
\hline
\end{tabular}

Obs: valores \% de FEC e DEC em relação à Topologia 1

Os valores de FEC são representados pela figura 6.1:

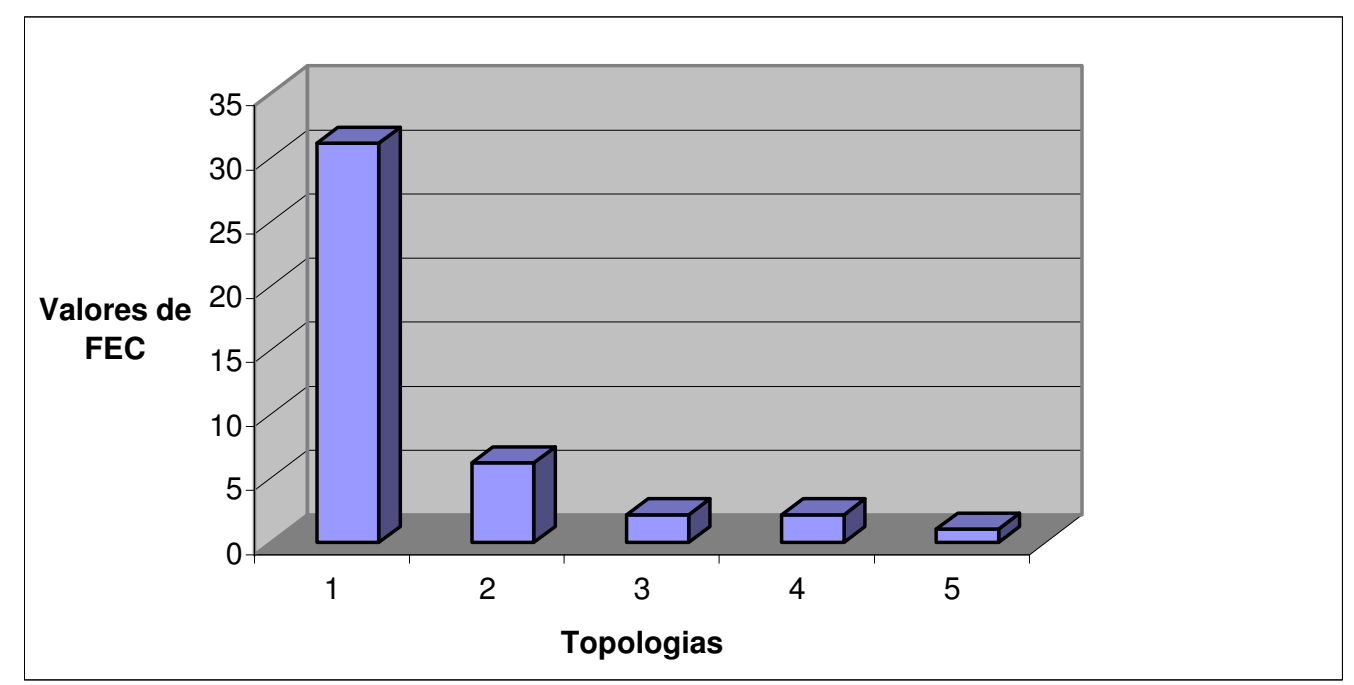

Figura 6.1 - Valores de FEC referentes às topologias

Os valores percentuais de FEC são representados pela figura 6.2: 


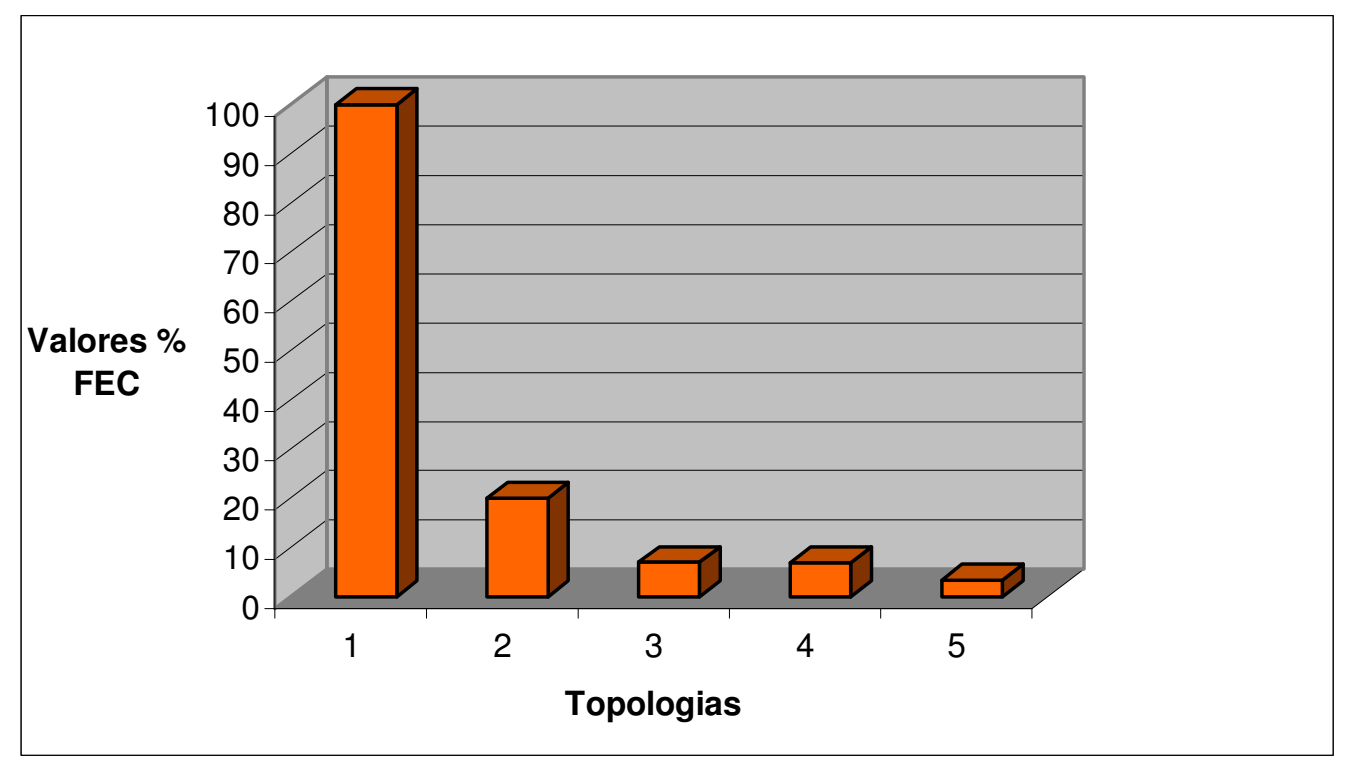

Figura 6.2 - Valores percentuais de FEC referentes às topologias

Os valores de DEC são representados pela figura 6.3:

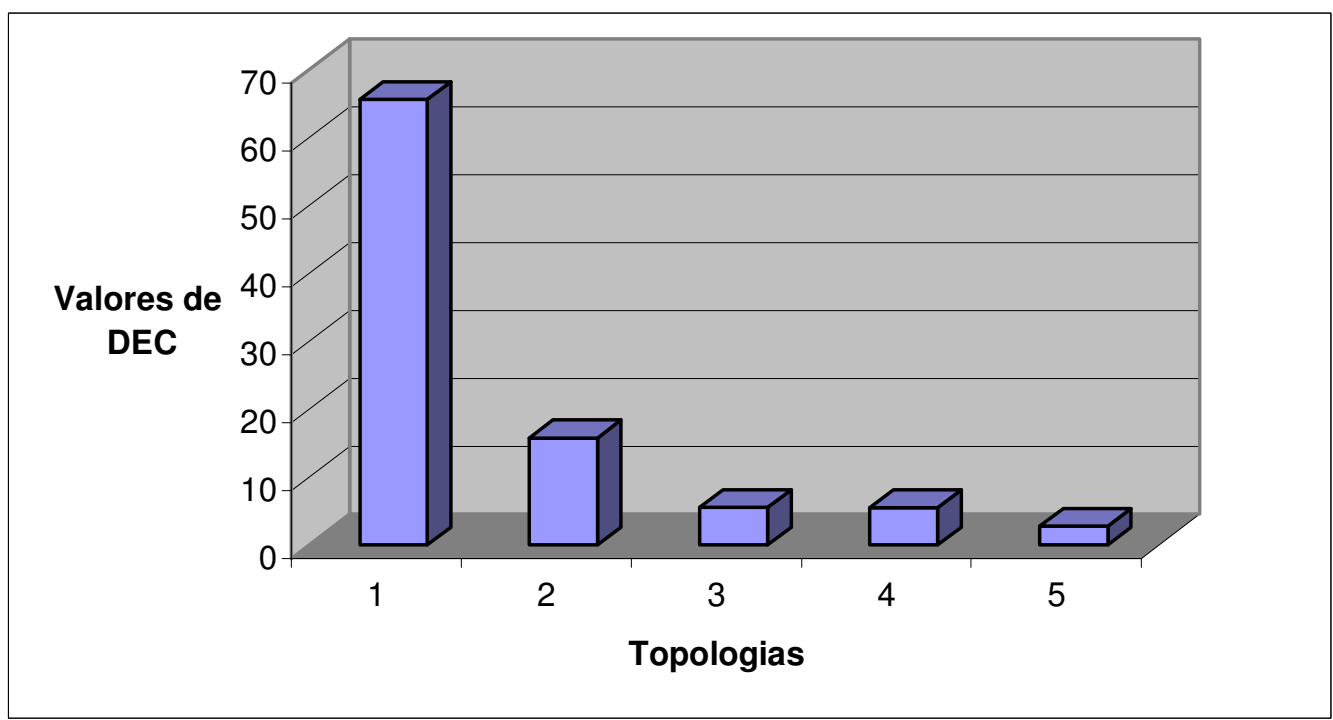

Figura 6.3 - Valores de DEC referentes às topologias

Os valores percentuais de DEC são representados pela figura 6.4: 


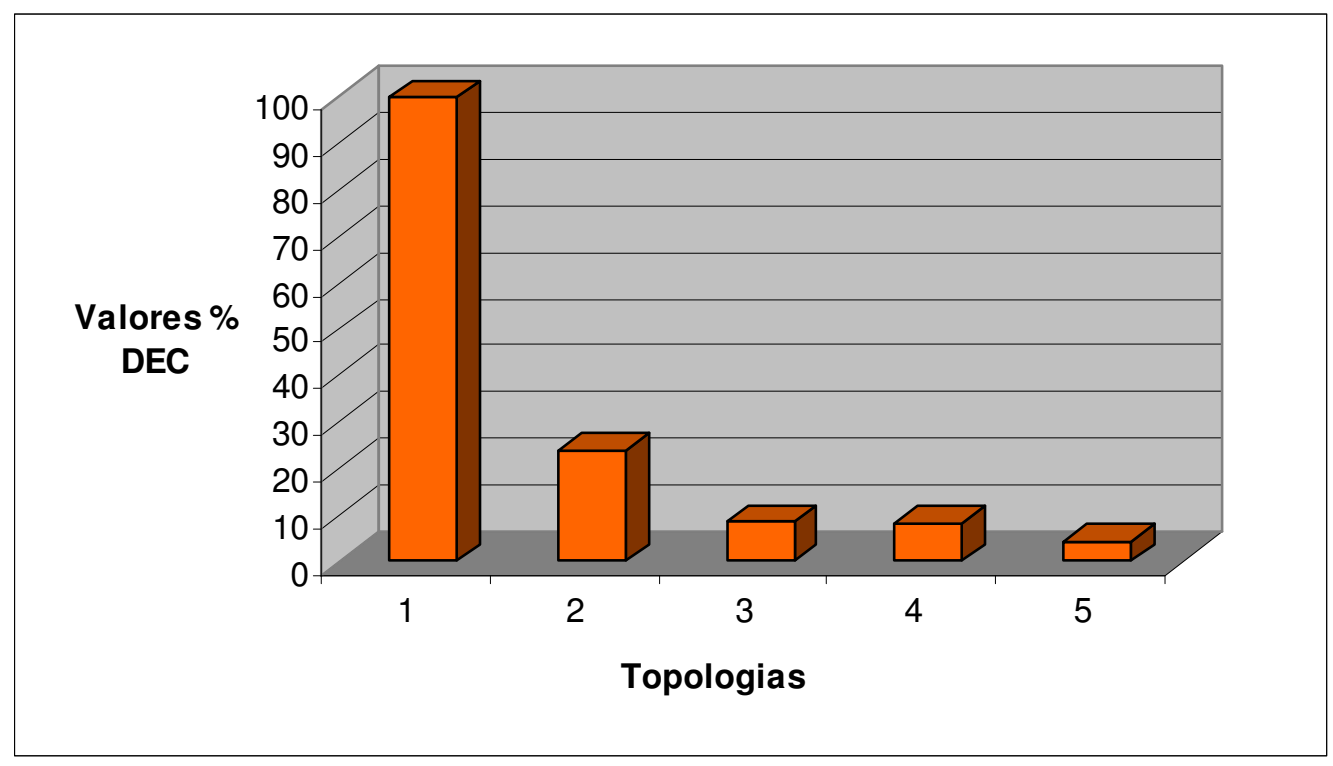

Figura 6.4 - Valores percentuais de FEC referentes às topologias

As topologias analisadas no Capítulo 4 apresentam os cálculos dos índices de continuidade DEC e FEC. Estes são resultantes da alocação de equipamentos de proteção ao longo do circuito elétrico, de acordo com o proposto pelo modelo de Bishop (1997). Observa-se um comportamento esperado, ou seja, aumentando o número de equipamentos de proteção, houve a diminuição dos índices DEC e FEC. A alocação desses equipamentos segue uma metodologia baseada em regras implementadas no programa TEIAA, cujos resultados serviram para a aferição dos dados.

A alocação dos aparelhos depende de uma relação custo-benefício. Nesta, o aumento indiscriminado do número de dispositivos não leva necessariamente a bons resultados. Entretanto, existe um ponto de alocação ótimo, baseado na Figura 3.5 (Capítulo 3 deste estudo).

Uma vez constatado que o TEIAA comporta-se de acordo com as regras esperadas para um sistema de distribuição de energia elétrica, implementou-se o modelo referenciado pelo TEIAG. Para tanto, aplicaram-se as técnicas do AG. Seu objetivo foi encontrar a melhor configuração para a distribuição de energia.

A Tabela 6.1 revela que a melhor solução encontrada se assemelha à topologia 5. Esta não levou em consideração o custo dos equipamentos, mas somente seu desempenho técnico, além de experiência de campo e referências bibliográficas deste estudo. 
Assim, a topologia 5 oferece proteção contra falhas temporárias em grande parte do alimentador principal, garantida pelas características dos religadores alocados no sistema. Os religadores irão fornecer proteção aos fusíveis, localizados nos ramos laterais dos circuitos. Esse processo acontece devido às sequências de coordenação em religadores, munidos de controles microprocessados e eletrônicos.

\subsection{Análise da otimização do programa TEIAG (método)}

Após um número de simulações, observa-se que os resultados dos índices de continuidade e configuração dos circuitos convergem. Nota-se também que a solução otimizada assemelha-se àquela apresentada na topologia 5 , documentada no item 4.6 (Capítulo 4).

Constata-se que a solução otimizada é atingida por volta da 25a geração; em alguns casos, a convergência ocorre a partir da 18ª geração; em outros, em torno da 32a․ Entretanto, a solução final sempre resulta na solução otimizada, evidenciandose a característica convergente do AG. O resultado final é apresentado na Figura 6.5. Durante a execução do programa TEIAG, uma representação gráfica do circuito sinaliza os elementos de proteção, alocados de acordo com o estado atual do programa.

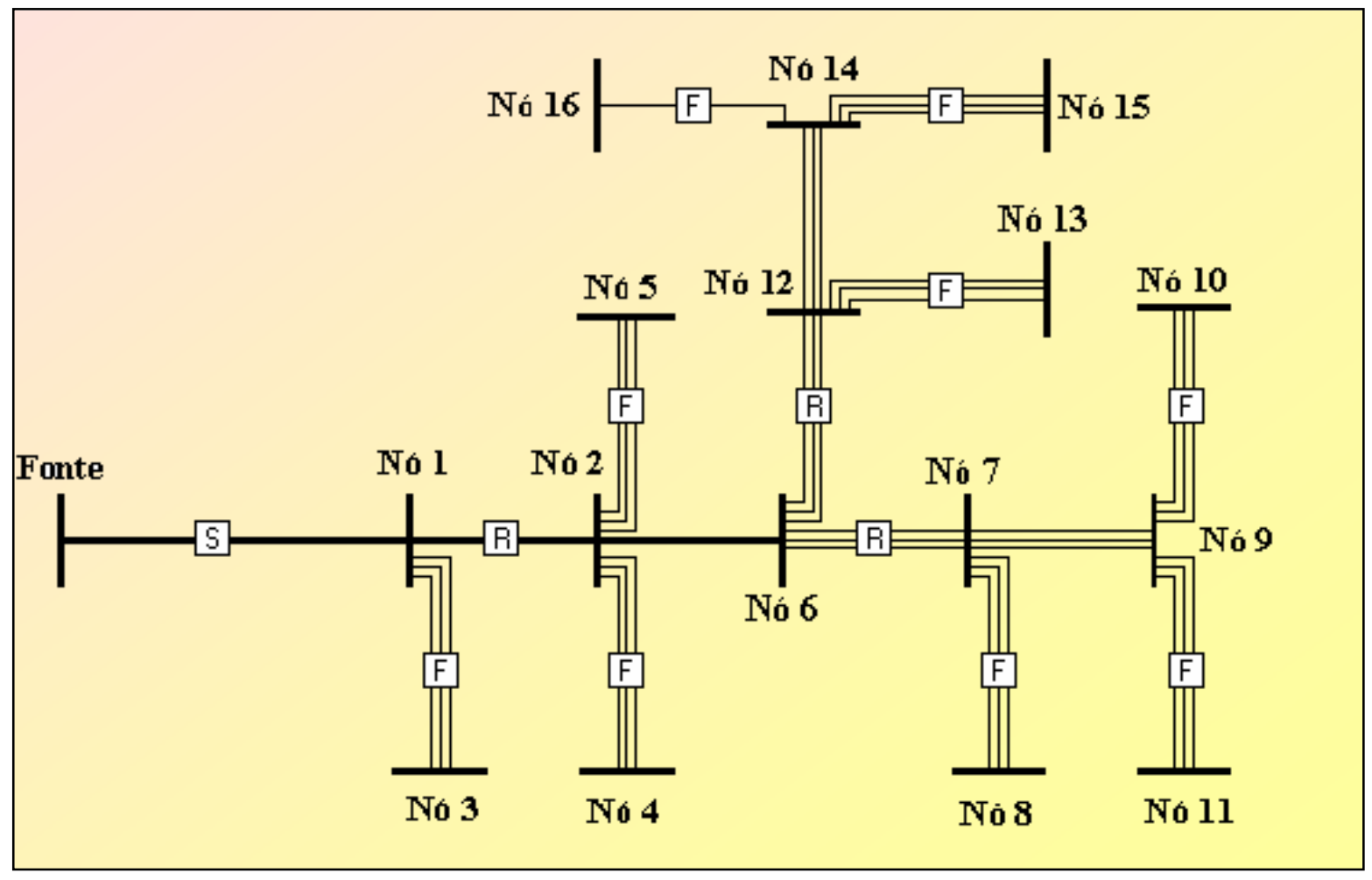

Figura 6.5 - Topologia final: solução otimizada 
A partir da solução otimizada, obteve-se a Tabela 6.2, que carrega as características do circuito final. Nota-se que este circuito é o mesmo da topologia 5, analisada no Capítulo 4. Tal cenário valida a aplicação do AG, pois a solução corresponde aos modelos, topologias e resultados apresentados por Bishop (1997).

As diferenças são pequenas (menores do que 0.1\%), quando comparadas diretamente à topologia 5, do Capítulo 4. Essa mínima oscilação deve-se ao fato de que Bishop (1997) não considera os custos de equipamentos, preocupando-se somente com a solução técnica.

Tabela 6.2 - Arquivo solução final

\begin{tabular}{|c|c|c|c|c|c|c|c|c|c|}
\hline 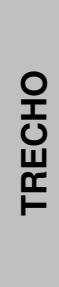 & $\frac{\sum}{\text { Ш⿱士心 }}$ & 올 & $\begin{array}{l}\frac{\mathbb{S}}{0} \\
\sum_{\mathbb{E}} \\
\frac{0}{0} \\
\end{array}$ & 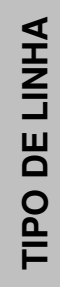 & 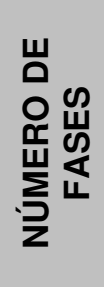 & 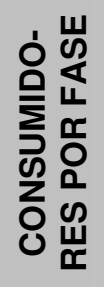 & 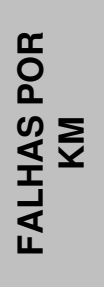 & 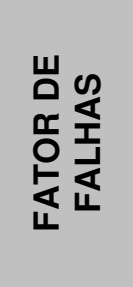 & 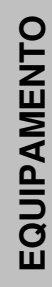 \\
\hline 1 & G00 & N01 & 16,093 & $\mathrm{~T}$ & 1 & 0 & 1 & 0,1367 & $S$ \\
\hline 2 & N01 & N02 & 100,581 & $T$ & 1 & 0 & 1 & 0,1367 & $\mathrm{R}$ \\
\hline 3 & N01 & $\mathrm{N03}$ & 16,093 & $M$ & 3 & 49 & 1 & 0,1367 & $\mathrm{~F}$ \\
\hline 4 & N02 & N04 & 64,372 & $M$ & 3 & 36 & 1 & 0,1367 & $\mathrm{~F}$ \\
\hline 5 & N02 & N05 & 56,325 & $\bar{M}$ & 3 & 49 & 1 & 0,1367 & $\mathrm{~F}$ \\
\hline 6 & N02 & N06 & 32,186 & $T$ & 1 & 0 & 1 & 0,1367 & $\mathrm{v}$ \\
\hline 7 & N06 & N07 & 69,199 & $M$ & 3 & 0 & 1 & 0,1367 & $R$ \\
\hline 8 & N07 & N08 & 77,246 & $\mathrm{M}$ & 3 & 36 & 1 & 0,1367 & $\mathrm{~F}$ \\
\hline 9 & N07 & N09 & 6,759 & $\mathrm{M}$ & 3 & 0 & 1 & 0,1367 & $\mathrm{v}$ \\
\hline 10 & N09 & N10 & 32,186 & $\mathrm{M}$ & 3 & 12 & 1 & 0,1367 & $\mathrm{~F}$ \\
\hline 11 & N09 & $\mathrm{N} 11$ & 64,372 & $\mathrm{M}$ & 3 & 36 & 1 & 0,1367 & $\mathrm{~F}$ \\
\hline 12 & N06 & $\mathrm{N} 12$ & 16,093 & $\mathrm{M}$ & 3 & 0 & 1 & 0,1367 & $\mathrm{R}$ \\
\hline 13 & $\mathrm{~N} 12$ & $\mathrm{~N} 13$ & 80,465 & $\mathrm{M}$ & 3 & 49 & 1 & 0,1367 & $\mathrm{~F}$ \\
\hline 14 & $\mathrm{~N} 12$ & N14 & 16,093 & $\mathrm{M}$ & 3 & 0 & 1 & 0,1367 & $\mathrm{v}$ \\
\hline 15 & N14 & N15 & 12,472 & $M$ & 3 & 49 & 1 & 0,1367 & $\mathrm{~F}$ \\
\hline 16 & N14 & N16 & 77,246 & $M$ & 1 & 72 & 1 & 0,1367 & $\mathrm{~F}$ \\
\hline
\end{tabular}

O campo Diagnóstico do programa TEIAG é ilustrado na Figura 6.6. Ele apresenta os valores dos índices de continuidade DEC, FEC, além de CustoS (Disjuntor da Subestação), CustoR (Religador), CustoF (Fusível) e o Custo Total da solução final, em valores de referência. Expõe ainda um item de penalidade (fator $\beta$ ), que é aplicado em caso de utilização de equipamento e que servirá como referência aos cálculos realizados pelo INVENTTEIA. 


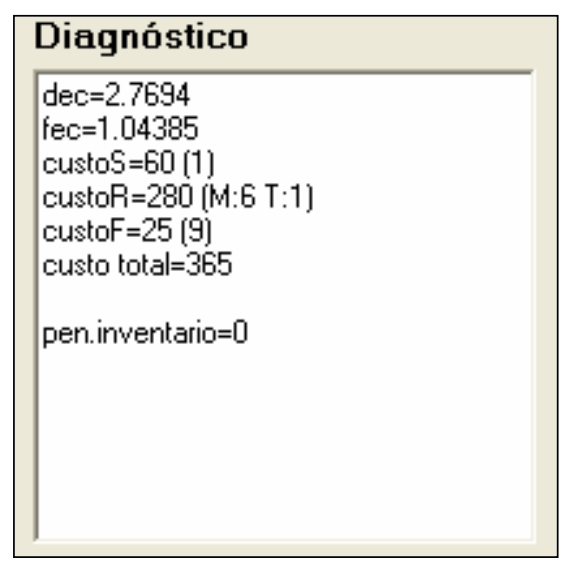

Figura 6.6 - Campo Diagnóstico

O cálculo dos custos considera alguns parâmetros (CustoS, CustoR, CustoF), que são fornecidos por meio de um arquivo de parâmetros de controle. Observa-se também o número de fases nos ramos protegidos pelos equipamentos. $\mathrm{O}$ arquivo com esses parâmetros de controle não pertence ao programa TEIAG. Assim, ele pode ser atualizado conforme a necessidade da concessionária. O cálculo é executado pela função da Figura A.3, do Anexo A. Um exemplo desse arquivo é apresentado na Figura 6.7.

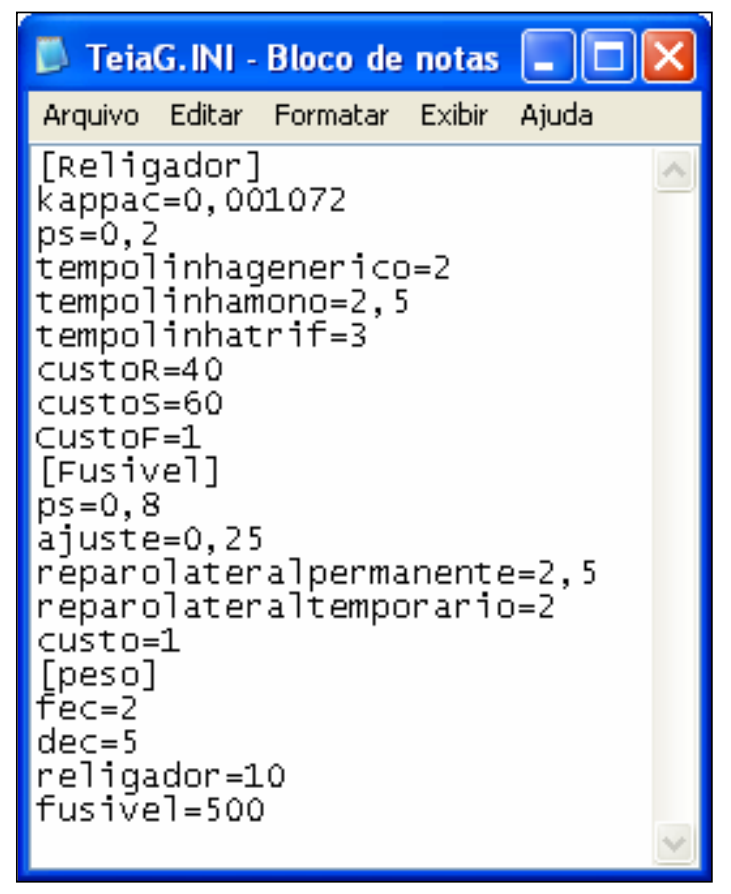

Figura 6.7 - Arquivo de parâmetros de controle do programa TEIAG

Mencionam-se, como exemplo, os religadores do circuito otimizado alocados nos trechos 2 (trifásico), 7 (monofásico) e 12 (monofásico). O custo estimado de- 
penderá do número de equipamentos alocados e de seu valor unitário. Assim, o CustoR será calculado como $40^{*}(1+3+3)$, ou seja, cada religador representa 40 unidades de valor. Neste caso, foram alocados 1 religador trifásico e 6 religadores monofásicos, resultando em 280 unidades de valor. Observa-se que esses custos são utilizados para exemplificar os cálculos, podendo ser alterados de acordo com as necessidades da concessionária de energia elétrica e os valores de mercado. Conclui-se que o custo dos religadores, na topologia referente ao circuito otimizado, é de 280 unidades monetárias, tomando-se como referência o custo de um fusível. 0 mesmo raciocínio é aplicado aos disjuntores e aos próprios fusíveis.

Realizou-se uma simulação com um número elevado de gerações, bem acima do ponto de convergência do sistema para a solução otimizada. Nesta hipótese, foi analisado o comportamento do AG, em caso de superdimensionamento do número de gerações. Observa-se que, apesar da convergência da solução, surgem anomalias resultantes de mutação (devido ao operador "x - mutação"). A influência desse processo é imediatamente eliminada na próxima geração. Esse comportamento pode ser observado na Figura 6.8: há picos aleatórios (linha vermelha) que não afetam a solução otimizada (linhas verde e azul). A taxa de mutação, apesar de ser elevada, não altera o melhor resultado, devido à robustez do método AG.

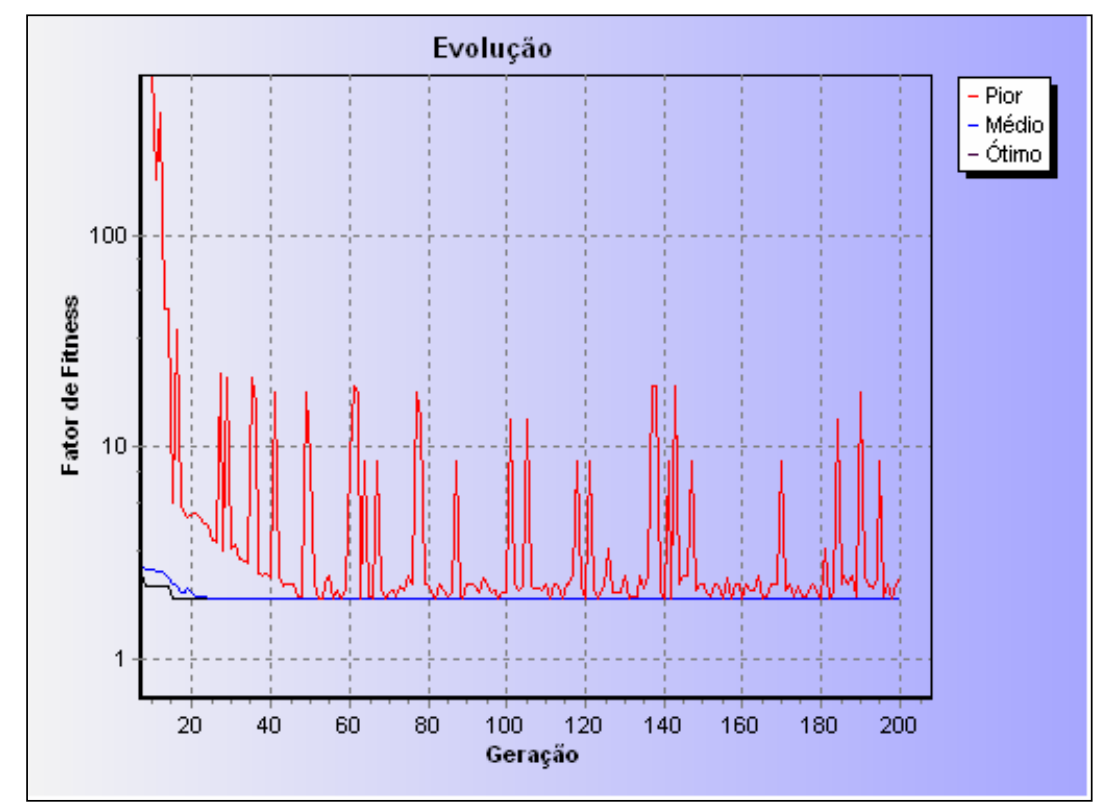

Figura 6.8 - Comportamento do programa TEIAG em 200 gerações 


\subsubsection{Cálculo do coeficiente de custo $-\kappa_{c}$}

O melhor indivíduo de cada geração (representado por uma diferente topologia) teve seu fator de fitness calculado com base nos índices de continuidade DEC, FEC e custos de equipamentos.

Conforme discutido no Capítulo 5, um coeficiente necessário para os cálculos é o fator de custo $\boldsymbol{K}_{\mathrm{c}}$.

Este fator é obtido por meio das equações (5.4), (5.5) e (5.6), do Capítulo 5, de acordo com a Figura 6.9. $\bigcirc \kappa_{\mathrm{C}}$ resultante desses cálculos é 0,001072.

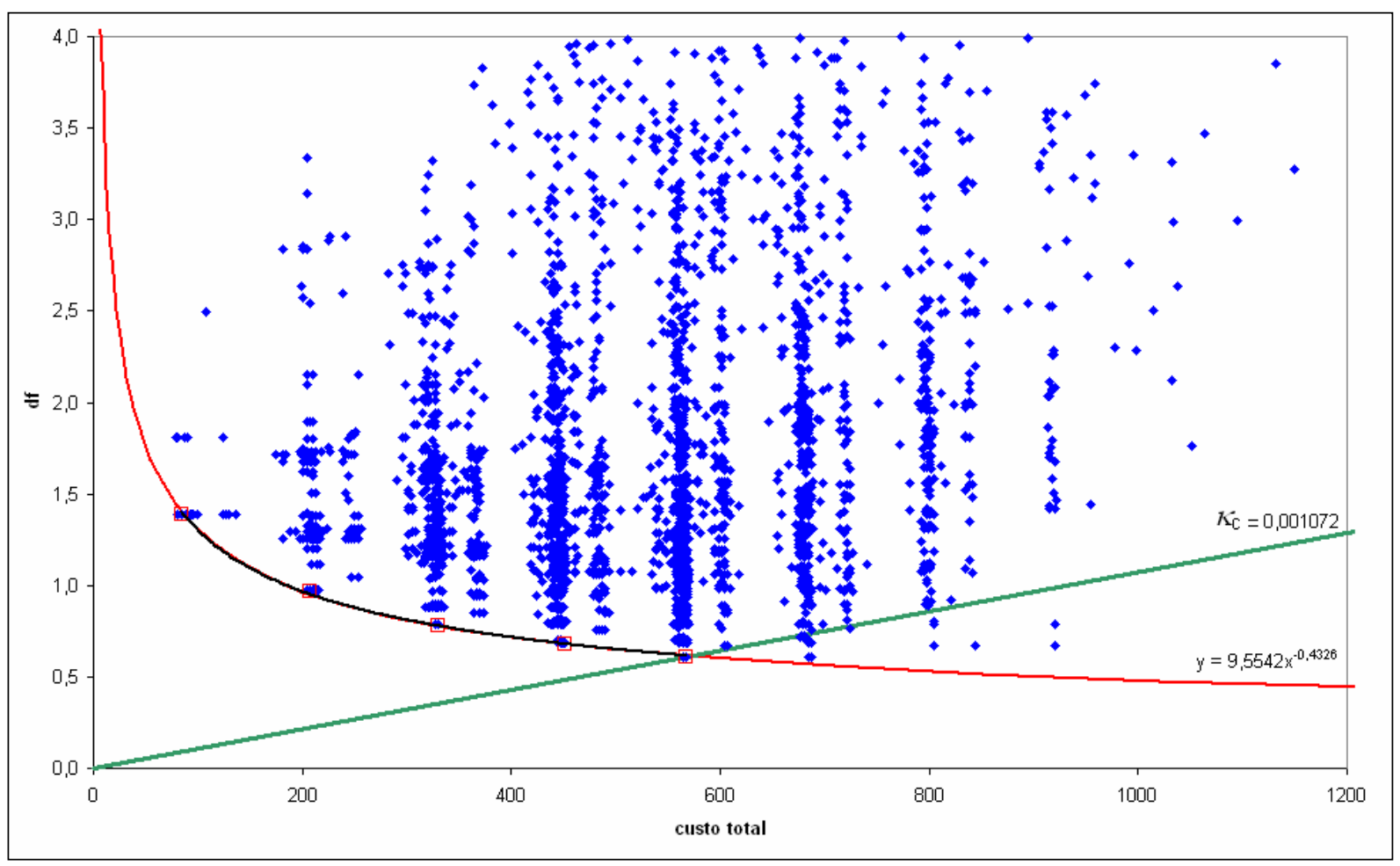

Figura 6.9 - Gráfico para o cálculo de $\kappa_{\mathrm{c}}$

Apesar de cada solução intermediária não servir como aquela final, o conjunto das soluções apresenta um comportamento estatístico característico (representado pelos gráficos das figuras 6.10 e 6.11). Esse perfil considera a concentração de valores do índice de continuidade FEC pelo custo total, por intermédio das distribuições verticais hipotéticas. Tal fato ocorre devido ao caráter discreto de alocação dos equipamentos, não havendo faixas de custos quando se muda de uma configuração para outra.

O referido aspecto torna-se mais evidente quando se analisa o caráter discreto imposto pela distribuição dos religadores (Figura 6.11). 
Comparando-se a figuras 6.10 (Capítulo 6) e 3.5 (Capítulo 3), observa-se que o ponto de mínimo do ff não corresponde àquele aparentemente extraído da distribuição DEC \& FEC versus custo total. Esta última equivale a uma função exponencial indicada pela equação 5.8 .

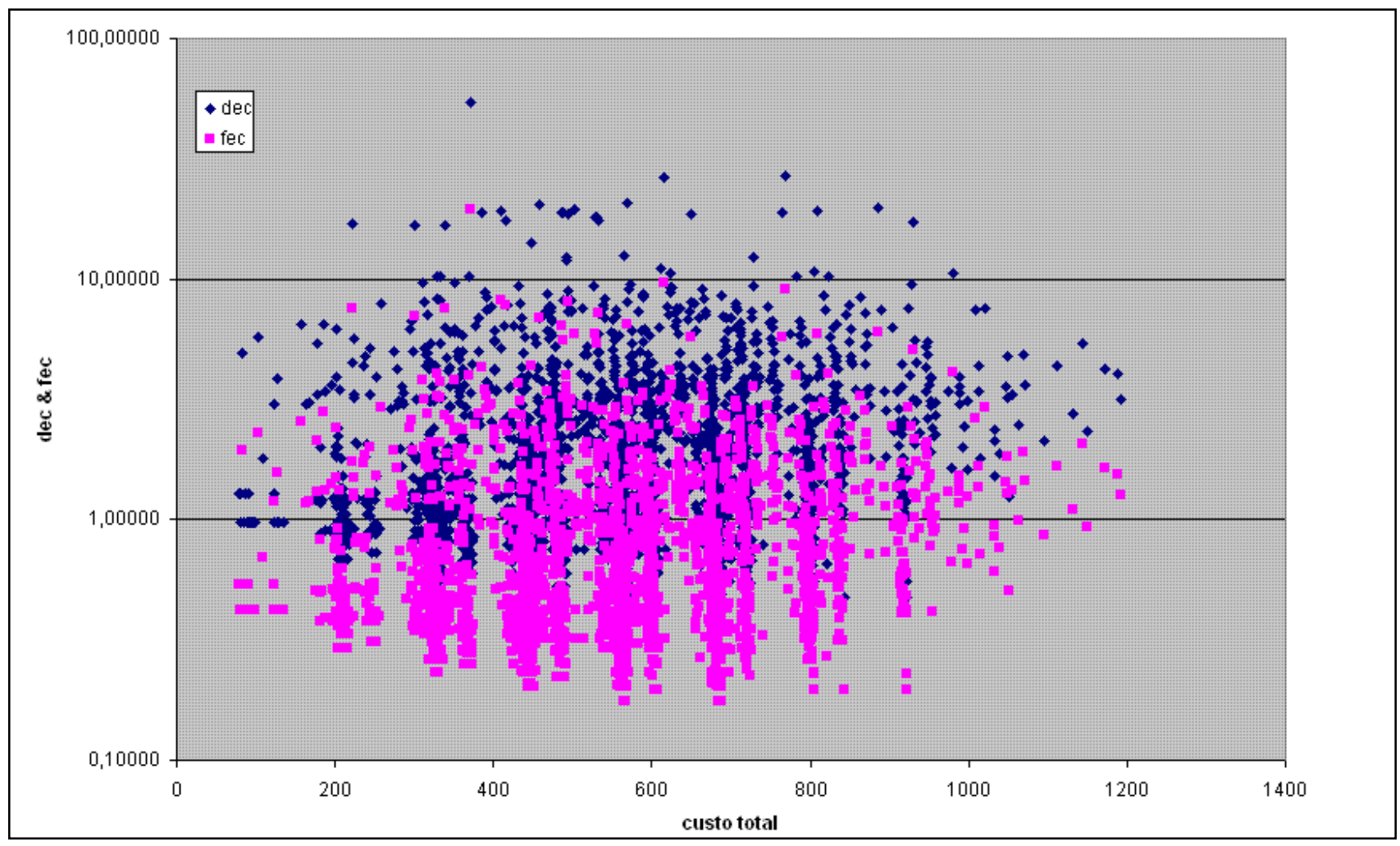

Figura 6.10 - Distribuição de valores de DEC \& FEC versus custo total dos equipamentos

O comportamento de ff (equação 5.6) indica um ponto de mínimo - objetivo da otimização do AG - que é evidenciado na Figura 3.5.

O comportamento da curva é demonstrado na Figura 6.12, a partir do cálculo do fator de fitness. Tal processo ocorre de acordo com o esperado, conforme revela a Figura 3.5, que indica também o ponto de custo total e a composição de todos os fatores envolvidos. 


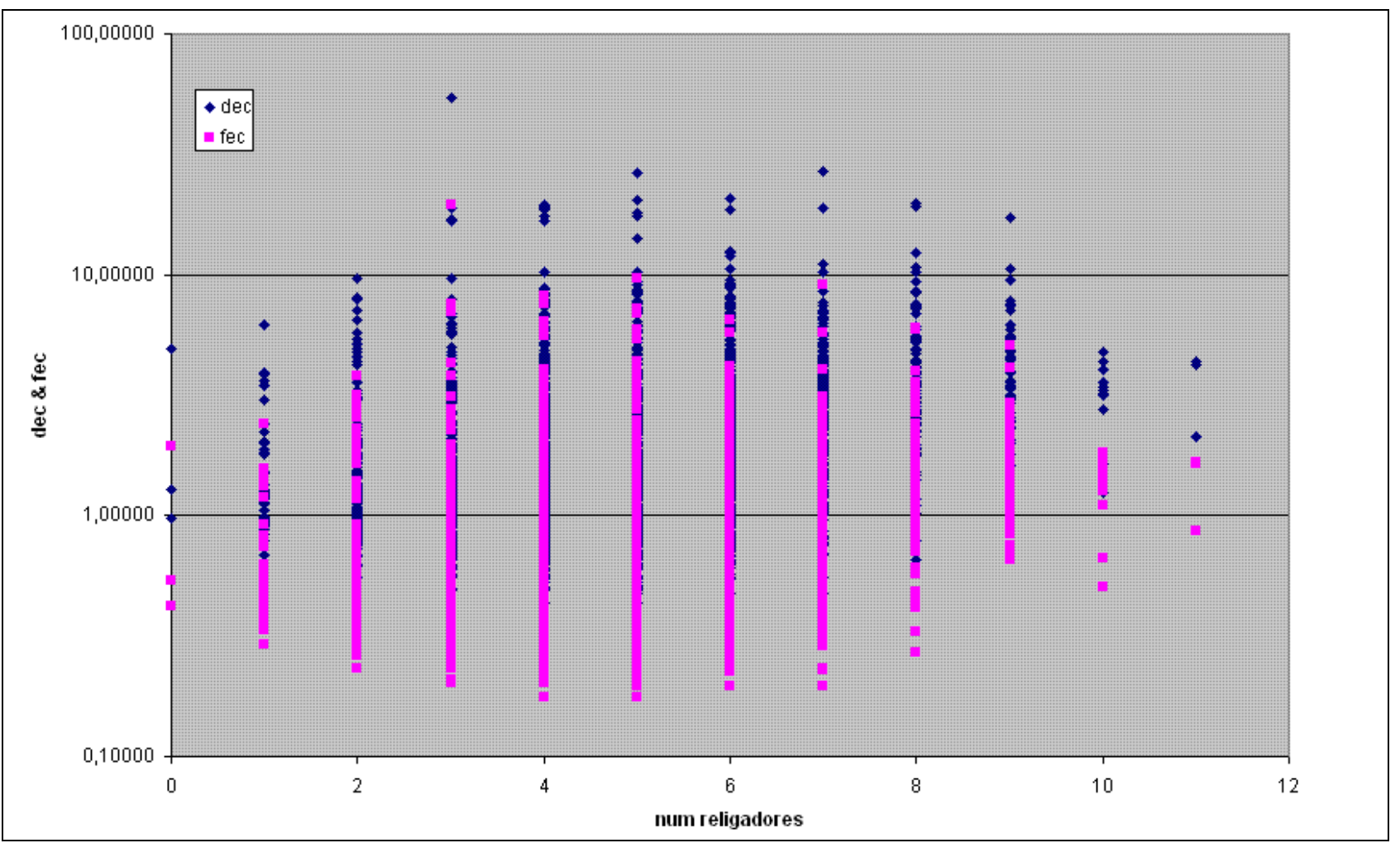

Figura 6.11 - Distribuição de valores de DEC \& FEC versus número de religadores alocados

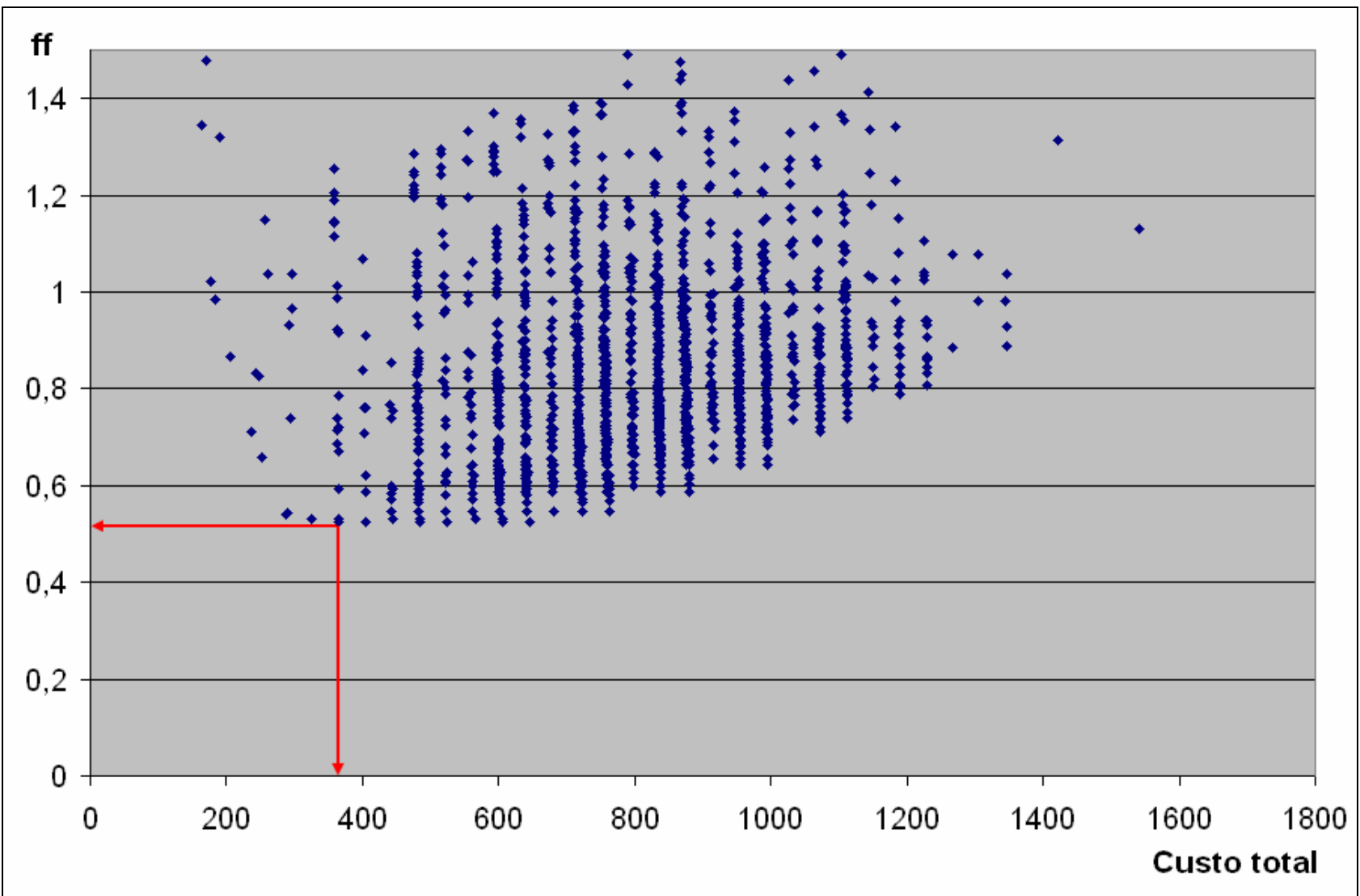

Figura 6.12 - ff versus custo total 


\subsubsection{Análise do comportamento do AG - programa TEIAG}

Observa-se que os melhores valores dos índices DEC e FEC se encontram para 7 religadores ( 6 monofásicos a jusante do nó 6 e 1 trifásico entre os nós 1 e 2).

O comportamento da distribuição é compatível com valores da solução final, representada pela Tabela 6.3.

Tabela 6.3 - Valores da solução otimizada

\begin{tabular}{|c|c|c|c|c|c|}
\hline DEC & FEC & $\begin{array}{c}\text { CUSTO S } \\
\text { (NÚMERO EQUI- } \\
\text { PAMENTOS) }\end{array}$ & $\begin{array}{c}\text { CUSTO R } \\
\text { (NÚMERO EQUIPA- } \\
\text { MENTOS) }\end{array}$ & $\begin{array}{c}\text { CUSTO F } \\
\text { (NÚMERO EQUI- } \\
\text { PAMENTOS) }\end{array}$ & $\begin{array}{c}\text { CUSTO } \\
\text { TOTAL }\end{array}$ \\
\hline $\mathbf{2 , 7 6 9 4}$ & $\mathbf{1 , 0 4 3 8 5}$ & $\mathbf{6 0}(\mathbf{0 1}$ & $\mathbf{2 8 0}(\mathbf{0 3})$ & $\mathbf{2 5}(\mathbf{9})$ & 365 \\
\hline
\end{tabular}

A Tabela 6.3 aponta que os valores dos índices DEC e FEC são muito próximos daqueles da topologia 5, desenvolvida no Capítulo 4 deste estudo. A referida topologia foi obtida a partir da experimentação e da análise de equipamentos alocados, conforme experiência de campo [Bishop (1997), Bishop et al. (1995) e McCarthy et al. (1999)].

O AG realizou a pesquisa de um grande número de soluções e configurações em 50 gerações, demostrando-se uma ferramenta robusta para esse tipo de análise de dispositivos. Seus resultados convergiram para a solução da topologia 5 , analisada no Capítulo 4.

A partir de uma topologia com uma proteção existente, verifica-se que o programa poderá desenvolver a topologia otimizada, que eventualmente realocará com exclusão ou inserção os equipamentos de proteção já existentes.

\subsection{Resultados - Programa CONTITEIA}

O programa CONTITEIA foi desenvolvido para analisar um histórico de contingências, visando obter:

- comportamento de um circuito sujeito a situações reais;

- modo de funcionamento das chaves de proteção, da chave-seccionadora (NC e NO) e das chaves de socorro - NO [Kagan (2005)];

- índices de continuidade definidos pela ANEEL: DIC, FIC, DMIC, a partir de uma análise a posteriori. 


\subsubsection{Resposta do circuito em relação à tabela de contingências}

Após a análise do histórico de contingências, representado na Tabela 6.4, chegou-se aos índices DIC, FIC e DMIC.

Tabela 6.4 - Histórico de contingências

\begin{tabular}{|l|}
\hline Contingencia(1) \\
Falha(3) \\
Corte(3) \\
Duracao(120) \\
Fim \\
\hline Contingencia(2) \\
Falha(9) \\
Corte(6) \\
Duracao(50) \\
Corte(9) \\
FechaTrecho(6) \\
Duracao(110) \\
Fim \\
\hline Contingencia(3) \\
Falha(6) \\
Corte(1) \\
Duracao(40) \\
Corte(6) \\
FechaTrecho(17) \\
Duracao(30) \\
Fim \\
\hline Contingencia(4) \\
Falha(8) \\
Corte(8) \\
Duracao(80) \\
Fim \\
\hline Contingencia(5) \\
Falha(14) \\
Corte(12) \\
Duracao(205) \\
Fim \\
\hline
\end{tabular}

A Tabela 6.4 representa o histórico de contingências, com 5 ocorrências distintas:

- Contingência 1:

- falha no trecho 3 (nós 2 e 4) - chave aberta;

- corte no trecho 3 - chave aberta;

- duração de 120 minutos;

- geração de DIC, FIC e DMIC para nós 2 e 4.

- Contingência 2:

- falha no trecho 9 (nós 9 e 10) - chave aberta;

- corte no nó 6 - chave aberta;

- duração de 50 minutos; 
- geração de DIC, FIC e DMIC para os nós 6, 7, 8, 9, 10 e 11;

- corte no trecho 9 (nós 9 e 10);

- abertura de chave de proteção no trecho 6 (nós 6 e 7);

- duração de 110 minutos;

- geração de DIC e DMIC acumulados para os nós 9 e 10, considerando 1 ocorrência para o FIC.

- Contingência 3:

- falha no trecho 6 (nós 6 e 7) - chave aberta;

- corte no trecho 1 (nós 1 e 2) - chave aberta;

- duração de 40 minutos;

- geração de DIC, FIC e DMIC para o nó 1;

- geração de DIC e FIC acumulados para os nós 2 e 4, mantendo DMIC;

- geração de DIC, FIC e DMIC para o nó 5;

- geração de DIC e FIC acumulados para os nós 6, 7 e 8, mantendo DMIC;

- geração de DIC e FIC acumulados para os nós 9 e 10, mantendo DMIC;

- geração de DIC e FIC acumulados para o nó 11, mantendo DMIC;

- geração de DIC, FIC e DMIC para nós 12, 13, 14, 15, 16 e 17.

- Contingência 4:

- falha no trecho 8 (nós 7 e 9) - chave aberta;

- corte no trecho 8 - chave aberta;

- duração de 80 minutos;

- geração de DIC, FIC e DMIC acumulados para o nó 7;

- geração de DIC, FIC acumulados para os nós 9 e 10, mantendo DMIC;

- geração de DIC, FIC e DMIC acumulados para o nó 11.

- Contingência 5:

- falha no trecho 14 (nós 14 e 15) - chave aberta;

- corte no trecho 12 (nós 12 e 13) - chave aberta;

- duração de 205 minutos; 
- geração de DIC, FIC e DMIC acumulados para os nós 12, 13, 14 e 15.

Após a ocorrência das contingências, o programa CONTTEIA retornou os valores de DIC, FIC e DMIC para cada nó do circuito, conforme Tabela 6.5.

Tabela 6.5 - Valores de DIC, FIC e DMIC

\begin{tabular}{|c|c|c|}
\hline DIC & FIC & DMIC \\
\hline G00: 0 & G00: 0 & G00: 0 \\
\hline N01: 70 & N01: 1 & N01: 40 \\
\hline N02: 190 & N02: 2 & N02: 120 \\
\hline N03: 0 & N03: 0 & N03: 0 \\
\hline N04: 190 & N04: 2 & N04: 120 \\
\hline N05: 70 & N05: 1 & N05: 40 \\
\hline N06: 120 & N06: 2 & N06: 50 \\
\hline N07: 200 & N07: 3 & N07: 80 \\
\hline N08: 120 & N08: 2 & N08: 50 \\
\hline N09: 310 & N09: 3 & N09: 110 \\
\hline N10: 310 & N10: 3 & N10: 110 \\
\hline N11: 200 & $\mathrm{~N} 11: 3$ & N11: 80 \\
\hline N12: 275 & N12: 2 & N12: 205 \\
\hline N13: 275 & N13: 2 & N13: 205 \\
\hline N14: 275 & N14: 2 & N14: 205 \\
\hline N15: 275 & N15: 2 & N15: 205 \\
\hline N16: 70 & N16: 1 & N16: 40 \\
\hline G01: 0 & G01: 0 & G01:0 \\
\hline N17: 70 & N17:1 & N17: 40 \\
\hline
\end{tabular}

Após as ocorrências, obteve-se a configuração final do circuito elétrico, indicado pela Figura 6.13. 


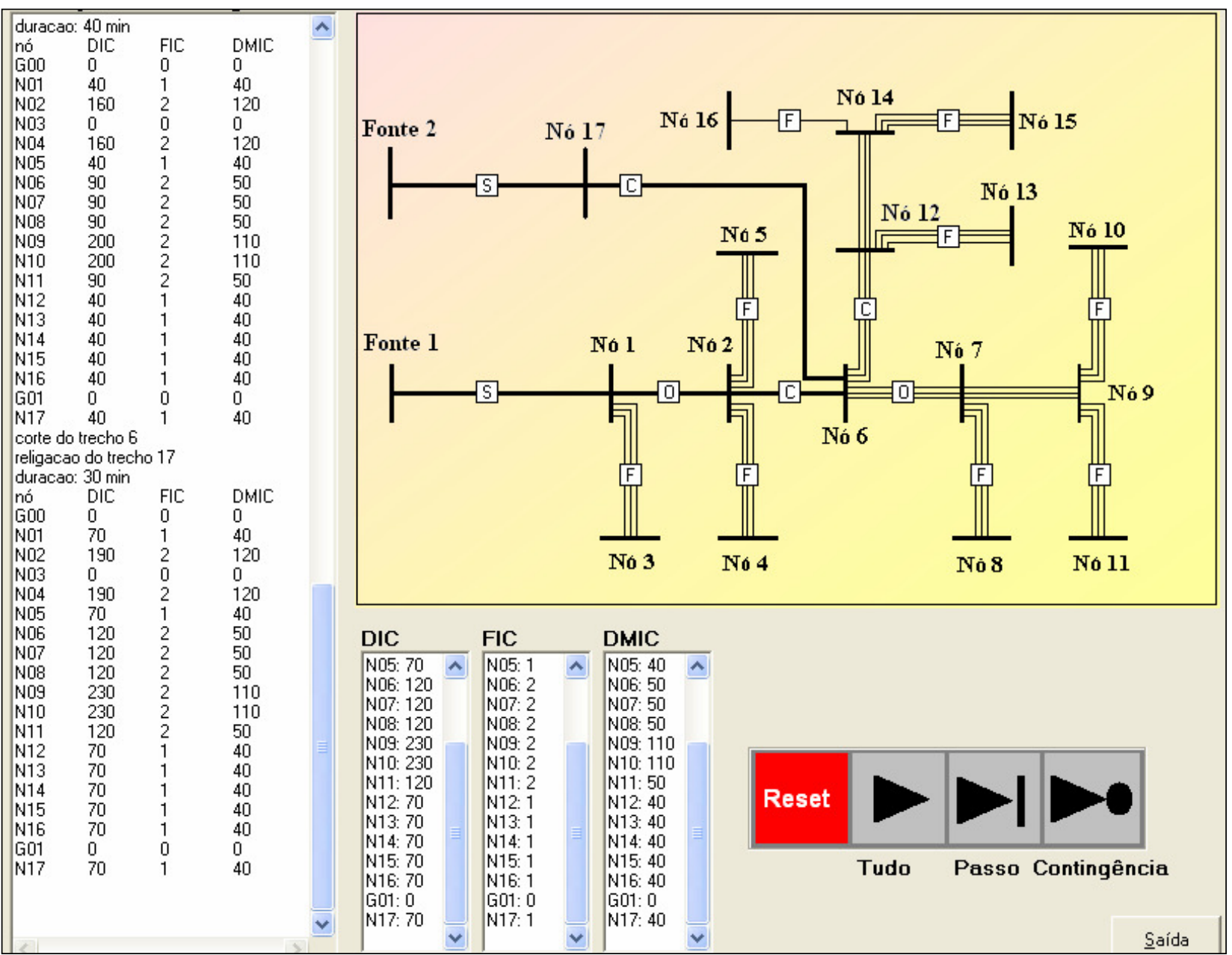

Figura 6.13 - Circuito resultante da ação das contingências

\subsection{Resultados - Programa INVENTEIA}

Durante o desenvolvimento do TEIAG, buscou-se obter o melhor circuito em termos de custo-benefício. Dessa maneira, consideraram-se as regras de alocação de equipamentos de proteção, as características técnicas, o número de equipamentos e os custos.

Cada região possui uma realidade específica para as concessionárias e cooperativas de energia elétrica. Essa informação explica porque a solução otimizada para um caso nem sempre atende a todos os demais interesses. Os equipamentos podem estar indisponíveis para uso no estoque da companhia. É necessário considerar verbas limitadoras para a compra; em algumas situações, o processo burocrático para liberação de equipamentos pode levar meses ou anos.

Para solucionar tais problemas, o desenvolvimento do programa INVENTTEIA fornece ao corpo de engenharia uma ferramenta que compara a solução otimizada, muitas vezes hipotética, com a solução real. Neste contexto, os equipamentos são alocados de acordo com o inventário da concessionária. 
A tela principal do programa INVENTTEIA é visualizada na Figura 6.14.

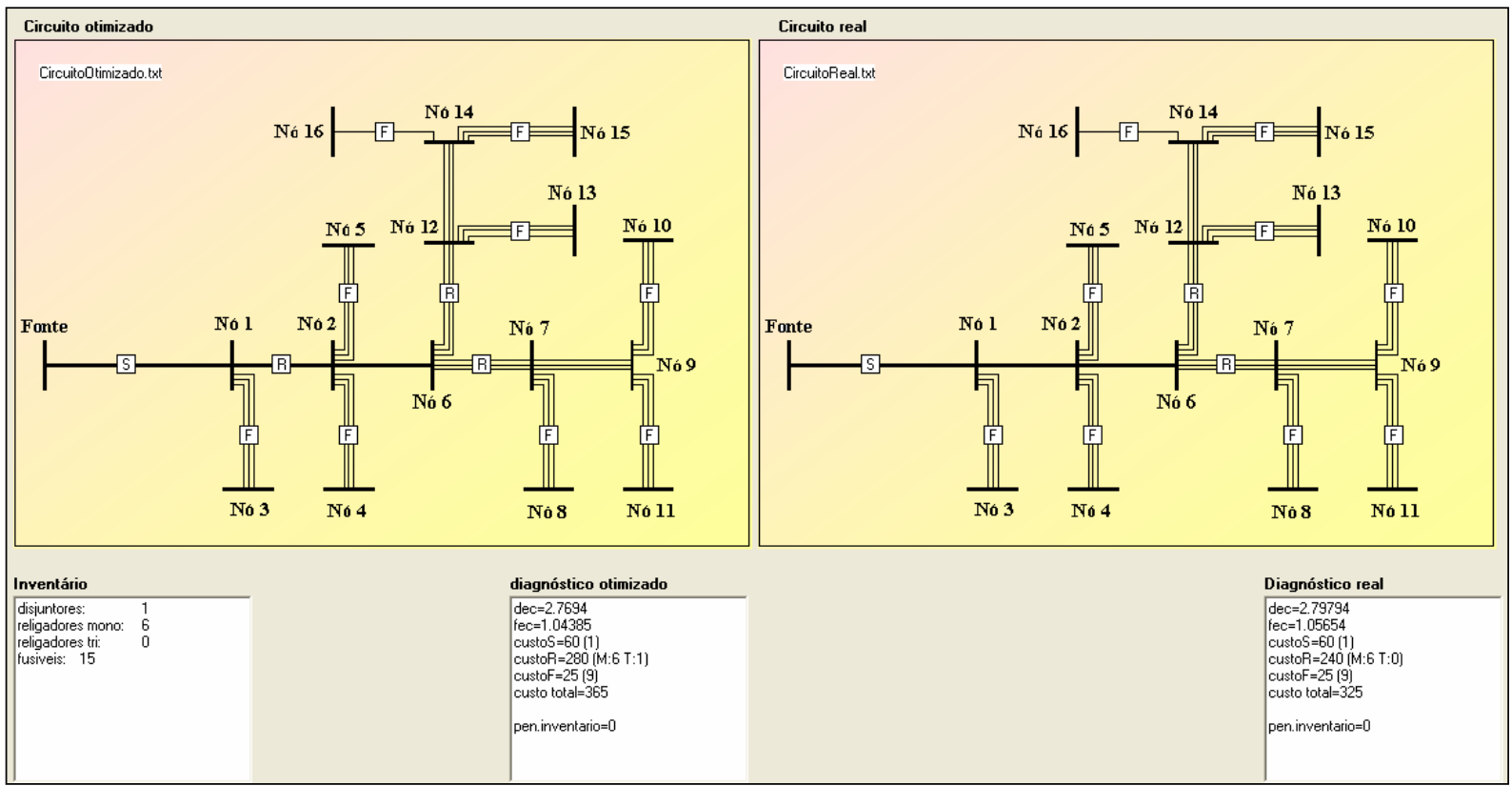

Figura 6.14 - INVENTTEIA e a comparação entre dois circuitos

\subsubsection{Análise do inventário}

A Figura 6.14 denota que existe um campo referente ao inventário do cliente, o qual deve ser lido a partir de um banco de dados. Este estudo utilizou como banco de dados um arquivo de entrada, para facilitar o tratamento das informações.

O programa INVENTTEIA forneceu como saída:

- O circuito otimizado, demonstrado na Figura 6.15; 


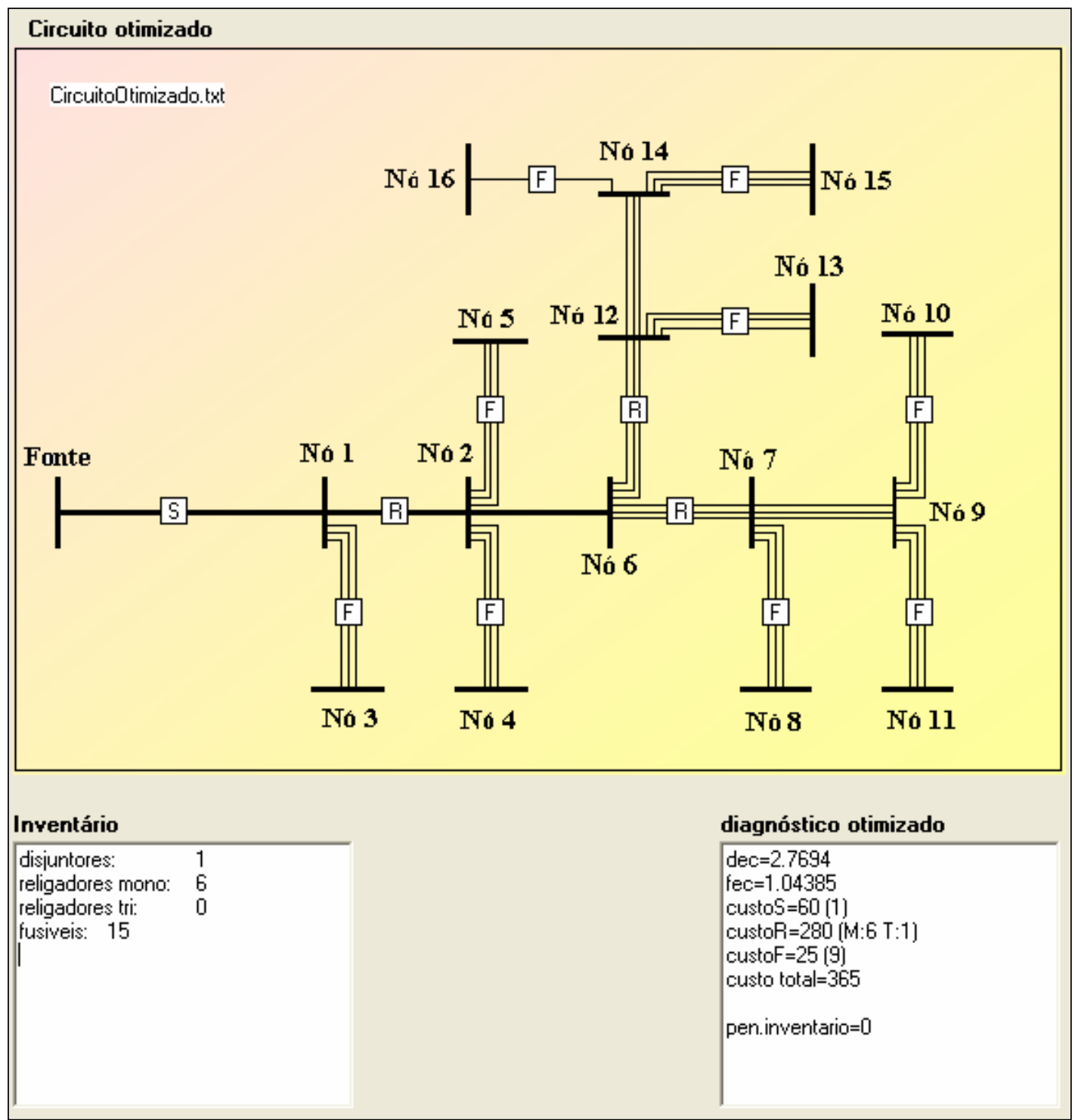

Figura 6.15 - Circuito otimizado

- O melhor circuito com o número máximo de equipamentos presentes no estoque, como informa a Figura 6.16; 


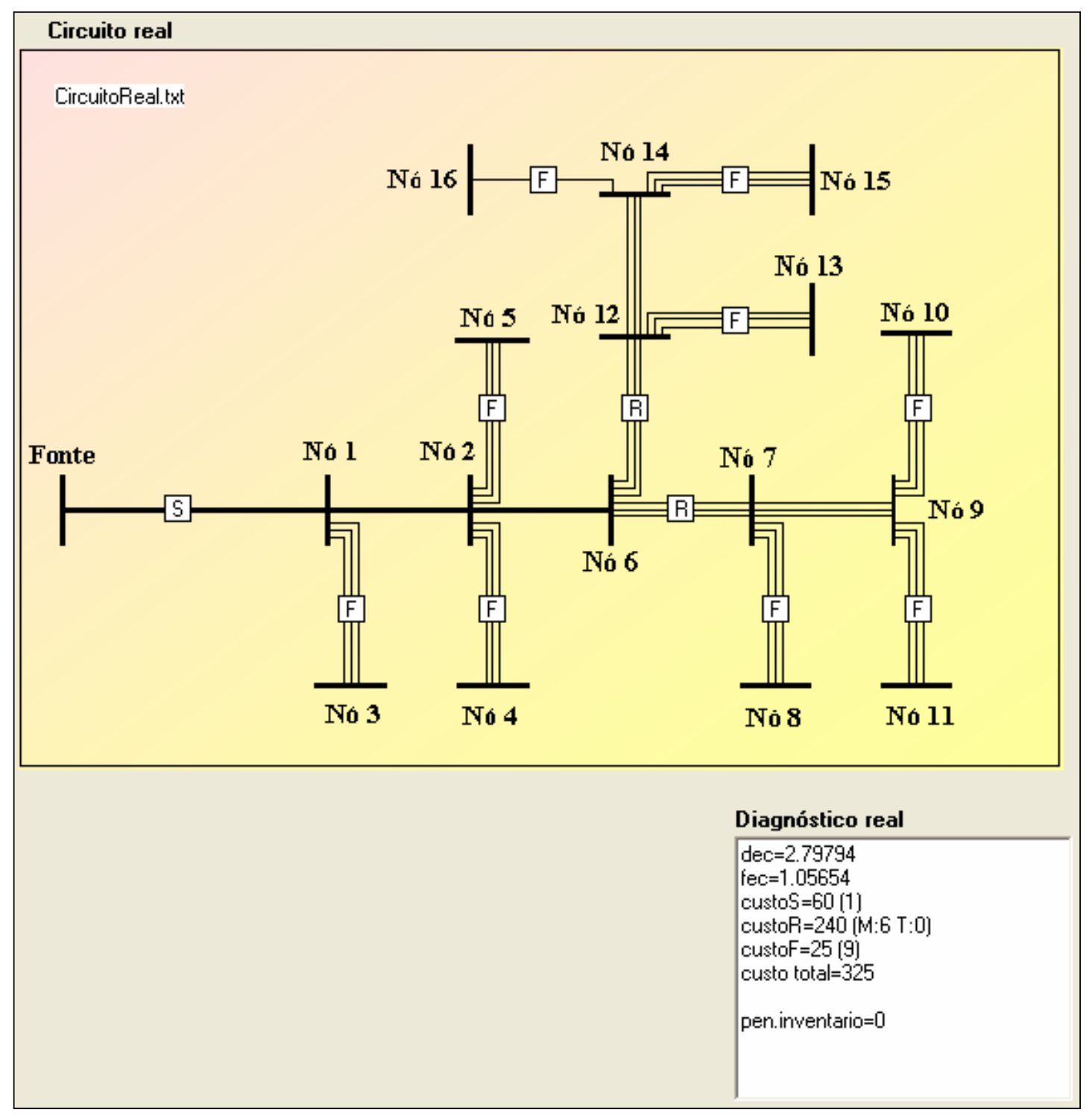

Figura 6.16 - Circuito real 
Capítulo 7

\section{Conclusões e Considerações Finais}

\section{Conclusões e Considerações Finais}

Esta pesquisa apresenta uma nova metodologia no contexto de alocação de equipamentos de distribuição de energia elétrica em comparação com as melhores práticas existentes na literatura técnica existente. Buscou-se analisar a contribuição desses equipamentos para os cálculos de índices de continuidade definidos pela ANEEL [ANEEL № 24 (2000)]. Assim, aplicou-se o conceito de Algoritmos Genéti$\cos (A G)$, para se chegar a um circuito otimizado. Paralelamente, desenvolveram-se outros programas para as análises de histórico de contingências e do inventário de uma concessionária. A finalidade desse processo foi obter uma solução otimizada, porém com os equipamentos disponíveis.

O presente estudo iniciou-se com o modelo apresentado por Bishop (1997) e desenvolvido por Burian (2001). Havia a necessidade de se adaptar o modelo inicial e migrar os cálculos apresentados em Burian (2001) para um programa computacional.

A Linguagem C (padrão ANSI), em princípio, foi escolhida devido ao seu caráter estruturado e à facilidade de desenvolvimento de soluções. Porém, foi logo descartada, porque havia dificuldade em se desenvolver uma interface moderna, que atendesse aos padrões de mercado (interface amigável). A escolha definitiva foi o $\mathrm{C}++$ Builder, devido à robustez da linguagem e à sua interface amigável.

Uma vez definida essa etapa, o próximo passo foi retornar ao modelo de Bishop (1997) e desenvolver uma metodologia para implementar os cálculos. Assim, criou-se uma linguagem para representar o circuito radial, por meio de um arquivo texto.

A próxima sequência de tarefas foi implementar as regras de alocação dos equipamentos, de maneira direta, pela leitura do arquivo. Houve a necessidade de 
verificar a veracidade dos valores encontrados, ou seja, os índices de continuidade DEC e FEC. Para atender a esse requisito, transformaram-se os cálculos apresentados em um conjunto de fórmulas, desenvolvidas no Capítulo 4, que pudessem ser implementadas.

Partiu-se, em seguida, para o desenvolvimento do programa TEIAA, a fim de realizar o cálculo dos índices de continuidade.

Usando os conceitos de modelo de software, detalhados no Capítulo 5, iniciou-se o desenvolvimento da interface TEIAA, que apresentou como resultados os cálculos dos índices de continuidade. Por meio de respostas adequadas, foi possível checar os resultados obtidos, incorporando-se o programa TEIAA ao TEIAG.

O desenvolvimento do programa TEIAA exigiu busca literária que apontasse uma solução algoritmica suficientemente robusta e que conseguisse realizar os cálculos de alocação de equipamentos de proteção. O objetivo era obter um circuito otimizado, caracterizando uma solução ótima em termos de número de equipamentos e custo, além de DEC e FEC menores. Após a análise de várias opções, discutidas ao longo deste trabalho, escolheu-se o Algoritmo Genético (AG). Este baseia-se no modelo desenvolvido por Hetem et al. (2007) e Rojas et al. (2008). Ressalta-se ainda que o AG foi adaptado dos estudos de Goldberg (1989) e Kagan (1999). Optou-se por uma solução de AG funcional e referenciada pela literatura.

Uma necessidade apresentada, desde o início, referia-se ao modo de realizar o percurso do circuito nó-a-nó, com a possibilidade de efetuar os cálculos. Adotaram-se, então, os algoritmos recursivos, pois alguns cálculos privilegiam valores à montante e à jusante de equipamentos. Além disso, notou-se que a estrutura em árvore adequa-se muito bem ao modelo apresentado [Cormen et al. 2002].

O TEIAG conseguiu retornar o circuito otimizado, com valores compatíveis quando comparados aos modelos estudados no Capítulo 4 - , esforço computacional otimizado e convergência de valores. Vale salientar o aspecto positivo obtido com o uso de uma metodologia para o desenvolvimento das soluções de software, em especial, o modelo em cascata. Essa opção permite desenvolver todos os seus blocos funcionais dentro do processo, de acordo com os dados documentados no Capítulo 5.

Foi necessário obter outros índices de continuidade, como DIC, FIC e DMIC, para complementar o trabalho. Dessa maneira, utilizou-se um histórico de contingências que pudesse simular o comportamento do circuito físico, inclusive com o 
emprego de chaves de manobra. Tais circunstâncias exigiram que se desenvolvesse uma linguagem para a entrada desses dados no programa CONTTEIA. A exigência foi satisfeita por meio de um arquivo texto, que lia os dados e simulava o comportamento do circuito. Essa ferramenta previa situações como cortes, falhas, atuação das chaves de proteção e manobra, realimentação por outra fonte de tensão. Adicionalmente, calculava os índices de continuidade assinalados, complementando o modelo inicial, que servia para obter o circuito otimizado e os índices DEC e FEC.

A utilização dos arquivos texto - que atuavam como entrada de dados e eram empregados no histórico de contingências - facilitou o tratamento e a manipulação das informações de entrada.

Um aspecto importante a ser explorado pelas concessionárias refere-se aos arquivos de saída, que dispõem dos valores finais dos índices de continuidade e de informações gráficas do circuito otimizado. Trata-se de dados que proporcionam uma análise rápida sobre o comportamento do circuito.

O fator de fitness e a probabilidade de mutação foram alvos de um estudo mais detalhado. Executou-se uma pesquisa na literatura existente (item 3.2.1 do Capítulo 3), de modo que os índices utilizados refletissem o modelo a ser reproduzido, com valores compatíveis àqueles das concessionárias.

O programa INVENTTEIA tem como principal função aproximar o conteúdo deste trabalho da realidade vivida pelas concessionárias, além de utilizar o AG para obter o melhor circuito com os equipamentos existentes.

Nas concessionárias, busca-se a excelência tecnológica. Contudo, nem sempre a melhor solução técnica é a que vai ser implementada, pois fatores econômicos e burocráticos acabam bloqueando a alternativa mais adequada. O INVENTTEIA possibilita que o provedor da solução obtenha uma alternativa condizente com tal realidade.

\subsection{Contribuições para estudos futuros}

Os programas desenvolvidos sugerem a continuidade do trabalho e a expansão de suas funcionalidades. Uma análise preliminar contribui para as seguintes propostas:

- um estudo financeiro, com a criação de tabelas para análises e comparação de soluções, utilizando o programa INVENTTEIA; 
- realização de uma análise circuital, partindo dos índices de continuidade, em vez de obtê-los, em conjunto, com uma análise do inventário do cliente;

- desenvolvimento de uma interface para a representação automática de circuitos;

- gerenciamento das figuras circuitais, via banco de dados relacional multimídia;

- no caso do TEIAG, é possível definir os índices, em primeiro lugar, além disso, o programa pode desenvolver o circuito e desenhá-lo;

- tratamento e modelos de soluções com variantes do AG, variações de ff e taxa de mutação; deve ser aplicado em casos de tratamento de circuitos com elevado número de nós;

- desenvolver ferramenta de proposta de manobra durante ocorrência de contingências, minimizando o efeito sobre os usuários;

- implementar as novas condições de contorno, tais como:

- Índices de continuidade;

- Fontes alternativas: cogeração;

- possibilidade de alterar cálculos visando incorporar DEC e FEC alvos na busca de uma solução otimizada por minimização de custo, a partir de valores de DEC / FEC propostos;

- considerar a existência de circuito-socorro no cálculo de DEC e FEC. 
Referências Bibliográficas

\section{Referências Bibliográficas}

[Almeida (2000)] Almeida, Marcos A. Dias de. Apostila de Proteção de Sistemas Elétricos. Fevereiro 2000. Disponível em: http://www.dee.ufrn.br/ marcos/arquivos/Prote\%E7\%E3o/Apost.\%20prot.\%2099 \%20-\%20capa.pdf.

[Anderson (2003)] Anderson, P. M. Power System Protection. IEEE Press Series On Power Engineering, 2003.

[Andrade (2007)] Andrade, Alexandre Acácio. Desenvolvimento de Sistema Especialista com Operacionalidade de Aprendizado para Operar em Tempo Real com Sistemas Industriais Automatizados. Tese (Doutorado) - Escola Politécnica da Universidade de São Paulo, São Paulo, 2007.

[ANEEL № 24 (2000)] Resolução № 24, de 27 de Janeiro de 2000 - da Agência Nacional de Energia Elétrica - ANEEL - Documento retirado da Internet. Disponível: http://www.cpfl.com.br/conselho/pdf/resolucao_24_de_27_jan_00.pdf.

[Barros (1998)] Barros, Haroldo. Proteção Contra Sobrecorrentes em Circuitos de Distribuição. $1^{a}$ Edição, Rio de Janeiro - Publicação Light Serviços de Eletricidade S. A. , 1998.

[Barros et al. (2003)] Barros, Edson de Almeida Rego; Zamboni, Lincoln César; Pamboukian, Sérgio Vicente Denser. C ++ Builder para Universitários. Páginas e Letras Editora e Gráfica, 2ª Edição, São Paulo, 2003.

[Bazaraa et al. (1993)] Bazaraa, M.S.; Sheraly, H.D.; Shety, C.M. Nonlinear Programming. Theory and algorithms. John Wiley, New York, 1993.

[Benito et al. (2006)] Benito, Edwin; Meza, Mitacc. Depuração de Parâmetros de Redes Elétricas Via Estimação de Estado e Algoritmos Genéticos. Tese de Doutorado apresentada ao Curso de Pós- Graduação em Computação da Uni- 
versidade Federal Fluminense. Área de concentração: Aplicações. Sub-área: Computação em Potência. Niterói, 2006.

[Bentley (2002)] Bentley, Peter J. Biologia Digital. Editora Berkeley, 2002.

[Bentley et al. (2002)] Bentley, Peter J; Corne D. W. Creative Evolutionary Systems. Morgan-Kaufmann, San Francisco, 2002.

[Billington et al. (1996)] Billington, R., Jonnavithula, S. Optimal Switching Device Placement in Radial Distribution Systems. IEEE Transaction on Power Delivery, Vol. 11, no 3, July 1996.

[Bishop (1997)] Bishop, M.T. Establishing Realistic Reliability Goals. The Tech Advantage 97 Conference \& Electric Expo, March 1997.

[Bishop et al. (1995)] Bishop, M.T.; Jones, A.G.; Israel, W.F. Overcurrent protection alternatives for underground distribution systems. Power Delivery, IEEE Transactions on Volume 10, Issue 1, Jan. 1995, pag.: 252 - 257 - Digital Object Identifier 10.1109/61.368392.

[Bishop et al. (1996)] Bishop, M.T.; Mendis, S.R.; Witte, J.F.; Myers, P. Overcurrent protection device miscoordination issues that result in plant outages and costly down time. Petroleum and Chemical Industry Conference, 1996, Record of Conference Papers. The Institute of Electrical and Electronics Engineers Incorporated Industry Applications Society 43rd Annual - 23 - 25 Sept. 1996 Page(s):183 - 189-Digital Object Identifier 10.1109/PCICON.1996.564886.

[Bishop et al. (1999)] Bishop, M.T.; Mendis, S.R.; Witte, J.F.; Myers, P. Device miscoordination affects plant reliability. Industry Applications Magazine, IEEE - Volume 5, Issue 2, March-April 1999, pag.:32 - 37 - Digital Object Identifier 10.1109/2943.750390.

[Bishop et al. (2000)] Bishop, M.T.; McCarthy, C.A.; Josken, J. Considering reliability in the selection of distribution system overcurrent protection devices. Rural Electric Power Conference, 2000 - 7-9 May 2000, pag.: A3/1 - A3/5 - Digital Object Identifier 10.1109/REPCON.2000.848036.

[Bledsoe (1961)] Bledsoe, W. W. The use of biological concepts in the analytical study of systems. Paper presented at the ORSA-TIMS National Meeting, San Francisco, CA., 1961. 
[Bremermann (1962)] Bremermann, H. J. Optimization through evolution and recombination. In M.C. Yovits, G. T. Jacobi, \& G.D. Goldstein (Eds), Selforganizing systems. Washington, D.C., Spartan Books, 1962.

[Brown et al. (1996)] Brown, R. E.; Gupta, S. Christie, R. D.; Venkata, S. S. A genetic algorithm for reliable distribution system design. In: International Conference on Intelligent Systems Applications to Power Systems. ISAP96. Orlando. EUA. Anais, p. 29-33, 1996.

[Burden et al. (2003)] Burden, Richard; Faires, J. Douglas. Análise Numérica. São Paulo, Pioneira Thomson Learning, 2003.

[Burian (2001)] Burian, Reinaldo. Eficiência Operativa e Confiabilidade de Equipamentos Associados à Automação de Sistemas de Distribuição de Energia Elétrica. Dissertação de Mestrado - Escola Politécnica da Universidade de São Paulo - Departamento de Engenharia Elétrica. São Paulo, 2001.

[Burian et al. (2007)] Burian, Reinaldo; de Lima, Antonio Carlos; Jr. Hetem, Annibal. Cálculo Numérico. Rio de Janeiro, LTC, 2007.

[Burian et al. (2009)] Burian, R. ; de Moraes, C., C. ; Hetem, A. Electric Power Distribution Protective Devices Allocation with Genetic Algorithms. Conferencia Iberoamericana en Sistemas, Cibernética e Informática (CISCI 2009) - EUA, Julho de 2009.

[Carvalho et al. (2003)] Carvalho, A. C. P. L.; Braga, A. P.; Ludemir, T. B. Computação Evolutiva, In Rezende, S. O. (coord), Sistemas Inteligentes - Fundamentos e Aplicações, 1aㅡ Edição, cap. 9, São Paulo, Brasil, 2003, Editora Manole.

[CEMIG (1994)] CEMIG .Proteção Contra Sobrecorrentes em Redes de Distribuição Aéreas. Diretoria de Distribuição. Estudo de Distribuição - ED - 3.3, Novembro de 1994.

[Cláudio et al. (1994)] Cláudio, Dalcídio Moraes; Marins, Jussara Maria. Cálculo Numérico Computacional: teoria e prática. $2^{\underline{a}}$ Edição - São Paulo: Atlas, 1994.

[Coate et al. (2001)] Coate, Brian D.; Wareham, Don C. IEEE TRANSACTIONS ON INDUSTRY APPLICATIONS. Vol. 37, No. 2, MARCH/APRIL 2001. 
[Cooper (1990)] Cooper Power Systems. Electrical Distribution-System Protection - A Textbook and Practical Reference on Overcurrent and Overvoltage Fundamentals, Protective Equipment and Applications. Charles V. Walker, Editorial and Marketing Services, 1990.

[Cooper (1998)] Cooper Power Systems. Switch vs. Recloser-Inovations. April 1998.

[Cormen et al. (2002)] Cormen, T. H.; Leiserson, C. E.; Rivest, R. L.; Stein, C. Algoritmos, 2ª Edição, Editora Campus, 2002.

[Darwin (1859)] Charles Darwin. On The Origin of Species, 1st edition, Harward University Press, MA, 1859.

[Delamaro et al. (2007)] Delamaro, Marcio Eduardo; Maldonado, José Carlos; Jino, Mano. Introdução ao Teste de Software. Elsevier, Rio de Janeiro, 2007.

[Eiben (2002)] Eiben, A. E. Evolutionary Computing: the most powerful problem solver in the universe? Dutch Mathematical Archive (Nederlands Archief voor Wiskunde), 2002. Disponível em: http://www.cs.vu.nl./ gusz/papers/ec-intronaw.ps.

[Eiben et al. (2004)] Eiben, A. E.; Smith, J. E. Introduction to Evolutionary Computing. Springer Verlag NY, 2004.

[Fernandez et al. (1989)] Fernandez, Porto Marcial; Pedroza, P. Aloysio de Castro; Rezende, J. F. Implementação de Políticas de Gerenciamento com Lógica Fuzzy e Algoritmo Genético visando à Melhoria da Qualidade de Serviço (QOS). 1989.

[Flake (1998)] Flake, Gary William. The computational beauty of nature: computer explorations of fractals, chaos, complex systems, and adaptation. Bradford Book, 1998.

[Fogel (2002)] Fogel, D. B. Evolutionary Computation. IEEE Press, 1995.

[Goldberg (1989)] Goldberg, David E. Genetic Algorithms in Search, Optimization, and Machine Learning. Addison Wesley, 1989.

[Goldberg (1991)] Goldberg, David E. A Note on Boltzman Tournament Selection for Genetic Algorithms and Population - Oriented Simulated Annealing. Complex System 3, 1991. 
[Grefenstette (1991)] Grefenstette, J. Conditions for Implicit Parallelism. Navy Center for Applied Research in Artificial Intelligence, Internal Report, Washington, 1991.

[Hetem et al. (2007)] Hetem Jr., Annibal; Hetem, Jane Gregorio. The use of genetic algorithm to model protoplanetary discs. Fundação Santo André- FAFIL e Universidade de São Paulo, IAG-USP, Dezembro 2007.

[Holland (1975)] Holland, J. H. Adaptation in Natural and Artificial Systems, 1975).

[Jardini (1996)] Jardini, José A. Sistemas Digitais para Automação da Geração, Transmissão e Distribuição de Energia Elétrica. Edição Acadêmica, 1996.

[Kagan (1999)] Kagan, Nelson. Configuração de Redes de Distribuição através de Algoritmos Genéticos e Tomada de decisão Fuzzy. Tese de Livre Docente - Universidade de São Paulo - Engenharia Elétrica - EPUSP - 1999.

[Kagan et al. (2005)] Kagan, Nelson; De Oliveira, Carlos César Barioni; Robba, Ernesto João. Introdução aos Sistemas de Distribuição de Energia Elétrica. ${ }^{a}$ Edição, São Paulo - Blucher, 2005.

[Kalyvas (2001)] Kalyvas, Efstathios. Using neural networks and genetic algorithms to predict stock market returns. Thesis submitted to the University of Manchester for the degree of master of science in advanced computer cience Faculty of science and engineering, Department Of Computer Science, 2001.

[Koza (1994)] Koza J. R. Genetic Programming II: Automatic Discovery of Reusable Programs. MIT Press, 1994.

[Leung et al. (2003)] Leung, Frank H. F.; Lam, H. K.; Ling, S. H.; Tam, Peter K. S. Tuning of the Structure and Parameters of a Neural Network Using an Improved Genetic Algorithm. IEEE Transactions on Neural Networks, Vol. 14, no 1, January 2003.

[Linden (2006)] Linden, Ricardo. Algoritmos Genéticos - Uma importante ferramenta da Inteligência Computacional. Editora Brasport, 2006. 
[Ling et al. (2006)] Ling, S. H.; Leung, Frank H. F. An improved genetic algorithm with average-bound crossover and wavelet mutation operations. Soft Comput - DOI 10.1007/s00500-006-0049-7 - Springer-Verlag 2006.

[Ling et al. (2007)] Ling, S. H.; Leung, Frank H. F.; Lam, H. K. Input-dependent neural network trained by real-coded genetic algorithm and its industrial applications. Soft Comput - DOI 10.1007/s00500-007-0151-5 - Springer-Verlag 2007.

[Magrini (1995)] Magrini, Luiz C. Concepção de um Sistema Digital de Supervisão e Controle para Subestações de Energia Elétrica. Dissertação (Mestrado) - Escola Politécnica da Universidade de São Paulo. São Paulo, 1995.

[Mayr (1988)] Mayr, E. Toward a New Philosophy of Biology: Observations of an Evolutionist. Belknap, Cambridge, MA, 1988.

[McCarthy et al. (1999)] McCarthy, C.A.; Bishop, M.T.; Rose, V.G.; Stanek, E.K. Considering momentary and sustained reliability indices in the design of distribution feeder overcurrent protection. Transmission and Distribution Conference, 1999 IEEE Volume 1, 11-16 April 1999, pag.:206 - 211 vol.1 - Digital Object Identifier 10.1109/TDC.1999.755342.

[McCarthy et al. (2000)] McCarthy, C.A.; Bishop, M.T.; Witte, J.F.; Day, T.R.; DeAlcala, G. Distribution system reliability improvements justified by increased oil production. Industry Applications, IEEE Transactions on Volume 36, Issue 6, Nov.-Dec. 2000, pag.:1697 - 1703 - Digital Object Identifier $10.1109 / 28.887224$.

[Mendis et al. (1991)] Mendis, S.R.; Bishop, M.T.; Gonzalez, D.A. Rule-based coordination program evaluates distribution transformer overcurrent protection alternatives. Computer Applications in Power, IEEE - Volume 4, Issue 2, April 1991, pag.: 31 - 36, Digital Object Identifier 10.1109/67.75873.

[Mendis et al. (1993)] Mendis, S.R.; Bishop, M.T.; McCall, J.C.; Hurst, W.M. Overcurrent protection of capacitors applied on industrial distribution systems. Industry Applications, IEEE Transactions on Volume 29, Issue 3, May-June 1993 pag.:541 - 547 - Digital Object Identifier 10.1109/28.222424. 
[Michalewicz et al. (1997)] Michalewicz, Z.; Baeck, T.; Fogel, D. B. Handbook of Evolutionary Computation. Editora Taylor \& Francis USA, 1997.

[Miranda et al. (1994)] Miranda, V.; Ranito, J. V.; Proença, L. M. Genetic algorithms in Optimal multi-stage distribution network planning. IEEE Transactions on Power Systems, vol. 9, n. 4, Nov. 1994.

[Mishra et al. (2007)] Mishran S.; Reddy, G. D.; Eswar Rao, P. Santosh, K. Implementation of New Evolutionary Techniques for Transmission Loss Reduction. 2007 IEEE Congress on Evolutionary Computation, pag.: 2331, 2007.

[Nara et al. (1992)] Nara, K.; Shiose, A.; Kitagawa, M.; Ishihara, T. Implementation of genetic algorithm for distribution systems loss minimum reconfiguration. IEEE transactions on Power Systems, vol. 7, n. 3, p. 1044-51, Aug. 1992.

[Narayanan et al. (2005)] Narayanan, Ajit; Keedwell, Edward; Savic, Dragan. Data mining neural networks with genetic algorithms. School of Engineering and Computer Science University of Exeter, Exeter EX4 4PT, United Kingdom, 2005.

[Natschläger et al. (2004)] Natschläger, Thomas; Kossak, Felix; Drobics, Mario. Extracting Knowlegde and Computable Models from Data - Needs, Expectations and Experience. Software Competence Center Hageberg - A-4232 Hagenberg, Austria - IEEE 2004.

[Neelakanta et al. (1994)] Neelakanta, P. S.; DeGroff, Dolores. Neural Network Modeling: Statistical Mechanics and Cybernetic Perspectives. CRC Press, CRC Press LLC, ISBN: 0849324882, 1974.

[Neto et al. (2005)] Neto, Paulo S. G. de Mattos; Petry, Gustavo G.; Ataide, João P. de M; Ferreira, Tiago A. E. Combinação de Redes Neurais Artificiais com Algoritmo Genético Modificado para a Previsão de Séries Temporais. XXV Congresso da Sociedade Brasileira de Computação. Rio Grande do Sul, 2005.

[Oliveira et al. (2004)] Oliveira, Humberto César Brandão de. Adaptação do Algoritmo Genético no Tratamento do Problema de Roteamento de Veículos com Janela de Tempo. Universidade Federal de Minas Gerais - UFMG, 2005. 
[Pereira (2007)] Pereira, Ricardo Dejanir. Um Sistema de Software para execução de estudos de coordenação e seletividade em Sistema de Distribuição. Dissertação (Mestrado) - Universidade Federal de Itajubá - MG, 2007.

[Pereira et al. (1996)] Pereira, Allan Cascaes; Severo Bernardo. Digitalização de Subestações Industriais, incluindo Proteção Digital. Revista Eletricidade Moderna. Novembro, 1996.

[Pressman (2002)] Pressman, Roger S. Engenharia de Software. McGraw-Hill, Rio de Janeiro, 5ª Edição, 2002.

[Rechenberg (1965)] Rechenberg, I. Cybernet solution path of an experimental problem. Farnborough Hants: Ministry of Aviation, Royal Aircraft Establishment, 1965.

[Reed (1993)] Reed, Russell. Pruning Algorithms - A Survey. IEEE Transaction on Neural Networks, vol. 4, num. 5, September 1993.

[Rocha et al. (2001)] Rocha, Ana Regina Cavalcanti da Zebulum, R. S.; Pacheco, M. A. C.; Vellasco, M. M. B. R. Evolutionary Electronics - Automatic Design of Electronic Circuits and Systems by Genetic Algorithms. The CRC Press International Series On Computational Intelligence, 2001.

[Rojas et al. (2008)] Rojas, G.; Gregorio-Hetem, J; Hetem Jr., A. Towards the main sequence: detailed analysis of weak line and post-T Tauri stars. Monthly Notices of the Royal Astronomical Society, v. 387, p. 1335-1343, 2008.

[Russell et al. (2003)] Russell, Stuart J.; Norvig, Peter. Artificial Intelligence: A Modern Approach. 2nd Edition, Upper Saddle River, NJ: Prentice Hall, pag. 111-114, ISBN 0-13-790395-2.

[Siqueira et al. (1988)] Siqueira, Gustavo F. G.; Achkar, Luiz Roberto; Yamanaka, Alberto S.. Os Benefícios da Automação de Sistemas Elétricos para a Qualidade de Energia. Revista Eletricidade Moderna, Abril 1988.

[Soares (1997)] Soares, Gustavo Luís. Algoritmo Genético: Estudo, Novas Técnicas e Aplicações. Dissertação de Mestrado - CPDEE - UFMG - 1997.

[Sommerville (2007)] Sommerville, lan. Engenharia de Software. Pearson Addi-

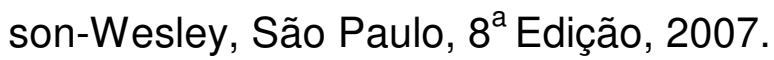


[Souza (2005)] Souza, Emilio Celso de. Otimização da Alocação de Empuxo em Sistema de Posicionamento Dinâmico. Dissertação de Mestrado - Escola Politécnica da Universidade de São Paulo - Departamento de Engenharia Mecânica. São Paulo, 2005.

[Vasconcelos et al. (2001)] Vasconcelos, J. A.; Ramirez, J. A.; Takahashi, R. H. C.; Saldanha, R. R. Improvements in Genetic Algorithms. IEEE Transactions on Magnetics, Vol. 37, N 5, September 2001.

[Westinghouse (1964)] Westinghouse Electric Corporation. Electrical Transmission and Distribution Reference Book. Publicação Westinghouse, Pennsylvania, 1996.

[Whitley (2007)] Whitley, Darrell. A Genetic Algorithm Tutorial. Computer Science Department_Colorado State University, 2007.

[Witte et al. (1992)] Witte, J.F.; Mendis, S.R.; Bishop, M.T.; Kischefsky, J.A. Computer-aided recloser applications for distribution systems. Computer Applications in Power, IEEE - Volume 5, Issue 3 July 1992, pag.: 27 - 32 - Digital Object Identifier 10.1109/67.143271.

[Yeh et al. (1996)] Yeh, E. C.; Venkata, S. S.; Sumic, Z. Improved Distribution System Planning Using Computational Evolution. IEEE Transactions on Power Systems, Vol. 11, N 2, May 1996.

[Zebulum et al. (2001)] Zebulum, R. S.; Pacheco, M. A. C.; Vellasco, M. M. B. R. Evolutionary Electronics - Automatic Design of Electronic Circuits and Systems by Genetic Algorithms. The CRC Press International Series On Computational Intelligence, 2001. 
Anexo A

\section{Funções Específicas dos Programas TEIAA, TEIAG, CONTITEIA e \\ INVENTEIA}

\section{Anexo A - Funções: TEIAA, TEIAG, CONTITEIA e INVENTEIA}

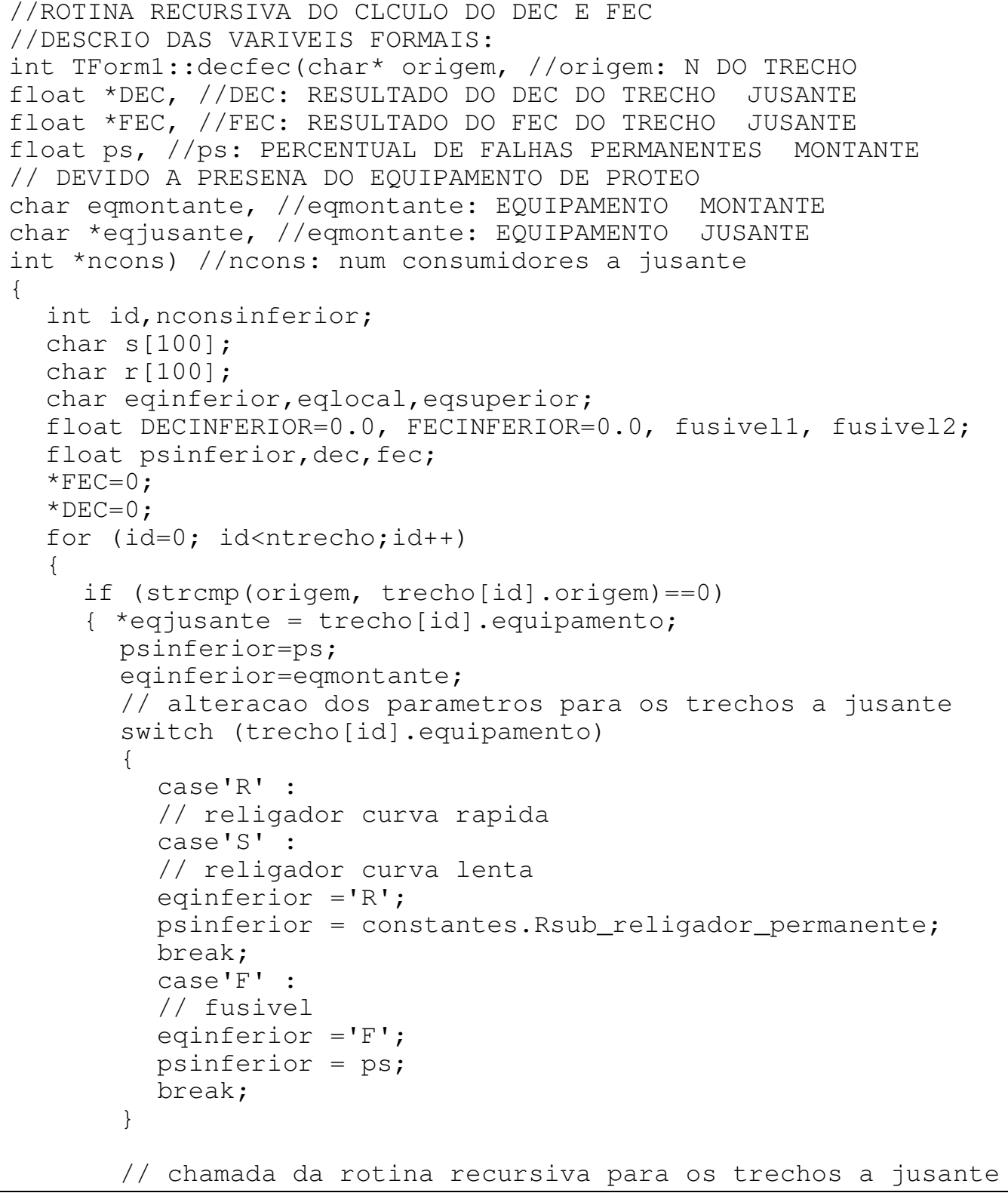




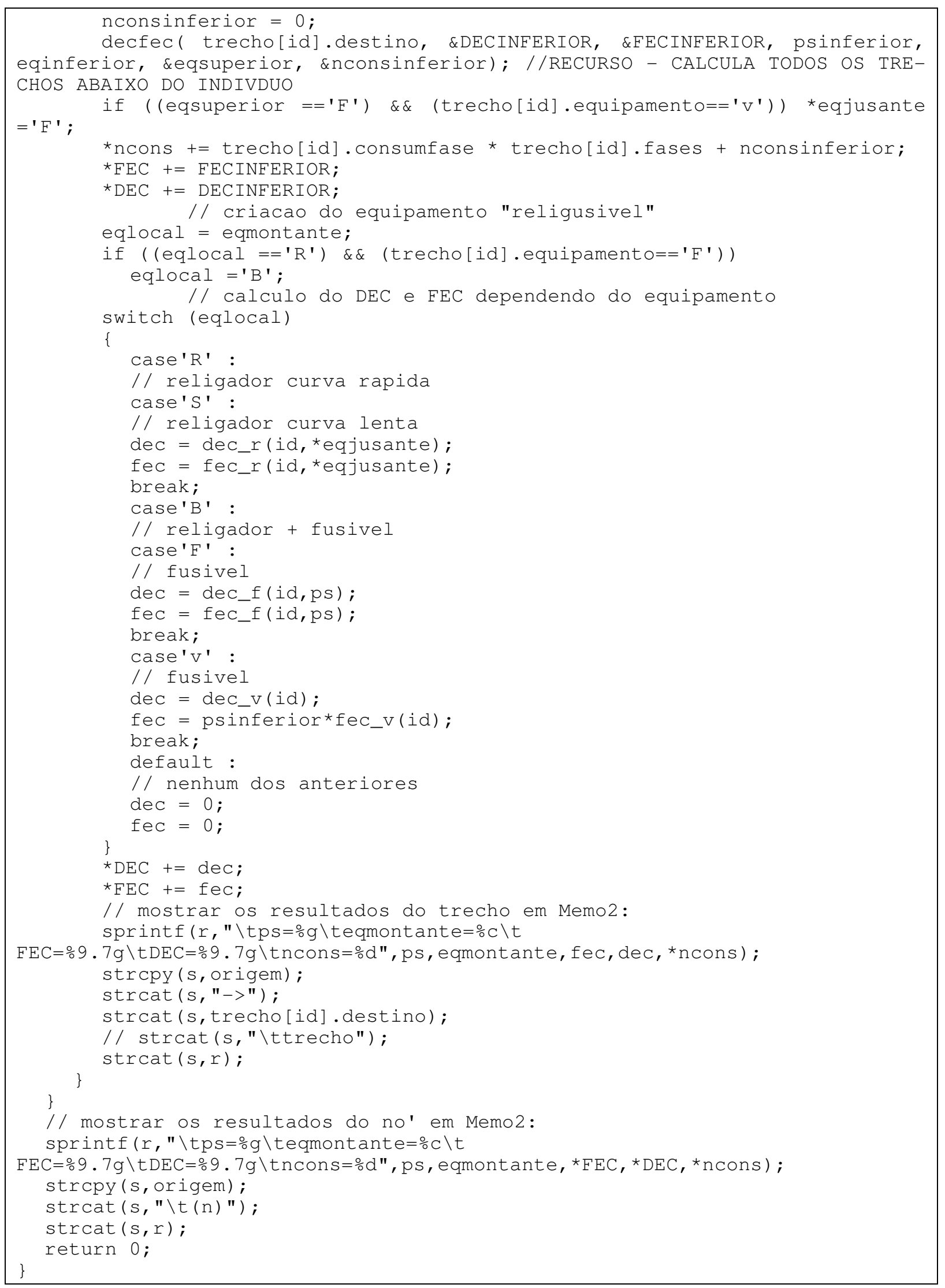

Figura A.1 - Função DecFec 


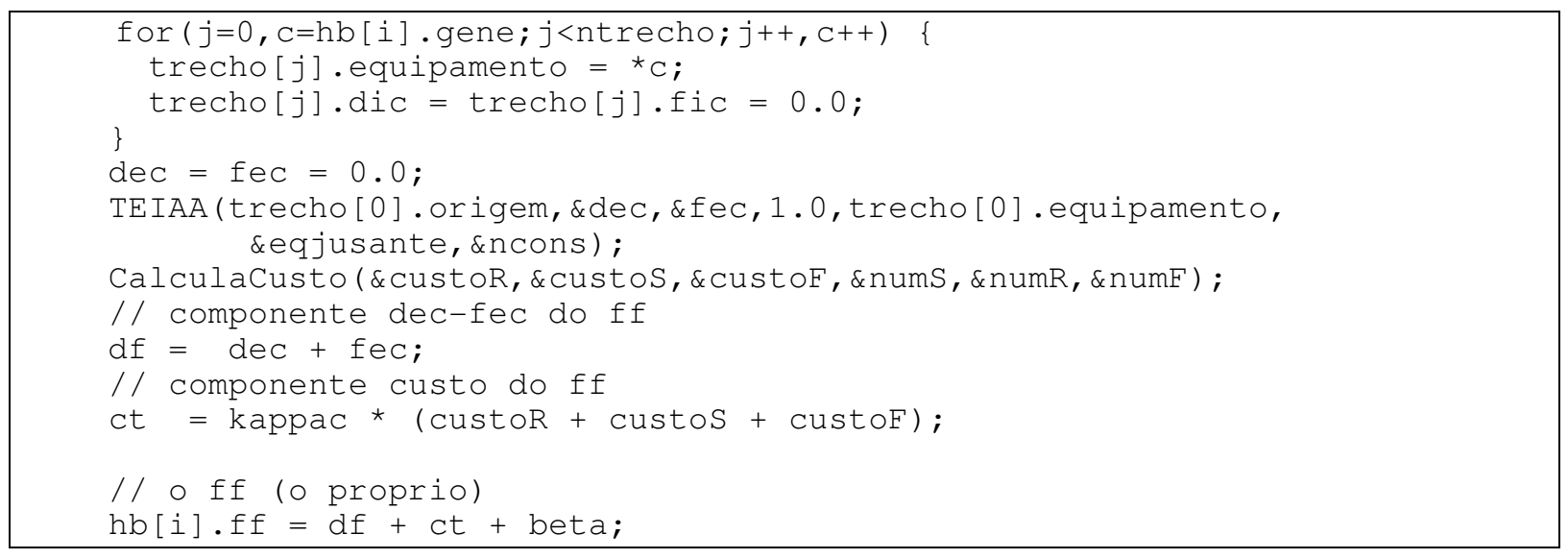

Figura A.2 - Cálculo do fator de fitness

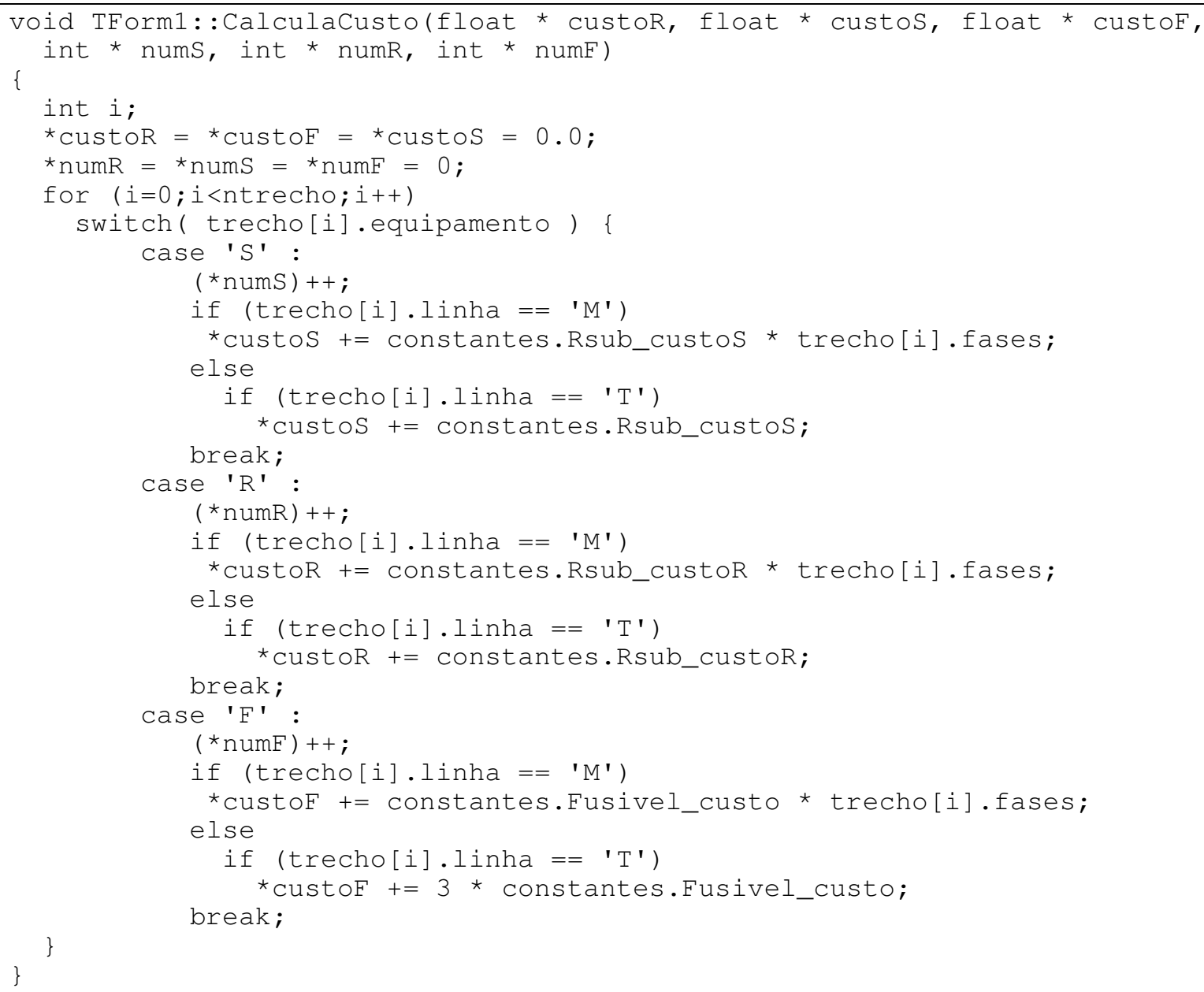

Figura A.3 - Função CalculaCusto 


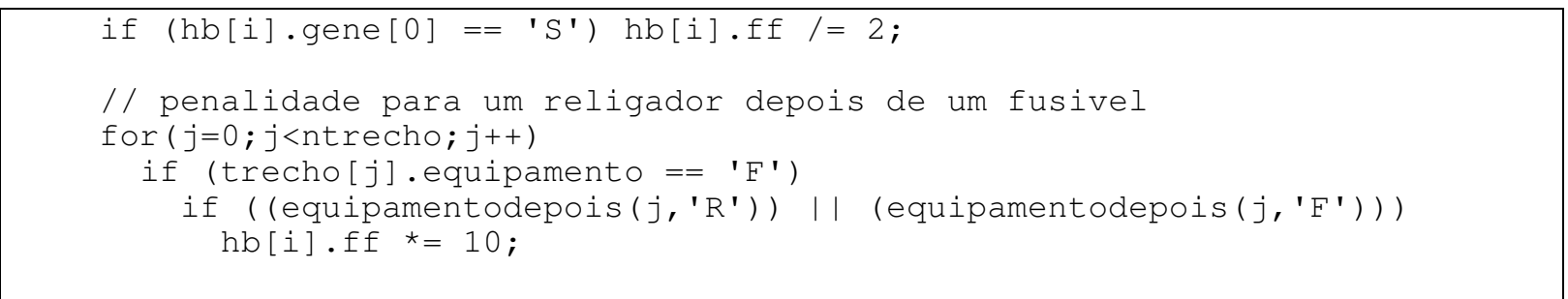

\section{Figura A.4 - Regras para alocação de equipamentos}

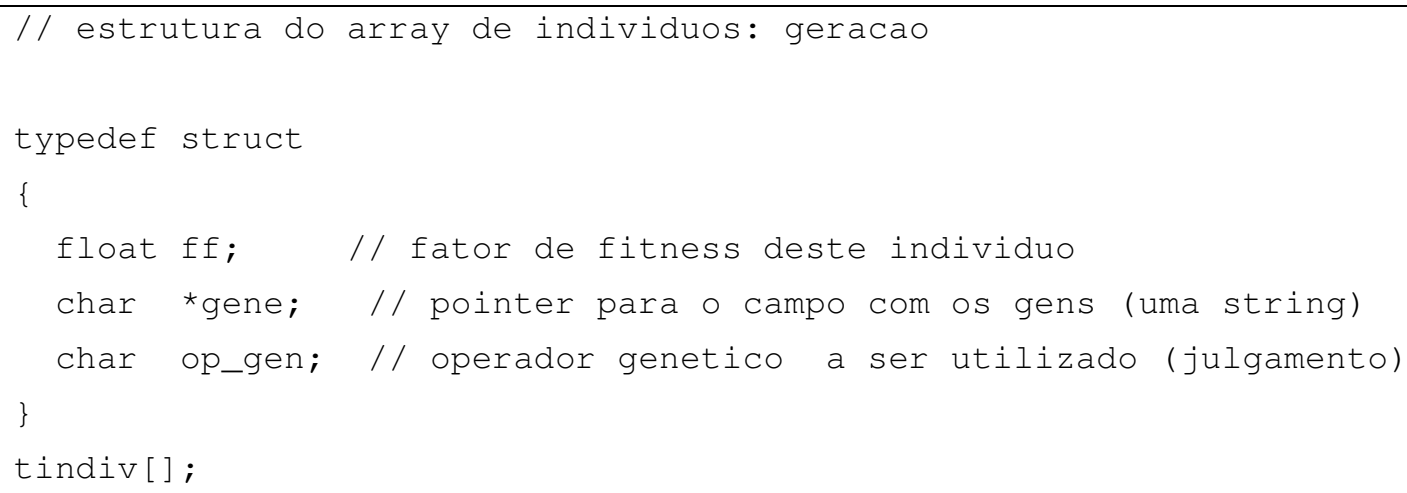

Figura A.5 - Estrutura array utilizada

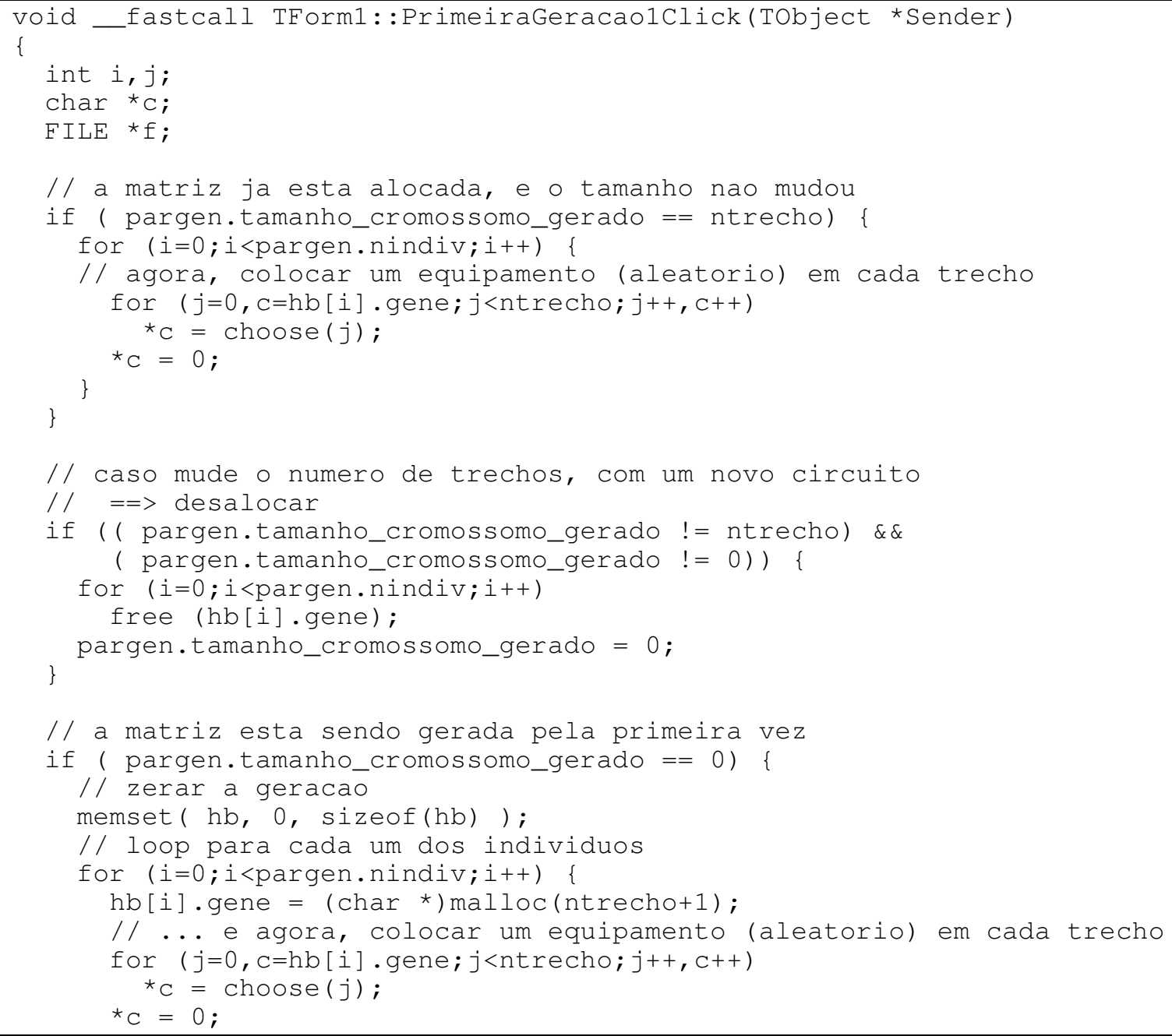




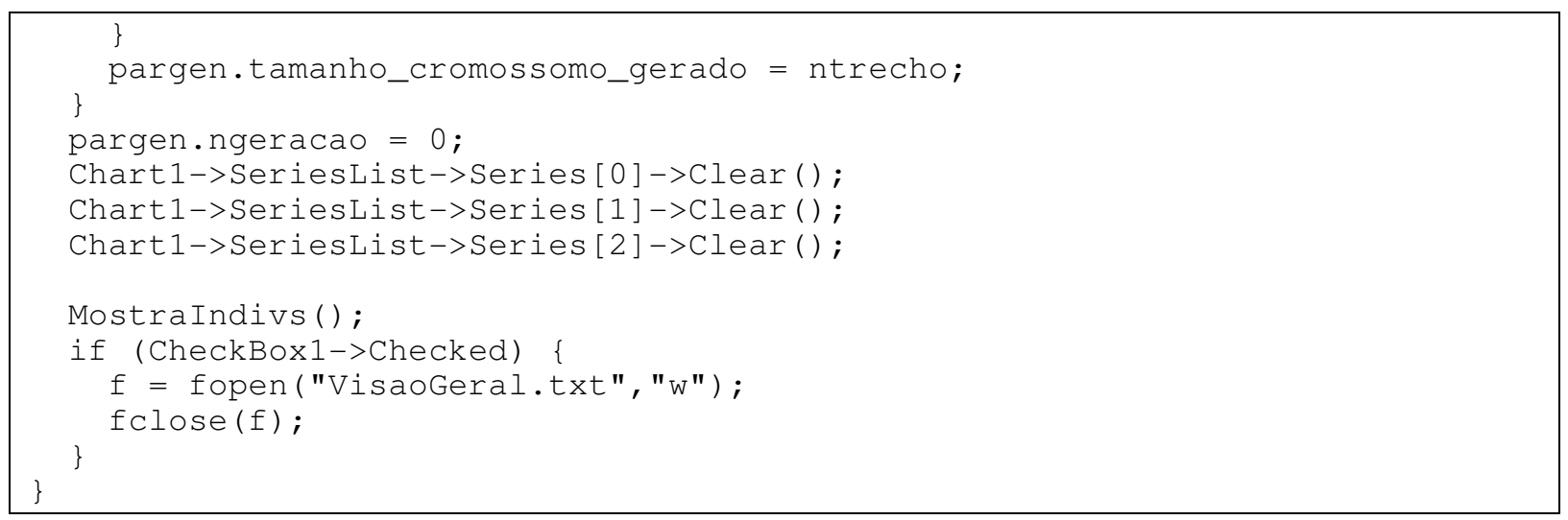

Figura A.6 - Primeira geração

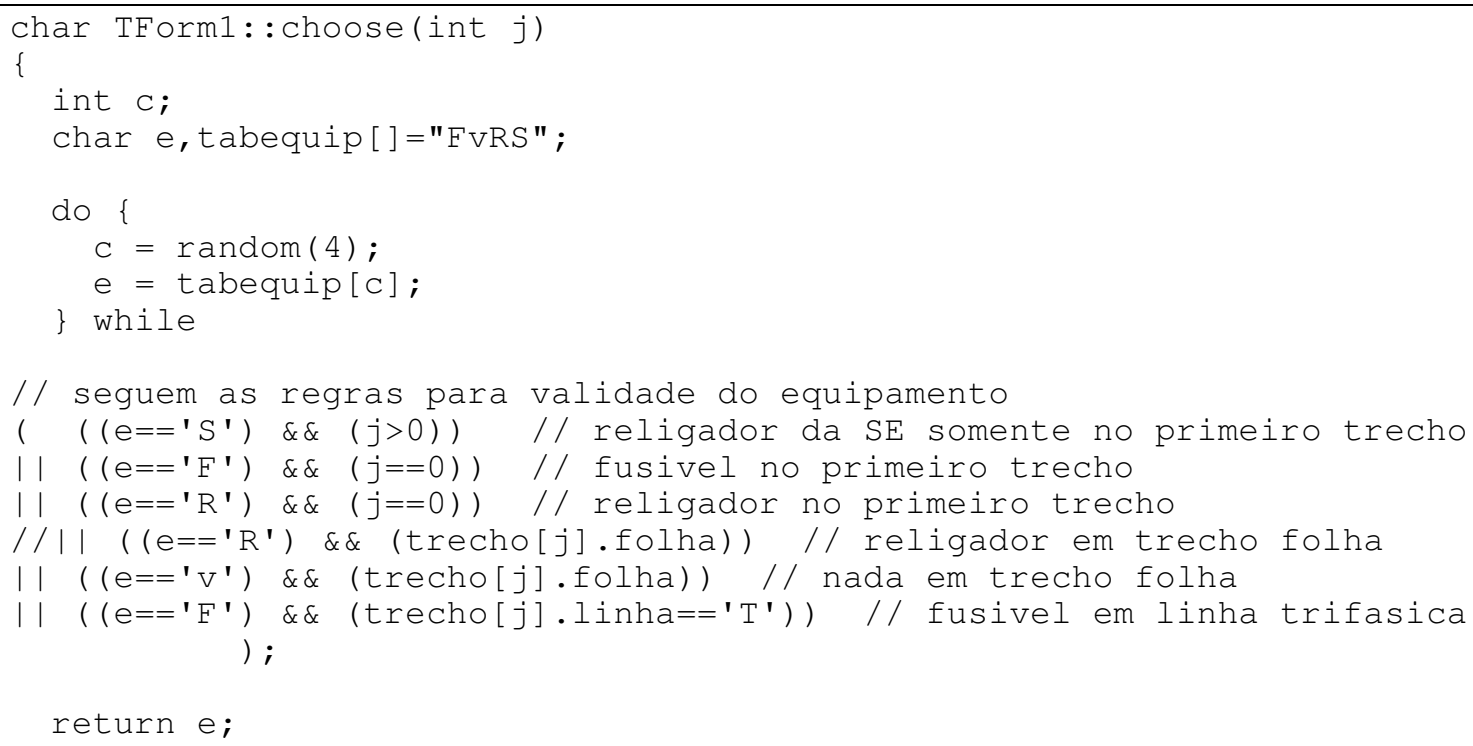

Figura A.7 - Função que escolhe um equipamento de proteção (gene)

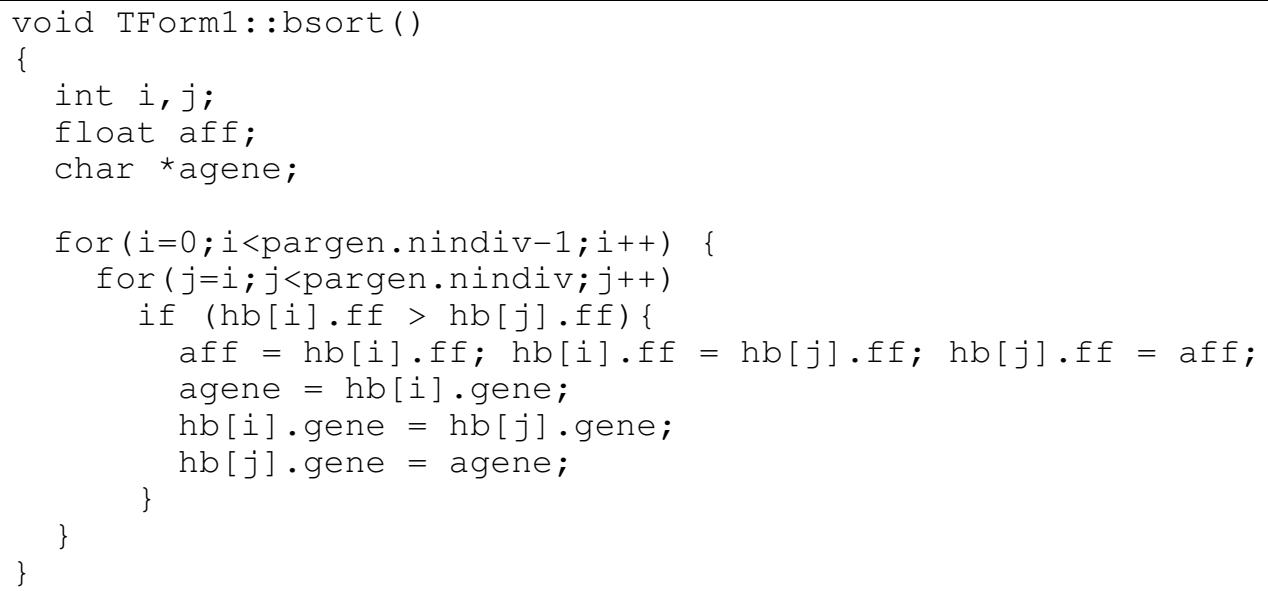

Figura A.8 - Rotina de ordenação dos cromossomos por fator de fitness 


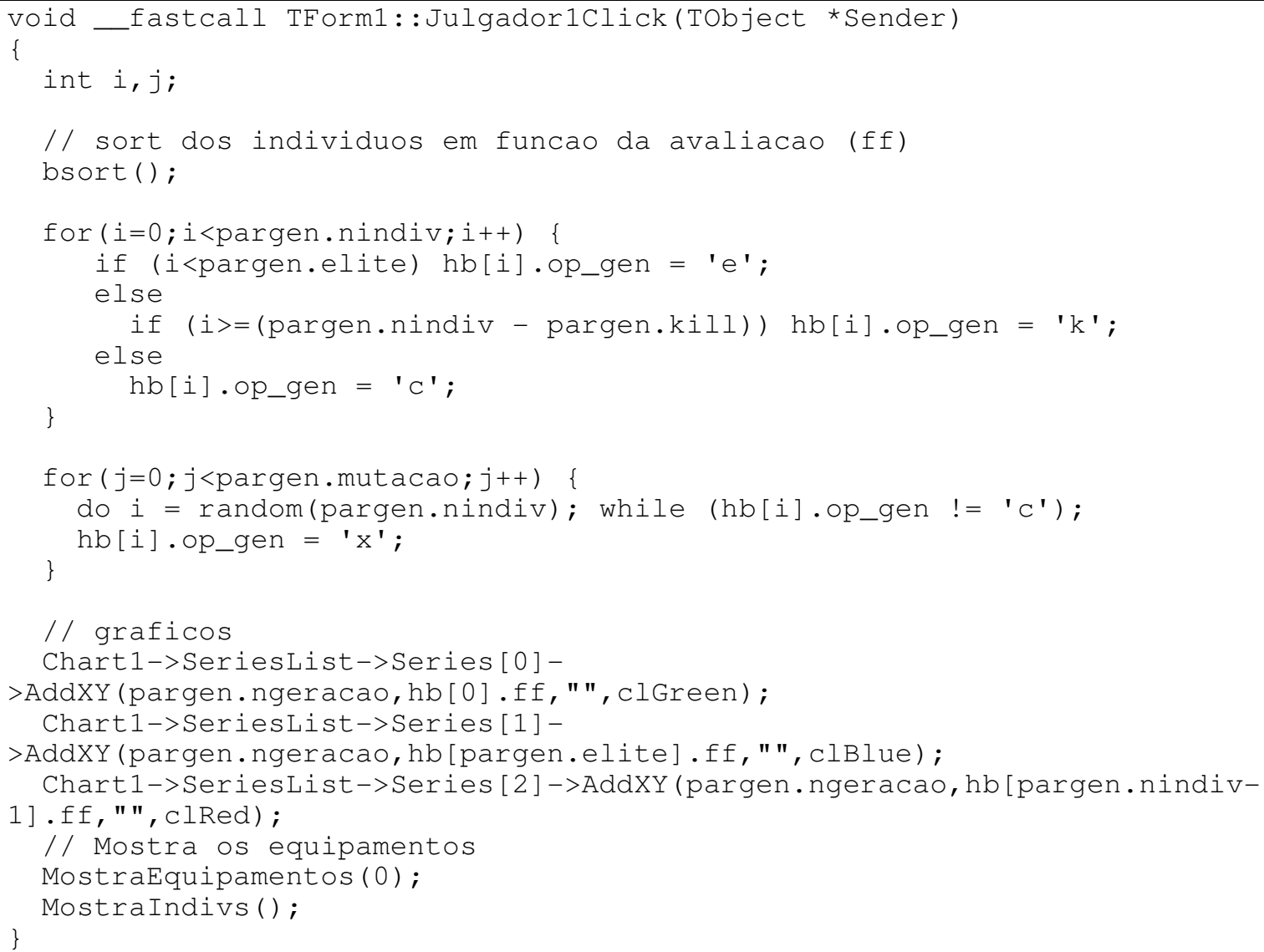

Figura A.9 - Função Julgadora

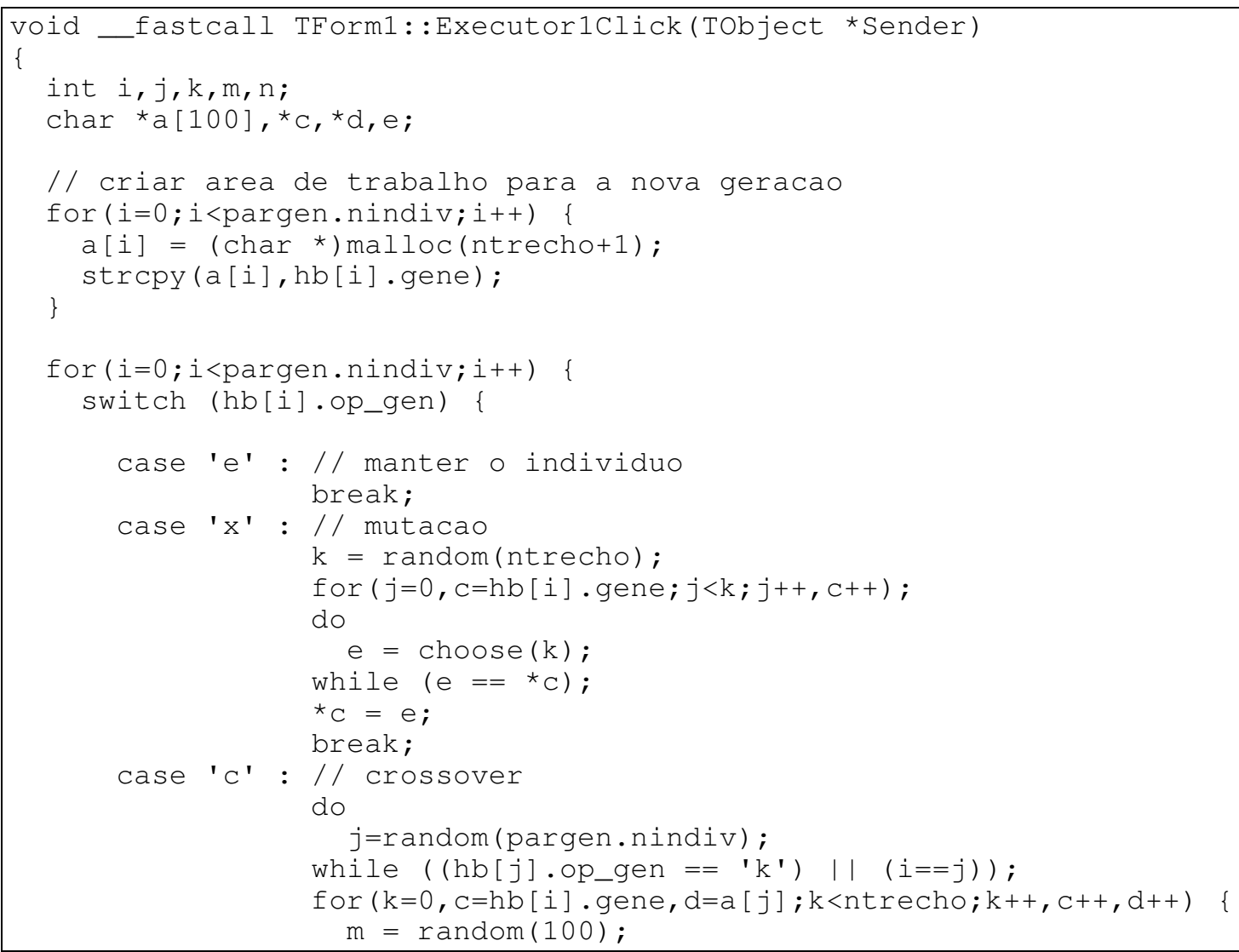




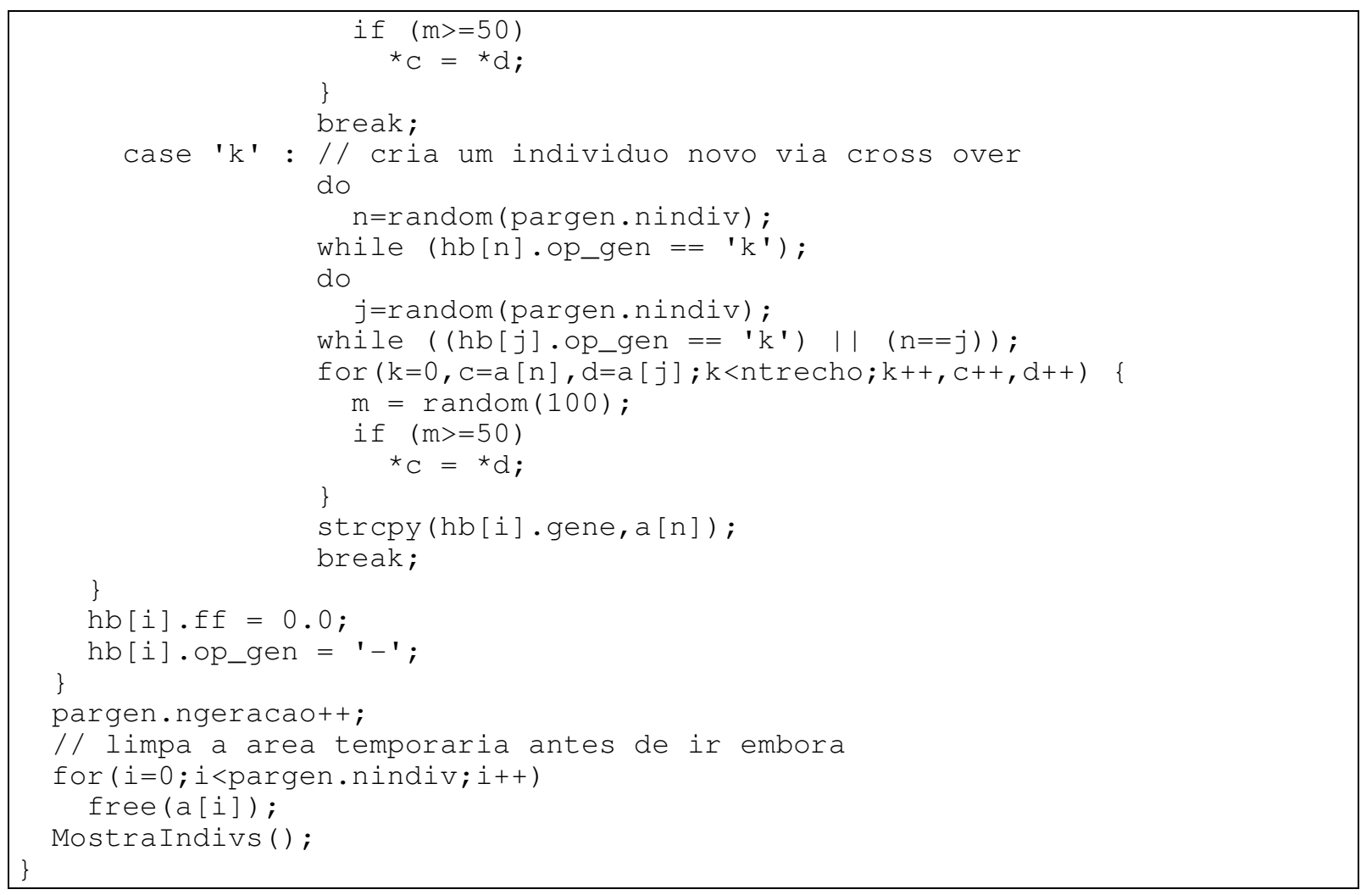

Figura A.10 - Função Executora

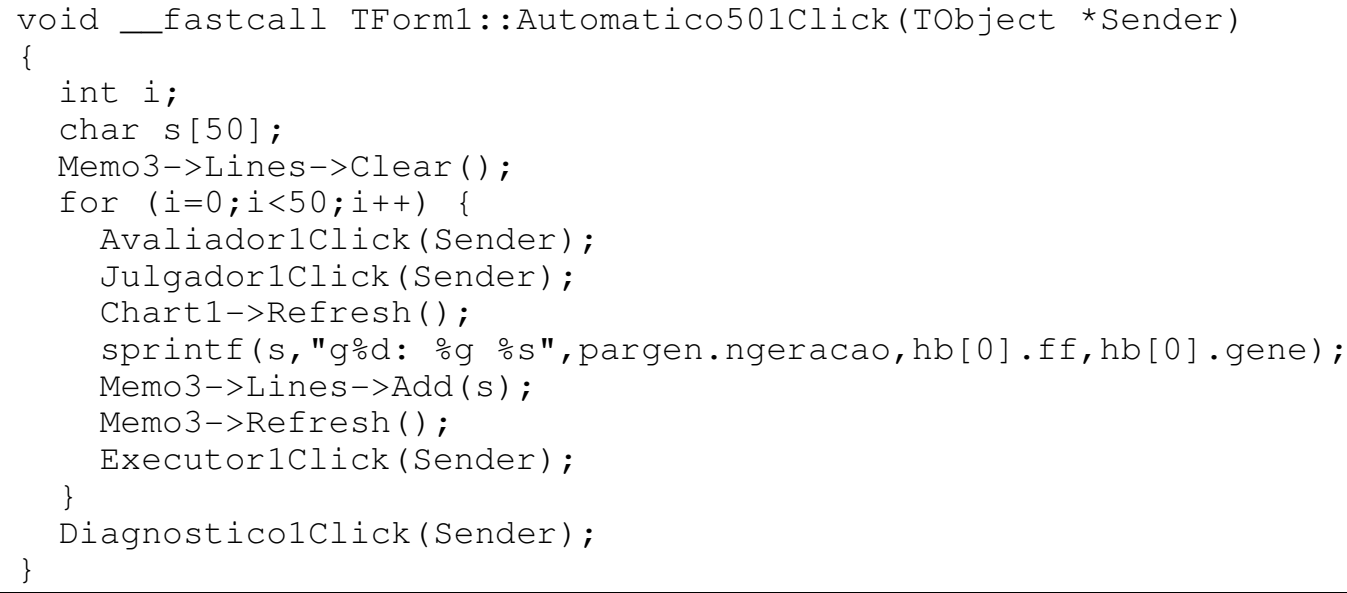

Figura A.11 - Função Automático 50

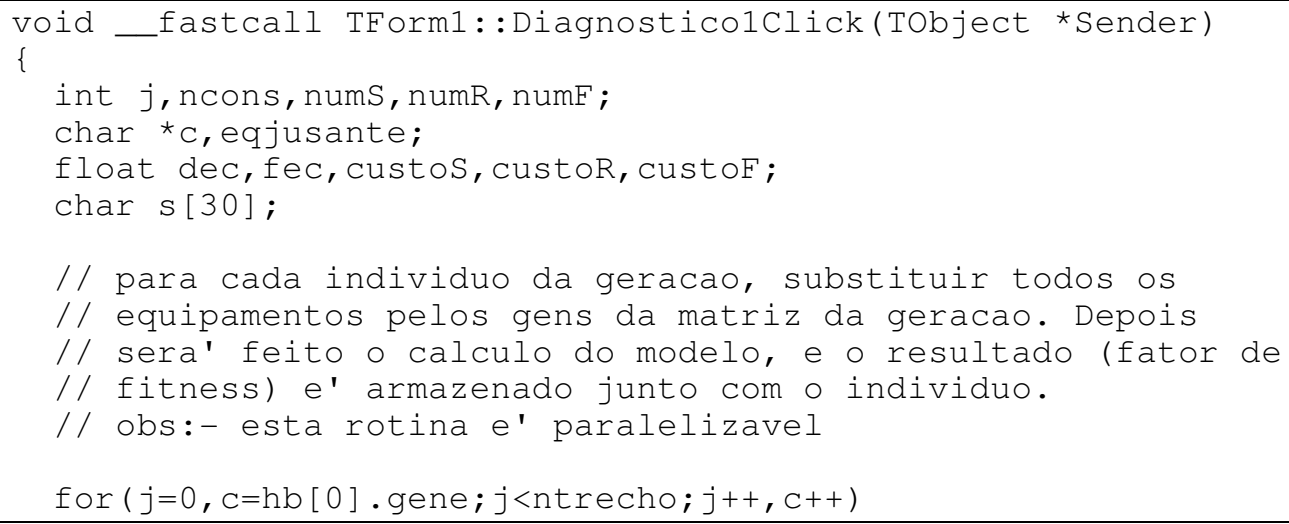




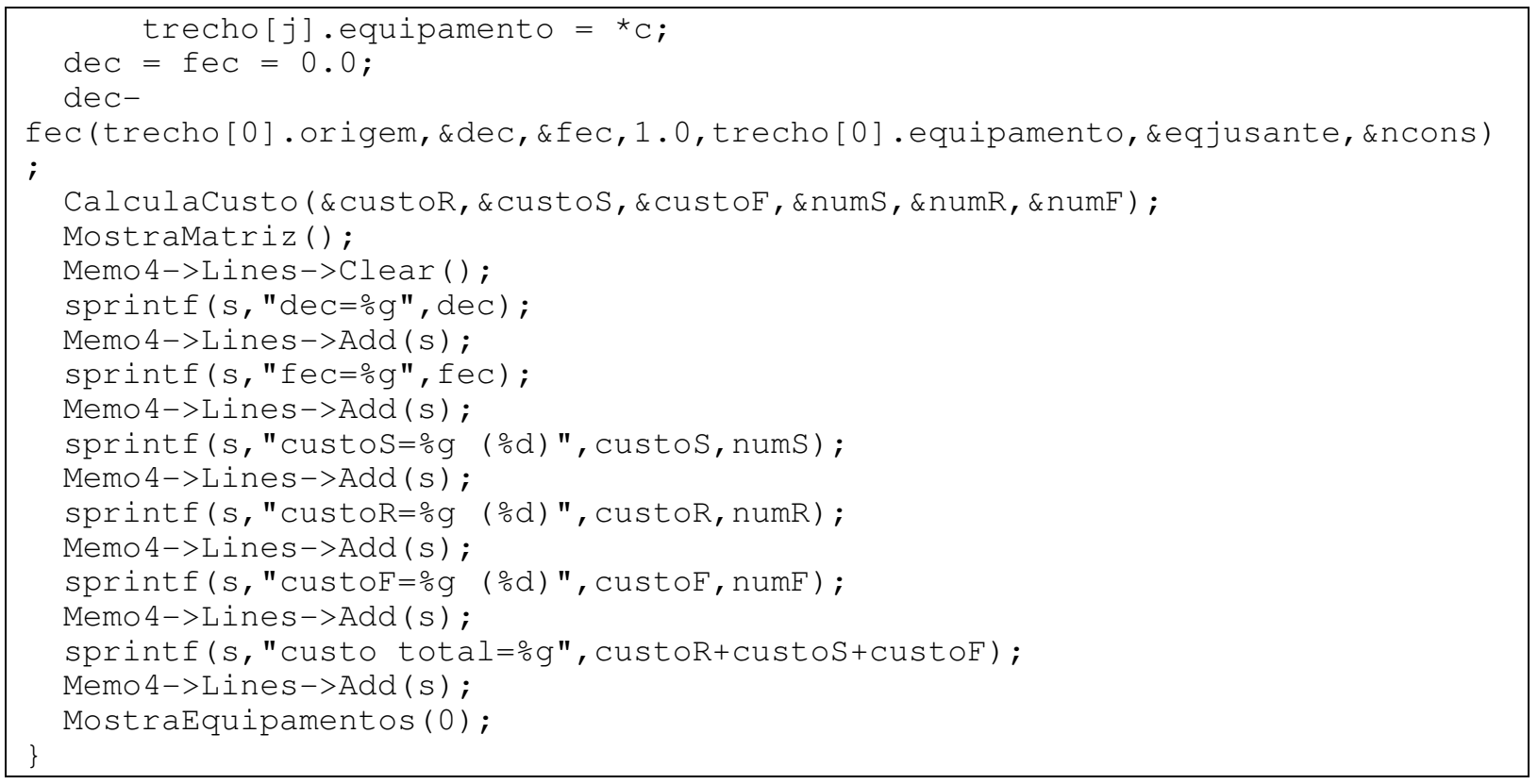

\section{Figura A.12 - Função Diagnóstico}

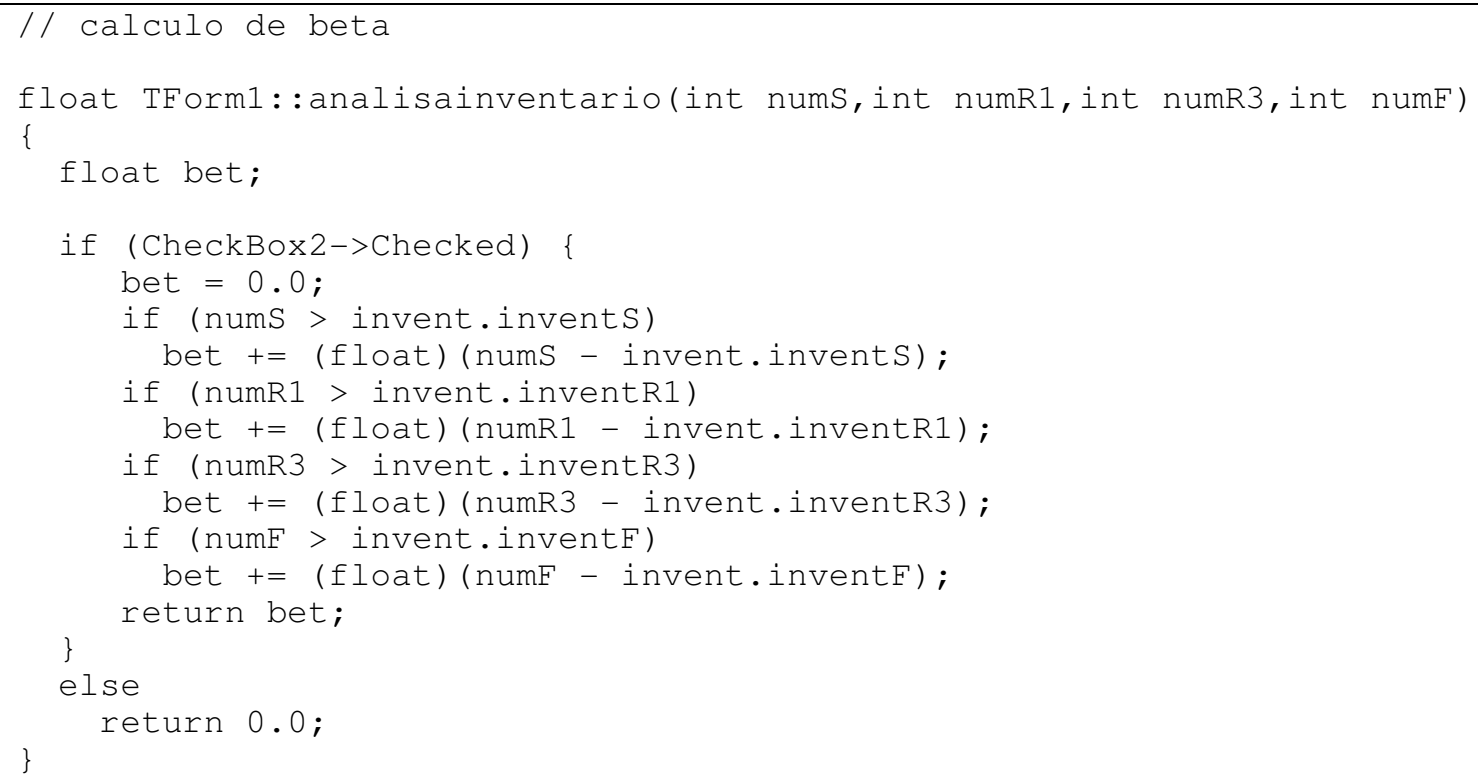

Figura A.13 - Cálculo do valor de $\beta$ 
Anexo B

\section{Equipamentos de proteção para a distribuição de energia elétrica}

\section{Anexo B - Equipamentos de proteção para a distribuição de ener- gia elétrica}

Este anexo apresenta uma descrição dos equipamentos de proteção utilizados na distribuição de energia elétrica.

\section{B.1 Equipamentos de proteção para a distribuição de energia elétrica}

A continuidade de serviços elétricos pode ser maximizada quando o centro de controle do sistema elétrico obtém informações em tempo real, durante a operação do sistema. O ideal é que, a partir desses dados, este centro possa realizar ações individuais. Estas seriam executadas nos equipamentos distribuídos ao longo da rede ou presentes nas subestações, como reconfigurações de circuitos e parâmetros de aparelhos. Tal procedimento levaria o sistema a adaptar-se às condições de operação.

Neste contexto, é necessário dispor de soluções de mercado que possibilitem monitorar e controlar os referidos sistemas.

No circuito elétrico, as linhas de distribuição apresentam características diferentes das linhas de transmissão e subtransmissão. As primeiras operam com tensões mais baixas do que as segundas. Assim, as linhas de distribuição são, usualmente, radiais e possuem cargas chaveadas que não se restringem somente aos terminais.

Com relação à estratégia de proteção, esse tipo de configuração envolve otimização da continuidade do serviço elétrico para um número máximo de usuários, por um custo mínimo. Assim, aplica-se a combinação entre disjuntores, religadores automáticos e fusíveis. Adicionalmente, responde-se às falhas temporárias com religamentos rápidos e isolamento de falhas permanentes. Para tanto, utiliza-se uma estratégia apropriada de chaveamento da rede [Anderson (2003)]. 


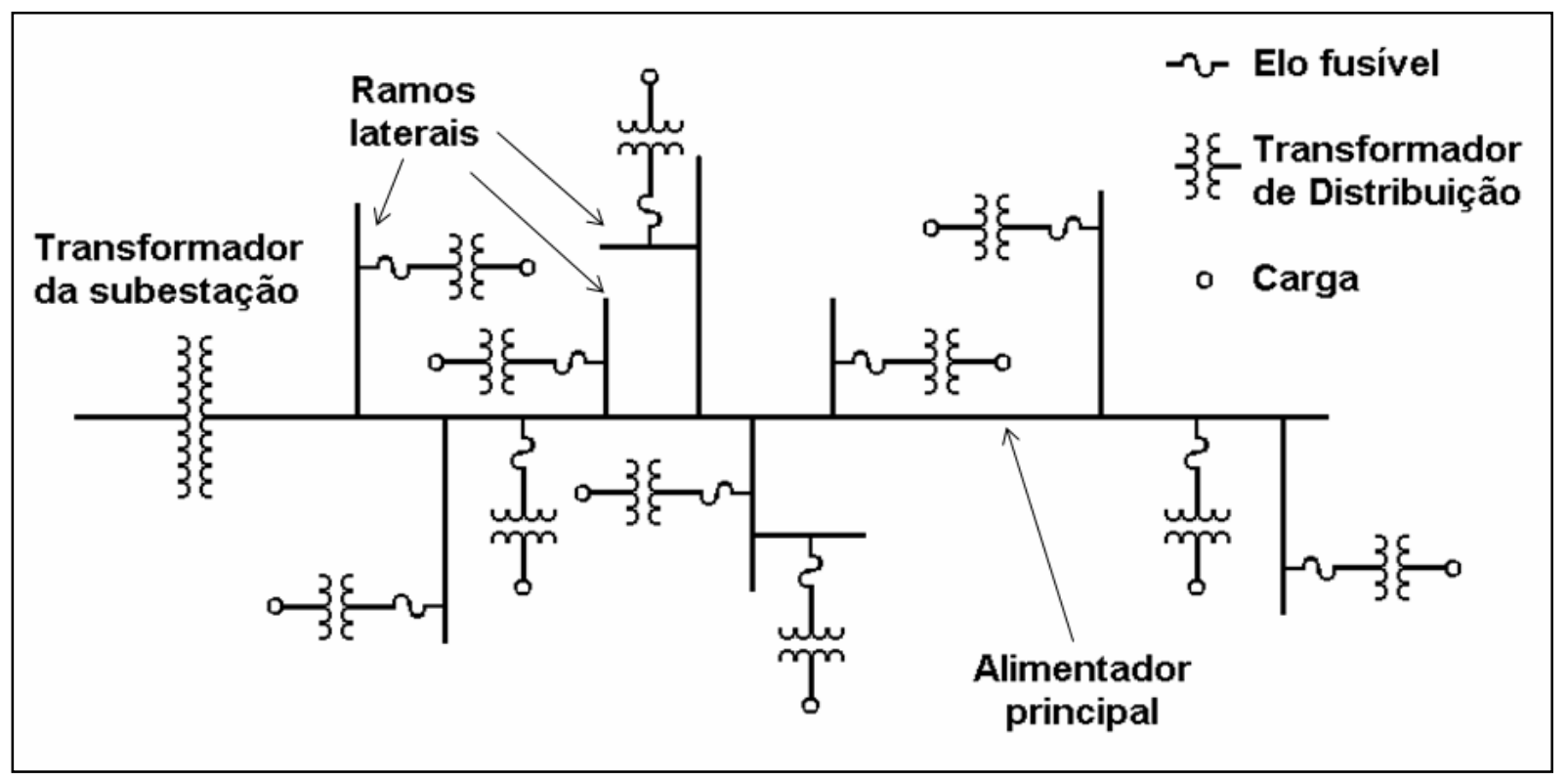

Figura B.1 - Diagrama unifilar de um circuito de distribuição de energia elétrica

Entende-se um sistema de distribuição radial como aquele composto por um alimentador principal trifásico e ramos laterais, que podem ser trifásicos, bifásicos ${ }^{19}$ ou monofásicos. Normalmente, o sistema tem uma ligação em triângulo conectada à terra e ao transformador do alimentador.

Na Figura B.1, baseada em Anderson (2003), observa-se uma configuração com um alimentador principal composto por vários ramos, além de transformadores de distribuição ao longo de sua extensão e ramos laterais.

O circuito da Figura B.2, baseada em Anderson (2003), é um sistema pequeno. Porém, ele serve como exemplo de alimentador para um sistema de distribuição com número maior de dispositivos alocados. Trata-se de uma situação em que cada transformador corresponde a uma dada carga em kVA por unidade de comprimento do alimentador.

\footnotetext{
${ }^{19}$ Devido ao modelo inicial, não serão estudados modelos bifásicos, embora seja possível adaptar o software para esta hipótese.
} 


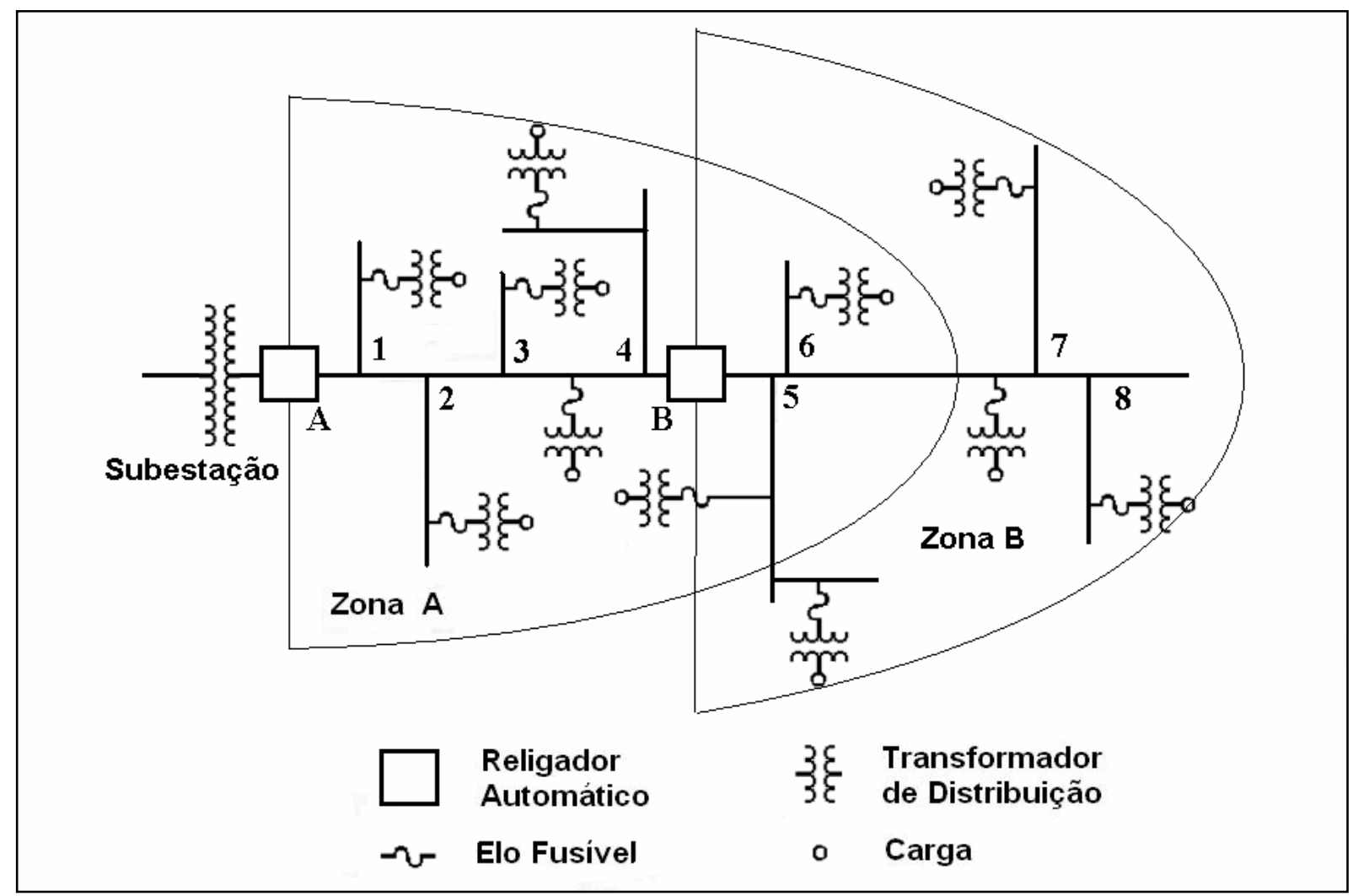

Figura B.2 - Exemplo de diagrama unifilar - circuito de distribuição de energia elétrica e elementos de proteção alocados

Observa-se que cada transformador de distribuição tem um fusível associado, que pode ser externo. Este localiza-se, normalmente, à jusante de um fusível interno associado ao transformador (autoprotegido). Em ambos os casos, o propósito do fusível é, mediante uma falha, isolar o transformador do sistema de distribuição.

Os circuitos de proteção deverão ser alocados em locais estratégicos, ao longo do alimentador. Seu objetivo é detectar a ocorrência de falhas, eliminando-as, bloqueando-as ou reconfigurando o circuito, na hipótese de falhas permanentes. Para se alcançar esse grau de coordenação, é necessário, muitas vezes, seccionar o alimentador principal, seja por um religador, disjuntor ou chave seccionadora.

O propósito da proteção de ramo é isolar falhas permanentes e permitir a restauração do serviço normal ao circuito, exceto no trecho sob presença do erro. Desta maneira, a Figura B.2 revela que os ramos laterais podem ser protegidos por fusíveis, de modo particular, caso o ramo tenha mais do que $1 \mathrm{~km}$. Esses fusíveis precisam ser coordenados com os religadores do alimentador principal, sendo que aqueles presentes nos ramos são mais baratos em relação a religadores e seccionaliza- 
dores. Assim, fornecem uma proteção a preço baixo, garantindo a continuidade do serviço para a maioria dos usuários favorecidos pelo alimentador principal.

A estratégia de proteção do sistema de distribuição de energia elétrica deve ser projetada para assegurar o máximo de proteção a um custo mínimo. Isto inclui o custo de restauração, satisfação do cliente e as receitas provindas do ganho de energia, que precisam ser balanceadas e confrontadas em relação ao preço do equipamento de proteção.

Em contrapartida, os sistemas de distribuição são frequentemente expostos a falhas, devido a raios, queda de árvores, acidentes de trânsito e outros acidentes naturais ou causados pelo homem. Nestas circunstâncias, a instalação de fusíveis de proteção deve eliminar falhas. Contudo, se o número de falhas for elevado e de natureza temporária, pode ser mais barato proteger o sistema utilizando religadores ou disjuntores com relés de religamento. Uma alternativa - diante da necessidade de proteger os circuitos contra falhas temporárias e permanentes - é usar uma combinação de diferentes dispositivos de proteção.

Os fornecedores de equipamentos de proteção repassam grandes quantidades de dados técnicos para auxiliar os engenheiros no estudo da coordenação entre equipamentos de proteção. É preciso definir o tipo de sistema que predomina na instalação. Uma vez esclarecida esta informação, será possível definir graus de curto-circuito que possam ocorrer no sistema. Tal processo deverá orientar a escolha do equipamento de proteção a ser utilizado. Considerando também o tipo de topologia existente, finalmente, é possível chegar a um consenso sobre o modo mais adequado de atuação da rede, na eventual ocorrência de um problema. A partir desse momento, vislumbram-se, então, possíveis ações de manutenção.

\section{B.2 Finalidade da proteção}

Nos sistemas aéreos de distribuição primária, a proteção contra sobrecorrentes deve atender aos seguintes aspectos:

- Evitar que os condutores e equipamentos fiquem submetidos a sobrecorrentes com duração superior à sua capacidade, colocando em risco a integridade do sistema e a segurança dos operadores e transeuntes.

- Facilitar a localização e a remoção do defeito, restringindo a interrupção do suprimento ao menor trecho possível. Para tal, realiza-se um arranjo seletivo adequado, propiciando menores índices de continuidade. 
- Evitar interrupções permanentes do fornecimento de energia elétrica, causadas por defeitos de natureza transitória. Trata-se de uma iniciativa que favorece a continuidade do serviço.

Dependendo do interesse e dos recursos disponíveis, cada concessionária de energia elétrica tem sua própria filosofia de proteção. Essa precaução serve não só para aumentar cada vez mais a qualidade do serviço prestado aos clientes, como também para atingir ou melhorar os índices de continuidade e de frequência das interrupções estabelecidos pela ANEEL [ANEEL № 24 (2000)].

\section{B.3 Localização dos equipamentos de proteção no sistema de distribuição primário}

Para o estabelecimento do esquema de proteção de um circuito, a primeira providência é a determinação dos pontos do sistema em que serão instalados os equipamentos de proteção.

\section{B.3.1 Critérios de localização dos equipamentos}

Nos sistemas aéreos primários de distribuição, devem ser instalados:

- disjuntores comandados por relés nas saídas dos circuitos de subestações de grande porte;

- religadores nas saídas dos circuitos de subestações de pequeno porte, alimentadas pelo sistema de subtransmissão;

- chaves-fusível na entrada de subestações de pequeno porte, como proteção do transformador de força;

- religadores em pontos onde o equipamento de proteção de retaguarda não é sensibilizado pelo curto-circuito mínimo;

- chaves-fusível em ramais onde o equipamento de proteção de retaguarda não é sensibilizado pelo curto-circuito mínimo e onde a carga é máxima, isto é, sem pontos de recurso com outros ramais;

- religadores no início de grandes ramais aéreos, derivados de um sistema subterrâneo, cuja proteção não permita religamentos automáticos;

- religador situado logo após um consumidor importante ou uma grande concentração de cargas;

- religadores no início de grandes ramais sujeitos a defeitos transitórios. 
Na proporção em que se amplia um esquema de proteção de sobrecorrente, por razões tecnológicas e econômicas, é necessário utilizar diversos tipos de dispositivos de proteção em série.

Um equipamento mais barato e menos complexo deve ser utilizado em pontos mais afastados da subestação. Já um aparelho mais caro e sofisticado deve ser aplicado nas subestações ou próximo a elas.

\section{B.4 Compatibilidade do equipamento com o sistema de distribuição de ener- gia elétrica}

A próxima etapa é a especificação dos equipamentos de proteção, considerando os parâmetros elétricos que caracterizam o sistema em estudo. Neste sentido, deve-se considerar:

- tensão nominal do equipamento: deve ser compatível com a classe de tensão do circuito;

- tensão de isolamento do equipamento: deve ser compatível com o nível de isolamento do circuito;

- frequência nominal do equipamento: deve ser compatível com a frequência do circuito;

- corrente nominal: deve ser compatível com a demanda máxima prevista à jusante do equipamento.

\section{B.5 Equipamentos utilizados}

No estudo da proteção dos circuitos aéreos de distribuição, considera-se o uso dos equipamentos:

- disjuntores comandados por relés eletrônicos ou microprocessados;

- religadores;

- chaves-fusível;

- chaves-seccionadoras.

\section{B.6 Disjuntor}

É o equipamento de manobra utilizado na energização e interrupção de circuitos elétricos. Pode ser usado nas saídas dos alimentadores das subestações de distribuição. Sob condições de falha, o disjuntor é comandado por relés de sobrecorrente associados ou não a relés de religamento. Assim, estes podem seccionar circuitos, funcionando como dispositivos de proteção [CEMIG (1994)]. 
O disjuntor deve permitir, quando estiver fechado, que a corrente nominal percorra o circuito sem que se configure operação indevida. Além disso, ele é capaz de interromper as correntes de curto-circuito, suportando as sobretensões de manobra que surgem mediante defeitos.

Em cada equipamento, a capacidade disruptiva de correntes de curto-circuito e o comportamento para suportar as sobretensões de manobra variam de acordo com o princípio utilizado para a extinção do arco elétrico, quando do momento da interrupção de energia. As tecnologias utilizadas pertencem às companhias.

\section{B.6.1 Disjuntores a óleo}

São divididos em disjuntores de:

- Grande Volume de Óleo (GVO): esse tipo de disjuntor ainda é adotado, apesar de apresentar alto risco de incêndio ou explosão, devido à grande quantidade de óleo;

- Pequeno Volume de Óleo (PVO): trata-se de um tipo muito utilizado nos circuitos de proteção, possuindo várias câmaras em série para aumentar a capacidade de interrupção. Também apresenta a vantagem de ser praticamente insensível à Taxa Transitória de Restabelecimento (TTR). Assim, um defeito distante do ponto de instalação do disjuntor não causa qualquer problema de interrupção.

\section{B.6.2 Disjuntores de Hexafluoreto de Enxofre $\left(\mathrm{SF}_{6}\right)$}

Este disjuntor tem a vantagem do meio isolante e de interrupção quando comparado ao ar. $\mathrm{O}$ gás $\mathrm{SF}_{6}$ é eletronegativo, portanto, dificilmente é ionizável. Apresenta elevada rigidez dielétrica e constante de tempo térmica baixa. Como resultado, revela uma diminuição muita rápida da condutibilidade do canal ionizado, após a passagem da corrente por zero, adquirindo boa capacidade disruptiva. 


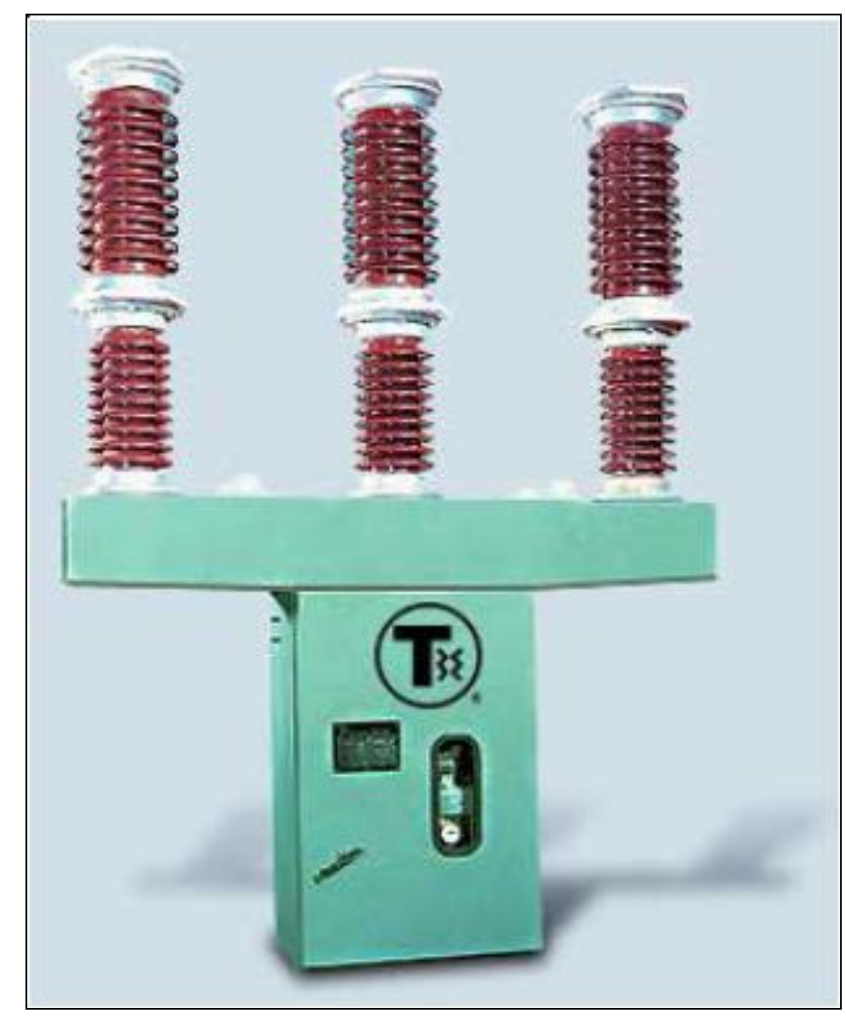

Figura B.3 - Exemplo de disjuntor de $\mathrm{SF}_{6}$

Estes disjuntores são utilizados na distribuição de energia para o controle e a proteção de linhas, subestações transformadoras, bancos de capacitores e outras aplicações. Contudo, nota-se que estão sendo gradualmente substituídos por outros tipos, com tecnologias menos agressivas ao meio ambiente.

\section{B.6.3 Disjuntores a vácuo}

Os disjuntores a vácuo têm a vantagem de apresentar baixa dificuldade de manobra para a abertura de circuitos elétricos e facilidade para interromper defeitos consecutivos. O vácuo é reconhecido pelas companhias como o melhor meio de extinção da corrente elétrica em Média Tensão (MT) [Pereira (2007) e Cooper (1998)]. Isso acontece porque ele proporciona isenção da manutenção na parte primária do equipamento de manobra e não oferece risco de explosão, exceto na condição de perda de vácuo. Essa categoria também está apta ao chaveamento de qualquer tipo de carga, não gera subprodutos, apresentando elevadíssimas confiabilidade e durabilidade [Pereira (2007) e Cooper (1998)]. 


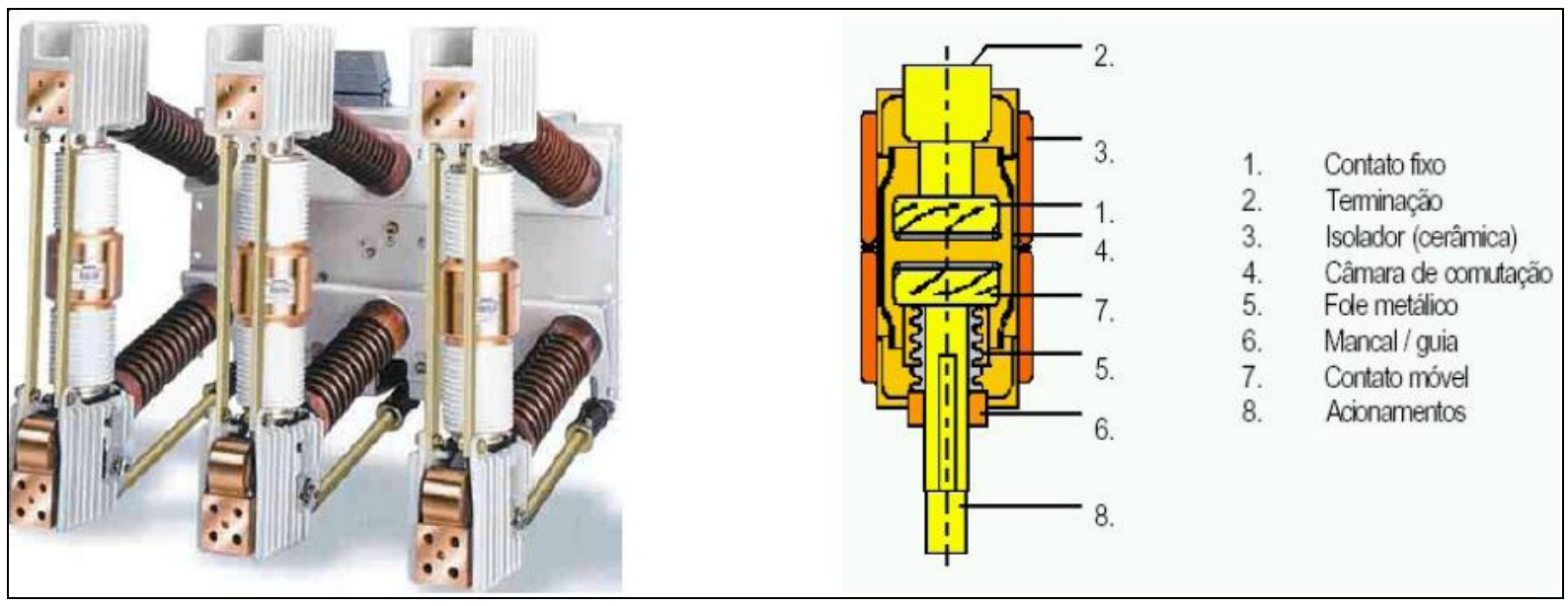

Figura B.4 - Exemplo de disjuntor a vácuo

\section{B.7 Relé de sobrecorrente}

Os relés de sobrecorrente supervisionam a intensidade de corrente que circula no alimentador, comandando a abertura do disjuntor quando a intensidade de corrente atinge ou ultrapassa um valor prefixado, chamado "corrente de pick-up" ou "corrente de disparo do relé".

É possível classificar os relés de sobrecorrente como:

- primários;

- secundários;

- eletromecânicos;

- eletrônicos;

- microprocessados.

No presente estudo, percebe-se uma crescente tendência no uso desses dipositivos, principalmente, de relés microprocessados. Estes têm como objetivo um desempenho elevado, permitindo satisfazer as mais exigentes aplicações. Dispõem de uma grande capacidade de controle e comando, graças às características de controlador programável integrado à interface de comunicação.

Essa associação reduz consideravelmente a quantidade de relés auxiliares e suas fiações. As informações disponíveis e a capacidade de comando à distância permitem a integração a um sistema de gestão de energia que envia informações à central de operação. Nesse posto, o operador é informado sobre o processo em tempo real e pode tomar as medidas adequadas, sem que haja necessidade de deslocamento. 


\section{B.8 Religador}

É um equipamento capaz de realizar, automaticamente, aberturas e fechamentos de seus contatos principais quando ocorrer uma sobrecorrente no trecho sob sua proteção.

O objetivo é permitir que um defeito transitório seja eliminado sem a necessidade de deslocamento de pessoal de manutenção, ou seja, tentar vários religamentos (máximo de 3 religamentos) e verificar se realmente o defeito é permanente. $\mathrm{A}$ partir dessa verificação, há a interrupção do trecho sob corrente de falha.

Um religador é constituído por um mecanismo automático projetado para abrir e fechar circuitos em carga ou em curto-circuito. O mecanismo é comandado por relés de sobrecorrente de ação indireta - os quais são alimentados por TCs, geralmente, de bucha e realizam as funções 50 e 51 - e por um relé de religamento (função 79).

Atualmente, os dispositivos sensores e de controle de um religador são microprocessadores dedicados que realizam as funções $50,51,79$ e outras. São os chamados "religadores microprocessados" ou "numéricos de multifunção".

Para extinguir os arcos elétricos, inerentes às operações de chaveamento de circuitos em carga ou curto-circuito, os religadores usam mecanismos e meios de interrupção similares aos disjuntores.

Os meios de interrupção mais comuns são:

- óleo isolante;

- câmara de vácuo;

- gás (SF6).

O religador, ao constatar uma situação de sobrecorrente, interrompe o circuito, religando-o automaticamente, após um tempo predeterminado. No momento do religamento, se o defeito ainda persistir, repete-se a sequência "disparo versus religamento", até três vezes consecutivas. Após o quarto disparo, o mecanismo é travado, mantendo o circuito aberto.

A repetição da sequência "disparo versus religamento" permite que o religador verifique repetidamente se o defeito desapareceu, possibilitando diferenciar um defeito transitório de um permanente.

Geralmente, um religador é projetado para realizar, no máximo, 3 religamentos seguidos por 4 disparos. Entretanto, permite ajuste para trabalhar com 1, 2 ou 3 
disparos. Após o último religamento, previamente ajustado, o religador permanece aberto, até que seja fechado pela ação do operador. Os disparos podem ser rápidos (instantâneos) e lentos (temporizados).

Para o entendimento da operação, considere-se um religador instalado na saída de um alimentador e ajustado para desenvolver quatro disparos: dois rápidos (ou instantâneos), seguidos por dois lentos (ou temporizados).

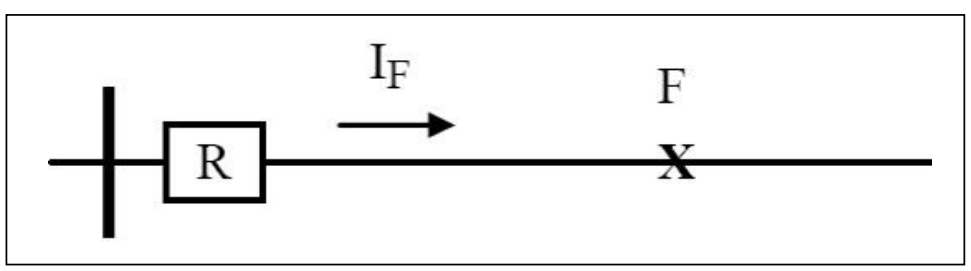

Figura B.5 - Religador instalado na saída do alimentador, na S/E

Se a falha for permanente, o religador desenvolverá a sequência completa, isto é, realizará 3 religamentos e 4 disparos. Após o quarto disparo, permanecerá aberto até receber o comando de fechamento, local ou remotamente.

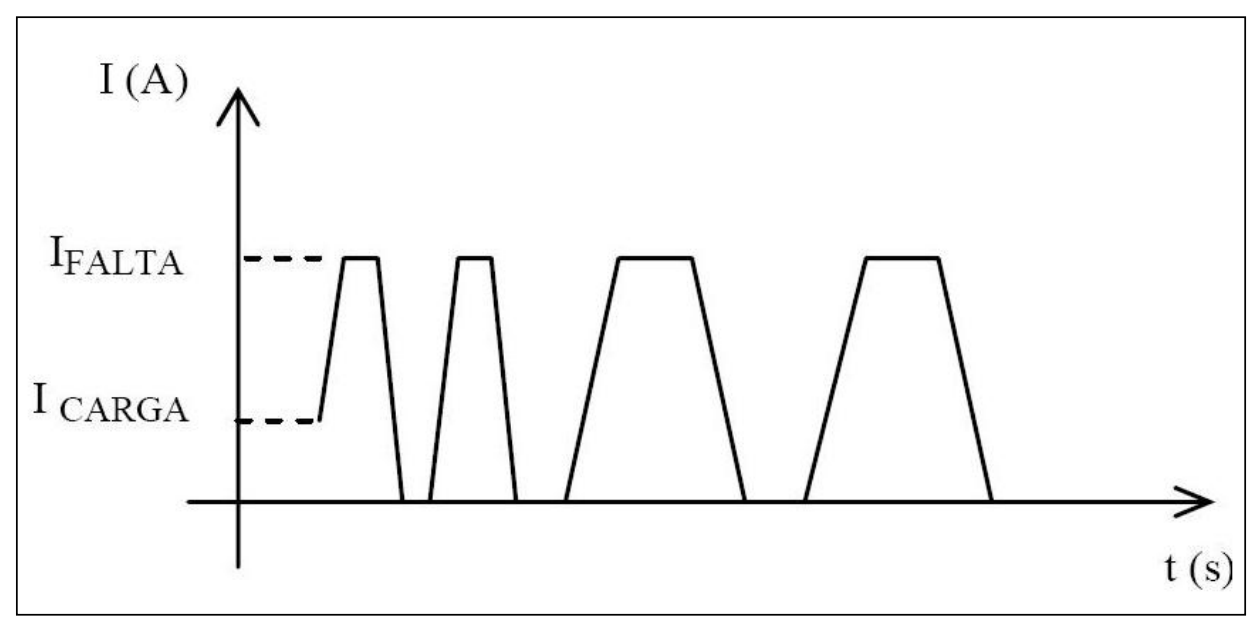

Figura B.6 - Ciclo de operações e correntes

Se a falha desaparecer antes do último desligamento, o religador não bloqueará o circuito. Dentro de um intervalo de segundos (tempo de rearme ou de restabelecimento), rearmará ou restabelecerá. Assim, o referido dispositivo estará preparado para realizar novamente a sequência ajustada. Na maioria dos religadores, este tempo é ajustado antecipadamente. 


\section{B.8.1 Princípio de funcionamento do religador}

O religador possui um elemento sensor que supervisiona a intensidade de corrente no circuito. Quando ocorrer um defeito, a intensidade atingirá ou ultrapassará o seu valor mínimo de atuação, e seus contatos principais serão abertos. O período em que os contatos permanecem abertos é chamado de "tempo de religamento". Em seguida, os contatos se fecharão automaticamente, reenergizando o circuito.

A Figura B.7 ilustra o ciclo de operações de um religador.

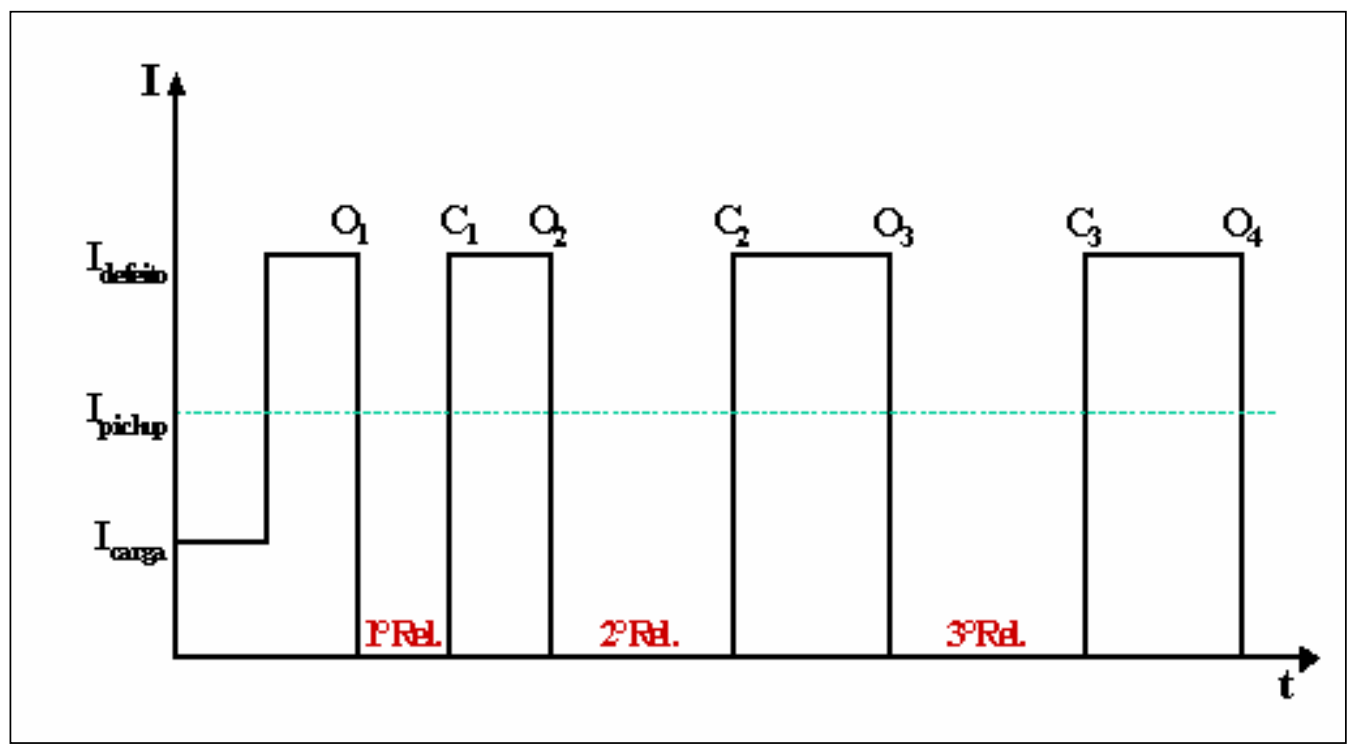

Figura B.7 - Ciclo de operações de um religador

Observa-se que $\mathrm{O} 1, \mathrm{O} 2, \mathrm{O} 3$ e $\mathrm{O} 4$ indicam tempos de ocorrências de abertura. Já C1, C2 e C3 sinalizam tempos de ocorrências de fechamentos, dentro do ciclo de religamento.

Se, após o religamento, a intensidade de corrente for menor do que o mínimo valor de atuação do religador, este continuará fechado. Depois de certo período, chamado "tempo de rearme", o dispositivo estará apto a realizar o seu ciclo completo de operações (4 aberturas e 3 religamentos).

Neste caso, o suprimento será restabelecido em todo o circuito, por se tratar de um defeito transitório.

Caso a corrente, após o religamento, seja igual ou superior ao mínimo valor de atuação do religador, este se abrirá e fechará seus contatos até completar o seu ciclo. Neste momento, o religador se bloqueará em estado aberto, isolando o trecho com defeito. 
Neste caso, o religador passa da operação automática para a operação manual, e o suprimento será restabelecido apenas para as cargas à montante do religador, por se tratar de um defeito permanente.

\section{B.8.2 Aplicação de religadores}

As redes de distribuição de energia elétrica podem ser divididas em:

- rede urbana: alta densidade de carga com redução de distâncias, para otimização da manutenção; apresenta elevado número de consumidores;

- rede rural: baixa densidade de carga e grande distância entre os centros de controle e os alimentadores. Isso acontece devido ao pequeno número de consumidores, em relação aos grandes centros.

Os religadores são classificados de acordo com o uso:

- religadores de poste: são os religadores instalados diretamente ao longo da linha de distribuição;

- religadores de subestação: são os religadores instalados na subestação de distribuição de energia.

É possível utilizar os mesmos equipamentos nas duas configurações. No entanto, devem ser considerados os diferentes níveis de curto-circuito. Assim, escolhese o equipamento que melhor se adapta à situação ou adota-se uma configuração mista.

\section{B.9 Tipos de controle para religadores}

\section{B.9.1 Controle hidráulico}

Nos religadores com controle hidráulico, as correntes são detectadas pelas bobinas de disparo de sobrecorrente, que estão ligadas em série com o circuito. Quando circula nessas bobinas uma corrente maior ou igual à corrente mínima de atuação, o núcleo móvel da bobina é atraído para o seu interior, provocando a abertura dos contatos principais do religador.

\section{B.9.2 Controle eletrônico}

Nos religadores com controle eletrônico, as correntes de defeito são detectadas por componentes eletrônicos, que são alimentados por Transformadores de Corrente (TCs). Quando circula uma corrente pelos TCs maior ou igual à corrente 
mínima de atuação, o circuito eletrônico comanda a abertura dos contatos principais do religador.

Os controles eletrônicos podem ser transistorizados ou microprocessados (controles digitais). Os religadores podem ter o controle totalmente hidráulico, eletrônico ou híbrido: hidráulico para defeitos fase-fase; eletrônico para defeito faseterra.

\section{B.9.3 Controles microprocessados}

Os controles microprocessados atuam em conjunto, com religadores trifásicos em linhas de distribuição de $2.4 \mathrm{kV}$ até $38 \mathrm{kV}$. São dotados de uma sofisticada capacidade de aquisição de dados, com a flexibilidade de uso de um microprocessador, em meio a uma operação simplificada e confiável.

\section{B.9.4 Benefícios dos controles microprocessados para religadores}

Os controles microprocessados fornecem muitos benefícios, dentre os quais mencionam-se:

- custos reduzidos de automação, na distribuição;

- análise simplificada de sistemas de distribuição;

- aumento da confiabilidade do sistema;

- confiabilidade no comportamento de surtos resistentes;

- planejamento na redução de custos, por meio da análise do histograma;

- extenso número de funções de medição;

- fácil atualização, devido ao projeto modular do controle.

O controle microprocessado orienta-se por componentes com características modulares baseadas em microprocessadores. Neste contexto, busca-se um aumento no desempenho de sistemas de distribuição de energia elétrica.

A elevada taxa de amostragem permite medidas mais precisas de valores eficazes de corrente, usados na proteção de sobrecorrente e medição.

O controle é projetado para fornecer a melhor precisão durante situações de falha e possibilitar a geração de alarmes em aplicações específicas. Disponibiliza-se a opção de, juntamente à placa mãe, conectar módulos independentes, adequando o painel frontal do elemento de proteção de acordo com a necessidade de uso. 


\section{B.9.5 Proteção de sobrecorrente com o uso de controle microprocessado para religadores}

A avançada tecnologia nos controles microprocessados permitiu uma elevada confiabilidade na proteção de sobrecorrente para sistemas de distribuição de energia elétrica.

Esses princípios aumentam a flexibilidade de operação, com a inclusão de múltiplos perfis para proteção, no momento da coordenação. A possibilidade de selecionar perfis de disparo dos controles proporciona ao usuário mais versatilidade para adaptar a proteção do religador a um sistema dinamicamente ativo, em condições ambientais.

Cada perfil proporciona vários tipos de curvas tempo versus corrente (TCC). Estas, por sua vez, incluem informações às quais o dispositivo está submetido.

O controle microprocessado possui várias características construtivas que visam à diminuição dos custos. Tal redução é acentuadamente efetuada por meio de um projeto integrado de proteção e comunicação. Trata-se de elementos que completam um pacote único, pronto para instalação.

As medidas de tensão, corrente e potência são características-padrão dos controles microprocessados, geralmente, com uma ampla gama de informações, disponível no software de programação. O conteúdo sobre medidas pode ser encontrado nos controles microprocessados. Ele é transmitido via software ou por intermédio de portas de comunicação serial.

\section{B.10 Meios de interrupção dos religadores}

Os religadores são classificados quanto ao meio de interrupção de sobrecorrentes, como:

- óleo;

- vácuo;

- gás.

Nos religadores a óleo, a interrupção da corrente é feita numa câmara de óleo; nos religadores a vácuo, a interrupção da corrente é efetuada em câmara de vácuo; a interrupção no gás é feita em uma câmara imersa em gás inerte $\left(\mathrm{SF}_{6}\right)$.

Nos religadores a gás, a interrupção da corrente é realizada nas câmaras de gás Hexafluoreto de Enxofre $\left(\mathrm{SF}_{6}\right)$, agindo como elemento dielétrico. 
A tecnologia que utiliza vácuo e gás oferece um desgaste dos contatos bem menor do que no funcionamento a óleo. Assim, do ponto de vista de manutenção, os religadores a vácuo ou a gás apresentam um desempenho cerca de 3 a 4 vezes melhor do que aqueles a óleo. A interrupção também pode ser feita com isolamento em Epóxi, material pelo qual a câmara de extinção é envolvida.

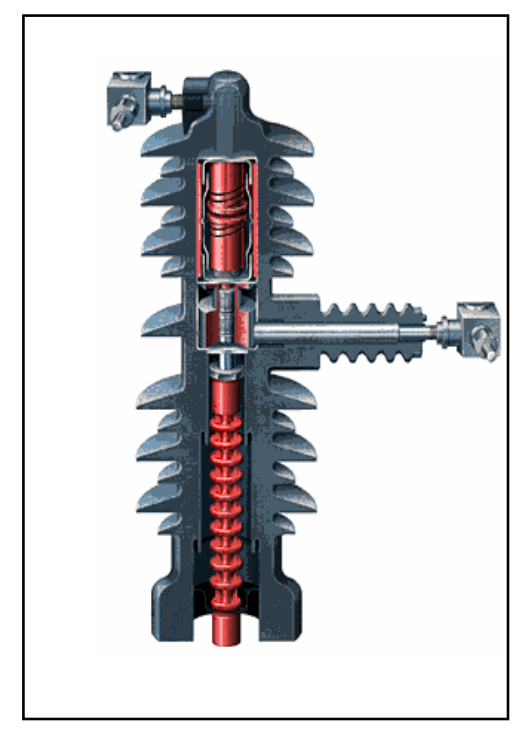

Figura B.8 - Vista em corte da câmara de interrupção a vácuo

\section{B.11 Curvas de atuação e operação de um religador}

Os religadores possuem um sistema de controle que permite àqueles serem operados com temporização dupla. Desse modo, pode-se escolher uma sequência de operação que efetue disparos rápidos e lentos, conforme os ajustes previamente definidos. A sequência é escolhida de acordo com a operação mais conveniente do sistema elétrico. Os disparos podem ser: todos rápidos, todos lentos ou uma combinação de ambos. O mais comum é ajustar a sequência para disparos rápidos, seguidos por lentos [Almeida (2000) e Cooper (1998)].

Os disparos rápidos são efetuados por unidades instantâneas (50) ou por unidades de tempo dependente (51), com curvas características rápidas (curvas baixas) dos tipos inversas ou definidas. Já os disparos lentos são alcançados por intermédio de unidades de tempo dependente (51), com curvas características lentas (curvas altas), também inversas ou definidas.

Os religadores permitem os seguintes ajustes: corrente mínima de atuação; sequência de operação; curvas características; intervalo de religamento; tempo de rearme. 
Considere-se um religador, ajustado para operar de acordo com as curvas INST. 1 e RET. 2 (Figura B.10, adaptada de Almeida (2000) e CPS (1990)). Seu ajuste prevê a seguinte sequência: 2 disparos rápidos (instantâneos), seguidos por 1 lento (temporizado). Esse percurso é ilustrado na Figura B.9, onde: $t_{R 1}$ e $t_{R 2}$ são os intervalos de religamentos previamente ajustados (tempos de religamentos); $t_{11}$ e $t_{2 T}$ são os tempos de disparos (tempos de desligamentos).

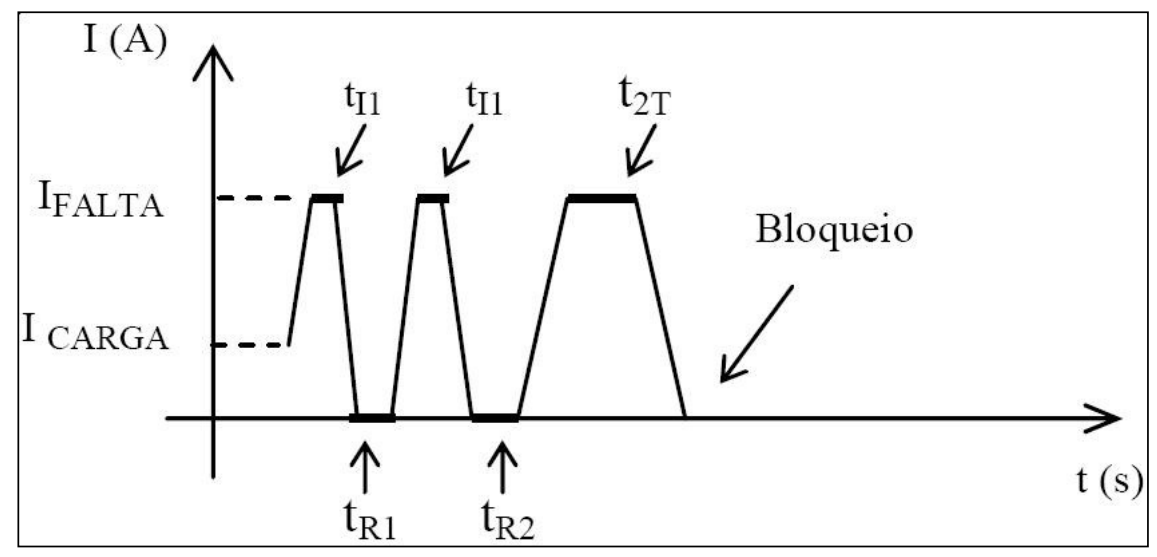

Figura B.9 - Exemplo de duas curvas rápidas e uma retardada + indicação de bloqueio

Os tempos $t_{11}$ e $t_{2 T}$ são obtidos das curvas INST. 1 e RET. 2 (Figura B.10), para a corrente de curto-circuito ( $\left.\mathrm{I}_{\mathrm{FALTA}}\right)$. No que se refere às curvas do controle de um religador, os tempos também são ajustados de acordo com a Figura B.10:

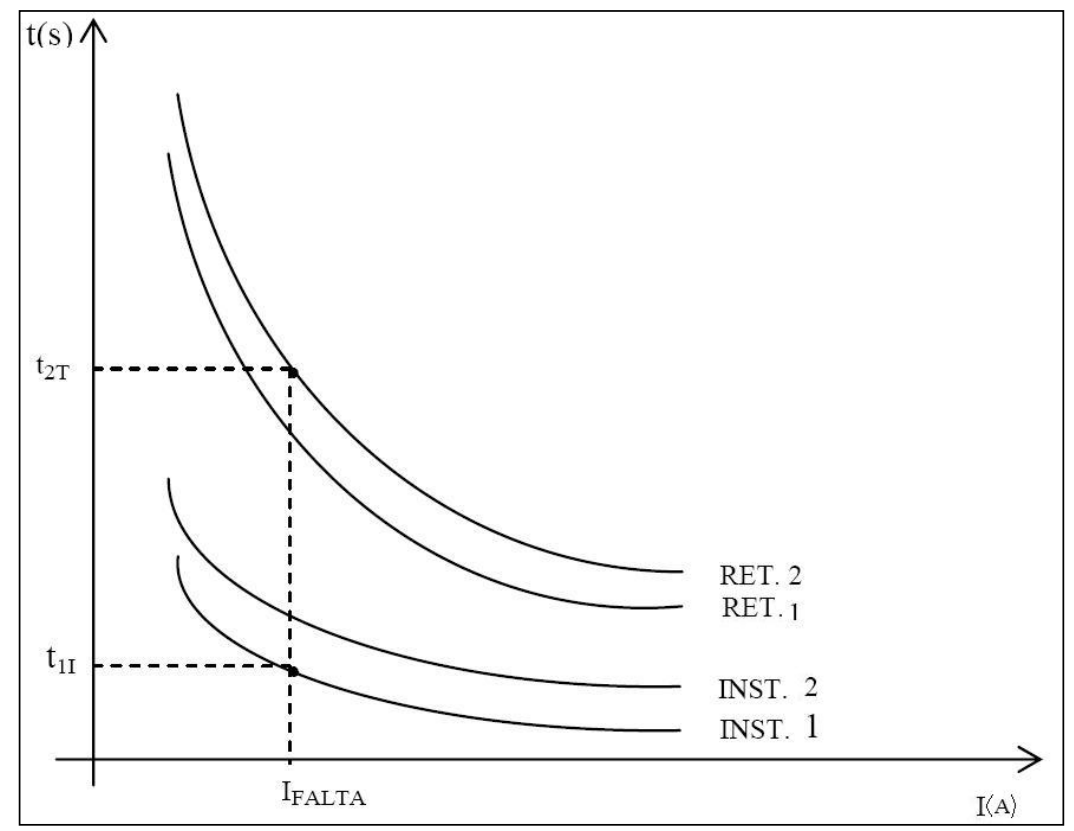

Figura B.10 - Curvas características de um religador, indicando momento da corrente de falha 


\section{B.12 Critérios para ajustes das curvas de atuação dos religadores}

Os religadores atuais possuem Transformadores de Corrente (TCs) internos (geralmente, chamados "TCs de bucha"). Alguns tipos de religadores necessitam que seja feito o dimensionamento desses transformadores; outros, não. Quando necessário, vale o emprego de determinados critérios:

-A corrente nominal primária do TC deve ser maior do que a razão entre o curto-circuito máximo (no ponto da instalação) e o fator de sobrecorrente do TC (FS). Geralmente, igual a 20.

Logo:

$$
\mathrm{I}_{\mathrm{N}, \mathrm{P}} \geq \frac{\mathrm{I}_{\mathrm{C}, \mathrm{MAX}}}{\mathrm{FS}}
$$

A corrente nominal primária do TC deve ser maior do que a máxima corrente de carga a ser considerada [Almeida (2000) e CPS (1990)].

$$
\mathrm{I}_{\mathrm{N}, \mathrm{P}} \geq \mathrm{k}_{1}{ }^{*} \mathrm{I}_{\text {CARGA,MAX }}
$$

\section{B.13 Coordenação religador versus elo-fusível do lado da carga}

O estudo de coordenação religador versus elo-fusível do lado da carga (Figura B.11) é muito frequente.

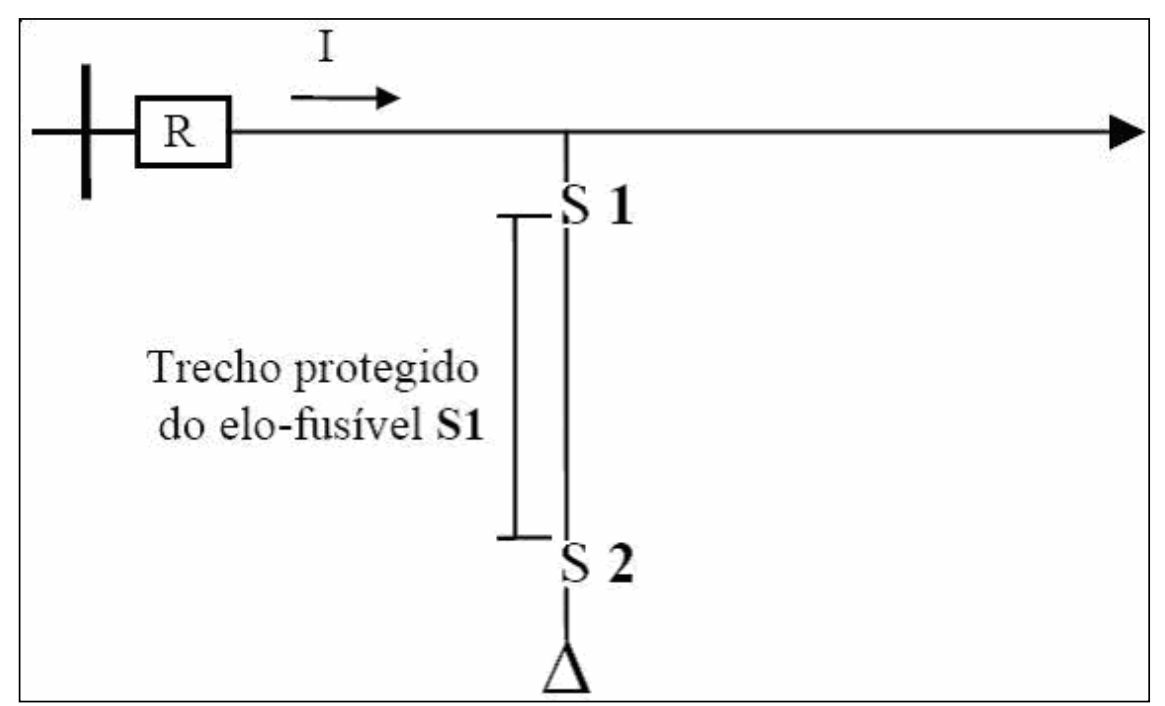

Figura B.11 - Religador após o alimentador, com o elo-fusível do lado da carga 
A coordenação está assegurada quando:

a) Para todos os valores de curto-circuito possíveis, no trecho do circuito protegido, o tempo mínimo de fusão do elo-fusível deve ser maior do que o tempo de abertura do religador na curva rápida multiplicada por um fator $\mathrm{k}$.

$\mathrm{t}_{\text {FUS }}>\mathrm{k}_{\mathrm{t}}{ }^{*} \mathrm{t}_{\text {ABERT.OP.RAPIDA }}$

Onde, $k_{t}$ é o fator que leva em conta a elevação da temperatura do elofusível, durante os intervalos de tempos de abertura rápida do religador.

Tabela B.1 - Fator de elevação da temperatura do elo-fusível

\begin{tabular}{|c|c|}
\hline Valor de $\mathbf{k}_{\mathbf{t}}$ & Número de operações \\
\hline $\mathrm{k}_{\mathrm{t}}=1,2$ & para 1 operação rápida \\
\hline $\mathrm{k}_{\mathrm{t}}=1,5$ & para 2 operações rápidas \\
\hline
\end{tabular}

b) Para todos os valores de defeitos possíveis no trecho do circuito protegido pelo elo-fusível, o tempo máximo de interrupção deve ser menor do que o tempo mínimo de abertura do religador na curva retardada.

$$
\mathrm{t}_{\text {INT }}<\mathrm{t}_{\text {ABERT.OP.RET }}
$$

A faixa de coordenação religador versus elo-fusível é determinada por essas duas regras. A "A" determina o limite máximo (corrente máxima), enquanto a "B" estabelece o limite mínimo (corrente mínima). Esse raciocínio é exposto na Figura B.12, onde: "A" é curva rápida; " $k_{t}$ versus A" é "A" deslocada; "B" é a retardada. Salienta-se que a faixa de coordenação não deve incluir as correntes dos pontos limites $I_{1}$ e $I_{2}$. 


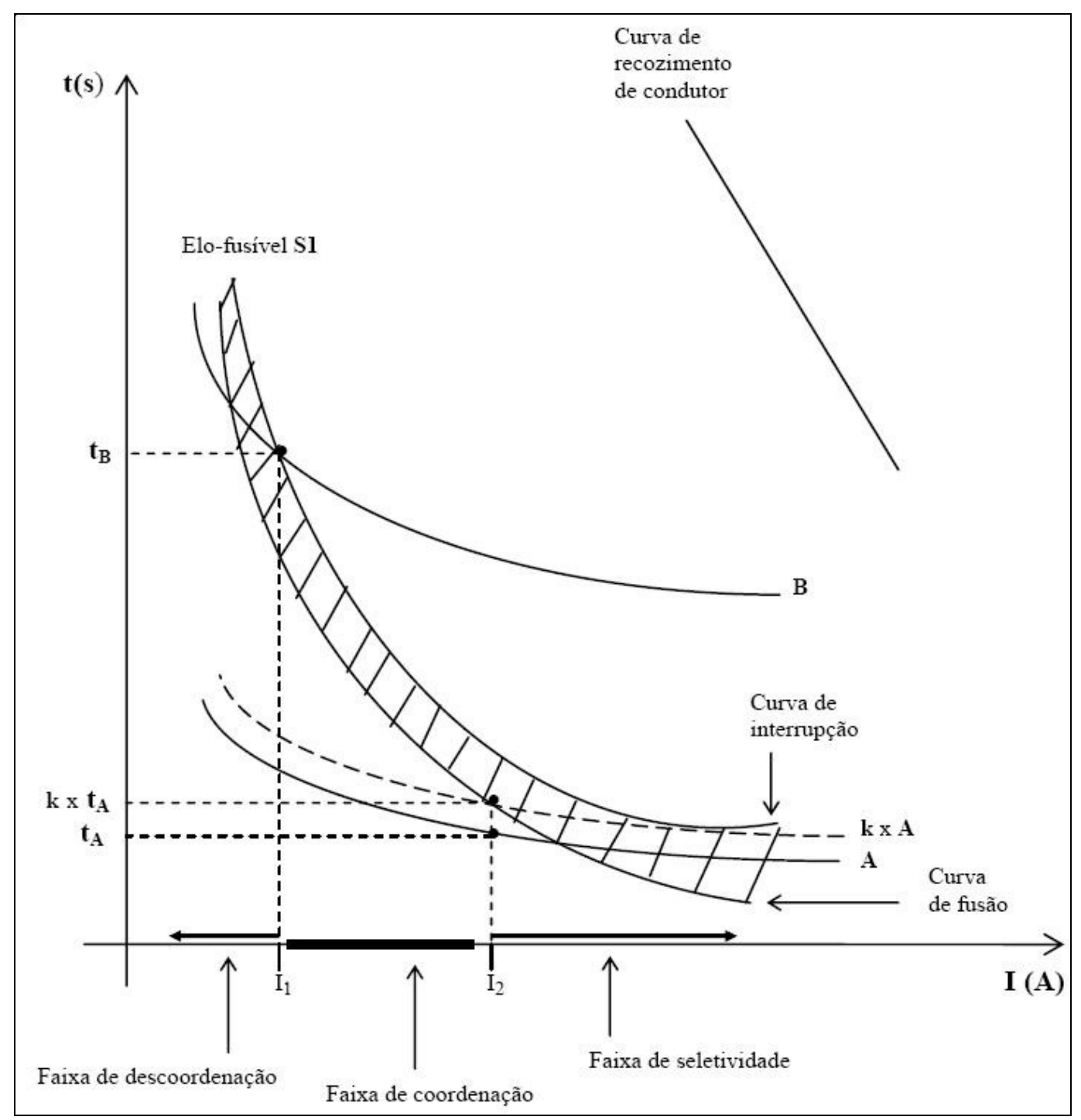

Figura B.12 - Religador versus elo-fusível do lado da carga

\section{B.14 Coordenação religador versus elo-fusível do lado da carga}

Este tipo de coordenação é visto com mais frequência em subestações de distribuição de energia elétrica. Nestas, as saídas são equipadas com religadores, e a proteção do transformador é feita com elo-fusível, no seu primário [Almeida (2000) e CPS (1990)]. 


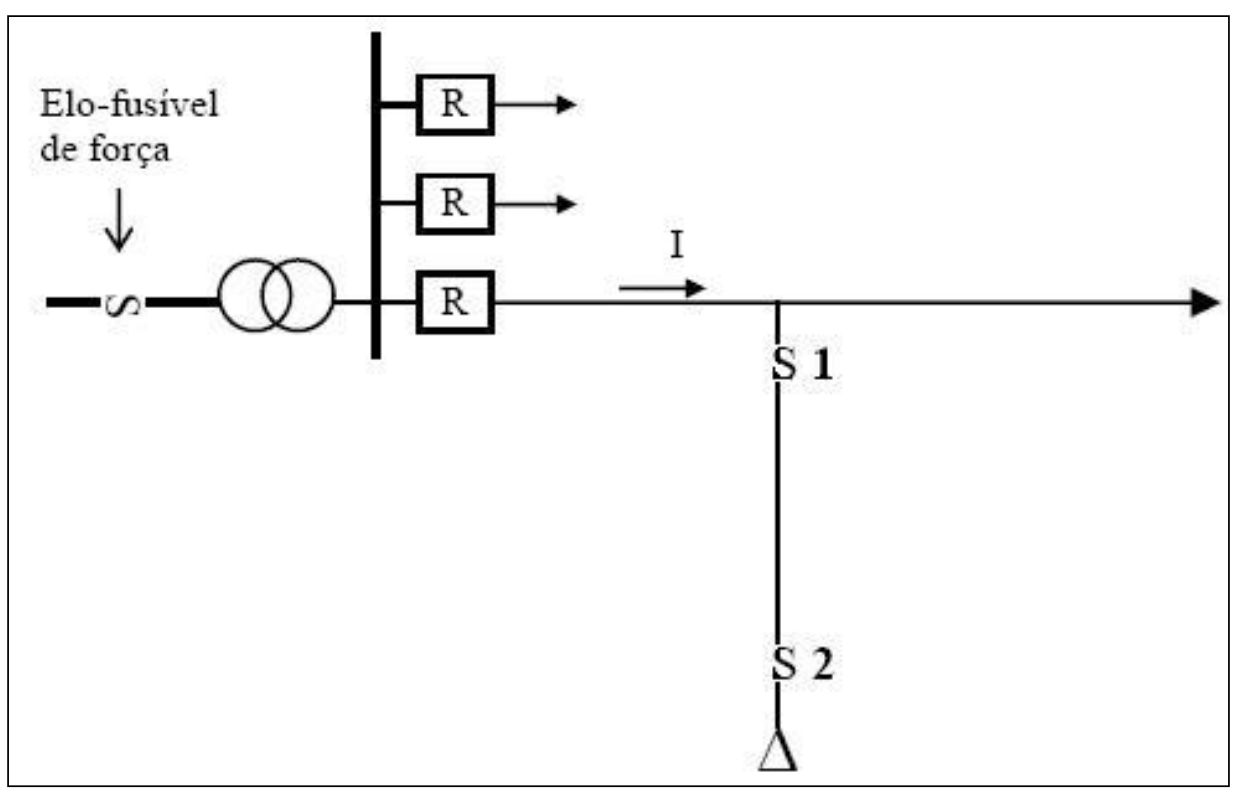

Figura B.13 - Elo-fusível protegendo o transformador e os religadores nas saídas dos alimentadores

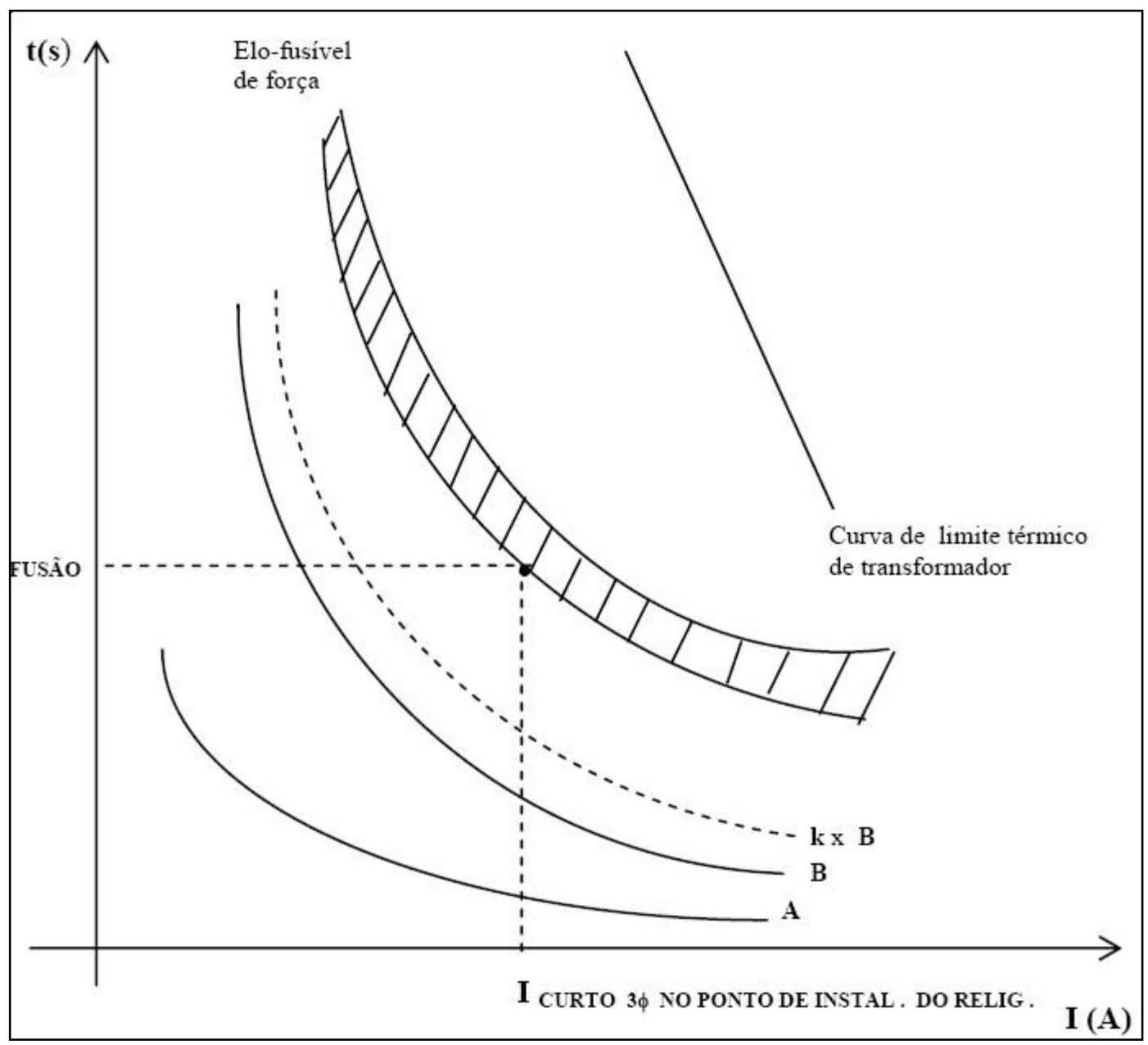

Figura B.14 - Religador versus elo-fusível do lado da fonte 
Garante-se a coordenação quando o tempo mínimo de fusão do elo-fusível for maior do que o tempo de abertura do religador atuando na curva retardada. Esta deve ser multiplicada pelo fator $\mathrm{k}_{\mathrm{t}}$, para o curto-circuito trifásico, no ponto de instalação do religador, de acordo com a Figura B.14.

\section{B.15 Coordenação religador versus religador}

Para a coordenação entre dois ou mais religadores deve-se estabelecer os critérios assinalados [Almeida (2000) e CPS (1990)]:

a) O religador à montante não deve atuar na sua zona de retaguarda, antes do religador à sua frente, para qualquer valor de curto-circuito, dentro da zona de proteção.

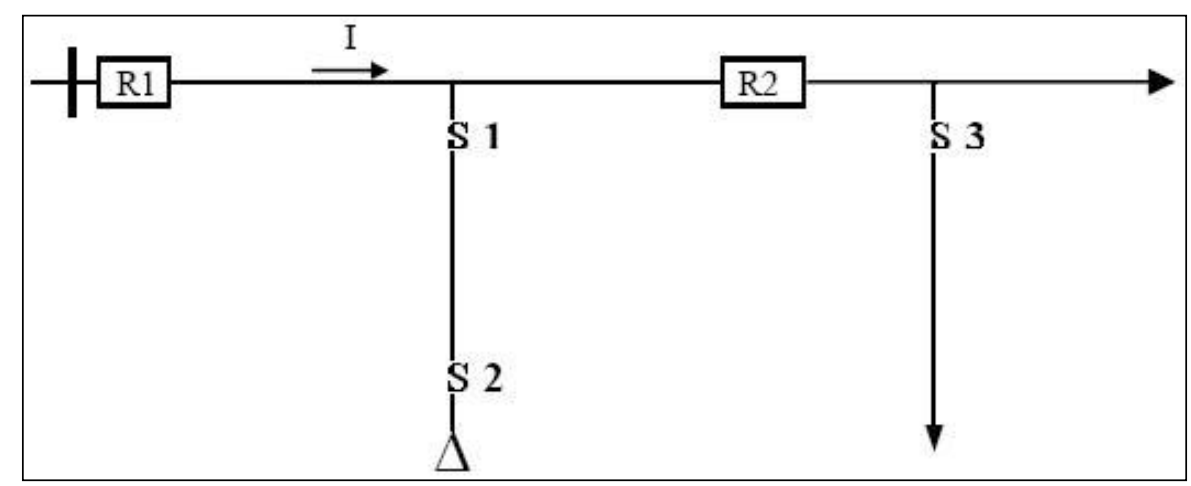

Figura B.15 - Religadores presentes na saída do alimentador e no tronco

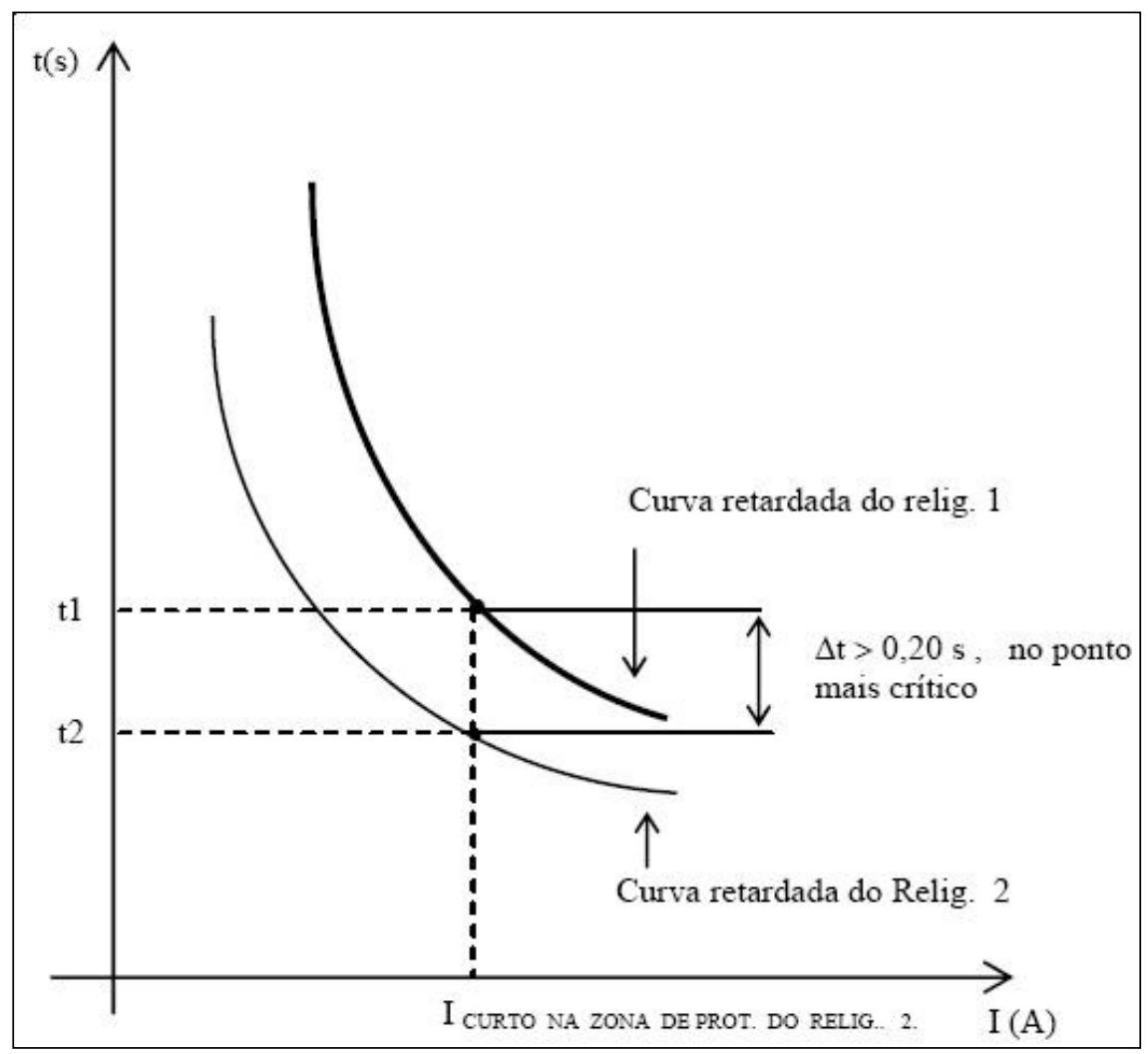

Figura B.16 - Religador versus religador 
b) A diferença entre os tempos de operação das curvas retardadas dos religadores deverá ser maior do que 0,2s, de acordo com a Figura B.16.

Sendo que:

$t_{\text {DISP.RETARD.RELIG.NA.RETAG. }}>\mathrm{t}_{\text {DISP.RETARD.RELIG.NA.FRENTE }+0.2 \mathrm{~s}}$

Observa-se que é muito difícil conseguir coordenação entre as curvas rápidas dos religadores. Isso acontece porque o intervalo de tempo entre elas é muito pequeno, admitindo-se operações simultâneas entre os religadores.

\section{B.16 Chaves-fusível}

As chaves-fusível são dispositivos eletromecânicos que têm como função básica interromper o circuito elétrico quando ocorre a fusão do elo-fusível.

Possuem as seguintes características:

- tensão nominal;

- Nível Básico de Isolamento (NBI) para impulso;

- frequência;

- corrente nominal;

- corrente de interrupção (capacidade de interrupção);

- corrente de curta-duração.

Com relação à corrente nominal, a característica mais importante é a corrente de interrupção. Esta deve ser especificada de acordo com o valor assimétrico da corrente de curto-circuito maior, no ponto de instalação da chave.

As chaves-fusível são classificadas em dois tipos:

a) Chaves-fusíveis de distribuição: identificadas pelas características inerentes aos sistemas de distribuição:

- NBI de sistemas de distribuição;

- construídas, mecanicamente, para a montagem em cruzetas;

- tensões nominais de sistemas de distribuição; no Brasil, as mais comuns são: 11,4kV, 13,2kV, 13,8kV (classe 15kV) e 34,5kV.

b) Chaves-fusível de força: empregadas em subestações para proteção de barramentos, transformadores, bancos de capacitores e bypass de disjuntores. Possuem NBI para classes de tensões mais elevadas (69kV, 138kV), cujos níveis básicos de isolação (NBI) são $350 \mathrm{kV}$ e $650 \mathrm{kV}$, respectivamente. 
As chaves-fusível empregadas até $25 \mathrm{kV}$ são consideradas "chaves-fusível de distribuição". Acima deste valor, são denominadas "chaves-fusível de força", não sendo essa uma regra rígida.

No que concerne à sua construção, as chaves-fusível podem ser dos tipos:

- fechada: o cartucho e as garras são montados dentro de uma caixa protetora de material isolante;

- aberta: o cartucho e as garras não possuem caixa protetora.

Quanto ao modo de operação, podem ser:

- de expulsão;

- imersas em óleo;

- limitadora de corrente.

No Brasil, são fabricadas e largamente empregadas: chaves-fusível de expulsão; monofásicas; com cartucho em fibra isolante; abertas. Há ainda aquelas não repetitivas e indicadoras, conhecidas também como "chaves Matheus", ilustradas na Figura B.17.

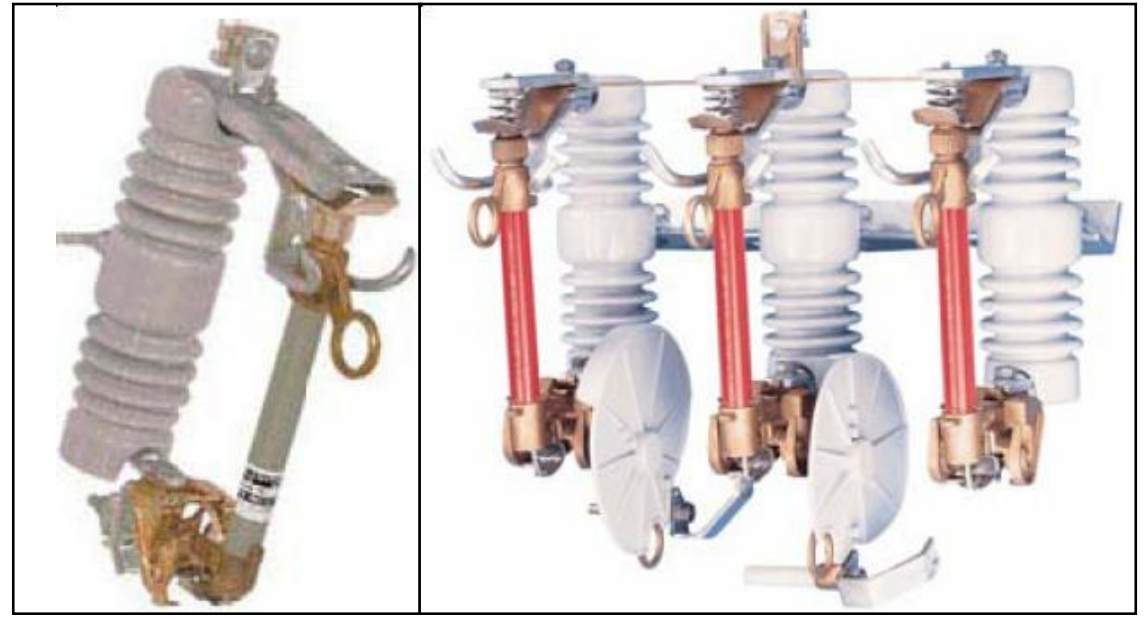

Figura B.17 - "Chave Matheus" e chave-fusível tripolar religadora

O princípio de funcionamento considera a extinção do arco elétrico formado dentro do cartucho. Tal fato deve-se à abertura do circuito após a fusão do elofusível. O arco irá queimar o tubinho e/ou as paredes do cartucho, produzindo gases desionizantes ( $\mathrm{CO}_{2}$ e Nitrogênio), que irão extinguí-lo.

A expansão desses gases no interior do cartucho dá origem a uma intensa diferença de pressão interna, que irá expulsá-los pela parte inferior. A referida diferença ocasiona um empuxo para cima (princípio da ação e reação). Essa situação desconecta o contato superior do cartucho da chave, fazendo-o girar por meio de 
uma junta articulada. Após a operação da chave, o cartucho fica "pendurado", indicando a operação executada ("canela arriada"). Trata-se de uma propriedade indicadora ou sinalizadora visual .

Os principais componentes de uma chave-fusível tipo expulsão são :

- elo-fusível (liga de material condutor);

- cartucho ou canela (tubo de fibra isolante);

- isolador (porcelana ou resina epóxi);

- base ou dispositivo de fixação (aço zincado).

Observa-se que esse tipo de chave-fusível não deve ser empregado para manobra de circuito com carga, pois esta pertence à categoria "seca". Isso significa que os seus contatos não possuem meios de interrupção a arco (óleo, SF6).

A abertura de circuito com carga leva a um desgaste prematuro dos contatos da chave. Além disso, pode provocar danos físicos e risco de vida à pessoa que está realizando a operação de abertura, principalmente, nos dias chuvosos. O risco ocorre porque, no momento da abertura, o arco elétrico pode envolver a cruzeta e, estando esta aterrada, originará um curto-circuito fase-terra. Este, por sua vez, poderá produzir elevadas tensões de passo.

Existem acessórios para essas chaves que, quando instalados, possibilitam, com segurança, a abertura de circuitos com carga. Um desses acessórios, bastante utilizado, é o "gancho" próprio para o load buster. Outras chaves que são equipadas com câmara de extinção de arco.

Geralmente, o cartucho e o elo-fusível são intercambiáveis, isto é, podem ser substituídos por outros do mesmo fabricante ou similares. A instalação da chave na cruzeta deve formar um ângulo de aproximadamente $70^{\circ} \mathrm{em}$ relação à horizontal. Sua finalidade é, por meio da ação da gravidade, facilitar o giro do cartucho após a operação. 
Tabela B.2 - Modelos de chaves-fusível mais usadas no Brasil

\begin{tabular}{|c|c|c|c|}
\hline \multirow{2}{*}{$\begin{array}{c}\text { Tensão } \\
\text { Nominal } \\
(\mathbf{k V})\end{array}$} & \multirow{2}{*}{$\begin{array}{c}\text { NBI } \\
(\mathrm{kV})\end{array}$} & \multicolumn{2}{|c|}{ Corrente } \\
\cline { 3 - 4 } & & $\begin{array}{c}\text { Nominal } \\
(\mathrm{A})\end{array}$ & $\begin{array}{c}\text { De } \\
\text { interrupção } \\
\text { Assímetrica } \\
(\mathrm{kA})\end{array}$ \\
\hline 15 & 95 & 50 & 1,2 \\
\hline 15 & 95 & 100 & 2 \\
\hline 15 & 95 & 100 & 4 ou 5 \\
\hline 15 & 95 & 100 & 8 ou 10 \\
\hline 15 & 110 & 200 & 4 ou 8 \\
\hline 15 & 110 & 300 & 10 \\
\hline
\end{tabular}

\section{B.16.1 Dimensionamento de chaves-fusível}

Para especificar uma chave-fusível, é necessário o dimensionamento da capacidade de interrupção e da corrente nominal. Para tanto, é preciso conhecer as correntes de carga e de curto-circuito máximas no seu ponto de instalação.

A corrente nominal da chave deverá ser igual ou maior do que aquela de carga máxima, no seu ponto de instalação. Em seguida, deve ser multiplicada por um fator $\mathrm{K}_{1}$ ou superior ao valor da corrente admissível do fusível empregado, também multiplicado por $\mathrm{K}$.

$$
\mathrm{I}_{\mathrm{NOM}, \mathrm{CH}} \geq \mathrm{K}_{1}{ }^{*} \mathrm{I}_{\mathrm{C}, \mathrm{MAX}}
$$

$\mathrm{O}$ fator de segurança $\mathrm{K}_{1}$, é empregado para situações de remanejamento de carga, de sobrecarga ou para o próprio crescimento de carga do circuito. O seu valor é considerado de acordo com a condição de operação do circuito, geralmente, em situações mais desfavoráveis ou mais frequentes.

Para casos de crescimento de carga, o fator $\mathrm{K}_{2}$ é indicado pela expressão:

$$
\mathrm{K}_{2}=(1+\mathrm{a})^{\text {num }}
$$

Costuma-se utilizar o critério de corrente admissível do fusível adotado, ou seja:

$$
\mathrm{I}_{\mathrm{NOM}, \mathrm{CH}} \geq \mathrm{K}_{2}{ }^{*} \mathrm{I}_{\mathrm{ADM}, \mathrm{FUS}}
$$

A corrente de interrupção da chave deverá ser igual ou superior ao máximo valor assimétrico da corrente de curto-circuito no seu ponto de instalação. 


$$
\mathrm{I}_{\mathrm{INT}, \mathrm{CH}} \geq \max \left(\mathrm{I}_{\mathrm{CURTO}, \mathrm{ASSIM}}\right)
$$

\section{B.16.2 Elos-fusível}

Os elos-fusível constituem a parte ativa da chave-fusível, ou seja, são os elementos sensores que detectam a sobrecorrente e, juntamente ao cartucho, interrompem o circuito. Não devem fundir com a corrente de carga do equipamento ou do circuito protegido e precisam obedecer às curvas características tempo versus corrente, fornecidas pelos fabricantes.

Os elos-fusível são identificados por sua corrente nominal e pelo seu tipo, devendo ainda aparecer o nome ou a marca do fabricante. Constituem-se das seguintes partes:

- botão com arruela;

- elemento-fusível;

- tubinho;

- rabicho.

O presente estudo considerou os seguintes tipos de elos-fusível de distribuição:

- tipo K - elos-fusível rápidos;

- tipo T - elos-fusível lentos;

- tipo H - elos-fusível de alto surto (high surge), de ação lenta para surtos de corrente (a corrente transitória de magnetização de transformador). São fabricados somente para pequenas correntes nominais. Geralmente, são usados para proteger transformadores de pequenas potências (até 75 kVA) e pequenos bancos de capacitores.

Destacam-se ainda correntes nominais, normalmente, padronizadas para esses elos-fusível:

- Valores preferenciais para os tipos Ke T: 1, 2, 5, 6, 10, 15, 25, 40, 65, 100, 140 e $200 \mathrm{~A}$.

- Valores não preferenciais para os tipos Ke T: 8, 12, 20, 30, 50 e $80 \mathrm{~A}$.

- Valores para o tipo $\mathrm{H}:$ 1, 2, 3 e 5 A.

Os elos-fusível $\mathrm{K}$ e T, em geral, admitem correntes $50 \%$ acima da nominal (corrente admissível). 
O funcionamento do elo-fusível baseia-se na fusão do elemento fusível (geralmente, de liga de estanho ou prata). Atua por efeito Joule, quando a corrente passante é superior à corrente admissível. A maioria dos elos atinge o ponto de fusão em uma temperatura próxima a $230^{\circ}$ C. Para a corrente admissível, o elo trabaIha com temperatura em torno de $100^{\circ} \mathrm{C}$.

Devido ao arco elétrico, em tensões elevadas (classe $15 \mathrm{kV}$ ou superior), a fusão do elo não costuma interromper o circuito. Para interrompê-lo efetivamente, é necessário eliminar o arco. A interrupção é realizada por gases desionizantes, produzidos no interior do cartucho, em consequência da queima do tubinho e/ou das paredes internas do cartucho.

A energia liberada pelo arco será condicionada ao tempo, à tensão e à corrente. Caso o cartucho não seja adequado, dependendo da energia, podem ocorrer "inchaço", explosões ou outros danos mecânicos.

\section{B.17 Chaves-seccionadoras}

Destinam-se a abrir, fechar ou transferir ligações de um circuito elétrico. Só podem ser manobradas com tensão e sem carga. Alguns fabricantes disponibilizam, no mercado, chaves-seccionadoras que podem abrir ou fechar com carga. Porém, limitam o nível de tensão a ser seccionada. Na realidade, quem deve desligar o circuito com carga ou em curto é o disjuntor ou um religador com características específicas para operar em carga.

As chaves-seccionadoras funcionam em um meio isolante (o próprio ar), com óleo isolante. Além disso, são blindadas no sistema SF6.

\section{B.17.1 Tipos de acionamento de chaves seccionadoras}

A chave-seccionadora pode ser:

- individual: fecha um pólo de cada vez, por vara de manobra, tipo "H";

- manual: fecha os três pólos de uma vez;

- manual e motorizada: de comando local; remoto na sala de comando e remoto por telecomando. Nessas circunstâncias, não existem condições para fiação de comando ou controle.

As chaves-seccionadoras, geralmente, têm contatos auxiliares usados para sinalização e intertravamentos elétricos. Também existem contatos auxiliares nas fases, os quais se destinam à proteção dos contatos principais (possuem "chifres" 
para acabar com o arco elétrico nos contatos). Algumas são usadas em linha de 13,8 KV e possuem seus contatos principais protegidos por uma câmara de extinção de arco a seco. A câmara é dotada de um sistema de vácuo para possibilitar sua abertura, com carga de trabalho normal e não com carga de curto.

\section{B.17.2 Tipos construtivos das chaves-seccionadoras}

A chave-seccionadora pode ter os seguintes tipos de construção:

- pesada: montagem vertical ou horizontal invertida; até 1200 ampères;

- extrapesada: montagem vertical ou horizontal invertida; acima de 1200 ampères;

- isolador rotativo e abertura lateral: a faca desloca-se em plano paralelo àquele de sua base;

- isolador rotativo e abertura vertical: a faca desloca-se perpendicular ao plano de sua base;

- isolador basculante e abertura vertical: a faca e o isolador deslocam-se em plano perpendicular àquele da base, sendo muito bem distribuídos;

- isolador externo rotativo: tem abertura lateral e atua conforme o giro da cadeia de isoladores central;

- isolador rotativo e abertura bilateral: a faca é acionada no meio e em seus extremos. Neste ponto, localizam-se os contatos principais e três colunas de isoladores. O isolador do meio é aquele que gira;

- semi-pantográfica: possui um braço articulante; é muito usada em linhas de transmissão com dois ou mais condutores por fase;

- pantográfica: possui dois braços articulantes.

\section{B.17.3 Chaves-seccionadoras motorizadas 89 com disjuntor 52 associado}

Esta categoria é utilizada como chave-de-transferência ou seccionadora de by-pass, entre outros tipos de uso. Sua finalidade é transferir ligações ou equipamentos defeituosos para manutenção, em geral, sem interromper o fluxo da carga. Busca ainda fazer a transferência sem desligar o gerador que abastece a carga.

Evidenciam-se ainda outros tipos de uso:

- Uso como chave de aterramento: após o equipamento ser desligado e aberto, isto é, sem tensão, realiza-se o aterramento. Geralmente, a chave vem conjuga- 
da com a seccionadora comum. Ao abrir o circuito, uma outra lâmina da própria seccionadora é liberada e esta liga-se à terra. As chaves-seccionadoras possuem intertravamento mecânico e relé elétrico, ou seja, não se consegue aterrá-las se não estiverem com a faca fora da fase e vice-versa. Caso o circuito tenha de ser aberto com carga, o intertravamento desliga o disjuntor. Caso seja necessário aterrar o circuito ainda energizado, um alarme é acionado, provocando o desligamento do disjuntor.

- Intertravamento mecânico entre chaves-seccionadoras: o tracejado indica que as duas chaves não podem fechar ao mesmo tempo.

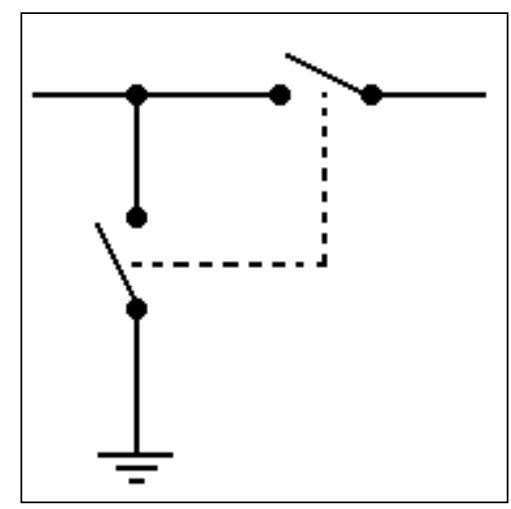

Figura B.18 - Intertravamento mecânico entre chaves-seccionadoras

- Intertravamento elétrico entre disjuntor e chaves-seccionadoras: o tracejado indica que a tentativa de abertura de uma da seccionadoras com disjuntor fechado provoca a abertura elétrica de disjuntor.

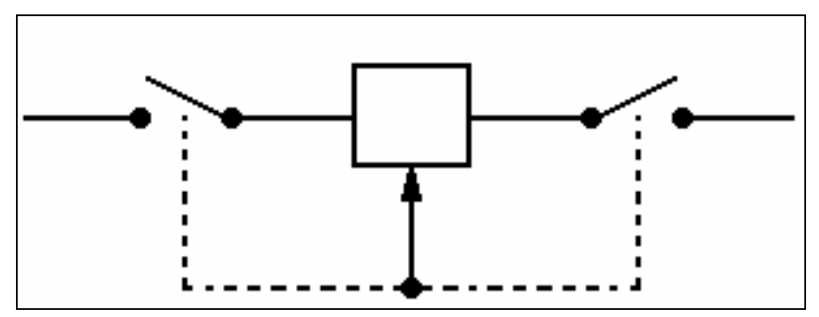

Figura B.19 - Intertravamento elétrico entre disjuntor e chaves-seccionadoras

- Uso como chave-de-aterramento rápido ou chave-de-proteção de retaguarda: quando o relé de sobrecorrente constata um defeito, ordena o desligamento do disjuntor, evitando o desdobramento do defeito. Se o disjuntor falhar ou estiver deslocado (somente por seccionadora de by-pass), a seccionadora - bem robusta, de acionamento elétrico e de alta velocidade - aterra automaticamente o circuito 
"com tensão e com carga". Esse procedimento provocará o desligamento de disjuntores de outras subestações (o defeito será desativado por outras maneiras).

- Uso como seccionadora do tipo combinação: atua em conjunto com reguladores de tensão em linhas de $13,8 \mathrm{KV}$ ou $34,5 \mathrm{KV}$; liga e desliga o regulador sem interromper o fluxo de carga. 